



\title{
AUGUST WEISMANN
}

SEIN LEBEN UND SEIN WERK

\author{
VON
}

\section{ERNST GAUPP †}

WEIL. O. Ö. PROFESSOR DER ANATOMIE UND DIREKTOR DES KÖNIGL. ANATOMISCHEN INSTITUTS DER UNIVERSITÄT BRESLAU

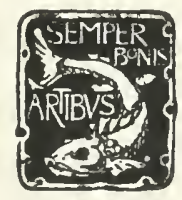

$$
\frac{173640}{1 / 9 / 22}
$$

\author{
JENA \\ VERLAG VON GUSTAV FISCHER \\ 1917
}




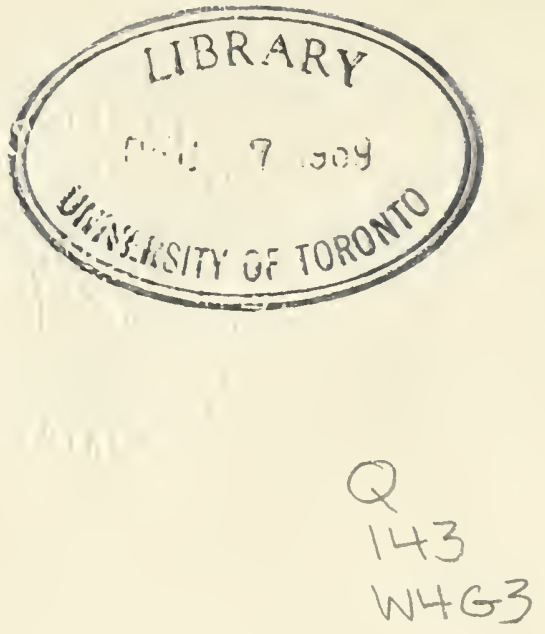

Alle Rechte vorbehalten. 


\section{Vorwort des Herausgebers.}

Ernst Gaupps Arbeiten wurden durch seinen plötzlichen Tod am 23. November I9I6 jäh abgebrochen. Jetzt muß fremde Hand dieses nachgelassene Werk herausgeben und legt es dem großen Kreis derer vor, die sich für Naturwissenschaft interessieren, nicht nur, wie es Gaupps Wunsch gewesen wäre, als ein Stück jüngste Geschichte der Biologie und eine lebendige Darstellung des Lebenswerkes eines ihrer genialsten Forscher und tiefsten Denker, sondern auch als ein schönes Zeugnis für das menschlich liebevolle, und zugleich wissenschaftlich so besonders feinsinnige Verständnis des Morphologen Gaupp für biologische Probleme.

Das Werk war druckfertig samt Anmerkungen, der Verfasser hätte vielleicht eine letzte Überarbeitung vorgenommen, denn er pflegte auch nach der stilistischen Seite seine Veröffentlichungen aufs Gewissenhafteste durchzuführen, der Herausgeber wollte aber hier keinen fremden Eingriff vornehmen und hat, von der Austilgung einiger offenbarer Fehler und der Vervollständigung einzelner Anmerkungen und des Literaturverzeichnisses abgesehen, nichts verändert.

Man darf wohl sagen, gerade beim Lesen dieses Werkes merken die jüngeren Generationen Naturforscher erst recht, wie selbstverständlich uns viele Dinge geworden sind, für die Weismann noch kämpfen mußte oder die erst er geschaffen hat. Man sieht, wir haben von seinem Werke schon den nötigen historischen Abstand, es verdiente geschichtliche Darstellung. So möge dieses Kabinettstück aus der Geschichte der Naturwissenschaften, wie es Gaupp meisterhaft gezeichnet hat, zugleich eine glänzende Darstellung der Weismannschen Theorie selbst und 
eine gelungene Einführung in die Gedankengänge moderner Vercrbungslehren, freundliche Aufnahme finden im großen Kreise derer, die der Aufschwung der Naturwissenschaften, die Schicksale des Materialismus, das Entstehen und Vergehen von Theorien fesselt als Teile und Entwicklungen unserer Gesamtkultur Kulturwissenschaft — wie auch bei jenen, die nur die Zoologie und Biologie als solche interessiert, und die schaffend oder aufnehmend mithelfen, die Rätsel der lebendigen Welt zu lösen und zu deuten - Naturwissenschaften - beide verbindend, die doch letzten Endes gerade hier wieder als eins gezeigt werden.

Ettlingen, Juli I9I7.

Eugen Fischer

(Freiburg i. B.) 


\section{Inhaltsverzeichnis.}

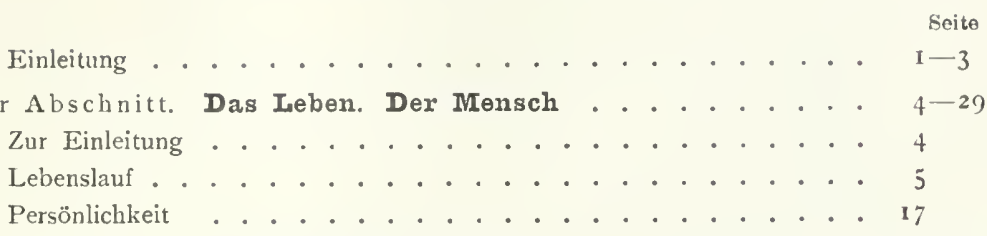

Zweiter Abschnitt. Die Spezialarbeitem . . . . . . . 30-56

Wissenschaftliche Tätigkeit Weismanns. Übersicht . . . . . 30

Chemische Arbeiten .. . . . . . . . . . 3 30

Histologische Arbeiten . . . . . . . . . . 3 I

Embryologische Arbeiten . . . . . . . . . . . 32

Allgemein-biologische Arbeiten .......... 32

Studien zur Deszendenztheorie ........... 34

Biologie der Süßwasserfauna, Daphnoidenstudien, parthenogonische und zyklische Fortpflanzung .. . . . . . . . . . 43

Die Hydromedusenstudien. Bildung der Keimzellen . . . . . 54

Dritter Abschnitt. Erste Stellungnahme zur Darwinschen Theo-

rie. Dauer des Lebens, Herkunft des Todes . . . . . . 57-72

Abstammungslehre von Darwin und Lamarck . . . . . . . 57

Erste Stellungnahme Weismanns zur Darwinschen Theorie: die Antrittsrede von I 868. Arbeitsprogramm ........ 64

Daner des Lebens. Herkunft des Todes . . . . . . . . 68

Vierter Abschnitt. Die Kontinuität des Keimplasmas als Grundlage der Weismannschen Vererbungslehre. Die Vererbung erworbener Eigenschaften . . . . . . . . . . 73-107

1. Vererbung: Bedeutung, Begriff, stoffliche Bedingtheit. Darwins Pangenesishypothese ............. . . 73

2. Die Kontinuität des Keimplasmas . . . . . . . . . 76

3. Die Vererbung erworbener Eigenschaften ......... 82

Das Problem .............. . . 82

Somatogene und blastogene Eigenschaften . . . . . . $8_{4}$

Angebliche Vererbung von Verletzungen und Verstümmelungen . 85

Angebliche Vererbung von funktionellen Abänderungen . . . . 87 
Harmonische Anpassung (Koadaption) . . . . . . . . . 88

Anpassungen der Ameisenneutra . . . . . . . . . . . . 89

Anpassungen der bloß ,passiv wirksamen" Teile und Merkmale . 92

Instinkte . . . . . . . . . . . . . . . . 96

Geistige Fähigkeiten, spezifische Talente. Der Musiksinn . . . 96

Zusammenfassung . . . . . . . . . . . . . . . . . 100

Vererbung von Veränderungen, die durch das Medium bedingt sind Ior

Ergebnisse. Übertragung derselben auf die Einzelligen . . . . 104

Die Mnemetheorie von Semon; Weismanns Stellung zu derselben. Io6

Fünfter Abschnitt. Befruchtung und Keimzellenreifung . . I08-125

I. Vererbung und Zweielternzeugung . . ... . . . . . . 108

2. Befruchtung . . . . . . . . . . . . . . . . 109

Ältere Auffassung. Entwicklung der Tatsachenkenntnisse . . . 109

Befruchtung und Konjugation als Amphimixis und als Quelle erb-

licher Variation. . . . . . . . . . . . . . . . I/2

3. Reifung der Keimzellen . . . . . . . . . . . . . . . 113

Bildung und Bedeutung der Richtungskörperchen, erste Deutung . II 3

Das Reduktionsproblem. Frühere Auffassung Weismanns . . . I I 5

Spätere Auffassung der Reduktionsvorgänge; Beziehungen zu den

Mendelschen Vererbungserscheinungen . . . . . . . I20

4. Reifung und Befruchtung als Quelle erblicher Variation . . . 124

\section{Sechster Abschnit. Weiterer Ausbau der Keimplasmatheorie:}

die Determinantentheorie . . . . . . . . . . . . 126-154

„Das Keimplasma. Eine Theorie der Vererbung“. . . . . . . 126

Fragestellung . . . . . . . . . . . . . . . . . 126

I. Der Bau des Keimplasmas. . . . . . . . . . . . . . 1 27

Vererbungssubstanz. Die Chromosomen als Träger der Vererbungstendenzen . . . . . . . . . . . . . . . . . I 27

Nägelis Idioplasma, Umgestaltung des Idioplasmabegriffes durch

Weismann. Biophoren und Determinanten . . . . . . I 29

Die Ide. Wechsel der Anschauung Weismanns hinsichtlich der

Natur der Chromosomen . . . . . . . . . . . 132

2. Die Betätigung des Keimplasmas in der Ontogenese . . . . . 139

Das Problem . . . . . . . . . . . . . . . . 139

Ontogenetische Zerlegung des Keimplasmas . . . . . . . 140

Kampf der homologen Determinanten untereinander; Bedeutung für

die Vererbungserscheinungen; alternierende Vererbung (Mendel) I 4 I

Beeinflussung der Entwicklung durch äußerc Einwirkungen . . . 144

Neben- (Reserve-, Regenerations-) Idioplasma . . . . . . . 145

Erbgleiche und erbungleiche Teilung . . . . . . . . . 146

3. Allgemeine Betrachtung der Determinantenlehre . . . . . . 147

Die Determinantentheorie als Theorie der Vererbung . . . . 147

Die Determinantentheorie als Theorie der Entwicklung . . . . 149

Hypothetischer Charakter der Theorie . . . . . . . . 153 
Siebenter Abschnitt. Personalselektion: natürliche und geschlechtliche Zuchtwahl . . . . . . . . . . . . I55-2I7

I. Artenzüchtung (natürliche Zuchtwahl, Naturzüchtung) . . . . . I56 Wesen und Begründung der Zuchtwahllehre. Notwendigkeit ihrer Prüfung . . . . . . . . . . . . . . . . . . I56 Übersicht über Weismanns Stellung zu Darwins Zuchtwahllehre . I59 Prüfung der Zuchtwahl im einzelnen . . . . . . . . . I6I I. Aufgabe . . . . . . . . . . . . . . . . I6 I

2. Möglichkeit und Wahrscheinlichkeit der Naturzüchtungsvorgänge 162

a) Einfluß der Isolierung auf die Artbildung . . . . . . 162

b) Selektionswert der Anfangs- und Steigerungsstufen der Abänderungen. Abänderungen in kleinen Schritten . . . I64

c) Freiwillig gewählte Änderungen in den Lebensbedingungen. Divergente Entwicklung auf demselben Gebiete . . . . I66

d) Die natürlichen Beschränkungen in der Wirksamkeit der Naturzüchtungsvorgänge . . . . . . . . . . . . I69

Beschränkungen, die aus dem WVesen der Naturzüchtung selbst folgen. . . . . . . . . . . . 170

Beschränkungen der Naturzüchtung, die in den Organismen liegen . . . . . . . . . . . . . . I72

Beschränlsungen der Naturzüchtung, die in den Verhältnissen der Umwelt liegen . . . . . . . . . I74

3. Leistungsfähigkeit der Selektionstheorie für die Erklärung der phyletischen Entwicklung der Organismen . . . . . . I74

a) Fragestellung . . . . . . . . . . . . . . . 174

b) Zuchtwahl oder inneres Vervollkommnungsprinzip? . . . I 74

Nägelis Theorie der direkten Bewirkung . . . . . I75

Die Organismen als Anpassungskomplexe . . . . . 178

Regeneration als Anpassungserscheinung . . . . . 185

Die Schicksale der Arten als Anpassungserscheinungen. . 187

Mutationstheorie . . . . . . . . . . . . 188

c) Zuchtwahl oder direkte Bewirkung durch äußere Einflüsse und Funktion? . . . . . . . . . . . . . . . I90

a) Direkt umwandeInder Einfluß der äußeren Bedingungen $\mathbf{9 0}$

$\beta$ ) Direkte Anpassung durch Gebrauch und Nichtgebrauch 193

Phyletische Vervollkommnung eines Teiles durch Personalselektion . . . . . . . . . . . I94

Phyletische Verkümmerung nutzloser Teile als Folge von Personalselektion . . . . . . . . . 195

Beweise gegen den Lamarckismus . . . . . 196

Funktionelle Anpassung (Roux). Partialauslese . . 200

4. Ergebnis der Prüfung der Zuchtwahllehre: Neo-Darwinismus . 206

II. Sexuelle Züchtung (geschlechtliche Zuchtwahl) . . . . . . . . 207

III. Ergänzungsbedürftigkeit der Darwin-WVallaceschen Zuchtwahllehre . 2I2 
Achter Abschnit,. Herkunft erblicher individueller Variationen.

Germinalselektion . . . . . . . . . . . . . 218-250

Variabilität der Organismen. Erbliche und nichterbliche Abänderungen 2 I 8

Die erblichen individuellen Variationen, ilrre Ursache und Art . . 219

Variabilität als Folge der Wechselwirkung der äußeren Einflüsse und der physischen Natur der Organismen . . . . . . . . 220

Variabilität als Folge der Vermischung der Individuen (Amphimixis) . 223

Variabilität als Folge von Germinalselektion . . . . . . . . 226

Die verschiedene Ernährung der Determinanten als Grund für ihre Veränderung . . . . . . . . . . . . . . . . . . 228

Beibehaltung der eingeschlagenen Variatíonsrichtung; Grenzen der Schwankungen; Korrelation der Determinanten . . . . . . . 229

Wesen der Determinantenveränderungen; Wirkurgen auf das Soma (die Determinaten). . . . . . . . . . . . . . . 232

Ursachen der Ernährungsschwankungen. Spontane und induzierte Germinalselektion . . . . . . . . . . . . . . . 234

Germinalselektion und Personalselektion . . . . . . . . . 237

Bedeutung der Lehre von der Germinalselektion. . . . . . . 242

Erweiterung der Machtsphäre des Selektionsprinzips durch die Lehre von der Germinalselektion . . . . . . . . . . . 248

Die verschiedenen Formen der Auslese. . . . . . . . . 249

Neunter Abschnitt. Entwicklung des Organismenreiches. Schluß 251-273

Anmerkungen . . . . . . . . . . . . . . . . . 274-289

Verzeichnis der Schriften August Weismanns . . . . . . . . . 290-297 
Die vorliegende Schrift ist eine ausführliche Bearbeitung eines Vortrages, den ich am 17. Juni I9I5 in der physikalischökonomischen Gesellschaft zu Königsberg i. Pr. gehalten habe. Ich übergebe sie hiermit in der neuen Form der Öffentlichkeit, mit dem Wunsche, daß sie dazu beitragen möge, bei den vielen, insbesondere auch bei den vielen Medizinern, die in Freiburg Weismanns Schüler gewesen sind, die Erinnerung an den großen Forscher und Lehrer lebendig zu erhalten.

Der Vortrag in seiner ursprünglichen Form behandelte vor allem Leben und Persönlichkeit Weismanns, seine wissenschaftlichen Arbeiten und Anschauungen aber naturgemä $B$ nur kurz und in den Hauptpunkten. Bei der Ausarbeitung sind diese Abschnitte viel umfangreicher und schließlich zu einer zwar durchaus nicht erschöpfenden, aber doch ziemlich eingehenden Darstellung von Weismanns wissenschaftlichem Lebenswerk geworden. Das lag einmal in einem persönlichen Moment: je mehr ich mich wieder in Weismanns Schriften versenkte, um so mehr übten sie auch wieder den alten Reiz aus, den wohl jeder empfunden hat, der sie seinerzeit bei ihrem Erscheinen las, und zugleich wurde die Erinnerung an Weismanns Persönlichkeit und seine Vorlesung, die ich in Freiburg noch als Prosektor hören konnte, wieder lebendig. Und dazu gesellte sich dann die Empfindung, da $B$ dem Andenken Weismanns nicht damit gedient wäre, gewisse allgemeine Redensarten und Schlagworte zu wiederholen, daß es aber nützlich sein könnte, seine Anschauungen, ihre historisch bedingte Stellung, ihre Begründung und ihren mannigfachen Wechsel möglichst gewissenhaft darzustellen. Ich hoffe, damit auch denen, die sich mit Weismanns Ansichten zu beschäftigen haben, die Arbeit zu erleichtern und Urteile zu verhüten, die auf ungenügender Kenntnis dieser Ansicht beruhen. Eine gerechte Würdigung eines Forschers kann ja immer nur erfolgen, wenn man ihn aus seiner Zeit heraus betrachtet, 
und ganz besonders muß das gelten auf dem Gebiete, auf dem sich Weismanns bedeutungsvollste Arbeiten bewegen: dem Gebiete der Vererbungslehre, das erst seit wenigen Dezennien der wissenschaftlichen Behandlung unterliegt, und auf dem die vereinte Arbeit zahlreicher Kräfte in diesem Zeitraum erst eine Sammlung und Sichtung eines großen Tatsachenmateriales vornehmen und Klarheit über die Fragestellung schaffen mußte. Unter denen, die an dieser Arbeit teilgenommen haben, steht Weismann in erster Linie, und viele Anschauungen, mit denen heute allgemein gerechnet wird, sind von ihm zum ersten Male aufgestellt oder doch erst von ihm in ihrer ganzen Wichtigkeit erkannt und in das allgemeine Bewußtsein übergeführt worden. Um das zur Geltung zu bringen, habe ich gesucht, bei der Darstellung der Gedanken Weismanns wenigstens kurz den damaligen Stand der betreffenden Fragen zu umreißen, und im Anschluß daran die Wandlungen mitberücksichtigt, denen, wie schon angedeutet, aus ganz den gleichen oben angeführten Gründen Weismanns Ideen in manchen Fragen im Laufe der Zeit unterworfen wurden. DaB ich hier und da diese Anschauungen mit Weismanns eigenen Worten wiedergegeben habe, ohne das immer besonders zu erwähnen oder kenntlich zu machen, wird hoffentlich keinem Tadel begegnen.

Eine eingehende Kritik der Lehren Weismanns war naturgemä $\beta$ hier nicht am Platze; ebensowenig wird erwartet werden, daß alle die vielen Probleme, zu denen der Gelehrte Stellung gcnommen hat, und die fortwährend Gegenstand eifriger Bearbeitung von verschiedenen Seiten sind, nach allen Richtungen hin dargestellt und in der Entwicklung verfolgt werden, die sie in den letzten Jahren genommen haben. Es ist zu erwarten, daß von anderer Seite eine mehr ins einzelne gehende kritische Darstellung der Weismannschen Auffassungen gegeben werden wird. Im übrigen aber finden sich alle die zahlreichen Darstellungen der Abstammungsund Vererbungslehre mit Weismanns Anschauungen in irgendeiner Weise $\mathrm{ab}$ und unterrichten genauer auch über die anderen Forscher*).

Bei der Zusammentragung des biographischen Materials haben mich in freundlichster Weise unterstützt: in erster Linie die Tochter Veismanns, Frau Regierungsrat Schepp, sowie Herr Gcheimer

*) Einige Lehrbuchliteratur ist in Anm. 26 angeführt. 
Rat Wiedersheim; ferner der derzeitige Dekan der philosophischen Fakultät in Freiburg, Herr Geheimer Hofrat Finke, durch dessen Vermittelung ich in den Besitz einer Abschrift der kurzen Lebensskizze gelangte, die Weismann selbst bei seiner Habilitierung der Freiburger medizinischen Fakultät eingereicht hat; weiter die Verwaltungen der Bibliotheken in Freiburg, Göttingen und Rostock; endlich Herr Privatdozent Dr. Richard Wegner in Rostock. Ihnen allen, insbesondere aber Frau Regierungsrat Schepp und Herrn Geheimen Rat Wiedersheim, möchte ich dafür hiermit nochmals meinen herzlichsten Dank aussprechen. 
Erster Abschnitt.

\title{
Das Leben. Der Mensch.
}

\author{
Zur Einleitung. - Lebenslauf. - Persönlichkeit.
}

\section{Zur Einleitung.}

Am 5. November I9I4 ist in Freiburg im Breisgau August Weismann gestorben, und mit ihm ein Forscher, dessen Name zu den am meisten genannten in der biologischen Wissenschaft der letzten Jahrzehnte gehört, zugleich ein Lehrer, der mit der Macht seiner Persönlichkeit auf Tausende werdender Naturwissenschafter und Ärzte den nachhaltigsten Einfluß ausgeübt hat. Da sein Tod in die Spannung und Erregung der ersten Kriegsmonate fiel, so ist das Ereignis vorübergegangen, ohne die Beachtung zu finden, die ihm in Friedenszeiten sicherlich geschenkt worden wäre. Auch jetzt noch regiert Mars die Stunde, und mit blutigen Waffen wird der Kampf um die Daseinsberechtigung der deutschen Kultur gekämpft; aber trotzdem, ja gerade darum darf die deutsche Wissenschaft, für die wahrlich genug auf dem Spiele steht, nicht der großen Männer vergessen, die in friedlicher Geistesarbeit dazu beigetragen haben, sie auf die Höhe und zu der Achtung gebietenden Stellung zu führen, die sie unter den Völkern einnimmt, und die ihr von dicsen auch bereitwillig eingeräumt wurde, bcvor blinder Neid und $\mathrm{HaB}$ alle Sinne und alles Urteil verwirrten. Zu diesen bedeutenden Vertretern der deutschen Wissenschaft der letzten Jahrzehnte aber gehörte Weismann, und so ist es eine Ehrenpflicht biologischer Kreise, nun, wo sein Leben abgeschlossen ist, seiner und seines Werkes rückblickend $\mathrm{zu}$ gedenken.

Über sein Leben und besonders über die Zusammenhänge der äußeren Umstände desselben mit seiner eigenen Entwicklung als 
Forscher hat uns Weismann bei Gelegenheit seines 70. Geburtstages, im Jahre I904, die wichtigsten Tatsachen selbst mitgeteilt; ich gebe sie hier, zum Teil unter Benutzung seiner eigenen Worte, aber ergänzt durch die von anderer Seite erhaltenen Angaben, wieder ${ }^{1}$ ).

\section{Lebenslauf.}

August $W_{c i s m a n n}{ }^{2}$ ) wurde geboren am I7. Januar 1834 in Frankfurt a. M., wo sein Vater Johann August Weismann, (ine ideal veranlagte Natur, als Gymnasialprofessor Vertreter der klassischen Philologie war. Die Mutter, Elise Lübbren, künstlerisch hoch begabt und auch als Malerin ausïbend tätig, stammte aus Stade in Hannover. Von dem ältesten bekannten väterlichen Vorfahr, Valentin Weismann, wird berichtet, daß er in der ersten Hälfte des I7. Jahrhunderts Bürger in Weierburg in Oberösterreich war und in Wien als Märtyrer gestorben ist. Sein Sohn Johannes Weismann, aus seiner Vaterstadt Weierburg als Protestant vertrieben, kam I656 nach Northeim in Württemberg, wo er Lehrer wurde. Dessen Sohn Erich wurde Prälat und Abt des Klosters Maulbronn. Noch durch zwei weitere Generationen blieb die Familie in Württemberg, dann wanderte ein Enkel des eben genannten Abtes, Immanuel Gottlob Friedrich Weismann, geb. I773, als Kaufmann nach Frankfurt a. M. aus. Er ist der Großvater A ugust Weismanns. - Der Vater der Mutter Weismanns war Bürgermeister und Landrat in Stade; seine Gattin, eine geborene Römhild, Pfarrerstochter aus der Nähe von Bremen, soll eine ganz besonders bedeutende und ungewöhnliche Frau gewesen sein ${ }^{3}$ ). Das sind nur wenige Tatsachen aus der Weismannschen Ahnentafel, und doch lassen sie recht wohl die Bedeutung erkennen, die Vererbung und Tradition, diese beiden großen, Gaben spendenden und Richtung bestimmenden Kräfte im Menschenleben auch für Weismann gehabt haben. Als mütterliches Erbteil darf man wohl den künstlerischen Sinn und die Phantasie ansprechen, die den Sohn die Natur lieben ließen, ihn zur Aufstellung einer umfassenden Hypothese trieben und ihn befähigten, seinen Gedanken die klare schöne Form in Wort und Schrift zu verleihen; von väterlicher Seite aber dürften der Ernst und die rastlose Hingabe stammen, die den Forscher Weismann auszeichneten und selbst seine Gesundheit 
im Dienste der Wissenschaft aufs Spiel setzen ließen, dazu auch die Überzeugungstreue und der Mut, mit dem er für das als recht Erkannte seine ganze Persönlichkeit allezeit eingesetzt hat. „Der Mensch und sein Schicksal fließen aus dem Erbteil seiner Vorfahren, inbegriffen die Stelle, an welche es ihn hingesetzt hat" mit diesen Worten hat er selbst, zugleich bewußt und bescheiden, bei seinem 7o. Geburtstag seiner wissenschaftlichen Auffassung von dem stammesgeschichtlichen Züsammenhang der Lebewesen auch für seine Person und für sein Leben Geltung zugesprochen.

$\mathrm{Zu}$ jenen beiden großen Kräften der Vererbung und Tradition gesellte sich die dritte: die Gunst der äußeren Verhältnisse, in denen seine Anlagen frei und ungehindert, nur sorglich beaufsichtigt, sich entfalten konnten. Frühzeitig schon legte der Knabe Liebe zur Natur an den Tag, sammelte Schmetterlinge, Käfer und Pflanzen, züchtete Raupen und beobachtete alles Lebendige, so daß die Mutter bald den künftigen Naturforscher in ihm erkannte, und ältere befreundete Botaniker ihm die Botanik als Lebensstudium vorschlugen. Aber auch Physik und namentlich Chemie haben ihn lebhaft angezogen. Indessen, der Wunsch des Vaters und auch der Rat des berühmten Chemikers Wöhler veranlaßten ihn, nach beendeter Gymnasialzeit sich der Medizin als einem Berufe, der zunächst einmal eine gesicherte Lebensstellung versprach, zuzuwenden. Von I852-I856 studierte er Medizin in Göttingen, wo Jacob Henle, Wöhler, W. Weber, v. Siebold und andere hervorragende Männer seine Lehrer waren. Nach abgelegtem Staatsexamen und Erwerbung des medizinischen Doktorgrades (9. Juli $\left.\mathrm{I}^{86}\right)^{4}$ ) trat er eine Stelle als akademischer Assistenzarzt am Krankenhause in Rostock an, dessen Direktor der Leiter der medizinisch-chirurgischen Klinik, Obermedizinalrat Professor Dr. C. F. Strempel war. Und hier vollendete er seine erste, schon in Göttingen begonnene selbständige Arbeit, deren Thema ,Über den Ursprung der Hippursäure im Harn der Pflanzenfresser" von der Göttinger medizinischen Fakultät als Preisarbeit gestellt worden war. Sie erhielt I857 den Göttinger Preis $\left.{ }^{5}\right)$. Seiner Liebe zur Chemie, und dem Vorschlag seines väterlichen Freundes, des Chemikers Franz Schulze folgend, vertauschte er aber schon am I. April I 857 seine klinische Stelle mit der eines (unbesoldeten) Assistenten am Rostocker chemischen Institut bei Schulze, wo er sich nun 
weiter mit chemisch-physikalischen Studien beschäftigte und in Bearbeitung einer von der philosophischen Fakultät in Rostock gestellten Preisaufgabe eine Untersuchung über den Salzgehalt der Ostsee lieferte, der im Sommer I858 von der genannten Fakultät der Preis zuerkannt wurde ${ }^{6}$ ).

Zugleich lernte er aber in dieser Stellung auch einsehen, daß die Chemie nicht die Wissenschaft sei, für die er geschaffen war, daß ihm manche Anlagen fehlten, die der Chemiker zum erfolgreichen Arbeiten braucht, während er andere, wie den Formenund Orientierungssinn, besa $B$, die in der Chemie kaum Verwendung finden. So gab er denn mit Schluß des Wintersemesters I857/58 auch diese Stellung wieder auf, kehrte Rostock den Rücken und ließ sich, nachdem er noch die größeren Universitäten Deutschlands besucht und in Wien einen etwas längeren Aufenthalt genommen hatte, Ende $x 85^{8}$ in seiner Vaterstadt Frankfurt als praktischer Arzt nieder. Hier behielt er nun bei der anfangs nur geringen Praxis reichlich Zeit $\mathrm{zu}$ theoretischen, namentlich histologischen Arbeiten, die in der Folge auch zu einigen wichtigen Entdeckungen führten. Zunächst freilich erfahren sie bald eine Unterbrechung. Der Krieg Italiens und Frankreichs gegen Österreich brach aus, und da eine Beteiligung Deutschlands wahrscheinlich schien, sah sich Weismann, den es drängte, sein ärztliches Wissen und Können einmal entsprechend zu verwerten und ein großes Ereignis mitzuerleben, veranlaBt, als Oberarzt in das badische Heer einzutreten (Sommer 1859). Aber es kam nicht zum Eingreifen Deutschlands; der Krieg fand durch die Schlacht von Solferino ein rasches Ende, und Weismann blieb, wie anderen Feldärzten, nichts übrig, als auf Urlaub zu gehen, um sich in den österreichischen Lazaretten hilfreich zu erweisen. So kam er nach Verona, sah viel menschliches Elend in den Lazaretten, aber auch zum ersten Male die Schönheit Italiens und die Kunst seiner Städte, Padua, Venedig, Mailand, Genua, Pisa, Lucca, Florenz, und knüpfte auch in Genua die Beziehungen zu dem Hause Gruber an, aus dem er sich später (I866) die Lebensgefährtin wählte.

Zunächst kehrte er nun wieder nach Frankfurt in die frühere Beschäftigung zurück und widmete aufs neue seine ganze freie Zeit histologischen Untersuchungen, als deren Ergebnis mehrere für die Histologie der Muskeln bedeutungsvolle Arbeiten zu nennen sind, 
so der Nachweis, daß die Herzmuskulatur bei allen Wirbeltieren aus charakteristischen quergestreiften Elementen besteht, ferner die Untersuchungen über das Wachstum der quergestreiften Muskelfasern u. a. Immer mehr drängte sich ihm dabei die Überzeugung auf, da $B$ ein Fortschreiten dieses Seitenzweiges der Anatomie vor allem durch seine Verbindung mit der Zoologie und vergleichenden Anatomie zu erreichen sein müßte; und der Wunsch, selbst in dieser Richtung tätig zu sein und der hindernden und unbefriedigenden Scheintätigkeit des praktischen Arztes zu entgehen, veranlaßte ihn. die erste Gelegenheit dazu zu ergreifen und eine ihm angebotene Stellung als Leibarzt bei dem österreichischen Erzherzog Stephan anzunehmen, der auf dem Schlosse Schaumburg an der Lahn inmitten eines kleinen Hofhaltes in Zurückgezogenheit lebte. Bevor er sie antrat, suchte er zunächst sich noch in der Zoologie weiter zu vervollkommnen; er ging Ende des Jahres I860 nach Paris, hörte bei Geoffroy St. Hilaire, Milne Edwards, Serres und Duméril, und erhielt die Erlaubnis, in den Sammlungen des Jardin des plantes zu arbeiten. Diese Studien wurden zu Anfang des Jahres I86r in Gießen unter Rudolph Leuckart fortgesetzt, in dessen Gemeinschaft Weismann zwei Monate verlebte, die er später selbst als ganz besonders fruchtbar und ergebnisreich bezeichnet hat. Eigenes angestrengtestes Arbeiten und dazu der tägliche Verkehr mit dem hoch bedeutenden und mitteilsamen Manne ließen ihn noch im späten Alter gestehen, daß er kaum je wieder eine wissenschaftlich so anregende Zeit verlebt habe, wie damals in Gießen. Dem verehrten Forscher hat er später auch zum 7o. Geburtstag das berühmte Hauptwerk seines Lebens „Das Keimplasma“ gewidmet. Der zweijährige Aufenthalt auf Schloß Schaumburg (I86I bis I863) bot ihm, was er erhofft hatte: geringe berufliche Inanspruchnahme und dafür Muße, in Wald und Wiese, Berg und Tal zoologisch zu forschen und dazu eine größere Spezialuntersuchung in Angriff zu nehmen. Es war das bis dahin wenig behandelte Gebiet der Insektenentwicklung, dem er sich mit lebhaftem Interesse zuwandte. Die erste Arbeit ,Über die Entwicklung der Dipteren im Ei" wurde in Schaumburg bereits vollendet.

So fühlte er sich denn im Jahre I863 reif, seinem Lieblingswunsch zu folgen, die Zoologie als Lebensfach zu ergreifen und sich der Universitätslaufbahn zuzuwenden. Im Mai i 863 habilitierte 
er sich als Privatdozent für Zoologie und vergleichende Anatomie in der medizinischen Fakultät zu Freiburg im Breisgau, wo damals die Zoologie noch von dem Ordinarius der Physiologie (- in jener Zeit: Otto Funke -) vertreten wurde, mit einer Arbeit ,Über die Entstehung des vollendeten Insekts in Larve und Puppe "7). Voll frohester Hoffnungen begann er seine neue Tätigkeit; die geringe Lehrtätigkeit lie $B \mathrm{ihm}$ reichlich Zeit $\mathrm{zu}$ wissenschaftlichen Forschungen, und mit vollster Hingabe ging er an die Aufgabe, das Arbeitsfeld, das sich ihm in Schaumburg erschlossen - die Embryologie der Insekten - nach allen Richtungen auszubeuten. Aber dieses reine Gliicksgefühl sollte nicht lange datuern, die übermäßige Anstrengung der Augen durch das Mikroskopieren rächte sich, und schon I Jahr später, Sommer x 864, traf ihn das schier schwerste Geschick, das einen Naturforscher treffen kann: er wurde augenleidend. Die Erkrankung, die ihn plötzlich, beim Mikroskopieren befiel, bestand zunächst nur in einer außerordentlich großen Überempfindlichkeit der Retina, während objektiv nur eine geringe Hyperämie der letzteren festzustellen war; doch an Mikroskopieren war zunächst nicht zu denken. Leider erwies sich auch die Hoffnung, durch Ruhe und Schonung bald eine Wiederherstellung zu erzielen, als trügerisch. Wochen, Monate und Jahre vergingen, ohne daß es Weismann möglich war, zu den begonnenen Forschungen zurückzukehren; müßig mußte er, wie er klagt, in der arbeitsfreudigsten Zeit des Lebens zusehen, wie andere auf den Bahnen weiterschritten, die er eröffnet hatte. - Ein Glücksstrahl in jenen traurigen Jahren war (I866) seine Verlobung und im folgenden Jahr (20. Mai I867) seine Verheiratung mit Marie Gruber, aus dem alten Kaufmannshause Gruber in Genua, die ihm dann 20 Jahre hindurch eine treue Lebensgefährtin gewesen ist. Verständnisvoll nahm sie in jener traurigen Zeit Anteil an allem, was Weismann trieb, musizierte mit ihm, las ihm vor und half ihm bei Experimenten, die er allein nicht hätte ausführen können. Und auch in seiner akademischen Laufbahn machte er Fortschritte: I 865 schon war er a. o. Professor der Zoologie und provisorischer Mitdirektor des zoologischen Institutes (neben O. Funke) geworden, und am 4. April 1867 erfolgte seine Ernennung zum etatsmäßigen a. o. Professor sowie die definitive Übertragung der Lehrkanzel und des Institutes (zunächst noch in der medizinischen Fakultät). Seine Antrittsrede, die er 
am 7. Juli I 868 hielt, handelte, ,Über die Berechtigung der Darwinschen Theorie"; es war die erste öffentliche Betätigung Weismanns auf dem Gebiete, dem er sich in der Folge immer ausschlieBlicher zuwandte. Immer mehr mußte er aber einsehen, daß der Zustand seiner Augen die wichtigste Lebensfrage für ihn bedeute, - hatte ihm doch $\mathrm{KuBmaul}$ geradezu geraten, die Zoologie wieder aufzugeben und zur praktischen Medizin zurückzukehren! Dieser letzte Ausweg mußte dem begeisterten Naturforscher denn doch zu verzweifelt erscheinen, und so versuchte er es zunächst erst noch einmal mit einem völligen Entsagen auf jede Inanspruchnahme der Augen, auch auf das Lesen, und ließ sich auf 2 Jahre von der Universität beurlauben. Nun endlich durfte er sich eines, wenn auch nur vorübergehenden, Erfolges erfreuen. Den Winter I869/70 brachte er in Rom zu, und hier schon zeigte sich eine Besserung, die dann nach seiner Heimkehr langsam zunahm. So konnte er nach Ablauf der 2 Jahre seine Lehrtätigkeit, und I874 - also Io Jahre nach Beginn der Erkrankung - auch seine Arbeiten, ja selbst das Mikroskopieren, wieder aufnehmen. Das vorhergehende Jahr hatte ihm auch schon (4. April I873) die Ernennung zum ordentlichen Professor in der philosophischen Fakultät gebracht, womit zugleich in Freiburg der erste ordentliche Lehrstuhl für Zoologie errichtet wurde. (Den Grad eines Dr. phil. h. c. verlieh ihm die Freiburger Fakultät am I6. Mai I879.)

Zehn weitere Jahre durfte er sich nun des Glückes, wieder selbständig forschen und beobachten zu können, erfreuen, und die Studien zur Deszendenztheorie, die Beiträge zur Naturgeschichte der Daphnoiden, die Untersuchungen über die Entstehung der Sexualzellen bei den Hydromedusen, alles umfangreiche Werke von bleibender Bedeutung, legen Zeugnis ab für den rastlosen Eifer, mit dem er diese Zeit ausnutzte. Empfand er doch, wie er selbst bekennt, die Rückkehr zur Spezialforschung auch darum als ein besonderes Glück, weil er, bei aller Freude an der spekulativen Arbeit, doch sich darüber klar war, daß ,ein möglichst großes und ausgebreitetes, zugleich ins einzelnste eindringendes Wissen der Untergrund alles naturforschenden Denkens und Spekulierens bilden müsse". Leider aber wirkte diese Tätigkeit aufs neue auf seine Augen zurück, und ziemlich genau Io Jahre nach Wiederaufnahme der mikroskopischen Arbeiten begann das linke Auge ernster, unter objektiv 
sichtbaren Veränderungen, zu erkranken. Nunmehr war aufs neue äußerste Schonung geboten, und Weismann sah sich wieder, und nunmehr dauernd, zu einer Beschränkung der eigenen mikroskopischen Tätigkeit gezwungen. Zum Glück behielt das rechte Auge seine Leistungsfähigkeit, und noch der Siebzigjährige konnte von sich sagen, daß keiner seiner Schüler die feinsten Einzelheiten eines mikroskopischen Bildes besser zı erkennen vermöge, als er selbst. So blieb ihm die Möglichkeit, mit seinen Schülern weiter zu arbeiten, und sie ist ihm geblieben bis in die letzten Jahre seines Lebens. Zahlreiche und bedeutungsvolle Arbeiten sind in dieser Zeit aus dem Freiburger zoologischen Institut hervorgegangen und haben Zeugnis abgelegt von dem wissenschaftlichen Geist, der in ihm lebte; ihre Verfasser, A. Gruber, C. Ishikawa, V. Haecker, O. vom Rath, H. E. Ziegler, W. Schleip, K. Günther, E. Snethlage, A. Petrunkewitsch, R. Woltereck, R. Kühn u. a. nehmen geachtete Stellung in der zoologischen Wissenschaft ein und erhalten die Erinnerung an ihren geistigen Führer und an eine glảnzende Zeit der Blüte, die unter ihm das Freiburger zoologische Institut erlebte.

Aber freilich, in erster Linie ist es eine gewaltige Denkarbeit, die Weismann in diesen letzten 30 Lebensjahren geleistet hat. Heldenhaft fand er sich mit seinem Schicksal ab, indem er, da ihm das Sehorgan versagte, die Fülle der Tatsachen, deren Erkenntnis er fortwährend, indem er sich vorlesen ließ, zu vermehren strebte, mit dem Organ des Geistes zu durchdringen, und allgemeine Gesetze aus ihnen zu erschließen suchte. Schon in den sechziger Jahren, bei seiner ersten Erkrankung, war er bei dem Suchen nach Aufgaben, die er trotz der Augen bewältigen könnte, auf das durch Darwin neu erschlossene und kaum noch in Angriff genommene Gebiet der Deszendenztheorie gekommen. „Über die Berechtigung der Darwinschen Theorie", so hatte der Titel der Antrittsvorlesung gelautet, die er im Jahre I868 als etatsmäßiger Professor gehalten. Sie bildete das erste Ergebnis der Beschäftigung mit der Deszendenztheorie und damit den Anfang einer Tätigkeit, die erst mit der dritten Auflage seiner ,Vorträge über Deszendenztheorie“ im Jahre I9I3, also kurz vor seinem Tode, ihren äußerlich erkennbaren Abschluß gefunden hat. Durch sie vor allem ist Weismanns Name in den weitesten Kreisen bekannt geworden als der eines der ersten 
und erfolgreichsten Vertreters und Fortbildners der Darwinschen Theorie in Deutschland. Darwins ,Entstehung der Arten“ hatte I859 wie ein Blitzschlag in die naturwissenschaftlichen Kreise eingeschlagen und mit unerhörter Schnelligkeit allenthalben gezündet. Noch im Alter gedachte Weismann mit Lebhaftigkeit jenes umwälzenden Ereignisses, das in die Zeit seiner empfänglichsten Jugend gefallen war. Was Wunder, daß die neue Botschaft auch sein Denken lebhaft erregte. Die Abstammungslehre beschäftigte ihn in den Jahren der ihm aufgezwungenen Arbeitspause und zeitigte hier (I872) eine Abhandlung über den Einfluß der Isolierung auf die Artbildung, die sich kritisch mit dem von Moritz Wagner aufgestellten ,Migrationsgesetz“ auseinandersetzt; in Beziehung zur Deszendenztheorie standen auch die Untersuchungen, die er nach Wiederaufnahme seiner mikroskopischen Tätigkeit von I874 an vorgenommen. So war er immer tiefer in die allgemeinen Fragen hineingekommen, und seine erneute Erkrankung war ihm ein Fingerzeig, in dieser Richtung nun weiterhin seine ganze Kraft einzusetzen. Schon im Jahre I88I hatte er auf der Naturforscherversammlung in Salzburg den Aufsehen erregenden Vortrag über die Dauer des Lebens gehalten und damit die Reihe kleinerer Schriften eröffnet, die gewisse, mit der Abstammungslehre in näherer oder fernerer Verbindung stehende biologische Einzelfragen behandeln. Von den Erörterungen über die Dauer des Lebens und den Ursprung des Todes wandte er sich in ihnen den Erscheinungen der Vererbung und der Fortpflanzung zu und gab ihnen einen vorläufigen Abschluß mit dem Aufsatz über die Amphimixis, die das Befruchtungsproblem zum Gegenstand hat. In den Kreisen der Biologen, aber auch weit über dieselben hinaus wohl bekannt, haben gerade diese Schriften, die dann auch später gesammelt erschienen, und von denen die wichtigsten ins Englische übersetzt worden sind, durch ihren Inhalt wie durch ihre Form berechtigtes Aufsehen erregt und in steigendem Naße den Ruf ihres Verfassers begründet wie das Interesse für die behandelten Fragen wach gerufen und zu ihrer Klärung beigetragen. Weismann wendet sich mit den meisten von ihnen an einen weiteren Leserkreis; ein Teil von ihnen ist auch geradezu aus Vorträgen hervorgegangen, die vor einer größeren Zuhörerschaar gehalten worden waren. Wit ihnen ist Weismann in die Reihe der ersten, im besten Sinne populären Schrift- 
steller getreten, die Namen allerbesten Klanges, wie Helmholtz, Ferdinand Cohn, Eduard Strasburger, E. Haeckel u. a. aufweist, und auf die die deutsche Wissenschaft mit besonderem Stolze blicken darf. Beherrschende Kenntnis eines ausgedehnten Tatsachenmateriales und geistige Durchdringung desselben vereinen sich hier mit der Gabe fließender rednerischer Darstellung, die in der Fähigkeit, auch schwierige Dinge klar und einfach zum Ausdruck zu bringen, außerordentliche Sprachbeherrschung, angeborenes Formentalent, aber auch einen vielseitig gebildeten Geist erkennen läßt. Väterliches und mütterliches Erbteil, der Philologe und die Künstlerin, verbinden sich hier, wie in allen Werken Weismanns, zu schönster Wirkung $\left.{ }^{8}\right)$. Diese Periode erhielt ihren Abschluß im Jahre I 892 mit dem Erscheinen des großen Werkes über das Keimplasma, in dem Weismann eine bis ins einzelnste durchgearbeitete Theorie der Vererbung entwickelt hat.

Sein äußeres Leben erfuhr in dieser Zeit eine tief einschneidende schmerzliche Veränderung: seine Gattin starb am I. Oktober I886. Ihr Tod beraubte ihn der Lebensgefährtin, mit der ihn 20 Jahre lang die innigste Gemeinschaft verbunden, die ihm über die schwerste Zeit seines Lebens hinweggeholfen hatte, und die ihm, bei der Schonungsbedürftigkeit seiner Augen, als Vorleserin eine ganz besonders große Hilfe gewesen war; er nahm seinen fünf Kindern, vier Töchtern und einem Sohn - eine fünfte Tochter war sehr jung gestorben - die Mutter, die ihnen noch so viel hätte sein können. Um so enger gestaltete sich in der Folge der Zusammenschluß der Kinder mit dem Vater ${ }^{9}$ ).

Wieder vergingen nun, von I892 an, Io Jahre rastloser Arbeit, in denen Weisman $n$ seine Theorie zu ergänzen und mit den Ergebnissen neuerer Forschungen in Einklang zu bringen, sie aber auch gegen Einwände zu verteidigen und immer besser zu festigen suchte. Denn an Einwänden hat es ihr freilich nicht gefehlt. Sie richteten sich gegen einzelne Punkte wie gegen ihre Grundgedanken. Weismann prüfte jeden, erkannte auch manchen Irrtum an, hielt aber an dem Grundsätzlichen, namentlich an seiner Überzeugung von der hohen Bedeutung des Selektionsgedankens, unerschütterlich fest und fügte 1896 in sein Ideengebäude den bedeutungsvollen Schlußstein mit der Aufstellung der Germinalselektion, die das Prinzip des auslesenden Wettbewerbs auf die 
kleinsten Teilchen innerhalb des Keimes überträgt, dabei aber allerdings von der eine Zeit lang zu weit getriebenen Bewertung der eigentlichen Darwinschen Zuchtwahllehre zurückkommt.

Aber nicht nur der Ausbau der eigenen Theorie nahm Weismanns Kraft in diesen ro Jahren in Anspruch, - diese war auch noch auf einem anderen Gebiete tätig: in der immer vollkommeneren Ausgestaltung seiner Vorlesung über Deszendenztheorie. Schon seine Antrittsrede im Jahre I868 war der letzteren gewidmet gewesen, $1874 \mathrm{kam}$ es versuchsweise $2 u$ einer ersten kurzen Sommervorlesung über dieses Gebiet, die einfach darauf ausging, den Darwinschen Ansichten Verbreitung zu verschaffen, und von r 880 $a b$ wurde die Vorlesung ziemlich regelmäßig in jedem Jahre gehalten. Im Laufe der Zeit änderte sich freilich ihr Aussehen recht beträchtlich. In dem Maße, wie die Abstammungslehre den Forscher immer mehr, immer vollkommener erfüllte, fügte sich Fremdes und Eigenes allmählich hinzu; bald war sie nicht mehr bloß ein Mittel, um für die Theorie eines Anderen Stimmung zu machen, sondern sie wurde die Form, in die Weismann alles, was ihm von innen und von außen an Tatsachen und fruchtbaren Ideen zuströmte, hineingoß, und in der es Gestaltung erlangte. Kein Wunder, daß diese Vorlesung von Jahr zu Jahr an Ruf und Zulauf wuchs, daß sie weit über die Grenzen Freiburgs, Badens, Deutschlands, ja Europas berühmt wurde, so daß von überallher die Studierenden und auch ältere Forscher zusammenströmten, um sie zu hören. Auch hier waren es Stoff und Form, beherrscht von einer lebendigen kraftvollen Persönlichkeit, die gleichmäßig anzogen und den Hörer in ihren Bann zwangen. Nicht um ein Semester lang sich über Deszendenzlehre vortragen zu lassen, sondern um Weismann zu hören, ging man nach Freiburg; Vertreter aller Fakultäten konnte man in dem Hörsaal des Freiburger zoologischen Institutes antreffen, und in Freiburg studiert und Weismann nicht gehört zu haben, wäre für einen Mediziner oder Naturwissenschafter kaum denkbar gewesen. Was Wunder, daß sich in Weismann selbst der Wunsch regte, die wirkende Kraft dieser Vorträge nicht mit dem eigenen Ich ersterben zu lassen, sondern über seine Lebensgrenze hinaus zu erhalten und damit zugleich, wie er selbst es ausdrückt, die Hauptergebnisse seines arbeitsfreudigen Lebens, zu einem abgerundeten und in sich harmonischen Bilde zusammen- 
gefaßt, als ein Vermächtnis den Nachkommenden zu hinterlassen. So erschienen denn I902 die "Vorträge über Deszendenztheorie" zum ersten Male, schon I904 wurde die zweite, I9I3 die dritte Auflage notwendig, - für ein umfangreiches wissenschaftliches Werk gewiß ein großer Erfolg. Aber diese Vorträge boten auch dem Hörer, der sie gehört, und bieten jetzt dem Leser, der sie liest, sehr viel mehr, als ihr Titel erwarten läßt: sie bilden eine Einführung in das weite Gebiet der allgemeinen Biologie, wie sie anregender wohl nicht geboten werden kann. Kaum ein Problem aus der allgemeinen Lebenswissenschaft, das hier nicht erörtert wird, und zwar erörtert von einer Persönlichkeit, die die eigene Anteilnahme an den Problemen durch die Kraft der Darstellung auf den Hörer und Leser zu übertragen vermag.

Weismann war 68 Jahre alt, als er I902 seine Vorlesungen zum ersten Male erscheinen ließ, und konnte wohl mit Befriedigung auf sein Lebenswerk blicken, das in ihnen zusammengefaßt nunmehr vorlag. Aber abgeschlossen hat er dieses Lebenswerk damit nicht. Die I2 Jahre, die ihm noch vergönnt waren, hat er immer weiter der Arbeit gewidmet. Freilich werden die selbständigen Veröffentlichungen spärlicher. Zı nennen wären noch die sehr eingehende Besprechung des Werkes von Semon über die Mneme und die Vererbung erworbener Eigenschaften (I9o6), ferner ,Eine hydrobiologische Einleitung", die er für die Internationale Revue der gesamten Hydrobiologie und Hydrographie verfaßte, endlich aus dem Jahre 1909 ein Aufsatz über die Selektionstheorie, den er für die Festschrift der Universität Cambridge zu Darwins Ioo. Geburtstag verfaßte, und die Rede, die er am I2. Februar I9o9 bei derselben Gelegenheit iiber ,Charles Darwin und sein Lebenswerk" in Freiburg gehalten hat. In alter gewohnter Weise frei vorgetragen, wird sie allen, die sie gehört, unvergeßlich bleiben. Daneben aber nahm die weitere Ausgestaltung der ,Vorträge“ seine Kraft in Anspruch: schon I904 wurde, wie gesagt, die zweite, I9I3 die dritte Auflage notwendig. Bei dem gewaltigen Aufschwung, den in diesem Zeitraum die Forschung über die Vererbung genommen hat, der Hochflut von Arbeiten auf den Gebieten, die die "Vorträge“ behandeln, war die Anforderung, das Buch in Fühlung mit der Wissenschaft zu halten, eine sehr große. Es konnte sich dabei ja auch nicht etwa nur um eine Einschaltung und Hinzufügung neuer Tatsachen 
handeln, sondern diese Tatsachen, namentlich die Ergebnisse der Mendel-Forschung verlangten eine Prüfung der persönlichsten theoretischen Vorstellungen. Mit Genugtuung konnte Weismann feststellen, daß die wichtigsten Grundlagen seiner Theorie sich auch den neuen Ergebnissen gegenüber als leistungsfähig erwiesen, während allerdings manches aus dem weiteren Aufbau entfernt und durch anders gestaltete Teile ersetzt werden mußte. Wenn man bedenkt, da $B$ es ein hoher Siebziger war, der sich hier mit den Ergebnissen einer rastlos vorschreitenden Forschung, aber auch mit den manchmal etwas rasch fertigen Werturteilen subjektiver, die geschichtliche Entwicklung auch der wissenschaftlichen Anschauungen nicht immer genügend berücksichtigender Überzeugungen abzufinden hatte, so wird man auch diese dritte Auflage noch als eine bedeutende geistige Leistung anerkennen müssen, wenn auch zuzugeben ist, daß die Durcharbeitung nicht mehr ganz glcichmäßig ist, ja, daß stellenweise auch Sätze aus den früheren Auflagen unverändert übernommen worden sind, die mit den sonst rorgenommenen Änderungen nicht mehr übereinstimmen.

In seinem häuslichen Leben hatten die Jahre nach dem Tode seiner Frau (I886) manche Veränderungen gebracht. Die Töchter verheirateten sich und verließen das Haus, und eine Zeitlang blieb er in diesem allein mit seinem Sohne Julius, der sich immer bestimmter der Musik zuwandte, und mit dem ihn die Liebe zu dieser ganz besonders verband. In Jahre I 895 entschloß er sich zu einer zweiten Ehe, aber sie führte nicht zu Familienglück - nach 6 Jahren trennten sich die Gatten und er lebte wieder einsam. Erst in der zweiten Hälfte der neunziger Jahre belebten sich die Räume des Hauses wieder mehr: seine älteste, frühzeitig des Gatten beraubte Tochter, Frau Regierungsrat Therese Schepp, zog mit ihren Kindern zu dem Vater und ward diesem, wie einst die Mutter, nicht nur eine treue sorgende Hausfrau und Begleiterin, sondern auch eine geistige Gefährtin, die ihm vorlas und seine mannigfachen Interessen mit ihm teilte. So erblühte ihm im Alter noch cinmal ein glückliches Familienleben, und sein Herz blieb jung im Zusammensein mit dem jugendfrischen Leben der Enkel.

Ein Höhepunkt seines Lebens war die eindrucksvolle Feier seines 70. Geburtstages am I7. Januar I904. Regierung, Stadt, Universität, wissenschaftliche Vereine, Fachgenossen, Schüler und 
Freunde, zum Teil von auswärts herbeigeeilt, huldigten dem verehrten Forscher; in vielen äußeren Zeichen, einer Marmorbüste (von dem Frankfurter Bildhauer Josef Kowarzik), einer Festschrift, Adressen und in zahlreichen Ansprachen kamen Dankbarkeit, Verehrung und Liebe zum Ausdruck. Auf alle Ansprachen erwiderte Weismann, zum Teil mit längeren Reden, in jugendlicher Frische, mit der Nacht des ihm so glänzend zu Gebote stehenden Wortes. Bei dem Festmahl gab er eine Übersicht über sein Leben, zugleich ein Bekenntnis über seine Lebensauffassung. Als den roten Faden, den leitenden Gedanken, der sich durch dasselbe hinzieht, bezeichnete er da den Idealismus, der in dem Streben liegt, die eigene Kraft da einzusetzen, wo sie, der einmal gegebenen Kombination von Anlagen entsprechend, am meisten erreichen mußte - kurz das Streben, den richtigen Lebensweg zu finden. Und mit einem herrlichen Wort, das sich jetzt glänzend bewahrheitet, und das für alle Zeiten gelten möge, schloß er: „Die Größe und Bedeutung unseres Vaterlandes beruht wesentlich auf dem Idealismus unseres Volkes. Nicht, daß wir diese Kultur schaffende Geistesrichtung allein besäßen, aber was wir als Volk geleistet haben, das haben wir durch sie geleistet."

Im Frühjahr Igr2 sah sich der Achtundsiebzigjährige genötigt, von seinem Amte zu scheiden, die Jahre verlangten ihren Zoll. Ein deutlicher Verfall der Kräfte und eigentlich krankhafte Erscheinungen stellten sich aber erst im Herbst I9I4 ein und führten dann zu einer raschen Auflösung. Wie sich später herausstellte, war es ein Leberleiden, das sein Ende herbeiführte. Am 5. November I9I4 verschied er. Über seine letzten Tage berichtet sein Schwager Wiedersheim: ,Eine große Freude war es für ihn noch in seinen letzten Tagen, daß er seinen Sohn ständig um sich haben durfte. Viele Stunden erquickte er sich noch an dessen meisterhaftem Klavierspiel, und während die Töne ihn umrauschten, breiteten sich über ihn die Schatten des Todes."

\section{Persönlichkeit.}

"Ein arbeitsfreudiges Leben", so hat Weismann in der Vorrede zur ersten Auflage der Vorträge von sich selbst gesagt, und in der Tat, die Freude am rastlosen Schaffen, an der Arbeit für die Wissenschaft und an sich selbst, beherrschte ihn bis zum Ende 
seiner Tage. Sein wissenschaftliches Lebenswerk muß schon lediglich seinem Umfange nach Bewunderung erwecken, eine Bewunderung, die sich zur Ehrfurcht steigert, wenn man das schwere Hemmnis berücksichtigt, das ein widriges Geschick ihm mit dem quälenden Augenleiden aufbürdete. Wenn er trotz desselben und trotz der Schonung und selbst zeitweiliger völliger Arbeitsunterbrechung, die es ihm auferlegte, so viel ausgeführt hat, so war das nur möglich durch äußerste Ausnutzung der Zeit und der Kräfte, durch konzentriertestes und zugleich planmäßiges, zielbewußtes Arbeiten. In der Aufeinanderfolge und dem inneren Zusammenhang der einzelnen Arbeiten läßt sich diese Planmäßigkeit leicht erkennen. Non multa, sed multum; seine Untersuchungen sind nicht angestellt, um hier und da eine Lücke auszufüllen, sondern aus einem inneren Drang, um zur Klarheit über bestimmte Fragen zu kommen; sie ordnen sich großen allgemeinen Gesichtspunkten unter und werden durch diese verbunden. Daraus ergab sich aber keineswegs beschränkte Einseitigkeit. Im Gegenteil, das Verzeichnis seiner Spezialarbeiten und ihr Inhalt zeigen, daß er sich seine Arbeitsstoffe aus den verschiedensten Gebieten wählte, und die ,,Vorträge über Deszendenztheorie" legen auf jeder Seite Zeugnis ab von der Vielseitigkeit seiner Interessen und Kenntnisse. Freilich hatte ihm das Geschick, das ihm den vollen Gebrauch des für ihn wichtigsten Sinnesorganes raubte, auch viel gegeben: seiner Arbeitsfreudigkeit gesellten sich die hohe geistige Begabung, der echte Forscherdrang, der zum Wissen und Erkennen kommen will, und ein berechtigtes Kraftgefühl, das, weit entfernt von eitler Überhebung, sich des eigenen Könnens und des Wertes der eigenen Leistung bewußt war. Dazu kam mancherlei Gunst der äußeren Verhältnisse. In einer geistig belebten Atmosphäre war er aufgewachsen, sorgfältig erzogen von hochstehenden, verständnisvollen Eltern, beeinflußt von manchem bedeutenden Menschen. Ungehindert durch Existenzsorgen konnte er sich seinen Lehrberuf wählen, konnte er die Wissenschaft nur um ihrer selbst willen treiben. Das Glück leitete ihn auch bei der Wahl seines Aufenthaltsortes. In Freiburg, wo er sich habilitierte, lagen die Verhältnisse in seinem Fache sehr günstig, so da $\mathrm{B}$ sich seinen Leistungen auch gleich die Anerkennung und der äußere Erfolg, Arbeitsfreudigkeit und Kraftgefühl belebend und steigernd, hinzugesellten, und der lähmende Einfluß langdauernder 
Erfolglosigkeit ihm erspart blieb. Dazu kam die wunderbare Natur Freiburgs, der Vorzug der kleineren Stadt, wo die Kräfte nicht $i_{n}$ dem Betriebe großstädtischen Lebens aufgerieben, und die Stunden schon zur Überwindung räumlicher Entfernungen zerstückelt und gemordet werden. Und wie mußte gerade auf einen Forscher, der die Natur so liebte, wie Weismann, die Lage Freiburgs wirken, Freiburgs, dem einst Lorenz Oken die begeisterten Worte zum Abschied zurief: ,wer in Dir den offenen Sinn für Schönheit der Natur, für Kunst, für Freundschaft und Frohheit des Lebens nicht erhält, der findet ihn nimmermehr!“ In vollen Zügen hat auch Weismann die Schönheit dieser Natur genossen und aus ihr Erfrischung und neue Arbeitskraft gewonnen, als ein wahrer Weiser hat er die Segensquellen des Ortes sein Leben befruchten lassen. Hier schuf er sich, abseits von dem Leben der Stadt und doch nicht zu fern von seinem Institut, sein Haus mit dem prachtvollen großen, Ruhe spendenden Garten, mit dem Blick auf den Schloßberg, mit den beiden hochragenden dunklen Zypressen vor dem Eingang, die wie ein Wahrzeichen auf das hohe ernste Streben hindeuteten, das an dieser Stelle herrschte. Aber auch edle Geselligkeit, namentlich in Verbindung mit Pflege der Musik, zog hier oft ein, denn Weismann war im Grunde eine gesellige Natur, und nur sein Augenleiden verhinderte eine regere Betätigung in dieser Hinsicht.

Die herrliche Umgebung Freiburgs zog Weismann unwiderstehlich hinaus. In jüngeren Jahren besonders unternahm er bei jeglichem Wetter kleinere und größere Wanderungen, wo möglich in Gesellschaft von Kollegen. Mit solchen gründete er schon in den sechziger Jahren die „Philambulatoria“, einen Verein wanderlustiger Kollegen, zu denen damals Binding, de Bary, später auch Windelband, Rümelin und viele andere bedeutende Männer gehörten. Aber seine Wanderungen und Reisen dienten nicht nur der Erholung, sondern auch der Belehrung. Weismann war ein guter Botaniker und besa $\beta$ vortreffliche Kenntnisse der heimischen Flora, und daß die Landesfauna dabei mit erforscht wurde, ist wohl selbstverständlich. Hier war es besonders das buntschillernde Heer der Schmetterlinge, das ihn anzog und zu wissenschaftlichen Fragestellungen anregte, aber auch das Fischnetz wurde oft in die Tiefe des Titisees, des Boden- und Züricher Sees und in den Lago maggiore versenkt, und manchen Tag, aber auch manche 
klare oder stürmische Nachtstunde hat Weismann im Boote zugebracht, um das Material für seine Monographie der Daphnoiden zu sammeln.

Die Ferien verbrachte er in früheren Jahren häufig am Bodensee auf dem Lindenhof, dem Besitztum der Gruberschen Familie, aus der seine Frau stammte, oder auch in Genua in dem dortigen Stammhause der Familie Gruber. Hier konnte er in gleicher Weise sich der Erholung wie der Arbeit widmen, und hier empfing er die Anregung zu manchen Untersuchungen: in Schachen zu der Studie über das Tierleben des Bodensees und namentlich zu der großen „Naturgeschichte der Daphnoiden“, an der Riviera zu den Untersuchungen über die Hydromedusen, die er dann in Le Croisic in der Bretagne sowie in Neapel ergänzte.

Auch sonst hat er manches schöne und interessante Stück Welt kennen gelernt; so hat er Italien mit seinen Hauptkunststätten, ferner Korsika, Sardinien, die weitere Riviera, aber auch England, Belgien, Holland und in den neunziger Jahren auch Griechenland und Konstantinopel aufgesucht und durchstreift.

$\mathrm{DaB}$ er zeitlebens, in weiser Verwendung seiner Kräfte, Arbeit und Erholung vereinen konnte, das dankte er außer den glücklichen Verhältnissen, in denen er lebte, auch dem Entgegenkommen einer weitschauenden Regierung, die in voller Würdigung seines Wertes und seiner Bedeutung für die Freiburger Universität nicht nur, wo es ging, seinen Wünschen bezüglich des Institutes entgegenkam, sondern auch mehrfach den erbetenen Urlaub zur Vollendung bestimmter Unternehmungen erteilte. Bei dem Zusammenwirken so glücklicher Verhältnisse versteht man es, daß er Freiburg zeitlebens treu blieb und Rufe nach auswärts (Breslau, Bonn, vor allem München I884) ausschlug. Das kam beiden Teilen zugute: ihm selbst blieb der Zeitverlust und die Unterbrechung der ruhigen Arbeit erspart, die ein Wechsel des Aufenthaltsortes und ein Einleben in neue Verhältnisse notwendig zur Folge gehabt hätten; der Universität Freiburg aber blieb ein Lehrer erhalten, der ihren Ruf weit über die Grenzen Deutschlands hinaus getragen und zu ihrem glanzvollen Aufschwung in den letzten Dezennien an erster Stelle beigetragen hat.

An äußerer dankbarer Anerkennung seines Wirkens hat es ihm nicht gefehlt. Die badische Regierung ehrte ihn durch hohe 
Auszeichnungen, sein Großherzog ernannte ihn zum Wirklichen Geheimen Rat mit dem Prädikat Exzellenz, und verlieh ihm nach anderen hohen Orden das Großkreuz des Zähringer Löwenordens, vom König von Bayern erhielt er den Maximiliansorden für Kunst und Wissenschaft; die Stadt Freiburg ernannte ihn zu ihrem Ehrenbürger. Groß war auch die Zahl der Ehrungen seitens wissenschaftlicher Gesellschaften des In- und Auslandes. Er war Mitglied der Akademien von Berlin, München, Heidelberg, Stockholm, der Royal Societies von London und Edinburgh, Mitglied der Linnean Society, Doctor of Common Law der Universität Oxford, Doktor der Botanik von Utrecht, Ehrenmitglied der Deutschen zoologischen Gesellschaft. Von sonstigen wissenschaftlichen Vereinigungen sei die Internationale Gesellschaft für Rassenhygiene erwähnt, die ihn ebenfalls, in Anerkennung seiner Verdienste auf dem Gebiet der Vererbungslehre und seines Eintretens für den Selektionsgedanken, zu ihrem Ehrenmitglied ernannte.

Aber diese Ehrungen konnten ihn nicht zur Täuschung über sich selbst und zur Kritiklosigkeit gegenüber seiner Arbeit verleiten. Zu seinem 8o. Geburtstag schrieb sein Nachfolger Doflein: ,Weismann gehört und hat immer zu jenem Typus von akademischen Lehrern gehört, den ich am höchten stellen möchte, nämlich zu jenen Männern, welche unabhängig an der Vervollkommntung ihrer eigenen Persönlichkeit arbeiten. Nur wenn sie selbst mit den Resultaten ihres Denkens und Arbeitens zufrieden sein können, glauben solche Männer, ihren Schülern Genüge z11 tun." Diese Strenge gegen sich selbst hatte denn freilich zur Folge, daß er auch anderen gegenüber große Anforderungen stellte und ein scharfer Kritiker war. Ernstes Streben und wirkliche Leistungen wurden von ihm rückhaltlos anerkannt und gefördert; Minderwertiges wies er zurück. Die Reizbarkeit, die durch die Empfindlichkeit seiner Augen fortwährend gesteigert wurde, ließ dabei gelegentlich einmal sein Urteil auch unnötigerweise schroff und selbst verletzend werden, und den persönlichen Umgang mit ihm etwas schwierig gestalten. Als natürliche Folge davon ergab sich, daß er mehr Bewunderer als nahe stehende Freunde hatte und zeitweise in eine Isoliertheit geriet, die ihm, bei voller Erkenntnis ihrer Ursache, manche trübe Stunde bereitete. Und doch besaß er nicht nur einen scharfen Geist und eine vornehme Gesinnung, sondern auch ein 
reiches Gemüt und ein warm empfindendes Herz. In schlichten Worten herzlicher Dankbarkeit erzählte er bei Gelegenheit seines 70. Geburtstages von seiner Kindheit, seinen Eltern und den Lehrern, die auf sein Leben Einfluß gehabt, und bei derselben Gelegenheit konnte der Dekan seiner Fakultät es aussprechen, daß noch nie ein sorgenschwerer Kollege sich Weismann offenbart habe, ohne die herzlichste Teilnahme und, wenn möglich, die tatkräftigste Unterstuitzung gefunden zu haben.

Die Empfindlichkeit der Augen war aber auch eine unmittelbare Veranlassung für ihn, große Geselligkeit zu meiden, ihn in erster Linie auf ein Leben in stiller Zurückgezogenheit und in konzentrierter geistiger Arbeit zu verweisen. Doch nahm er an dem wissenschaftlichen Leben Freiburgs regsten Anteil, insbesondere an der Tätigkeit der Naturforschenden Gesellschaft, in der er selbst manchen Vortrag gehalten hat. Die vielen Vorträge, die er auf Naturforscherversammlıngen und bei anderen öffentlichen Gelegenheiten in Deutschland und dem Ausland vor einer großen, durchaus nicht nur aus Fachleuten bestehenden Zuhörerschaft gehalten, zeigen ja auch zur Genüge, daB er die Wissenschaft nicht als ein Monopol eines eng begrenzten Kreises betrachtete, sondern sie allen Gebildeten zugänglich machen wollte; sie offenbaren auch die besondere Gabe, die er dafür besaß. Auch dem Leben der Universität widmete er seine Zeit und seine Kraft. „,Seit 30 Jahren sind Sie Mitglied unserer Fakultät, seit 30 Jahren nehmen Sie regsten Anteil an allen unsere Fakultät interessierenden Fragen, haben ausgeharrt in mancher nicht gerade kurzweiligen Sitzung, bescheiden still sich zurückhaltend, wenn es um weniger wichtige Fragen sich handelte, gern Ihren erfahrenen Rat erteilend, wenn schwierigere Sachen zur Entscheidung standen, ohne Scheu, männlich fest in die vordersten Reihen sich stellend, wenn es galt, die Rechte der Universität, die Freiheit der Wissenschaft zı verteidigen" - mit diesen Worten kennzeichnete an seinem 70. Geburtstag der Fakultätsdekan diese Seite seiner Tätigkeit.

Seine Arbeit galt natürlich in erster Linie seiner Wissenschaft; ihr widmete er sich forschend im Institut, allein oder mit seinen Schülern, lehrend im Hörsaal, lernend zu Hause und bei den Referierabenden, die er eingerichtet hatte. Wie viel ihm daran lag. durch Verfolgung der Literatur, mit den Fortschritten der Wissen- 
schaft Fühlung zu behalten, lehrt die Forderıng, die er einmal ausspricht $\left.{ }^{10}\right)$ : daB nur in wenigen Sprachen publiziert werden soll. Das ist ihm die unumgängliche Grundlage eines weiteren gemeinsamen Zusammenarbeitens der Völker an dem Bau der Wissenschaft. Indessen dürfe die Sache nicht etwa vom Standpunkte der Nationalitätsfrage betrachtet werden, sondern allein von dem höheren, der allgemeinen Menschenbildung. Nicht ein Unterdrücken der kleineren Nationalitäten durch die größeren soll erreicht werden, sondern ein freiwilliger Verzicht aller der Völker auf den Gebrauch der eigenen Sprache auf wissenschaftlichem Gebiet, deren Sprache entweder keine weiteVerbreitung oder doch noch keine große wissenschaftliche Literatur hat. Dieses Opfer muß gebracht werden, im Dienste der Wissenschaft, wie im eigenen Interesse der Arbeitenden selbst. - Es wäre in der Tat schön, wenn diese Auffassung überall Geltung hätte!

Für die internationale Verbreitung der Ergebnisse wissenschaftlicher Forschung ist Weismann uibrigens nicht nur mit dem Wort, sondern auch mit der Tat eingetreten; es dürfte wenig deutsche Forscher geben, von denen so viele Werke, auch reine Spezialarbeiten, zugleich in fremder, besonders englischer, Sprache erschienen sind. Auch persönlich war im Vaterlande Darwins der Nachfolger des großen Britten kein Fremder: mehrfach hat er dort, von gelehrten Gesellschaften aufgefordert, Vorträge gehalten. Aber auch in Frankreich, in Amerika, in Japan, - wo wäre Weismanns Name nicht bekannt gewesen?

$\mathrm{DaB}$ er mit ganz besonders regem Interesse und freudiger Genugtuung den Einflu $B$ verfolgte, den der Entwicklungsgedanke, die Vererbungslehre, insbesondere seine Vererbungslehre, sowie die Selektionslehre auf allen Gebieten erlangten, nicht nur auf dem Gebiete der Pathologie und klinischen Medizin, sondern auch auf dem der sogenannten Geisteswissenschaften, wie für die Betrachtung der kulturellen und sozialen Zustände und als leitende Gedanken bei den auf die Reform der letzteren gerichteten Bestrebungen ist wohl selbstverständlich. Die Ehrenmitgliedschaft der Internationalen Gesellschaft für Rassenhygiene nahm er an; für das Archiv für Rassen- und Gesellschaftsbiologie schrieb er eine kritische Besprechung von Semons ,Mneme“.

Aber Weismann war nicht einseitiger Fachmann und erschöpfte sich nicht in der Zoologie; Geschichte, Kunst, Literatur 
bildeten nicht minder die Bereiche, aus denen er sich vorlesen ließ, - denn darauf war er freilich angewiesen, - und auf den verschiedensten Gebieten war er wohl bewandert. Die Natur hatte ihm eine reiche Fülle geistiger Gaben in die Wiege gelegt, und in ernster Arbeit und Selbstzucht strebte er, sie zu entwickeln. Neben seiner Wissenschaft steht in erster Linie die Kunst, namentlich die Musik, und diese vermochte es auch am häufigsten, ihn aus der Arbeitsstube heraus und unter Menschen zu locken. Die Erfahrungstatsache, die sich in Universitätsstädten oft genug beoachten läßt, daß gerade unter den Medizinern und den Vertretern der organischen Naturwissenschaften musikalische Veranlagung ganz besonders häufig zu finden ist - man denke an berïhmte Beispiele: Billroth, Mikulicz, Neisser, die Chirurgen Nußbaum, Engelmann u. v. a. - wurde auch durch Weismann bestätigt. Weiteren Kreisen ist das bekannt geworden durch seinen Aufsatz über die Musik bei Tieren und Menschen; in Freiburg wußten es alle, die sich um Musik kümmerten; die hohe stattliche Erscheinung mit dem großen grünen Augenschirm, der die empfindlichen Sehorgane vor dem blendenden Lichte schützen sollte, war in Konzertsälen wohl bekannt. Viel kleiner freilich war der Kreis derer, die ihn selbst sein Instrument, das Klavier, haben spielen hören; sich zu produzieren, war nicht seine Sache. Nur ein einziges Mal, in der ersten Zeit meines Freiburger Aufenthaltes, habe ich selbst dazu Gelegenheit gehabt: bei dem gemeinsamen Spiel der G-Dur(I. Alexander-)Violinsonate von Beethoven. Er spielte gut und besa $B$, wie seine Angehörigen bekunden, ein glänzendes Gedächtnis, das ihn befähigte, ein großes musikalisches Repertoir auswendig zu beherrschen, - eine besonders glückliche Gabe angesichts seines Augenleidens. Sein Herz gehörte den alten großen Meistern; im tiefsten Innern seiner Natur lag es begründet, daß er von dem folgerichtigen Aufbau und der Geschlossenheit der Form nicht absehen konnte. So sind seine Vorträge stets sorgfältig gegliedert und kommen zu einem wirklichen Abschluß, einem Ergebnis, das oft die Form einer Sentenz, einer allgemeinen Wahrheit annimmt, so strebte er darnach, seine Keimplasmatheorie in sich als Ganzes abzuschließen, - und so widerstrebte ihm das Ruhe- und Endlose Wagnerscher II usik. Erst durch seinen Sohn Julius, in dem die musikalische Veranlagung des Vaters in gesteigertem Maße weiter lebt, und der 
als Komponist sich einen geachteten Namen geschaffen hat, gewann er auch mit der modernen Musik etwas mehr Fühlung. Sein Urteil. sowohl über Werke wie über ihre Wiedergabe, konnte recht scharf sein; ,,keine Weihe“ — das war einmal die kurze Kritik einer Aufführung der Matthaeus-Passion. -

Aber auch zeichnerisch war er - ein Erbteil der Mutter über Durchschnitt begabt; bei weitem die meisten Abbildungen für die viclen Tafeln seiner Spezialarbeiten hat er selbst angefertigt. So war auch sein Sinn für Werke der bildenden Kunst hoch entwickelt. Davon zeugte manches schöne Gemälde in seinem Hause, und die Gallerien von Rom, Florenz, München konnten ihn, wie sein Schwager Wiedersheim bekundet, zu leidenschaftlicher Begeisterung hinreißen. In der Geschichte der bildenden Kunst war er wie in der der Musik wohl bewandert.

Das entsprach ja aber auch nur seiner Geistesrichtung, die ihn trieb, überall nach dem großen Zusammenhang der Erscheinungen zu forschen, das Seiende als Gewordenes aus dem Werdegang zu begreifen. Mit ciesem wahrhaft historischen Sinn betrachtete er die Natur und so auch das Leben der Menschen und die Geschicke der Völker. Ein glühender Patriot, trat er schon in den sechziger Jahren mit Treitschke für ein einiges Deutschland unter Preußens Führung ein, -- damals eine kühne Tat, die ihm viele Feinde zuzog. Den Ausbruch des Weltkrieges hat er noch erlebt, und bis in die letzten Tage seines Lebens hat er die Ereignisse desselben mit innerster Anteilnahme verfolgt. Wie er selbst über den Urheber des Krieges und seine Motive dachte, brachte er zum Ausdruck, indem er sich der verschiedenen Ehren und Würden, die ihm von englischer Seite geworden waren, entäußerte.

Eine so bedeutende, vielseitige Persönlichkeit konnte auf keinen geeigneteren Platz gestellt werden, als auf den des deutschen Hochschullehrers mit seinen drei großen Aufgaben des Lernens, Forschens und Lehrens. Wenn je einer, so hat Weismann diesen Ehrenplatz voll ausgefüllt. Was er seinen Hörern sagte, war erarbeitet in intensivster Geistestätigkeit, empfunden mit dem Herzen und gekleidet in die Form einer schön vollendeten Sprache. Sein vortreffliches Gedächtnis und seine angeborene Gestaltungskraft gestatteten ihm, frei zu sprechen, mit nur gelegentlicher Benutzung kurzer Notizen. Er sprach gewöhnlich sitzend, mit dem Rücken 
gegen das Fenster gekehrt, mit halber Wendung gegen sein Auditorium, den einen Arm auf die Stullehne aufgelegt, beide Hände ineinander verschränkt. So, ein Bild völligster Sammlung, holte er die Gedanken aus dem Innersten heraus und formte sie wie in einem zwanglosen Gespräch. Dadurch gewann sein Vortrag etwas ungemein Fesselndes und zwang zum Mitdenken. Ganz im Gegenteil zu denen, die in der Überleitung einiger Tatsachen auf den Zuhörer die ganze Aufgabe des akademischen Lehrers sehen und den Standpunkt nicht elementar genug wählen zu können glauben, suchte er vielmehr die Hörer zu seiner Höhe herauf zu ziehen, ihnen immer den Zusammenhang der Einzeltatsachen mit größeren allgemeinen Fragen zu zeigen, auf sie seine Begeisterung für diese zu übertragen und sie geradezuals Mitarbeiter aufzurufen. Ihm war die Universität etwas anderes als die Mittel- oder Fachschule, und der deutsche Universitätsprofessor ein Lehrer und Erzieher der akademischen Jugend, der sich allezeit bewußt war, daß unter dieser Jugend auch die Besten des Volkes, die geistigen Führer der Zukunft, vor ihm saßen. Der glänzende Erfolg, den er als akademischer Lehrer gehabt, die Verehrung, die die Studentenschaft ihm entgegengebracht, zeigten ihm, wie recht er mit dieser Auffassung hatte. Nicht die gewöhnliche „Beliebtheit" war es, was ihn mit der Studentenschaft verband; weder strebte er darnach durch geschickte Vermittelung von Examenskenntnissen noch durch väterliche Beaufsichtigung und Bevormundung studentischer Unreife; das Band, das ihn mit der akademischen Jugend verknüpfte, war ein edleres. In schöner Weise kam das zum Ausdruck in den Ansprachen bei der Feier seines 70. Geburtstages. „Jung sind Sic geblieben in Ihrem Berufe als Lehrer, bei dem Sie noch jetzt mit der Frische des Eifers, mit der Wärme der Überzeugung die Herzen aller Hörer zwingen. Jung aber in einem noch viel tieferen Sinne, als führender Geist ciner Wissenschaft, die in unserer Zeit der Ausblick auf neue Ziele mit einem neuen, jugendlichen Geiste erfüllt hat, auf Ziele, denen die vorurteilsfreie Jugend überall freudig zuströmt, während die Alten noch hier und da zögernd zur Seite stehen. So gehen Sie heute noch mitten unter uns Jungen. Aber Sie gehen mit uns nicht nur als Lehrer, sondern auch als Berater, Sie begeistern uns nicht nur mit der Kraft der Jugend, sondern Sie halten uns auch mit Besonnenheit, die das bessere Gut des reiferen 
Alters ist. Und das tut not. .. " In der Erwiderung auf diese Worte des Vertreters der Studentenschaft sagte Weismann: „Es ist für einen Lehrer der Jugend wahrlich nicht gleichguiltig, ob er sich im Kontakt fühlt mit seinen Hörern, ob er glauben darf, daß sein Wort bei ihnen zündet, da $B$ er ihnen nicht nur neuen Wissensstoff überliefert, sondern sie auch zugleich zur Wissenschaft selbst hinleitet, ihnen Begeisterung für dieselbe einflößt und sie so dazu anregt, ihm auf die Pfade $\mathrm{zu}$ folgen, welche er selbst gewandelt ist. Verstehen Sie mich recht. Ich meine nicht, daß jeder von Ihnen forschender Naturbeobachter werden solle oder gar jeder Zoologe oder Biologe! Nein! Die meisten von Ihnen werden einen praktischen Beruf verfolgen, werden nützliche Diener des Staates und der menschlichen Gesellschaft werden und nur verhältnismäßig sehr wenige werden sich der Wissenschaft selbst widmen und versuchen, dieselbe durch eigene Forschungen weiter zu führen. Es wäre ja auch schlimm, wenn wir auf unseren Hochschulen lauter Naturforscher und Philosophen erzögen oder lauter Geschichts- oder Sprachforscher! Der größte Teil von Ihnen wird praktisch anwenden, was er von der Universität nach Hause mitbringt, aber ein jeder wird, so hoffe ich und so muß es ein, auch mit einem Tropfen idealistischen Öles gesalbt sein, und das ist das Beste, was Ihnen die Universität geben kann - nicht das eigentliche Spezialwissen, so notwendig und so unentbehrlich dasselbe auch ist, sondern die Ehrfurcht vor der Wissenschaft selbst als solcher, als des Weges zur Erkenntnis, zu dem geistigen Ziele der Menschheit, dem sie sich mehr und mehr anzunähern bestrebt ist." Das war die ideale Auffassung seines akademischen Lehrberufes. Sie wird immer die höchste bleiben und, wenn dem Wollen das Können und Vermögen entspricht, auch die wirkungsvollste bleiben. Das Gefühl meilenweiter Entfernung, das der Schüler gegenüber der Ehrfurcht gebietenden Persönlichkeit eines überragenden Gelehrten und Forschers empfindet, wandelt sich in ein Gefühl der Gemeinschaft auf edelster Grundlage, wenn dieser selbst sich als Diener der Wissenschaft bekennt und seine Schüler aufruft zur Mitarbeit in diesem Dienste. So erfüllt auch die Hochschule ihre Aufgabe, mehr zu sein als eine bloße Fachschule: eine Bildungsund Erziehungsstätte, die nicht nur praktisch verwertbare Kenntnisse übermittelt, sondern vor allem die besten Kräfte, die in dem 
Schüler selbst liegen, zur Entfaltung bringt. An diese Macht der Wissenschaft glaubte Weismann: „Denn Sie werden nicht mit so manchen Gedankenlosen glauben, da $B$ die Wissenschaft in erster Linie dazu da sei, nützliche Entdeckungen zu machen, vor allem solche Kenntnisse der Naturkräfte oder der Lebewesen zu gewinnen, die unser Leben erleichtern oder sichern: Dampfmaschinen, Telegraph, Telephon, antiseptische Wundbehandlung, Kenntnis der Fieberparasiten des Blutes usw. So ungemein wichtig alle diese und viele andere Fortschritte auch für die Menschheit sind, man wïrde nie zu ihnen gelangt sein, hätte man nur um ihrer Willen Naturforschung getrieben. Sie sind alle nur Abfälle in der Werkstatt der Naturforschung, deren eigentliches Arbeitsziel immer nur die reine Erkenntnis ohne alle Nebenziele sein kann“... „,Die Wissenschaft nimmt bereitwillig solche praktische Verwertungen ihrer Resultate an und verwendete sie fürs menschliche Leben, aber sie arbeitet und strebt ursprünglich und in erster Linie immer nur nach der reinen Erkenntnis, und das ist es, was ich den Idealismus der Wissenschaft genannt habe. Das Streben nach Erkenntnis ist dem menschlichen Geist tief eingeprägt, und dies Streben ist es, was unser Leben und Denken mehr vertieft und unser Wesen hebt und vervollkommnet - nach allen Richtungen, nicht nur nach der des Verstandes, sondern auch nach der des Ethischen, nach der des Humanismus im eigentlichen Sinne." Diese Worte enthalten gewissermaßen das Glaubensbekenntnis Weismanns, die Richtlinien, die sein Leben bestimmt haben.

In den Erinnerungsworten auf Romanes, der, einer der bedeutendsten Nachfolger Darwins auf englischem Boden, zu Weismann vielfach in Gegensatz getreten war, sagte dieser (I894): „,So hat seine rastlose Tätigkeit erst mit dem Leben geendet, und man kann von ihm das Beste sagen, was man von einem hervorragenden Mann sagen kann: er hat die Gaben, mit welchen die Natur ihn ausrüstete, voll und ganz zur Entfaltung gebracht." Auch auf Weismann selbst lassen sich diese Worte anwenden. Auch ihm ist es beschieden gewesen, in Ausbildung der reichen Gaben, die ihm die Natur verliehen, sich zu einer vollen großen Persönlichkeit zu entwickeln. Eiserner Fleiß und unbeugsame Willenskraft, gefördert von einer idealen Lebensauffassung, ließen ihn die Hemmungen überwinden, die sich aus seinem körperlichen 
Leiden ergaben, und verhinderten ein Versinken in untätiger Resignation, wie es sich gerade bei dieser körperlichen Behinderung aus den sonstigen günstigen äußeren Verhältnissen, dem Wegfall eines rauhen Zwanges, leicht hätte ergeben können. Er bestätigte die Auffassung, der er selbst wiederholt Ausdruck gegeben hat: daß für hervorragende menschliche Leistungen nicht die angeborene intellektuelle Begabung allein maßgebend ist, sondern daB Fleiß, Beharrlichkeit, Selbstzucht hinzukommen müssen. In Vereinigung dieser Fähigkeiten schuf er sich lernend die breite Grundlage des Wissens und Könnens, drang er erfolgreich forschend in die Tiefen der Natur und wirkte er lehrend als berufener Erzieher der akademischen Jugend.

So wird Weismanns Name fortleben in der Wissenschaft als der eines der bedeutendsten biologischen Forscher und Denker; in der Erinnerung aller aber, die ihn gekannt, und insbesondere der Tausende, die zu seinen Füßen gesessen, wird seine ragende Gestalt mit dem schönen Gelehrtenkopf unvergessen bleiben, und wird sein Gedächtnis fortwirken als das eines großen Gelehrten, der seinen Schülern die größte nachhaltigste Anregung zum Denken gegeben, ihren Blick über den engen Kreis der besonderen Interessen auf die großen allgemeinen Fragen und die höchsten Ziele der Menschheit gelenkt, Begeisterung für wissenschaftliche Aufgaben erweckt, aber auch das Beispiel eines rastlos arbeitenden und vorwärtsstrebenden Menschen gegeben, - als das eines der edelsten Verkörperer des reinen Idealismus, dem Deutschland und insbesondere die deutschen Hochschulen ihre Größe verdanken. 
Zweiter Abschnitt.

\section{Die Spezialarbeiten.}

Wissenschaftliche Tätigkeit Weismanns, Übersicht. - Chemische Arbeiten. - Histologische Arbeiten. - Embryologische Arbeiten. - Allgemein-biologische Arbeiten: Studien zur Deszendenztheorie; - Biologie der Süßwasserfauna, Daphnoidenstudien, parthenogonische und zyklische Fortpflanzung; - Die Hydromedusenstudien, Bildung der Keimzellen.

\section{Wissenschaftliche Tätigkeit Weismanns, Übersicht.}

Die wissenschaftliche Tätigkeit Weismanns kennzeichnet sich als die eines Naturforschers großen Stiles, der nicht in der bloßen Feststellung des Tatsächlichen das Endziel der Forschung sieht, sondern aus der Beobachtung des normalen Seins und Geschehens allgemeine Gesetze zu erschließen und diese auch durch das zielbewußt angestellte Experiment zu prüfen und $\mathrm{zu}$ sichern sucht. Inhaltlich lassen sich die der Spezialforschung gewidmeten Arbeiten von denen unterscheiden, die die Deszendenztheorie und mit ihr zusammenhängende Fragen behandeln; chronologisch füllen die der ersten Gruppe in der Hauptsache auch die der ersten Schaffensperiode aus, die der zweiten Gruppe die zweite. Den Spezialarbeiten sind die nachfolgenden Blätter gewidmet, die durchaus keine eingehende Würdigung derselben versuchen, sondern mehr. im allgemeinen über ihre Absichten unterrichten sollen.

\section{Chemische Arbeiten.}

Seine wissenschaftlichen Sporen hat sich Weismann, wie aus der Darstellung seines Entwicklungsganges ersichtlich, auf dem Gebiete der Chemie erworben; von den Arbeiten über die Ent- 
stehung der Hippursäure im Harn und über den Salzgehalt der Ostsee sind besonders die ersteren bei den physiologischen Chemikern bekannt und gewürdigt. Für Weismanns persönliche Entwicklung sind sie darum von Wert, weil sie ihn mit Bestimmtheit erkennen ließen, daß nicht die anorganische, sondern die organische Natur das Feld sei, auf dem seine spezifischen Anlagen sich am besten entfalten könnten.

\section{Histologische Arbeiten.}

Jene ersten Arbeiten wurden abgelöst von den histolog ischen, unter denen die über die Muskelelemente die bedeutendsten und bekanntesten sind. Sie behandeln die glatten, quergestreiften und Herzmuskelelemente, unter anderem besonders Neubildung und Wachstum der quergestreiften Muskelfasern sowie die Verbindung der letzteren mit den Sehnen, und haben die Kenntnis auf diesen Gebieten wesentlich gefördert, auch einen technischen Fortschritt gebracht: die Anwendung der Kalilauge für die Untersuchung des Muskelgewebes. Vor allem von grundlegender Wichtigkeit aber sind die Untersuchungen über die Muskelelemente des Herzens beim Menschen und bei den Tieren; sie werden Weismanns Namen auch auf histologischem Gebiete nicht vergessen lassen. Eine kleine besondere Untersuchung ist dem Bau des Nabelstranges gewidmet, und endlich lieferte dem jungen Arzt ein an der eigenen Hand infolge einer Verletzung aufgetretenes und dann operiertes Neurom das Material zı Beobachtungen über die Neubildung von Nervenfasern. Kein Zweifel wohl, daß in diesen histologischen Arbeiten der Einfluß nachwirkt, den der Unterricht Jacob Henles in Göttingen auf den jungen Studenten ausgeübt. Um sie ihrem Werte nach voll zu würdigen, muß man aber bedenken, daß Weismann sie nicht in einem anatomischen Institute und nicht auf unmittelbare Anregung und unter den Augen eines beratenden Lehrers angestellt, sondern auf eigene Faust, als selbstgewählte Nebenbeschäftigung in den — allerdings reichlich zugemessenen Mußestunden, die ihm die Tätigkeit des praktischen Arztes in Frankfurt ließ. Und noch ein anderes verdient hervorgehoben zu werden: die Ausdehnung der Untersuchungen auf zahlreiche verschiedene Formen: Wirbeltiere, Gliedertiere, Würmer, Mollusken, Echinodermen, Coelenteraten, ein Ausdruck der hohen Bedeutung, 
die Weismann der vergleichenden Betrachtung auch für die Entwicklung der Histologie als selbständigen Zweiges der anatomischen Wissenschaft zuerkannte.

\section{Embryologische Arbeiten.}

Über die vergleichende Histologie gelangte Weismann auf ausschließlich zoologisches Gebiet, auf dem zunächst die Arbeiten iiber die Embryologie und die Metamorphose der Insekten zu nennen sind. Auch für sie dürfte dem jungen Forscher die Inspiration letzten Grundes aus dem Zusammensein mit hervorragenden Zoologen, namentlich aus dem Aufenthalt bei Rudolph Le uck a rt in Gießen zugeflossen sein, aber die Aufgabe im besonderen hat er sich wohl selbst gestellt, und bei ihrer Bearbeitung war er durchaus auf sich selbst angewiesen. Mit um so größerer Genugtuung konnte er sich der Anerkennung freuen, die diese Arbeiten in Zoologenkreisen gefunden, und des Einflusses, den sie auf die Forschung gehabt haben. Um so schwerer freilich auch mußte er das Geschick empfinden, das ihn zwang, diese Arbeiten vor der Zeit unvollendet wieder $\mathrm{zu}$ unterbrechen, einen großen Teil des angesammelten Materiales ungenützt liegen zu lassen und, was wohl das Schmerzlichste war, sehen zu müssen, wie andere die von ihm angeregten Fragen weiter verfolgten und mit Hilfe der damals aufkommenden Schnittmethode manches in einem anderen und zweifellos richtigeren Lichte sahen als er, der die Entwicklungsvorgänge nur am lebenden, sich entwickelnden Ei verfolgt hatte. So hat er nur noch einmal, I882, einen Nachtrag zu jenen Untersuchungen geliefert, darin manches anders dargestellt als früher, manche frühere Auffassung, so bezüglich der Keimblätterbildung bei den Insekten, geändert, auch manche wichtige neue Beobachtung hinsichtlich der ersten Entwicklungsvorgänge mitgeteilt (Bildung der Richtungskörper, frühe Bildung der Keimzellen) - im übrigen aber mit Resignation von diesen Arbeiten, die seinen wissenschaftlichen Aufstieg eingeleitet hatten, Abschied genommen.

\section{Allgemein-biologische Arbeiten.}

Als vierte Gruppe von Spezialarbeiten können die zusammengefaßt werden, die nach I 868 entstanden und von I874 an erschienen sind; mit einer gemeinsamen Bezeichnung könnte man sie als all- 
gemein-biologische kennzeichnen. Sie behandeln Bau und Lebenserscheinungen größerer Gruppen von Tieren, aber auch bestimmte Einzelfragen, und zeigen Weismann nicht nur als grïndlichen Beobachter am Mikroskop, sondern auch als planmäßig vorgehenden Experimentator und als den wahren Biologen, der mit Liebe und immer neuer Bewunderung das vielgestaltige Leben der Tiere betrachtet. Eins ist ihnen allen gemeinsam: sie alle zeigen mehr oder weniger innige Beziehungen zu der Deszendenztheorie, zu der Weismann durch die Schonungsbedürftigkeit seiner Augen geführt worden war, und zu der er I868 in seiner Antrittsvorlesung zum ersten Male öffentlich Stellung genommen hatte. Sie berühren alle mit dieser zusammenhängenden Fragen: die Variabilität, wobei die Frage nach dem direkt umgestaltenden Einfluß der äußeren Lebensbedingungen sowie die nach dem Walten einer etwaigen inneren Entwicklungskraft zu berücksichtigen waren; die Vererbung, die wieder zu einer eingehenderen Behandlung der Vorgänge führte, an die sie geknüpft ist: der Entstehung und Reifung der Keimzellen sowie der Fortpflanzung in ihren verschiedenen Formen; die Bedeutung der Selektion auf Grund des Überflusses von Variationen und unter dem auslesenden Einfluß der äußeren Verhältnisse, des Kampfes ums Dasein, zwecks Erzielung zweckmäßiger Anpassungen, endlich die Korrelation. Manche dieser Arbeiten sind geradezu mit der ausgesprochenen Absicht unternommen worden, über die genannten Fragen Klarheit zu erlangen, so die unter dem gemeinsamen Titel: „Studien zur Deszendenztheorie" herausgegebenen; bei anderen ist der Ausgang ein anderer, aber im weiteren Verlauf führen auch sie zu einer allgemeinen Betrachtung in einer der genannten Richtungen. So eröffnen sie eine neue Periode in Weismanns Schaffen, die wichtigste in seinem Leben, und bilden die Grundlage und weiterhin die Begleitung der theoretisch-zusammenfassenden Schriften, die von I88I an in den Vordergrund treten. Soweit sie vor diesem Jahre erschienen sind, leiten sie zu den theoretischen Anschauungen Weismanns, geben ihm den AnlaB, sich über die theoretischen Fragen, auf die es ankommt, klar zu werden, führen ihn allmählich auf den Weg zur Beantwortung dieser Fragen und schaffen die ersten Bausteine zu dem späteren Theoriengebäude herbei; vom Anfang der achtziger Jahre an gewinnt die Theorie feste Gestaltung, 
und bildet nun umgekehrt den Anstoß und Ausgang zur Vornahme besonderer Untersuchungen, die die Theorie prïfen sollen.

Die hierher gehörigen Arbeiten können in vier Gruppen geordnet werden. Eine erste beginnt mit den Abhandlungen, die Weismann selbst unter dem Titel: ,Studien zur Deszendenztheorie" zusammengefaßt hat, und erfährt eine Ergänzung durch eine spätere Untersuchung über den Saison-Dimorphismus der Schmetterlinge (I895); eine zweite hat zum Ausgang die Forschungen, die sich mit der Süßwasserfauna beschäftigen, und wird fortgesetzt durch die daraus hervorwachsenden Untersuchungen über Parthenogonie, Reifungs- und Befruchtungsvorgänge bei tierischen Eiern; eine dritte bilden die Studien an den Hydroidpolypen; eine vierte endlich umfaßt einige kleinere Untersuchungen der späteren Jahre: über Duftschuppen der Schmetterlinge, über Regeneration, über Umkehrversuche an Hydra. Über diese letzteren wird im Zusammenhang mit den allgemeinen Fragen, die sie behandeln, zu berichten sein.

\section{Studien zur Deszendenztheorie.}

Die ,Studien zur Deszendenztheorie" lassen schon in ihrem Titel die Absichten erkennen, die sie verfolgen; in der Vorrede zu ihrem zweiten Heft hat sich Weismann genauer darüber ausgesprochen. Das erste Heft (I 875 erschienen) enthält den ersten Bericht über die so bedeutungsvoll gewordenen Versuche, die Weismann über den Einfluß der Temperatur auf die Puppen gewisser Schmetterlinge angestellt hat, um die Frage $\mathrm{zu}$ prüfen, wie weit die direkt umgestaltenden Wirkungen äußerer Einflüsse bei der Artbildung eine Rolle gespielt haben mögen. Diese Versuche, deren Beginn mindestens schon in das Jahr I869 fällt ${ }^{11}$ ), gelten der von A. R. Wallace als Saison-Dimorphismus benannten Erscheinıng: der Verschiedenheiten im Aussehen der Frühjahrs- und der Sommergeneration einer und derselben Schmetterlingsart, Verschiedenheiten, die vielfach so bedeutend sind, daß beide Formen früher als ganz selbständige Arten beschrieben wurden. Vom Standpunkte der Transmutationslehre aus mußten gerade diese Fälle als günstiges Objekt erscheinen, um den Einflüssen, die bei den Umwandlungen der Arten mitspielen, nachzugehen. Als maßgebender Faktor bei den genannten Verschiedenheiten ergab sich 
bald die Temperatur, und so kam Weismann selbständig zu der Vornahme von Versuchen, wie sie - was ihm erst nach Abschluß derselben bekannt wurde — schon einige Jahre vor ihm (I864) zuerst von Dorfmeister veröffentlicht worden waren. Nach Weismann wurden sie dann von verschiedenen Forschern, H. W. Edwards, v. Reichenau und besonders, vom Ende der achtziger Jahre an, von Merrifield, Dixey, StandfuB, Brandes, E. Fischer u. a. in größerem Umfang fortgeführt und haben viel diskutierte Ergebnisse von weittragendster Bedeutung gezeitigt. Auch Weismann selbst ist in den achtziger Jahren noch einmal zu ihnen zurückgekehrt und hat sie an einer größeren Anzahl von Arten wiederholt, um noch bestimmtere Antworten auf seine Frage zu erhalten. Über diese zweite Serie von Versuchen und ihre Ergebnisse ist in dem „Keimplasma“ ( 1892 , S. 523 u. f.) sowie in einer besonderen Abhandlung vom Jahre 1895 berichtet.

An den klassisch gewordenen Objekten, dem Landkärtchen (Vanessa levana-prorsa) und dem kleinen Weißling (Pieris napi), auf die sich die ersten Versuche bezogen, konnte zunächst deutlich der Einfluß der Temperatur festgestellt werden: Puppen des Weißlings, die unter normalen Bedingungen die Sommergeneration ergeben hätten, ließen, in der Kälte aufgezogen, wieder die Winterform ausschlüpfen. Nicht ganz so vollständig gelangen die Versuche mit Vanessa: meist entstand durch die Kältewirkung statt der Sommerform (V. prorsa) eine Mittelform zwischen der Winterund der Sommerform, die sogenannte Vanessa porima, und nur in einigen Fällen schlüpfte eine nahezu vollständige Winterform (V. levana) aus. Der Einfluß der Temperatur auf die Färbung war damit jedenfalls erwiesen. Der Versuch Weismanns, daraufhin die stammesgeschichtliche Entstehung des Saison-Dimorphismus zu erklären, nimmt an, daß die Winter-(Levana-)Form die ursprüngliche ist und früher, in der Zeit des Diluviums, allein vorhanden war, da $B$ aber dann, als das Klima wärmer und der Sommer länger wurde, sich eine Sommergeneration, ja sogar deren zwei einschoben, die allmählich unter dem Einfluß der Wärme die Prorsa-Form annahmen, die nun allmählich durch Vererbung fixiert wurde. Die Levana-Form ist also die ältere, die Prorsa-Form die jüngere, und wenn jetzt durch den Einfluß abnormer Kälte die Prorsa-Form zur Annahme der Levana-Form gezwungen wird, so bedeutet das 
eine Rückkehr zur Stammform. Im Experiment wäre also die Kälte nur der Reiz, der diesen Rückschlag bedingt; nach Weismann könnten auch andere Reize in gleicher Weise wirken.

Die allgemeinen Ergebnisse dieser und der späteren Schmetterlingsexperimente sind nach verschiedenen Richtungen hin bedeutungsvoll. Als wichtigstes allgemeines Ergebnis betrachtete Weismann selbst I875 den Nachweis, daß lediglich durch den Einfluß veränderter äußerer Lebensbedingungen eine Art zum Abändern veranlaßt werden kann, und zwar zum Abändern in bestimmter Richtung, die wieder abhängig ist von der physischen Natur der variierenden Organismen, verschieden bei verschiedenen Arten, ja selbst bei den beiden Geschlechtern einer und derselben Art. Die Umwandlung der Art beruht nur zum Teil auf äußeren Einflüssen, zum anderen Teil auf der spezifischen Natur dieser einen Art. Diese spezifische Reaktion beruht aber nicht auf einer verborgenen neuen Form von Lebenskraft, sondern darauf, daß jede Art ihre eigene besondere Entstehungsgeschichte hinter sich hat. Damit hat Weismann schon hier in ganz bestimmter Weise zu der Lehre vom Vorhandensein einer besonderen, den Organismen innewohnenden Umbildungskraft Stellung genommen, einer Frage, a uf die er später noch wiederholt zurückgekommen ist. In zweiter Linie ist von Bedeutung die Schlußfolgerung, daß durch direkte Wirkung des Mediums, - hier: des Klimas - eine Art umgewandelt werden kann. Die dazu nötige und von Weismann damals auch ohne Bedenken gemachte Annahme, daß die Veränderungen, die durch jene direkte Einwirkung hervorgerufen werden, erblich sind, mußte ihm freilich solche Bedenken von dem Augenblick an erregen, wo er sich eingehend mit dem Vererbungsproblem befaßte und zu der Überzeugung kam, daß ,erworbene“ Eigenschaften nicht vererbt werden können. Der Klärung dieser Frage galten dann ganz besonders die in den achtziger Jahren aufs neue vorgenommenen Versuche, von denen einige, so die mit dem kleinen Feuerfalter (Polyommatus Phlaeas) angestellten ganz besonders bedeutungsvoll geworden sind. Sie führten zu einer Bestätigung, aber auch zu einer Erweiterung und Ergänzung der früheren Resultate. Bestätigt wurde die Auffassung, daß in der Tat manche Fälle von Saison-Dimorphismus in der früher erschlossenen Weise zu erklären seien: durch erbliche Häufung 
von Abänderungen, die unter dem direkten Einfluß des Klimas entstanden; erweitert wurde diese Auffassung durch eine - später zu behandelnde - Erklärung, wie diese direkten Mediumeinwirkungen und ihre Erblichkeit theoretisch gedacht werden müssen; ergänzend endlich aber kam hinzu die Schlußfolgerung, daß es neben dem ,direkten“ Saison-Dimorphismus noch einen ,,adaptiven" gibt. Das heißt: gewisse Fälle von Saison-Dimorphismus sind im Laufe der Stammesgeschichte entstanden unter dem indirekten Einfluß des Klimas; die Besonderheiten in Färbung, Zeichnung usw. der Sommer- wie der Winterform stellen besondere schützende Anpassungen an die zu den beiden Zeiten verschiedene Umgebung dar und sind das Ergebnis von Ausleseprozessen, die viele Generationen hindurch während der beiden Jahreszeiten wirksam waren, die günstig gefärbten Individuen mit ihren entsprechenden Vererbungstendenzen erhaltend, die ungünstigen ausmerzend. Die verschiedene Temperatur ist in diesen Fällen nicht die wirkliche Ursache der bestimmten Zeichnung, sondern nur der Reiz, der ihre Anlage auslöst, zur Entwicklung veranlaßt.

Endlich hat noch ein theoretischer, von Weismann zuerst geäußerter Gesichtspunkt in der Diskussion der später von Merrifield, StandfuB, E. Fischer u. a. erlangten Versuchsergebnisse eine Rolle gespielt: der Gedanke, daß die experimentell auf die Schmetterlingspuppen angewendete Kälte als Auslösungsreiz wirkt, der Rückschläge zur Stammform hervorruft. Insbesondere die durch extreme Kälte oder Wärme bei verschiedenen Vanessa-Arten erzeugten „Aberrationen“ sind später vielfach als Rückschläge auf phyletisch ältere Formen gedeutet worden.

Nicht vergessen neben diesen mehr speziellen Ergebnissen seien aber auch die Erörterungen, über das Verhältnis des ,,SaisonDimorphismus" zu dem ,Generationswechsel", über die verschiedenen Formen des letzteren und ihre Abgrenzung gegeneinander. Die Beschäftigung gerade mit diesen Fragen war dann wieder mit eine Veranlassung zum Studium der zyklischen Fortpflanzungserscheinungen bei den Daphnoiden, die uns noch beschäftigen müssen.

So sind Weismanns Schmetterlingsversuche nach verschiedenen Richtungen hin bedeutungsvoll und fruchtbar geworden.

Dem ersten Heft der ,,Studien“ folgte schon ein Jahr später (I876) ein zweites, in dem unter dem Gesamttitel: „Über die 
letzten Ursachen der Transmutationen" vier Abhandlungen vereinigt sind: drei, die naturwissenschaftliche Einzelheiten behandeln, und eine vierte, die unter dem Titel: ,Über die mechanische Auffassung der Natur" die Ergebnisse derselben zusammenfaßt, sie durch allgemeine Erwägungen noch weiter $\mathrm{zu}$ stuitzen und $\mathrm{zu}$ einer philosophischen Natur- und Weltauffassung zu gestalten sucht. Ausdrücklich gibt das Vorwort an, daß die Untersuchungen, über die hier berichtet wird, unternommen wurden, ,um Klarheit darüber zu erlangen, ob die von Darwin aufgestellten Prinzipien der Umwandlung: Variabilität, Vererbung, Kampf ums Dasein und Korrelation zum Verständnis der tatsächlich beobachteten Umwandlungserscheinungen ausreichen, ob wirklich die gesamte organische Welt nur als das Resultat des Aufeinanderwirkens von Organismus und Außenwelt gelten darf, oder ob wir damit nicht ausreichen, vielmehr genötigt sind, eine unbekannte, treibende Entwicklungskraft in den Organismen anzunehmen, wie eine solche von verschiedenen Forschern unter verschiedenem Namen in die Wissenschaft einzuführen versucht worden ist, so von Nägeli als ,Vervollkommnungsprinzip", von Kölliker als ,Schöpfungsgesetz', von Askenasy als ,bestimmt gerichtete Variation', von den Philosophen von Hartmann und Huber als ,organisches Entwicklungsgesetz' oder auch als ,Universalprinzip der organischen Natur', ein metaphysisches Prinzip, welches man wohl nicht unpassend als, phyletische Lebenskraft' bezeichnen und so der nur für das Gebiet der individuellen Entwicklung eingeführten (on tog enetischen) Le benskraft der alten ,,naturphilosophischen" Schule gegenüberstellen darf.

Die erste Abhandlung, über, ,die Entstehung der Zeichnung bei den Schmetterlingsraupen", unternimmt es, auf einem kleinen Gebiet, dem der Zeichnung der Raupen aus der Familie der Schwärmer oder Sphingiden, die Leistungsfähigkeit der von Darwin aufgestellten Prinzipien zu prüfen. Wie durchaus unvoreingenommen Weismann an die Untersuchung herantrat, geht aus seinen eigenen Worten hervor: „Zwei Möglichkeiten liegen hier vor, dieselben, welche sich uns in bezug auf die Entwicklung des organischen Lebens im großen und ganzen darbieten. Entweder die so eigentümlichen, verwickelten und für uns scheinbar unverständlichen Charaktere, welchen wir den Namen einer Zeichnung 
geben, verdanken ihre Entstehung der direkten und indirekten Einwirkung langsam sich ändernder Lebensbedingungen - oder sie entstehen aus rein inneren, im Organismus selbst gelegenen Ursachen, aus einer phyletischen Lebenskraft.“ . . . „Die ganze Untersuchung wäre von mir nicht angestellt worden, wenn ich zu denjenigen gehörte, welche sich von vornherein zur Allmacht der Naturzüchtung bekennen, wie zu einem Glaubensartikel oder einem wissenschaftlichen Axiom. Eine Frage, die nur auf induktivem Wege einer Lösung sich nähern kann, darf unmöglich nach den ersten Proben, die günstig für dieses Prinzip ausfielen, nun als gelöst, und weitere Proben als überflüssig angesehen werden. Gewiß hat die Annahme einer geheimnisvoll wirkenden phyletischen Kraft für unsern nach Erkenntnis strebenden Geist etwas sehr Unbefriedigendes; jedenfalls ist dieselbe aber nicht dadurch als widerlegt anzusehen, daß man die Entstehung hunderter von Charakteren auf Naturzüchtung zurückführen kann, die vieler anderer auf direkte Einwirkung äußerer Lebensbedingungen. Soll die absolute Abhängigkeit der Entwicklung der organischen Welt von den Einflüssen der Außenwelt nachgewiesen werden, so darf man nicht bloß beliebige Charaktere hier und dort herausgreifen, wie sie sich gerade für die Erklärung am besten zugänglich zeigen, sondern man muß vor allem den Versuch machen, sämtliche Charaktere einer bestimmten, wenn auch kleinen Erscheinungsgruppe vollständig auf die uns bekannten Umwandlungsfaktoren zurückzuführen. Es wird sich dann zeigen, ob dies möglich ist, oder ob ein aus den bekannten Prinzipien nicht erklärbarer Rest bleibt, der dann zur Annahme einer im Innern der Organismen liegenden Entwicklungskraft zwingen würde. Jedenfalls läßt sich die ,phyletische Lebenskraft' nur durch Eliminierung beseitigen, durch den Nachweis, daß alle überhaupt vorkommenden Charaktere der betreffenden Erscheinungsgruppe auf andere Ursachen zurückgeführt werden müssen, daß somit für die vorausgesetzte phyletische Lebenskraft nichts zu tun übrig bleibt" ${ }^{12}$ ). Dies die allgemeine Fragestellung; die besondere, auf den vorliegenden Fall bezügliche, würde lauten: ist die Raupenzeichnung ein ,rein morphologisches", biologisch bedeutungsloses Merkmal und somit hervorgerufen durch innere Ursachen, oder aber besitzt sie eine biologische Bedeutung, ist 
sie also nützlich und somit auf Selektionsprozesse zu beziehen, oder, allgemeiner gesprochen, lediglich die Reaktion des Organismus auf äußere Einflüsse? An einem in jahrelanger Beobachtung selbst zusammengebrachten Tatsachenmaterial studiert Weismann zur Beantwortung dieser Frage die Entstehung und allmähliche Ausbildung der Färbung und Zeichnung bei einer großen Anzahl von Formen und versucht sich über den biologischen Wert dieser Merkmale Rechenschaft abzulegen. Dabei ergab sich das überraschende Resultat, daß es in der Tat recht wohl möglich ist, für die vier Hauptformen der Zeichnung (I. gänzliche Abwesenheit jeder Zeichnung, 2. Längsstreifen, 3. Schrägstreifen, 4. Augenflecken und Ringflecken) einen biologischen Nutzen einzusehen. Abgesehen von den Flecken, die als Schreckmittel oder Widrigkeitszeichen Bedeutung haben, lassen sich alle als Anpassungen an die Umgebung, in der die Tiere leben, erklären, - als Schutzzeichnungen, durch die die letzteren innerhalb ihrer natürlichen Umgebung schwerer erkennbar werden. So finden sich die Längsstreifen hauptsächlich bei Formen, die zwischen Gräsern leben, überhaupt an Pflanzen mit dünnen, zahlreich nebeneinander aufsprießenden Stengeln, grasartigen Blättern oder auch an Pflanzen mit nadelartigen Blättern, die Schrägstreifen aber an solchen, die auf großblätterigen Sträuchern leben. Hier erscheinen sie als Nachahmung der Seitenrippen eines Blattes, manchmal von einem farbigen Saum begleitet, der die Täuschung erhöht, indem er wie der Schlagschatten der betreffenden Rippe aussieht. So führt die Untersuchung zu einem kaum erwarteten Ergebnis: sie gestattet eine Schlußfolgerung hinsichtlich der stammesgeschichtlichen Entstehung der Zeichnungen und rechtfertigt weiter den Schluß, daß jede der Zeichnungen, als Anpassungen an die ganz bestimmten Lebensverhältnisse biologisch wertvoll, lediglich durch Naturzüchtung und Korrelation entstanden und ausgebildet ist. Damit beantwortet sich jene Frage auf dem hier behandelten engen Gebiete jedenfalls dahin, daß für die Annahme einer phyletischen Lebenskraft keine Veranlassung vorliegt.

Von Schmetterlingen und Raupen handelt auch die zweite Studie: „Über den phyletischen Parallelismus bei metamorphischen Arten." Sie zeigt durch ausgedehnte Vergleiche an zahlreichen Formen, da $B$ Raupe und Schmetterling, trotzdem sie ein und dasselbe Individuum sind, doch ihren Bau bis zu einem 
hohen Grade unabhängig voneinander verändern, so da $B$, wenn man auf Grund der Morphologie der Raupen ein System aufstellt, dieses anders ausfällt als das auf die Morphologie der zugehörigen Schmetterlinge gegründete. In allen Gruppen des Systems, von der Varietät bis zu den Familiengruppen hinauf, kommen, ,Inkongruenzen“, Ungleichheiten der Formverwandtschaft vor. Am häufigsten wohl bei den Varietäten: oft haben sich hier nur die Raupen oder nur die Schmetterlinge in Varietäten gespalten, während das andere Stadium monomorph geblieben ist. Im Bereich der Gattungen ist die Übereinstimmung der Formverwandtschaft am größten; Arten, Familien, Familiengruppen lassen aber wieder beträchtliche Inkongruenzen erkennen. Die phyletische Entwicklung der beiden Stadien, Raupe und Falter, ist also nicht gleichmäßig, nicht parallel vor sich gegangen, sondern das eine Stadium muß sich rascher oder stärker verändert haben, als das andere. Woher rührt das? Sind es innere oder äußere Ursachen, welche die Abänderungen hervorrufen, ist es eine phyletische Lebenskraft, oder sind es nur die äußeren Lebensbedingungen? Eine Abwägung aller in Betracht kommender Erscheinungen und Erklärungsmöglichkeiten führt zu dem Schlusse, daß die Lebensbedingungen den Ausschlag gegeben haben. Die Formabstände entsprechen stets genau dem Abstand der Lebensweise; Gemeinsamkeit der Form tritt genau in demselben Umfange auf, wie Gemeinsamkeit der Lebensbedingungen. Bei Typen gleicher Abstammung, d. h. gleicher Blutsverwandtschaft, entspricht der Grad der Form verwandtschaft genau dem Grade der Differenz in den beiderseitigen Lebensbedingungen. Daraus ergibt sich aber ein wichtiger allgemeinster Schluß. So lange das Zusammenstimmen von Bau und Funktion nur für je eine Form und je eine Lebensweise betrachtet wird, kann darin immer noch das Resultat einer inneren zwecktätigen Kraft gesehen werden; wenn sich aber hier bei den „metamorphischen" Tierformen ein doppeltes Zusammenstimmen von Bau und Funktion findet, und sich zeigt, daß die Umwandlung der Form in den beiden Hauptstadien der Entwicklung in ganz ungleichen Schritten vor sich geht, so muß die Idee einer inmeren treibenden Umwandlungskraft aufgegeben werden. Sie muß dies aber nicht nur darum, weil sie nicht imstande ist, die Erscheinungen zu erklären, sondern auch, weil sie zur Erklärung derselben überflüssig 
ist. Denn die andere Annahme, daß Umwandlungen ausschließlich und nur als Reaktion des Organismus auf die Einwirkungen der Außenwelt erfolgen, erklärt alle Erscheinungen, auch die jener nachgewiesenen Inkongruenzen durchaus befriedigend. -

Probleme der Artbildung waren es auch, die Weismann veranlaßten, die berühmten Versuche anzustellen, den mexikanischen Axolotl zur Umwandlung in die landlebende Salamanderform des Amblystoma zu zwingen, - Versuche, die zwar ihm selbst zunächst nicht glückten, dann aber auf seine Veranlassung von Frl. Marie von Chauvin fortgesetzt wurden und dank deren Geduld und Sorgfalt zu einem vollen Erfolge führten ${ }^{13}$ ). Auch diese Arbeit, die 1875 zuerst erschien, ist unter die aufgenommen, die unter dem Titel: „Die letzten Ursachen der Transmutationen" als zweiter Teil der Studien zur Deszendenztheorie ( 1876 ) vereinigt sind; eine der besonderen Fragen, die darin behandelt wird, ist die nach dem Vorkommen plötzlicher, sprunghafter phyletischer Weiterbildungen, - eine Frage, die Weismann von jeher verneint hat. Uns Nachgeborenen kommt es wunderbar vor, daß man noch im Anfang der siebziger Jahre des vorigen Jahrhunderts die Umwandlung einer Salamanderlarve (- denn als geschlechtsreif gewordene „,neotenische“ Larvenform ist der Axolotl jetzt allgemein anerkannt -) als eine plötzliche phyletische Weiterbildung zu einer höheren Stufe auffassen konnte, mit der gewisse Axolotl-Individuen der phyletischen Entwicklung der iibrigen Artgenossen voraneilen, - aber derartige Erinnerungen sind recht nützlich, und sie sind notwendig, wollen wir dem Wirken der Forscher jener Zeiten gerecht werden. Näher kann auf die große theoretische Bedeutung dieser und späterer Axolotl-Experimente von Frl. v. Chauvin hier nicht eingegangen werden.

Das allgemeine Ergebnis der „,Studien zur Deszendenztheorie“ faßte Weismann in der vierten Abhandlung des zweiten Heftes zusammen. Sie führt den Titel: „Über die mechanische Auffassung der Natur" und sucht zu zeigen, daß das aus den Einzeluntersuchungen gewonnene Ergebnis: die Zurückweisung der Annahme einer besonderen phyletischen Lebenskraft, für alle Lebewesen Geltung hat. Eine innere metaphysische Entwicklungskraft ist ebenso zu leugnen, wie eine besondere Lebenskraft für die Erklärung der Vorgänge des individuellen Lebens zu verwerfen ist. Die Abhand- 
lung beschäftigt sich durchaus mit den Fragen des Darwinismus, und auch im einzelnen bewegen sich ihre Gedankengänge vielfach schon in den Bahnen der späteren theoretischen Schriften. Im Gegensatz zu Eduard v. Hartmann, der die wichtigsten Prinzipien des Darwinismus, Variabilität, Vererbung, Korrelation als nicht rein mechanische Prinzipien betrachtet und in ihnen ein metaphysisches zwecktätiges Prinzip annimmt, sucht Weismann nachzuweisen, daB diese drei Erscheinungen sich sehr wohl rein mechanisch auffassen lassen, und daß sie so aufgefaßt werden müssen, so lange man keine triftigen Gründe dafür aufbringen kann, daß noch etwas anderes in ihnen verborgen liegt, als physikalisch chemische Kräfte. Den Anschauungen, die Weismann hier über die genannten Prinzipien wie auch über die sprunghafte Entwicklung äußert, werden wir an anderer Stelle wieder begegnen. Ein zweiter Abschnitt dieses Aufsatzes handelt über „,Mechanismus und Teleologie“ und entwickelt den Gedanken, daß es wohl möglich ist, neben dem bloßen Mechanismus ein teleologisches Prinzip anzuerkennen, Mechanismus und Teleologie miteinander zu verbinden. Auch hierauf werden wir noch kurz zurückkommen.

\section{Biologie der Süßwasserfauna, Daphnoidenstudien, partheno- gonische und zyklische Fortpflanzung.}

Etwa gleichzeitig mit den Studien zur Deszendenztheorie begann Weismann Forschungen auf einem ganz anderen Gebiete: er wandte sich eingehender dem Tierleben der Süßwasserseen zu und entnahm aus ihm nicht nur die Anregung zur Behandlung allgemeiner, die Seefauna betreffender Fragen, sondern schöpfte aus ihm auch im eigentlichen Sinne des Wortes das Material zu seinen berühmten Arbeiten über die Daphnoiden. Die Aufforderung, sich diesem Gebiete zuzuwenden, lag für ihn freilich nahe genug: bespülen doch die Wellen des Bodensees den Garten des ,Lindenhofs“, des Tuskulums, in dem Weismann so oft seine Ferien zubrachte. Ein Ferienaufenthalt im Jahre 1873 gab denn auch den Anstoß zur eingehenden Inangriffnahme dieser Forschungen, die sich in der Folge dann auch auf andere Seen, vor allem den Züricher und den Lago maggiore, wie den von Freiburg aus leicht zu erreichenden Titisee im Schwarzwald ausdehnten. 
Die allgemeinen Ergebnisse seiner Untersuchungen hat Weismann, zusammen mit den Ergebnissen anderer Forscher, so besonders mit den berühmten Untersuchungen Forels über die Fauna der Schweizer Seen, in einem außerordentlich reizvollen populären Vortrag (Das Tierleben im Bodensee, I876) verarbeitet. Der Naturfreund, auch wenn er auf dem besonderen hier behandelten Gebiete Laie ist, wird nicht so leicht etwas lesen können, was ihm mehr Anregung bieten, seinen Anschauungs- und Gedankenkreis mehr bereichern könnte, als diese Darstellung. Das ist keine trockene Aufzählung von Tatsachen, sondern ein farbenreiches, anschauliches Bild von dem tierischen Leben im Süßwasser, aber entworfen nicht mit den nur blendenden schillernden Farben obertlächlicher Popularitätssucht, sondern mit dem ganzen sachlichen Ernst des Forschers, der die inneren Zusammenhänge der Erscheinungen aufzudecken und darzustellen strebt. Die Darstellung des tierischen Lebens im süßen Wasser muß ja, wie Weismann selbst hervorhebt, verzichten auf so manches, was die Schilderung meerischen Lebens von vornherein erleichtert und reizvoll macht. Das Tierleben des Meeres ist unendlich viel reicher, vielgestaltiger als das des Süßwassers, die Tierformen selbst sind mannigfaltiger, zahlreicher an Arten, ja an Klassen, fesselnder in ihrer äußeren Erscheinung, prächtiger in ihren Farben. Aber dieser Mangel des Stoffes wiegt die Darstellung Weismanns reichlich auf durch die Art der Betrachtung, die von ganz großen Gesichtspunkten ausgeht, wie sie die Naturbetrachtung yom Standpunkt der Deszendenzlehre aus ergab. Wir erhalten eine Erklärung dafür, warum das Leben des Sïßwassers ärmer ist als das des Meeres: wir lernen es begreifen aus dem mannigfachen Wechsel, dem die Sïßwasserbecken im Laufe der Erdgeschichte unterworfen waren, aus der häufigen Unterbrechung, die das tierische Leben in ihnen dadurch erlitt, und die eine stets neue Besiedelung nötig machte, Wir erhalten Auskunft über die Formen, die tatsächlich im Bodensee vertreten sind, über ihre Gliederung in die drei großen Gesellschaften: die littorale, pelagische und Tiefseefauna, über die verschiedenen Bedingungen, unter denen die Angehörigen dieser drei Gruppen leben, und die ihre Lebensgewohnheiten beherrschen. Manche interessante Einzelheiten über diese Lebensgewohnheiten werden berichtet und in ihrer Bedeutung erörtert; auch rätselhafte Erscheinungen, wie das nächtliche Auf- 
steigen der kleinen Krebse aus der größeren Tiefe an die Oberfläche des Wassers, werden als zweckmäßige Einrichtungen, als Anpassungen an die Lebensbedingungen zu deuten versucht. (Im Gegensatz zu Forel führt Weismann diese Erscheinung auf die Lichtscheue der Tiere, d. h. auf ihre Organisation für schwaches Licht zurück, diese aber wieder darauf, daß es den Tieren dadurch ermöglicht wird, eine sehr bedeutende Wasserschicht nach Nahrung zu durchsuchen, - am hellen Tag bis zu einer Tiefe von $50 \mathrm{~m}$, in der Nacht an der Oberfläche.)

Vor allem aber reizt den historischen Sinn Weismannscher Naturbetrachtung die Frage nach der Herkunft der tierischen Bevölkerung des Sees. Sie muß verschieden sein für die littoralen und pelagischen Formen einsereits und für die Tiefseefauna andererseits. Die beiden ersten kamen aus dem Meer, wanderten die Flüsse hinauf, oder kamen aus benachbarten Seen. Wir lernen die Hilfsmittel kennen, deren sie sich bei ihren Wanderungen bedienen, vor allem die Wichtigkeit, die widerstandsfähige Keime für die Verbreitung vieler Tierformen besitzen, wie die Wintereier der Wasserflöhe, die durch Wasservögel auf weite Entfernungen hin von einem Ort zum anderen getragen werden und neu entstandene Seen bevölkern können. Ganz anders die Tiefseetiere! Da weder sie selbst noch ihre Eier jemals an die Oberfläche gelangen, so können sie nicht von einem See zum anderen verschleppt werden; sie haben sich im See selbst gebildet, durch allmähliche Umprägung der Uferarten, die im Laufe der Generationen vom Ufer aus auf dem Boden hin in immer größere Tiefen sich hinab verbreiteten. So mündet die Betrachtung aus in der großen Frage der Artbildung, - und schließlich in einer ganz allgemeinen Betrachtung: in dem Gesetz vom Kreislauf der organischen Substanz. Im Wasser ist dieser Kreislauf auf engem Gebiete zu verfolgen: tote organische Substanz dient als Nahrung tausender von niederen Organismen und wandelt sich so in lebendige Wesen um, die ihrerseits wieder anderen, höheren Formen, Fischen, zur Nahrung dienen. Aber auch von diesen geht es wieder weiter, denn von ihnen leben wieder höhere Formen, Vögel, Fischottern, ja zum Teil selbst der Mensch. Überall Kampf, überall rücksichtslose Ausnutzung aller Bedingungen und aller Vorteile, überall Zerstörung, Vernichtung. Aber aus ihr entsteht immer wieder neues Leben, - und so klingt Weismanns 
Darstellung aus in jenem Ausspruch von Karl Ernst von Baer, es sei doch ein versöhnlicher Gedanke, daß auch ,,die Nahrung selbst eine Zeitlang lebendig ist und sich des Daseins freut".

Die Spezialuntersuchungen, zu denen Weismann durch die Seenforschungen angeregt wurde, betreffen die Daphnoiden, die zu den Krebsen gehörigen Wasserflöhe, die jetzt gewöhnlich als Cladoceren bezeichnet werden ${ }^{\mathbf{1 4}}$ ). Den Anstoß zu ihnen gab ein glücklicher Zufall, der im Jahre I873 dem Forscher eine ihm unbekannte kleine Krebsform in das fischende Netz führte. Erst bei genauerer Beschäftigung mit ihr stellte es sich heraus, daß es sich um die Leptodora hyalina handelte, die I860 von dem schwedischen Naturforscher Lilljeborg in die Wissenschaft eingeführt und benannt, dann von dem Dänen P. E. Müller und dem Russen $\mathrm{N}$. Wagner behandelt, im ganzen aber noch sehr wenig bekannt war, und deren genaue Untersuchung nicht nur eben aus diesem Grunde, sondern auch noch darum verheißungsvoll erscheinen mußte, weil das Tierchen im Verhältnis zu seinen Verwandten ziemlich groß und zudem völlig durchsichtig, also zu einer Untersuchung im lebenden Zustand ganz besonders geeignet ist. Die Beschäftigung mit der Leptodora zeigte zugleich, daß es sich sehr wohl lohnen würde, auch die übrigen Daphnoiden, die seit der großen Monographie Leydigs von I86o bereits als genügend bekannt galten, aufs neue zu untersuchen, und so dehnte Weismann seine Forschungen auch auf sie aus. Von den Süßwasserformen boten die genannten Seen ebenfalls reiches Material, und Weismann ließ es sich nicht verdrießen, stundenlang, auch im Sturm und bei Nacht - weil dann die Tiere aus der Tiefe an die Oberfläche kommen - im Boote zuzubringen, um es zu sammeln. Ein Aufenthalt in Neapel, im Frühling I877, bot ihm Gelegenheit, auch die marinen Formen (marine Polyphemiden) zu untersuchen. So entstanden die Arbeiten, die unter dem gemeinsamen Titel ,Zur Naturgeschichte der Daphnoiden" als zusammenhängende Reihe von I876-I878 aufeinander folgten und nach Umfang und Bedeutung des Inhaltes eine hervorragende Stelle in der zoologischen Literatur einnehmen. Eine Menge wertvoller Einzelbeobachtungen und grundlegender Erörterungen über allgemeinere biologische Fragen ist in ihnen niedergelegt. Abgesehen von einer Abhandlung über die Färbungen der Daphnoiden, die von Weismann als 
Schmuckfarben aufgefaßt werden und ihm Anlaß geben, das Prinzip der geschlechtlichen Auslese zu erörtern, behandeln sie Fragen der Fortpflanzung und Entwicklung: Bildung und Bau der Samenzellen, Bildung der Eier in ihren zwei Formen als Sommer- und Wintereier, die Aufzucht der Sommereier in einem nahrungsreichen Fruchtwasser, also unter "Brutpflege", und die Erscheinungen der zyklischen Fortpflanzung bei den Daphnoiden. Insbesondere für diese letzteren Erscheinungen, für die Weismanns Interesse durch die Studien über den Saison-Dimorphismus dor Schmetterlinge erweckt worden war, haben die Untersuchungen grundlegende Bedeutung erlangt, nicht nur hinsichtlich der Kenntnis der Tatsachen, sondern auch in bezug auf ihr theoretisches Verständnis. Nur auf sie sei hier noch kurz eingegangen.

Die Daphnoiden gehören zu den Tierformen, bei denen Jungfernzeugung oder Parthenogonie - wie man besser statt „Parthenogenese“ sagen sollte ${ }^{15}$ ) - vielfach vorkommt. Man versteht bekanntlich unter Parthenogonie die Erscheinung, daß Eier ohne vorherige Befruchtung sich entwickeln, und ist jetzt allgemein der Überzeugung, da $B$ diese Fortpflanzungsart sich aus der zweigeschlechtlichen, mit Befruchtung verbundenen, entwickelt hat (- also nicht etwa eine ursprünglichere Fortpflanzungsform darstellt -). Die enge Beziehung, die zwischen der Jungfernzeugung und der Zweielternzeugung besteht, kommt vor allem darin zum Ausdruck, daß jene nur sehr selten die alleinige Fortpflanzungsart bildet, viel häufiger dagegen mit der letzteren, der Zweielternzeugung, in regelmäßigem Wechsel auftritt. So kommt die besondere Form der ,zyklischen“ Fortpflanzung (Zyklogonie) oder des Generationswechsels (im weitesten Sinne) zustande, die den besonderen Namen der Heterogonie erhalten hat. $\mathrm{Zu}$ den Formen, die sie ganz besonders zeigen, gehören die Daphnoiden, und durch Weismanns Studien haben sie für die Forschungen auf dem Gebiete der Generationszyklen klassische Bedeutung erlangt. Weismann erbrachte den Nachweis, daB die Generationszyklen bei den verschicdenen Formen der Daphnoiden verschieden sind; er fand weiter eine einleuchtende Erklärung für diese Verschiedenheiten in den besonderen Lebensbedingungen der einzelnen Arten und zeigte endlich, wie die allmähliche historische Entwicklung dieser zyklischen Fortpflanzungsform aus der früheren rein 
zweigeschlechtlichen der Vorfahren zu denken ist. So stützte und vertiefte er jene Auffassung von dem Verhältnis der Parthenogonie zur Zweielternzeugung, die Auffassung, daß die Jungfernzeugung nicht ungeschlechtliche, sondern eingeschlechtliche Fortpflanzung und aus der $z$ weigeschlechtlichen entstanden ist, und legte auch den Grund für Forschungen, die aus den Erscheinungen der Generationszyklen Einblicke in das Problem der geschlechtsbestimnienden Ursachen zu gewinnen hoffen. „A. Weismann war der erste, der die große Bedeutung des Gegenstandes klar erkannte und durch genaues biologisches Studium der Generationszyklen der Daphnien wie durch Versuche, sie experimentell zu beeinflussen, die Grundlagen für unsere gesamten Kenntnisse des Gegenstandes legte", sagt R. Goldschmidt, eine Autorität auf dem Gebiete der Vererbungslehre. Diese Bedeutung werden die Arbeiten behalten, auch wenn an die Stelle der von Weismann gegebenen Erklärung der Erscheinungen eine andere treten müßte.

Man war bis Weismann der Ansicht gewesen, daB jener Generationszyklus sich immer nach dem gleichen Schema abspiele, das tatsächlich für manche Formen nachgewiesen war. Hier finden sich vom Frühjahr ab den Sommer hindurch nur weibliche Individuen, die aus zahlreichen kleinen und zarten unbefruchteten ,Sommer"-Eiern immer nur wieder Weibchen mit gleicher Fähigkeit hervorbringen. Nur einmal im Jahre, im Herbst, wird diese lange Reihe parthenogonischer Generationen unterbrochen. Eine Sexualperiode tritt ein; außer Weibchen schlüpfen nun auch Männchen aus den Eiern aus, und die Weibchen produzieren statt der vielen parthenogonischen Sommereier nur wenige große befruchtungsbedürftige „Winter-“ oder „Dauer“-Eier, die, nachdem sie von den Männchen befruchtet worden sind, mit fester Schale umgeben werden, um so den Winter durchzumachen. Die Kolonie selbst erliegt der Vernichtung durch die Winterkälte. Aus jedem solchen befruchteten Dauerei entsteht im Frühjahr, also nach längerer Latenzperiode, ein Weibchen, das wieder die Reihe der parthenogonischen Generationen beginnt. So das Schema, das als allgemeingültig betrachtet wurde. Gelegentliche Beobachtungen von Männchen und Dauereiern zu anderen Jahreszeiten wurden als Ausnahme und als direkte Folge äußerer Einflüsse (Eintritt von Kälte, Abnahme des Wassers) aufgefaßt. Demgegenüber zeigte Weis- 
mann zunächst durch ausgedehnte Beobachtungen und zielbewußte Versuche, daß die äußeren Lebensbedingungen direkt keinerlei Einfluß auf den Modus der Fortpflanzung ausüben, daß weder die Temperatur, noch die Quantität oder die Qualität des Wassers imstande sind, den einen Modus in den anderen umzuwandeln, da $B$ sie ihn also auch direkt nicht hervorgerufen haben können. Die Ursache dafür, daß nach einer Reihe von parthenogonischen Generationen zweigeschlechtliche Fortpflanzung eintritt, liegt somit nicht in momentanen äußeren Einflüssen, die das Individuum treffen, sondern ist in den allgemeinen Lebensbedingungen $\mathrm{zu}$ suchen, die seit lange alljährlich die Art getroffen haben. Der Generationszyklus hat sich allmählich festgestellt als indirekte Folge dieser Lebensbedingungen nach dem Selektionsprinzip: durch Beseitigung der für die Erhaltung der Art momentan weniger geeigneten Individuen. Entsprechend den Verschiedenheiten der Lebensbedingungen der Arten ist dann auch die Form des Zyklus verschieden: verschieden durch die $Z$ ahl der zweigeschlechtlichen Generationen, die im Laufe eines Jahres die Reihe der parthenogonischen unterbrechen. Stets erfolgt die Sexualperiode zu einer ganz bestimmten Zeit, von der Gründung einer Kolonie aus Wintereiern an gerechnet; diese Zeit aber ist für die verschiedenen Arten sehr verschieden. Je nachdem Vernichtungsursachen (Kälte, Austrocknen usw.) mehrmals im Jahre oder nur einmal oder gar nicht die Kolonien einer Art heimsuchen, lassen sich drei Gruppen unterscheiden: polyzyklische, monozyklische, azyklische. Die Gruppe der polyzyklischen Formen umfaßt Arten, bei denen schon nach wenigen parthenogonischen Generationen wieder eine geschlechtliche folgt, somit mehrere Zyklen sich im Laufe eines Jahres ablösen: es sind die Bewohner kleinerer Wassermengen, wie Pfützen, Tümpel, Teiche, Sümpfe, die während des Sommers austrocknen können. Als Anpassung an die dadurch mehr oder minder oft bedingte Gefahr der Vernichtung, die der Kolonie droht, erscheint die häufigere Unterbrechung der parthenogonischen Generationen durch eine Geschlechtsgeneration, deren befruchtete Dauereier jenen Gefahren widerstehen. Die Gruppe der monozyklischen Formen umfaßt Arten mit nur einer Sexualperiode, bei denen also nur einmal im Jahr, und zwar gegen den Winter hin, die lange Reihe parthenogonischer Generationen durch eine zweigeschlechtliche mit 
widerstandsfähigen Dauereiern unterbrochen wird: die pelagischen Formen der Seen, wahrscheinlich auch die wenigen marinen Formen, also Bewohner weiter, nicht austrocknender Wasserbecken, in denen nur die Winterkälte eine allgemeine Gefahr bildet und alljährlich zur Vernichtung der Kolonie führt. Endlich wird eine letzte Gruppe, die der azyklischen Formen, gebildet durch solche Arten, die auch im Winter ausdauern und sich fortpflanzen, somit die Bildung von Dauereiern überhaupt entbehren können und sich nur parthenogonisch fortpflanzen, - bei denen also die Bildung von Männchen überhaupt unterdrückt ist. Nur mit großem Genuß kann man die ausführliche Begründung dieser grundlegenden Vorstellungen sowie die scharfsinnigen Ausführungen Weismanns über die Ausbildung der verschiedenen Generationszyklen und die erstmalige Entstehung der zyklischen Fortpflanzung bei den Daphnoiden überhaupt lesen. Die zyklische Fortpflanzung der Daphnoiden ist nicht überkommen, sondern erst in und mit dieser Ordnung erworben. Die Urdaphnoiden hatten durchaus zweigeschlechtliche Fortpflanzung und produzierten befruchtungsbedürftige,,Latenzeier", die nach der Befruchtung und den ersten Entwicklungsstadien erst eine längere Latenzperiode während der für die Existenz der Kolonie selbst ungünstigen Zeit durchmachten. Nun folgte auf der Grundlage der individuellen Variabilität und Fixierung der günstigen Abänderungen durch Naturzüchtung eine allmähliche Umwandlung der Formen selbst und ihrer Eier. Erstere wurden kleiner und einfacher, ihre Ontogenese verkürzte sich, die früher vorhanden gewesene Metamorphose kam in Wegfall. Die Eier differenzierten sich in zwei Richtungen: die einen (Latenzeier) behielten die Befruchtungsbedürftigkeit bei und bildeten besondere Schutzhüllen aus, die anderen erlangten die Fähigkeit zu rascher Entwicklung (daher "Subitaneier", von subitus, plötzlich) und zugleich die zur Parthenogonie. Damit wurde die Bildung von Männchen nur noch für bestimmte Generationen beibehalten. Eine in viel rascherem Tempo erfolgende Vermehrung der Kolonie war die Folge all dieser Umwandlungen, und bildete damit das ZweckmäBigkeitsmoment, das diese Umwandlungen auf dem Wege der Selektion allmählich sich vollziehen und steigern ließ. Zunächst schaltete sich eine Subitangeneration ein, d. h. die Eier der ersten Generation wurden zu Subitaneiern; dann übertrug sich die Fähigkeit zur Bildung von 
solchen auch auf die zweite und die folgenden Generationen, - je nach Bedarf, d. h. unter dem regulierenden Einfluß der für jede Art gegebenen Lebensbedingungen. Die azyklischen Formen bilden das letzte Stadium: wo Vernichtung der Kolonie nicht mehr zu befürchten ist, ist die Hervorbringung von Latenz- oder Dauereiern ganz aufgegeben, und die Vermehrung erfolgt das ganze Jahr hindurch mit Subitaneiern.

Neben der scharfsinnigen Deutung der mannigfaltigen Erscheinungen von einem einheitlichen Gesichtspunkte aus: als zweckmäßige, durch Selektion in Anpassung an die Lebensbedingungen entstandene Einrichtungen, tritt in diesen Ausführungen noch ganz besonders ein Punkt als bedeutungsvoll hervor: die verhältnismäßig geringe Bewertung des Unterschiedes, der in der Befruchtungsbedürftigkeit einerseits und der parthenogonischen Entwicklungsfähigkeit der Eier andererseits gegeben ist. Für Weismann ist dieses Merkmal nicht, wie es auf den ersten Blick scheinen könnte, das hauptsächlichste; der Verzicht auf die Befruchtung ist vielmehr nur eine von den vielen Umwandlungen, die darauf abzielen, der Kolonie eine möglichst rasche und ausgiebige Vermehrung der Individuenzahl $\mathrm{zu}$ sichern. In dieser Betrachtungsweise spricht sich schon die Auffassung aus, der Weismann später besonderen Ausdruck verliehen hat: daß nämlich die Befruchtung für die Entwicklung nicht die hohe Bedeutung besitzt, die ihr gewöhnlich zugeschrieben wird.

Den größten Einfluß auf Weismanns Anschauungen mußte es aber doch haben, daß es ihm auch hier wieder gelang, die Verschiedenheiten in den Lebenserscheinungen einer ganzen Gruppe von Organismen als zweckmäßige, durch Selektionsprozesse gezüchtete Anpassungen zu erklären. Die Untersuchung und ihr Ergebnis gibt ihm Gelegenheit zu allgemeinen Erörterungen über das Selektionsprinzip und die einzelnen Faktoren, mit denen es rechnet: Variabilität, Vererbung und Kampf ums Dasein; er stellt den Generationswechsel der Daphnoiden dem gegenüber, der in dem Saisondimorphismus der Schmetterlinge in die Erscheinung tritt, und den er als durch die direkte Wirkung der Kilimaeinflüsse hervorgerufen erkannt hatte. Hier, bei den Schmetterlingen, erfolgte zuerst die Abänderung der ausgebildeten Tiere unter dem Einfluß der Umgebung und erst allmählich ergab sich daraus eine 
Beeinflussung des Keimes und damit eine erbliche Fixierung der Umwandlungen; dort, bei den Daphnoiden, traten, aus Gründen, die in den Organismen selbst liegen, zuerst Keimesabänderungen, Varianten, auf, und durch Züchtıng derselben veränderten sich im Laufe der Generationen die Gewohnheiten aller Individuen der Art. Diese Erörterungen bewegen sich im wesentlichen schon ganz in den Gedankengängen der späteren rein theoretischen Schriften.

Für die Richtigkeit seiner Auffassung, daß die Parthenogonie sekundär aus der zweigeschlechtlichen Fortpflanzung hervorgegangen ist, als Anpassung an Lebensverhältnisse, die eine möglichst rasche Vermehrung der Individuen wünschenswert machen konnte Weismann wenige Jahre später (I88o) eine sehr erfreuliche Bestätigung beibringen in dem Nachweis der Parthenogonie bei den Ostracoden (Muschelkrebsen). Der Umstand, daß diese Ordnung der Krebse unter ganz ähnlichen Lebensbedingungen lebt, wie die Daphnoiden, rechtfertigen die Erwartung, daß auch bei ihr Parthenogonie vorkomme, und die genauere Untersuchung bestätigte die Richtigkeit dieser Erwartung und lieferte damit der Vorstellung ïber die Herkunft und Bedeutung der Parthenogonie, die sich aus den Daphnoidenstudien ergeben hatte, eine wichtige Stütze.

Von größter Bedeutung wurde dieser Nachweis gleicher Fortpflanzungsart dann für Weismann in der Mitte der achtziger Jahre, als ihn die Frage nach der Bedeutung der bei der Eireifung auftretenden Richtungskörperchen beschäftigte. Damals entstanden die, zum Teil in Gemeinschaft mit C. Ischikawa angestellten wichtigen Untersuchungen über die Bildung der Richtungskörperchen bei parthenogonischen und befruchtungsbedürftigen Eiern, auf die noch zurückzukommen sein wird, sowie die über gewisse eigentümliche Vorgänge bei der Befruchtung der Daphnoideneier. Sie knüpfen an die alten Daphnoidenstudien an; es mag im übrigen genügen, sie erwähnt zu haben.

Endlich aber hat die Parthenogonie auch Ende der neunziger Jahre Weismann noch einmal besonders beschäftigt, als von verschiedenen Seiten Zweifel an der Richtigkeit der Auffassungen geäußert wurden, die seit den Beobachtungen des schlesischen Pfarrers und Bienenwärters Joh. Dzierzon (I845) und der wissen- 
schaftlichen Durcharbeitung derselben durch v. Siebold und Leuckart, über die Fortpflanzungsvorgänge im Bienenstaate und insbesondere über die fakultative Parthenogonie der Bienenkönigin herrschten. Durch zwei seiner Schüler, Paulcke und - nach dessen Ausscheiden - Petrunkewitsch, ließ Weismann die Frage aufs neue prüfen, und die vortrefflichen Untersuchungen namentlich von Petrunkewitsch brachten eine volle Bestätigung und neue einwandfreie Begründung der alten Lehre: die Drohneneier bleiben unbefruchtet, entwickeln sich parthenogonisch, während die Eier, aus denen weibliche Bienen entstehen sollen, alle befruchtet werden. Weismann selbst hat dariber in einem kleinen Aufsatz von rgoo berichtet.

So verbindet bei Weismann ein innerer Zusammenhang immer ganze Reihen von Arbeiten zu einer Kette; eine schließt sich an die andere an, wächst aus ihr hervor. Die Leptodora, die ihm der günstige Zufall in das Netz spuilte, veranlaßte die weiteren Forschungen über die Süßwasserfauna und die Studien über die Daphnoiden, und diese führten zu dem besonderen Problem der zyklischen Fortpflanzung und der Parthenogonie überhaupt, und damit weit weg von dem ursprünglichen Ausgang. Nur einmal noch ist Weismann zu jenem Ausgang zurückgekehrt: als 35 Jahre nach dem Beginn seiner Süßwasserforschungen (1908) die „Internationale Revue der gesamten Hydrobiologie und Hydrographie" ins Leben gerufen wurde, da glaubten die Herausgeber dem neuen Unternehmen keine bessere Empfehlung mitgeben zu können, als indem sie der Zeitschrift von einem Biologen des Süßwassers und einem solchen des Meeres das Geleitwort schreiben ließen. Für die erste Aufgabe wandten sie sich an Weismann, der denn auch bereitwillig der Bitte entsprach. Sein kleiner für den genannten Zweck verfaßter Aufsatz weist auf die große Bedeutung hin, die das eingehende Studium gerade des Tierlebens im Süßwasser für das Verständnis des biologischen Zusammenhanges der verschiedenen Formen besitzt, d. h. für die Aufhellung der verwickelten Beziehungen zwischen den nebeneinander lebenden Tieren und Pflanzen, und damit zugleich für die Kenntnis der einzelnen Arten und ihrer Anpassungen an die ihnen zugewiesene Lebensweise. Die Erforschung der tierischen Formen ist mit der Kenntnis ihrer bloßen Morphologie nicht abgeschlossen; darüber hinaus ergibt 
sich die Aufgabe, zu ermitteln, wa rum und wie diese Gestaltungen geworden sind, d. h. geworden im Laufe der Generationen in Anpassung an die ganze Umwelt, die natürlichen Lebensbedingungen und die Lebensgesellschaft, in die hinein sie gesetzt sind und in der sie den Konkurrenzkampf aufzunehmen haben. Weismann erörtert hier den Gedanken, dem er auch sonst wiederholt Ausdruck gegeben hat: daß wir in der Analyse der tierischen Formen noch lange nicht so weit gegangen sind, als es möglich wäre, daß für eine Menge längst bekannter Charaktere noch gar nicht einmal versucht worden ist, ihren Lebenswert, der doch ihr Vorhandensein rechtfertigen muß, zu ergründen. Fortschritte in dieser Richtung haben zur ersten Voraussetzung die genaueste Kenntnis der Lebensweise der Arten, ihrer Fortpflanzung, Ernährung usw. mit allen Einzelheiten der dabei mitspielenden Faktoren. Dafür aber bietet gerade das Tierleben der Süßwasserbecken die günstigsten Bedingungen, weil es sich auf eine übersehbare Zahl zusammenlebender Arten beschränkt, die dennoch innerhalb ihres Kreises reich gegliedert sind. Es ist also das Problem der Artbildung, für dessen Verständnis Weismann gerade aus dem Studium der Süßwasserfauna wichtige Förderung erwartet, insbesondere die viel erörterte Frage, wie weit die Merkmale der Arten ,Anpassungen“ darstellen oder in das Gebiet der sogenannten rein ,morphologischen“ Merkmale ohne erkennbare biologische Bedeutung fallen. Wir werden dieser Frage wieder begegnen.

\section{Die Hydromedusenstudien. Bildung der Keimzellen.}

Von besonders wichtiger Bedeutung für die Ausgestaltung der Weismannschen theoretischen Vorstellungen wurden endlich die Untersuchungen über die Bildung der Keimzellen bei den Hydromedusen, die, schon im Jahre I 878 an der Riviera begonnen, dann im Sommer 1880 in le Croisie in der Bretagne auf die atlantischen, und im Winter $188 \mathrm{o} / 82$ in Neapel auf die dortigen Mittelmeerformen ausgedehnt wurden, so daß sie sich im ganzen auf 38 verschiedene Arten stützen konnten. Der während der Untersuchungen sich aufdrängende Plan, den ganzen Bau der Hydromedusen zu bearbeiten, wurde bald wieder aufgegeben; waren doch auch die Ergebnisse in bezug auf die Geschlechtszellen bedeutungsvoll genug. Weismann hat über sie zum ersten Male 
I 880 berichtet, dann ergänzend und zum Teil abändernd, I88I; ausführlich in der großen, mit prächtigen Tafeln geschmückten Monographie von 1883 , endlich noch einmal zusammenfassend, im biologischen Zentralblatt von I884. Das wichtigste Ergebnis der Untersuchungen ist der Nachweis, daß die Keimzellen der Hydromedusen zwar stets aus Ektodermzellen entstehen, aber bei den verschiedenen Arten an sehr verschiedenen Stellen, und daß diese Verschiedenheiten der Ausdruck sind für eine in der Stammesgeschichte erfolgte Verschiebung der Keimstätte, die von ganz bestimmten Gesetzen beherrscht wird. Die Verlegung der Keimstätte an andere Stellen hat wesentlich die Bedeutung, die Keimzellenbildung auf frühere Stadien zu verlegen und damit die Geschlechtsreife zu beschleunigen; sie ist in der Stammesgeschichte Schritt für Schritt erfolgt, die Befunde bei den einzelnen Formen zeigen ihren Weg an. Die Verschiebungsprozesse beruhen aber, wie der Vergleich der Tatsachen zeigt, nicht darin, daß die Fähigkeit zur Keimzellenbildung launenhaft von einer Zellgruppe auf die andere ïberspringt, sondern darin, daß immer frühere Glieder einer und derselben Abstammungslinie die Differenzierung zu Geschlechtszellen eingehen. Von ganz besonderer Wichtigkeit sind dabei die zahlreichen Fälle, in denen die Bildung cler Keimzellen gar nicht im Ektoderm, sondern im Entoderm erfolgt: hier weisen die Befunde darauf hin, daß erst in der Ontogenese eine Einwanderung jener Elemente, die den Keimzellen den Ursprung geben, der Urkeimzellen, aus dem Ektoderm in das Entoderm erfolgt. Höchst seltsam ist daneben noch ein anderes Ergebnis: die Rückwärtsverschiebung der Keimstätte ist nicht verbunden mit einer Verschiebung der Reifungsstätte, vielmehr wandern in jeder Ontogenese die Keimzellen von ihrer heutigen Keimstätte zurück nach ihrer alten Reifungsstätte, dem Ektoderm des sogenannten ,Manubriums“. Diese Wanderungen der (männlichen und weiblichen) Keimzellen müssen auf Vererbung eines Triebes zum Wandern nach bestimmtem Ziele beruhen.

Theoretisch muß aus alle dem die wichtige Folgerung gezogen werien, daß nur bestimmte Körperzellen und Zellfolgen von dem befruchteten Ei her „Keimplasma“ mitbekommen und somit Keimzcllen zu bilden vermögen, - ein Ergebnis, das wesentlich dazu beigetragen hat, den Gedanken von der Kontinuität des Keim- 


\section{$-5^{6}-$}

plasmas, der in Weismann damals Gestaltung erlangte, zu begründen.

So reifen in den Arbeiten der siebziger Jahre allmählich die Gedanken heran, die dann von den achtziger Jahren an in ihrer vollen Tragweite erfaßt und nach allen Seiten hin verfolgt werden. Die Annahme einer inneren phyletischen Entwicklungskraft wird abgelehnt, die Bedeutung der Auslese als des Vorganges, der die Organismen in Einklang mit den Lebensbedingungen bringt, tritt immer klarer hervor. Daneben aber zwingen die Schmetterlingsversuche zu der Anerkennung eines direkt umgestaltenden Einflusses der äußeren Bedingungen, und dieselben Versuche weisen auch auf die große Bedeutung hin, die der gegebenen spezifischen Natur einer Art für die weitere Umwandlung zukommt. Endlich aber ergibt sich aus den Hydromedusen-Studien auch die Grundlage, auf der sich das Gebäude von Weismanns Vererbungstheorie erheben sollte. 


\section{Dritter Abschnitt.}

\section{Erste Stellungmahme zur Darwinschen Theorie. Dauer des Lebens, Herkunft des Todes.}

Abstammungslehre von Darwin und Lamarck. - EinfluB des Darwinismus auf die biologische Forschung. - Erste Stellungnabme Weismanns zur Darwinschen Theorie: die Antrittsrede von 1868. Arbeitsprogramm. - Dauer des Lebens, Herkunft des Todes.

Versuchen wir es nun, einen Überblick über das zu gewinnen, was Weismann auf dem weiten Gebiete, mit dem sein Name am engsten verbunden ist, geleistet hat: dem der Abstammungslehre und den mit ihr zusammenhängenden Fragen. Hier knüpft seine Tätigkeit an die Darwins an.

\section{Abstammungslehre von Darwin und Lamarck.}

Der Darwinismus begreift in sich, wie bekannt, mehrere Theorien, die sich zwar gegenseitig ergänzen, aber doch an sich voneinander unabhängig sind. Die zentrale Stelle innerhalb dieser Theorien nimmt die Deszendenzlehre selbst ein, die Lehre, daß die Arten nicht beständig sind, daß vielmehr die lebenden Pflanzenund Tierformen sich aus anderen, untergegangenen entwickelt haben, und da $B$ die größeren oder geringeren Übereinstimmungen des Baues, die in der Einordnung der Organismen in die Gruppen der Systeme (Stämme, Klassen, Ordnungen, Familien, Gattungen, Arten) zum Ausdruck kommen, zugleich der Ausdruck engerer oder weiterer Verwandtschaft sind. DaB diese Abstammungslehre nicht zum ersten Male von Darwin aufgestellt worden ist, ist genügend bekannt; ebenso unbestritten aber ist, daß sie erst durch Darwin zur Verbreitung und Anerkennung in den weitesten Kreisen der 
Wissenschaft gekommen ist. Keiner der Vorgänger war selbst so durchdrungen von ihrer Richtigkeit, war so unablässig für sie eingetreten, hatte sie auf so breiter und so fester Tatsachenbasis begründet, und keiner hatte auch mit so überzeugender Kraft die Frage erörtert, wodurch, unter dem Einfluß welcher Faktoren die Umwandlungen vor sich gegangen seien. An der Beantwortung dieser Frage aber hing sehr viel: sie mußte, wollte sie annehmbar erscheinen, auch einen Weg zeigen zum Verständnis für die vielen oft so wunderbaren Zweckmäßigkeiten im Bau der Lebewesen, für die Übereinstimmungen zwischen diesem Bau und den Lebensgewohnheiten sowie den Lebensbedingungen der Organismen, ohne auf eine zielbewußt wirkende Schöpferkraft zurückzugreifen. Wohl hatte der bedeutendste Vorgänger Darwins, Jean Lamarck, diese Frage erörtert, aber die Antwort, die er auf sie gegeben hatte, konnte unmöglich genügen, und besaß nicht die Kraft, den Deszendenzgedanken gegen die übermächtigen widerstrebenden Zeitströmungen, in die er hineingeworfen wurde, durchzusetzen.

Auch die Lehre Lamarcks setzt sich aus mehreren Elementen zusammen; erst das Streben nach Bildung kurzer Schlagworte hat in unserer Zeit dem „Lamarckismus“ eine eng begrenzte Bedeutung gegeben. Dem herkömmlichen Brauch, der die Organismenwelt in der Richtung von oben nach unten, vom Höheren zum Niederen betrachtete, setzte Lamarck die Lehre einer von unten nach oben führenden Stufenfolge gegenüber, einer fortschreitenden Entwicklung der Organisation, die von einer unbekannten Naturkraft angeregt, eine stufenweise und regelmäßig fortschreitende Vervollkommnung erstrebt, aber in ihrer Wirksamkeit durch die äußeren Verhältnisse, in denen die Organismen leben, vielfach beeinträchtigt wird, so daß zahlreiche Unregelmäßigkeiten vorkommen. Diese äußeren Verhältnisse (Klima, Nahrung, Lebensweise, Aufenthaltsort usw.), die sich im Laufe der Erdgeschichte oftmals verändert haben, wirkten umwandelnd auf die Organismen ein. Der umgestaltende Einfluß erfolgte aber bei Tieren nicht unmittelbar, sondern dadurch, daß die letzteren durch die veränderten Lebensbedingungen zu neuen Gewohnheiten veranlaßt wurden, und daß diese neuen gewohnheitsmäßigen Tätigkeiten, durch Generationen fortgesetzt und in ihren Wirkungen gesteigert, die tierische Organisation in zweckentsprechender Weise veränderten. Nicht 
die Gestalt des Körpers und seiner Teile haben die Gewohnheiten und Lebensweise der Tiere bestimmt, sondern umgekehrt: Gewohnheiten, Lebensweise und alle anderen einwirkenden Verhältnisse haben mit der Zeit die Gestalt des Körpers und der Teile der Tiere herbeigeführt. Diese wichtigste Seite der Lamarckschen Lehre legt, um die Entstehung der Zweckmäßigkeiten zu erklären, die alltägliche Erfahrung zugrunde, daß der Gebrauch ein Organ kräftigt, der Nichtgebrauch es allmählich verkümmern läßt, und überträgt diese Erfahrung auf die Vorgänge bei der natürlichen Entwicklung des Tierreiches. Ein mystisches Prinzip spielt aber auch hier hinein: die neuen Gewohnheiten werden von den Tieren angenommen auf Grund eines von diesen gefühlten, durch die Veränderung der Lebensbedingungen ausgelösten Bedürfnisses, das sogar imstande ist, an dem Tier ,,unmerklich durch Anstrengungen seines inneren Gefühls" neue Organe entstehen zu lassen. Bei Pflanzen, wo keine Tätigkeiten, und folglich auch keine eigentlichen Gewohnheiten vorhanden sind, waren es die Veränderungen in der Ernährung, der Menge der Wärme, des Lichtes, der Luft und Feuchtigkeit, durch die die äußeren Verhältnisse unmittelbar umwandelnd wirkten. -

Der wichtigste Bestandteil dieser Vorstellungen ist, daß die zweckmäßigen Anpassungen der tierischen Organismen auf den Gebrauch und den Nichtgebrauch der Teile zurückzuführen sind, - diese Lehre ist es auch, die heutzutage gewöhnlich allein gemeint wird, wenn von "Lamarckismus" die Rede ist. An sich ist es berechtigt, sie mit diesem Namen zu belegen. Nicht ganz so zutreffend ist es dagegen, wenn auch die Lehre von dem direkt verändernden Einfluß der äıßeren Bedingungen (- der ,Umwelt", des ,,Mediums" -) dem Begriff des Lamarckismus untergeordnet wird. Nur für die Pflanzen hat La marck einen solchen direkten Einfluß gelten lassen, während er seine Annahme für die Tiere ausdrücklich als Irrtum ablehnt und hier nur die mittelbare Wirkung der Lebensbedingungen auf dem Umwege neu erzwungener Gewohnheiten gelten läßt. Die Auffassung, daß auch die tierischen Organismen durch die äußeren Verhältnisse dirckt umgewandelt werden, wäre vielleicht richtiger mit dem Namen von Lamarcks Landsmann Etienne Geoffroy-St. Hilaire zu verbinden, des einstigen Freundes und späteren Gegners Cuviers, in Deutschland vor allem 
bekannt durch die Anteilnahme Goethes an seinem Streit mit Cuvier in der französischen Akademie, am I9. Juli I83o. -

Die Anschauungen Lamarcks und Geoffroys setzen die Erblichkeit der Wirkungen der Mediumeinflüsse wie derer des Gebrauches und des Nichtgebrauches voraus. Auch Darwin verwarf, als er die Abstammungslehre, aber unter Verzicht auf alle metaphysischen, mystischen Prinzipien, aufs neue begründete, jene Auffassungen nicht völlig, sondern schrieb der direkten Einwirkung der Lebensbedingungen wie dem Gebrauch und dem Nichtgebrauch einen Einfluß bei der Umwandlung der Formen zu. Der Notwendigkeit, die Erblichkeit jener Veränderungen vorauszusetzen, war er sich dabei durchaus bewußt; er prüfte die Frage und kam dazu, sie zu bejahen. Aber viel größere Bedeutung besitzt für ihn doch das andere Prinzip, das er selbst, gleichzeitig mit seinem Landsmann Wallace, aufstellte: das Prinzip von der natürlichen Auslese, dem er später noch das der geschlechtlichen Auslese ergänzend hinzufügte. Die individuellen Abweichungen, die sich unter den Angehörigen einer Art, auch bei den Nachkommen eines Elternpaares, stets bemerkbar machen, bilden den Ausgang für die Darwin-Wallacesche Zuchtwahllehre, deren Gedankengang im übrigen genügend bekannt ist. Jene individuellen Abweichungen, deren Erblichkeit seit langen Zeiten vom Menschen zu künstlichen Züchtungsversuchen mit Pflanzen und Tieren benutzt worden ist, werden bei dem Wettbewerb, den das Einzelindividuum mit seinesgleichen und mit anderen Formen um die notwendigsten Lebensbedingungen $\mathrm{zu}$ bestehen hat, von sehr verschiedenem Werte sein. Die Unerbittlichkeit dieses Wettbewerbes, des „Kampfes ums Dasein", wird die schlechter ausgerïsteten früher zugrunde gehen lassen, die besser ausgerüsteten länger erhalten. Diese haben daher die größere Aussicht, ihre begünstigenden Eigenschaften fortzuerben. So erfolgt durch die Natur selbst eine Auslese der am meisten begünstigten Individuen, d. h. derer, die den gegebenen Lebensverhältnissen am meisten genügen, ihnen am besten angepaßt sind, und wenn sich dies Generationen hindurch fortsetzt, so wird allmählich eine Umwandlung in der Richtung der begünstigenden Abänderung, in der Richtung der Nützlichkeit, erfolgen. Diese Richtung ist nicht durch innere Entwicklungstendenzen der Organismen bestimmt ; die Variationen an sich sind regel- und richtungs- 
los, erst die Zufälligkeiten der äußeren Lebensbedingungen wählen die zweckmäßigsten von ihnen aus, und die Umwandlung der Formen erfolgt somit, im Laufe ungeheuer langer Zeiträume, in allmählicher Anpassung an die Lebensbedingungen. So gelangen wir zu einem Verständnis der Zweckmäßigkeiten, ohne Annahme des Lamarckschen Anpassungsprinzipes, aber auch ohne Annahme einer zweckbewıßt wirkenden Kraft oder irgend eines unbegreiflichen vitalistischen Prinzipes.

Die Darwin-Wallacesche Selektionstheorie ist eine Nützlichkeitstheorie. Nur das hat nach ihr Aussicht anf Dauer und Bestand, was nützlich ist. Aufgestellt, um die ZweckmäBigkeiten der Organismen zu erklären, führt sie somit zugleich dazu, in allen Einrichtungen der Organismen ZweckmäBigkeiten a priori zu erwarten, alle Einrichtungen unter dem Gesichtswinkel der Frage nach ihrer Nützlichkeit zu betrachten. Auch als Zufallstheorie ist sie bezeichnet worden, da es zufällige, richtungs- und regellose Varietäten sind, an die nach Darwin die Umbildung der Formen anknüpft.

Es erhellt aus dem Gesagten aber auch, daß eine gegebene Art, unter verschiedene äußere Bedingungen geratend, auch ganz verschiedene Entwicklungswege einschlagen, und daß somit von einer und derselben Stammform unter divergenter Entwicklung eine ganze Anzahl sehr verschiedener anderer ausgehen muß. Daraus aber ergibt sich weiter, daß die Entwicklıng des Organismenreiches nicht nur nicht nach einem bestimmten feststehenden Plane, sondern auch nicht etwa in einer geradlinigen Aufwärtsbewegung stattgefunden hat, vielmehr in einer Weise, die viel eher eine Versöhnung des Deszendenzgedankens mit der alten gruppenbildenden Typentheorie Cuviers und Baers gestattete. Denn auch Darwins Auffassung ließ die Organismen in Gruppen beieinander und begründete nur diese Gruppen durch den engeren genetischen Zusammenhang ihrer Angehörigen, - und das schwächte die Widerstände, die dem Abstammungsgedanken aus den herrschenden Vorstellungen erwachsen mußten, und begünstigte seinen Erfolg.

Endlich aber ist noch ein philosophischer Gedanke, der in der Zuchtwahllehre liegt, hervorzuheben: das Zurücktreten der Bedeutung des Individuums gegenüber der der Art. Tausende von Individuen müssen erzeugt werden, um das nötige auslesefähige 
Material von Varietäten zu schaffen, der Zuchtwahl ,anzubieten“, Tausende von ihnen müssen bald wieder zugrunde gehen, weil sie „,mangelhaft angepaßt“ sind, - sie werden von der Zuchtwahl verworfen zugunsten der besser angepaßten, deren Erhaltung von weitaus größerer Wichtigkeit für die Art ist. -

Eine Ergänzung erfuhr, wie gesagt, das Prinzip der natürlichen Auslese durch das von der geschlechtlichen Auslese, in dem statt des „Kampfes ums Dasein“ der Wettbewerb um das andere Geschlecht (- meist der Männchen um die Weibchen -) den auslesenden Faktor darstellt, und das von Da rw in zur Erklärung gewisser Merkmale, die nur dem einen Geschlecht zukommen (insbesondere Waffen und Schmuckbildungen), verwendet wird.

Darwins Lehre enthielt in sich ein unermeßliches Arbeitsprogramm, das auch bis heute noch lange nicht erschöpft ist. Sie betrachtete die Organismenwelt historisch, ihren geschichtlichen Werdegang aber bedingt nicht durch einen vorausbestimmten Plan, sondern durch immer aufs neue wirkende biologische Faktoren. Je nach Anlage und Schulung haben die Forscher der folgenden Jahrzehnte mehr die eine oder die andere Seite gepflegt. Daß es dabei die historische Betrachtungsweise war, die zunächst und für längere Zeit in den Vordergrund trat, ist wenigstens bis zu einem gewissen Grade verständlich. Von dem Abstammungsgedanken ging nicht nur der Reiz der Neuheit aus, er eröffnete im Augenblick auch das ergiebigste Arbeitsgebiet, indem er zu seiner praktischen Verwertung im einzelnen aufforderte, zu der Betrachtung der vergleichend-anatomischen und embryologischen Tatsachen im Lichte der Deszendenzlehre und damit zu der Ermittelung verwandtschaftlicher Zusammenhänge zwischen den Organismen auf Grund ihrer Organisation. Die große Aufgabe fand die geeigneten Kräfte bereit: in Huxley, Haeckel, vor allem Gegenbaur erstanden die führenden Forscher, die, mit den ausgedehntesten vergleichend-anatomischen und embryologischen Kenntnissen ausgerüstet, die neue Betrachtungsweise begeistert aufgriffen, sie mit den Vorstellungen der alten, auf die Idee des Typus gegründeten Morphologie verbanden und so die Wissenschaft der modernen historischen Morphologie schufen. Demgegenüber waren die biologischen Faktoren, mit denen der Darwinismus rechnete, nicht so leicht angreifbar. Die mikroskopische Forschung war noch nicht 
so weit, um in den Fragen der Variabilität und Vererbung erfolgreich mitsprechen zu können, und was Experimente und sonstiges empirisches Beobachtungsmaterial anlangt, so hatte Darwin davon eine so große Menge zusammengebracht, daß man sich vorerst wohl einmal damit begnügen konnte. Begnügen vollends auch in bezug auf die Lehre von der Zuchtwahl, die so wie so nicht unmittelbar mit Tatsachen zu beweisen, sondern nur eine Annahme war, eine Annahme allerdings, die sich auf die Vorgänge bei der künstlichen Züchtung berufen konnte, und die in sich selbst eine sieghaft uiberzeugende Kraft barg. Immerhin kann es aber doch auffallen, daß der Selektionsgedanke, der notwendig dazu führen mußte, alle Einrichtungen der Organismen als zweckmäßige Anpassungen aufzufassen, nicht eine kräftigere Betätigung der physiologischen Betrachtungsweise auf vergleichend-anatomischem Gebiete entfacht hat, und daß die funktionelle Behandlung der vergleichenden Anatomie so ganz hinter der historischen verschwand, trotzdem doch in Bergmanns und Leuckarts, ,anatomischphysiologischer Übersicht des Tierreichs" bereits ein genialer grundlegender Versuch vorlag, eine physiologische Analyse des tierischen Baues konsequenter und durchgreifender als es früher geschehen war, zu geben, - eine Grundlage, auf der schon damals hätte weitergebaıt werden können, deren Absicht, eine vergleichende Physiologie schaffen zu helfen, aber erst in der neueren Zeit eifrige und erfolgreiche Vertreter gefunden hat. Mögen die Gründe für die berührte Erscheinung sein, welche sie wollen, - jedenfalls trat die biologische Seite des Darwinismus anfangs sehr zurück. Zu denen, die gerade ihr wieder Geltung und Beachtung verschafft haben, gehört als einer der ersten und erfolgreichsten Weismann, der Freund Rudolf Leuckarts. Aber wenn Weismann auch keine Stammbäume aufgestellt oder morphologische Homologiefragen erörtert hat, so hat er sich doch in allen seinen biologischen Betrachtungen als historisch denkenden Naturforscher gezeigt; aus der Deszendenztheorie nahm er nicht nur die Probleme, sondern auch die Methode des Vorgehens: auf die biologischen Probleme, die er in Angriff nahm, wandte er die historische Betrachtungsweise an. Ausgehend von den ersten Stufen der biologischen Erscheinungen bei den niedersten Formen suchte er die Verhältnisse bei den höheren zu verstehen. So hat er die Erscheinungen des Todes, der Vererbung, 
der Befruchtung, die Verschiedenheiten in der Entstehung der Geschlechtszellen bei den Hydromedusen wie die Besonderheiten der Fortpflanzungserscheinungen bei den Daphnoiden nicht nur in ihrer biologischen Bedeutung, sondern auch in ihrer historischen Entwicklung zu fassen und zu verstehen gesucht und hat, im Gegensatz zu Darwin, immer wieder betont, daß die Umwandlung der Formen nicht richtungs- und regellos erfolgt, sondern in bestimmten Richtungen, die dadurch gegeben sind, daß alle Formen eine bestimmte Geschichte hinter sich und damit eine ganz spezifische, nur bestimmter Abänderungen fähige Konstitution erworben haben. Ja, auch seine oft als viel zu weit gehend verurteilte und dabei doch durchaus Darwinistische Auffassung, daß die Organismen in erster Linie und zum weitaus größten Betrage Anpassungskomplexe sind, ist ein Ausfluß nicht nur seines biologischen, sondern auch seines historischen Sinnes: sie nimmt nicht nur das als Anpassung, was uns jetzt als solche leicht erkennbar in die Augen springt, sondern rechnet mit Anpassungen von gestern und von der Urzeit her, die in ihrer ursprünglichen Bedeutung uns nicht immer mehr erkennbar sind. Und wie die Abstammungslehre ihn zur Beschäftigung mit allgemeinen Fragen geführt und ihm die Einzelprobleme vorgezeichnet hat, so behandelte er diese alle auch im Hinblick auf sie und kehrte immer wieder zu ihr zurïck. Das letzte große Werk, in dem er die Früchte seiner Lebensarbeit zusammengefaßt hat, trägt den Titel: Vorträge zur Deszendenztheorie.

\section{Erste Stellungnahme Weismanns zur Darwinschen Theorie: die Antrittsrede von 1868. Arbeitsprogramm.}

Zum ersten Male trat Weismann für die Deszendenztheorie, und zwar in der besonderen Form der Darwinschen Theorie, ein in seiner Antrittsrede von I 868: ,Über die Berechtigung der Darwinschen Theorie." Sie bietet dem Leser von heute naturgemäß nichts Neues, für die damalige Zeit ist aber vieles in ihr sehr beachtenswert. Scharf trennt hier Weismann die Transmutationshypothese an sich von dem durch Darwin gegebenen Erklärungsversuch, zeigt die Überlegenheit der ersteren gegenüber der alten Schöpfungsgeschichte und zugleich die Leistungsfähigkeit der von Darwin aufgestellten Prinzipien vom Kampfe ums Dasein und von der natürlichen 'Züchtung, erörtert die Vererbung als die Mit- 
teilung einer ganz bestimmten Entwicklungsrichtung und die Variabilität als Folge der Einwirkung verschiedener äußerer Einflüsse auf die durch Vererbung übertragene Entwicklungsrichtung, als Resultate aus der ererbten Entwicklungsrichtung und den äußeren Einflüssen. Die letzten Triebfedern der Artbildung müssen in der Erblichkeit und in den äußeren Einflüssen gesehen werden, wobei letztere in zweifachem Sinn wirken, ,einmal als eine die Vererbung modifizierende, individuelle Eigentïmlichkeiten hervorbringende Kraft, und dann gewissermaßen als Regulator der entstandenen Variationen, als natürliche Züchtung“. Damit sind schon die Hauptfragen berührt, die Weismann dann im Laufe seines weiteren Lebens immer wieder verfolgt hat, und ebenso findet sich schon hier eine bestimmte Stellungnahme gegen die hauptsächlich durch Naegeli vertretene Annahme einer den Organismen innewohnenden Kraft, die von Zeit zu Zeit die Abänderung einer Art und ihre Umwandlung in eine neue mit Notwendigkeit bewirkte. Dem Vervollkommnungsprinzip Naegelis stellt er das Nützlichkeitsprinzip Darwins gegenüber. Andererseits aber weist er auch bereits darauf hin, daß in der spezifischen Natur der Organismen und in der Harmonie, die zwischen ihren Teilen herrscht, Grenzen für die Leistungsfähigkeit des letzteren Prinzipes gegeben sind. Jeder Organismus besitzt bestimmte nach Zahl und Qualität feststehende Eigenschaften, nicht aber alle erdenkbaren Eigenschaften zu gleicher Zeit, und daraus folgt, daß auch seine Fähigkeit abzuändern begrenzt ist: er kann nicht alle denkbaren Abänderungen hervorbringen, sondern nur bestimmte, wenn auch noch so zahlreiche. Wörtlich heißt es: „Es beruht auf einseitiger Übertreibung der Darwinschen Lehre, wenn oft behauptet wird, die Organismen könnten nach allen möglichen Richtungen hin variieren. Freilich nach allen möglichen, aber auch nur nach den möglichen, womit zugestanden wird, daß es auch unmögliche gibt!" Und ferner gibt Weismann schon hier eine Erklärung für das Vorhandensein und die Konstanz rein morphologischer, physiologisch wertloser Charaktere, denen gegenüber das Zuchtwahlprinzip versagt (Blattstellung der Pflanzen, Zahl und Stellung der Schilder auf dem Kopfe der Schlangen u. a.). Er findet sie in der den Züchtern schon lange bekannten und auch von Darwin gewürdigten Korrelation der Teile. „Individuelle Abweichungen 
entstehen durch Einwirkung äußerer Verhältnisse auf die ererbte Entwicklungsrichtung, sie sind nicht zufällig, sondern müssen so oder so ausfallen, je nach der Qualität der äußeren Einflüsse und der Natur des Individuums. Es können nun sehr wohl dieselben Einflüsse zugleich nützliche, physiologisch wichtige und physiologisch indifferente, rein-morphologische Abweichungen derart hervorrufen, daß die einen nicht ohne die anderen entstehen können, daß beide zugleich die Reaktion des Organismus auf den bestimmten äußeren Einfluß sind; beide Abänderungen werden dann erhalten werden und beide, da sie innerlich verbunden, die gleiche Konstanz erlangen müssen.“ „Es ist das die ,Korrelation der Teile“, welche es mit sich bringt, daß kein Teil eines Organismus verändert werden kann, ohne daß zugleich Veränderungen in anderen Teilen eintreten." So begreifen wir auch die Schöpfung als eine Notwendigkeit und nicht als einen bloßen Zufall, wie sie vom Standpunkt des reinen Nützlichkeitsprinzips erscheinen muß. Die Natur tappt nicht richtungslos herum nach neuen Lebensformen, sondern Zahl und Art der möglichen Variationen sind durch die Eigentümlichkeit einer jeden Art fest bestimmt, und die Arten sind die Resultanten aus der natürlichen Züchtung und der Variationsqualität ihrer Stammeltern. Die gesamte organische Welt hätte eine sehr andere werden müssen, wenn die äußeren Einflüsse andere gewesen wären; die Zahl der möglichen Schöpfungen lebender Wesen ist überaus groß, unter den einmal gegebenen Verhältnissen aber konnten nur gerade diejenige entstehen, welche wirklich entstanden.

So zeigt schon diese erste Äußerung zur Darwinschen Theorie, daß Weismann sich nicht damit begnügen mochte, nur für die Lehren eines anderen Stimmung zu machen, sondern bestrebt war, dieselben kritisch $z u$ prüfen und $z u$ vertiefen. In diesem Sinne ist er auch weiterhin tätig gewesen, und jene Rede bildet dabei gewissermaßen den ersten Entwurf eines Arbeitsprogramms und zugleich eine erste Stellungnahme zu den in Betracht kommenden Problemen. Deren einem gegenüber ist diese Stellungnahme auch in der Folgezeit unverändert geblieben: gegenüber der Abstammungslehre überhaupt. Daß diese, die Vorstellung einer Entwicklung der Organismenwelt, die einzige wissenschaftlich mögliche Hypothese über die Entstehung der organischen Welt ist, - an dieser Überzeugung ist Weismann keinen Augenblick wankend geworden. 
Aber von diesem festen Boden aus, das erkannte er bald, führt die Frage nach dem ,Wie?" der Entwicklung in unbekanntes Gebiet, auf dem der Widerstreit der Meinungen Berechtigung hat. Vier Faktoren hatte Darwin auf diese Frage nach dem "Wie" der Artbildung namhaft gemacht, und mit ihnen hatte sich die Antrittsrede des jungen Zoologie-Professors beschäftigt: die Variabilität, die Vererbung, die Zuchtwahl - in der Form der natürlichen und der sexuellen Auslese - , und die Korrelation. Aber diese Kräfte, ihre Wirkungsweise und ihre Leistungsfähigkeit, bedurften denn doch noch einer besonderen Prüfung. Die empirisch festgestellte Tatsache der Variabilität erforderte die Ermittelung der Gründe der Erscheinung und damit eine genauere Untersuchung des unmittelbar umwandelnden Einflusses, den die äußeren Verhältnisse auf die Organismen ausüben; das Problem der Vererbung verlangte erst einmal eine Klärung darüber, was denn eigentlich vererbt wird, und dann die Erörterung des „Wie“, d. h. der Erscheinungen, an die sie geknüpft ist: der Fortpflanzung und, dazu gehörig, der Bildung der Keimzellen sowie der Befruchtung, in ihrer allgemeinen Bedeutung wie in ihrem materiellen Ablauf; das Prinzip der Zuchtwahl, in den beiden Formen, in denen Darwin es aufgestellt, erforderte eine eingehende Beleuchtung von allen Seiten, um so mehr, als es seiner Natur nach einer unmittelbaren Beobachtung entrückt schien; die Tatsache der Korrelation endlich führte naturgemäß zu einer allgemeineren Erörterung der in den Organismen selbst gelegenen Bildungskräfte und zu der Frage, wie weit solche Kräfte neben oder gar an Stelle der Selektion für die Entfaltung des Organismenreiches und die Mannigfaltigkeit seiner Formen in der Jetztzeit verantwortlich gemacht werden müßten.

So war es eine ungeheure Aufgabe, an die Weismann heranging, und die Kühnheit ist bewunderungswürdig, mit der er sie in Angriff nahm. Bewunderungswürdig aber auch die Ausdauer und geistige Kraft, mit der er sie verfolgte. Manche der früheren Anschauungen mußten dabei aufgegeben, manche neu aufgestellten im Laufe der Zeit auch wieder verlassen und verändert werden, aber schließlich gestaltete sich ihm doch eine Theorie, die alle jene großen und vielgestaltigen Probleme unter einheitlicher Betrachtung vereinigte, ihre gegenseitigen Beziehungen feststellte, in ihrem 
Lichte eine Deutung der feineren sichtbaren Vorgänge der Entwicklung versuchte und schließlich die Möglichkeit zeigte, alle organische Gestaltung auf ein großes Bildungsprinzip, das des Kampfes unter allen Lebenseinheiten, zurückzuführen.

In den siebziger Jahren finden wir Weismann mit Beobachtungen und Experimenten über deszendenztheoretische Fragen beschäftigt, die im vorigen Abschnitt besprochen wurden. Sie ließen, wie dort gezeigt wurde, allmählich neue eigene Auffassungen in ihm entstehen and bereiten so die Epoche der rein theoretischen Schriften vor, die mit dem, am 2I. September I88I auf der Naturforscherversammlung in Salzburg gehaltenen Vortrag über die Dauer des Lebens ihren Anfang nahm.

\section{Dauer des Lebens. Herkunft des Todes.}

Das erste Einzelproblem, das von Weismann besonders durchgearbeitet wurde, betrifft Fragen, die auch für den Menschen von gröBter Bedeutung sind: die Dauer des Lebens und die Herkunft des Todes. In Gedankengängen, die mit seinem Namen stets eng verknüpft bleiben werden, zeigte Weismann in einer Reihe von Schriften während der Jahre I88I-I885, wie diese Erscheinungen, deren bisher allein gebräuchliche rein physiologische Betrachtung manches unklar lieB, im Lichte historischer Betrachtungsweise ein neues Ansehen gewinnen und in ihrer Zweckmäßigkeit begreifbar werden. Die Verschiedenheiten zunächst der Länge der Lebensdauer bei den einzelnen Tieren können nicht aus Verhältnissen wie der Körpergröße oder dem Tempo des Stoffwechsels und der Lebensprozesse, womit man sie meist in Zusammenhang gebracht hatte, verstanden werden. Wenn auch eine beträchtliche Größe eines Tieres im allgemeinen eine längere Lebensdauer nötig macht, weil zu ihrer Herstellung mehr Zeit nötig ist, so lehren doch viele Beispiele, daß hier keine stets gültige Gesetzmäßigkeit vorliegt. So erreichen Hechte und Karpfen unter Umständen dasselbe Alter (200 Jahre) wie der Elefant; Schwein und Flußkrebs werden etwa 20 Jahre alt, die nur faustgroße Seeanemone etwa 50 Jahre. Und was das Tempo der Lebensprozesse anlangt, so weisen gerade die schnell lebenden Vögel eine relativ sehr lange Lebensdauer auf und ïbertreffen darin die trägen Amphibien gleicher Körpergröße. Es müssen somit wohl andere Gesichtspunkte als 
maßgebend für die Lebensdauer in Frage kommen. Worin aber liegen dieselben? In dem Interesse der Art. Dieses allein kommt bei der Regulierung der Lebensdauer in Betracht, nicht das des Individuums. Nicht darauf kommt es an, ob das Individuum länger oder kürzer sich der süßen Gewohnheit des Daseins erfreut, sondern daranf, da $B$ es für die Art das zu leisten vermag, was für deren Erhaltung das wichtigste ist: die Hervorbringung neuer Individuen, die einen genügenden Ersatz darstellen für die durch Tod abgehenden. Hat es diese Aufgabe erfüllt, so hat es bei sehr vielen Formen überhaupt seiner Pflicht genügt und kann ,zur Ruhe gehen", und nur in den Fällen, wo die Eltern Brutpflege ausüben, die Kinder beschützen, ernähren und unterrichten, behält ihr Leben auch für die Art noch längeren Wert. Dem entspricht es, daß alle Vögel und Säugetiere die Fortpflanzungszeit überleben, während die meisten Insekten sehr bald nach derselben zugrunde gehen. Damit ist der große allgemeine Gesichtspunkt festgelegt, nach dem den verschiedenen Formen die Lebensdauer zuzumessen ist. Wie groß aber dieses Maß für die einzelnen ausfallen wird, das hängt von mancherlei verschiedenen Dingen $a b$, hauptsächlich von der Fruchtbarkeit der Art und von der Menge der Schädigungen, denen die Brut und die erwachsenen Formen ausgesetzt sind. So schloß bei den Vögeln die Rücksicht auf die Leichtigkeit des Fluges große Fruchtbarkeit aus - tatsächlich brüten die meisten Vögel nur einmal im Jahre und viele legen jährlich nur ein Ei -, dazu kommen die ganz besonders großen Gefahren, denen die Eier und die Jungen ausgesetzt sind, und für beides findet sich eine notwendige Kompensation in der durchschnittlichen langen Lebensdauer, die die Vögel besitzen, und die sich bei manchen Formen (Raubvögeln) auf Ioo und mehr Jahre steigern kann. Im Gegensatz dazu besitzen die kleinen Säuger eine viel größere Fruchtbarkeit, ihre Jungen sind außerdem durch die intrauterine Entwicklung gegen Schädigungen viel besser geschützt als die Brut der Vögel, und so konnte ihre Lebensdauer kürzer festgesetzt werden. In gleicher Weise läßt sich auch für die Insekten die Länge der Lebensdauer als Anpassung an die äußeren Lebensbedingungen verstehen. Bei ihnen spielt noch eine besondere Rolle die Menge der Schädigungen, denen die ausgebildeten Tiere ausgesetzt sind: insbesondere die Vernichtung durch so viele andere Tiere, die geradezu 
auf die Insekten als Nahrung angewiesen sind. Das Interesse der Art verlangte unter diesen Umständen eine möglichste Verkürzung des Lebens durch möglichste Beschleunigung der Fortpflanzung, da mit der Länge des Lebens natürlich die Gefahr einer Zerstörung durch solche Zufälligkéiten größer werden muß. So erklärt sich die bei den Insekten gewöhnliche Kombination: sehr große Fruchtbarkeit bei sehr kurzem Imagoleben, das gleich nach der kurzen Fortpflanzungsperiode sein Ende erreicht. Das äußerste in dieser Hinsicht leisten einige Arten von Eintagsfliegen, die bald nach dem Ausschlüpfen aus der Puppenhülle sich in die Luft erheben, sich fortpflanzen, sich dann aufs Wasser niederlassen, sämtliche Eier auf einmal ausstoßen und nun ihr Imagoleben, das etwa $4-5$ Stunden gedauert hat, beschließen.

So lassen sich aus dem Gesichtspunkte des Nutzens für die Art die Verschiedenheiten in der Länge der Lebensdauer als Anpassungen an die äußeren Lebensbedingungen erklären; der Mechanismus, durch den diese Anpassungen erfolgten, wird auch hier in Selektionsprozessen zu suchen sein.

Warum aber müssen überhaupt die Organismen sterben, was bedingt ihren Tod, $d$. h. natürlich ihren normalen physiologischen Tod, dem früher oder später jedes Geschöpf - wie es wenigstens nach der alltäglichen Erfahrung scheint - anheimfällt, auch wenn es vor der so häufigen Vernichtung durch Zufälligkeiten (Krankheiten, Katastrophen) bewahrt bleibt? Ist es eine im Wesen des Lebens begründete Notwendigkeit, und war ewige Dauer mit demselben unvereinbar? Weismann verneint diese Frage. Der natürliche Tod ist keine von vornherein gegebene Naturnotwendigkeit, sondern ist in das Organismenreich erst eingeführt worden als eine zweckmäßige nützliche Einrichtung. $D a B$ er nicht untrennbar mit dem Leben verbunden ist, lehren die Einzelligen: sie sind nicht notwendig dem Tode unterworfen. Die später soviel behandelte Frage von der „Unsterblichkeit der Einzelligen“ wird hier von Weismann zum ersten Male eingehend erörtert. Auch die Einzelligen können vernichtet werden, gewiß; aber einen normalen, physiologischen Tod gibt es für sie nicht. Der verbreiteten Auffassung, als ob mit der Teilung eines einzelligen Organismus in zwei Tochtergeschöpfe das Leben des Muttertieres beschlossen sei, und als ob somit hier Fortpflanzung und Tod zusammenfielen, 
stellt Weismann die Frage gegenüber: wo ist denn die Leiche? Was stirbt denn $a b$ ? Nichts stirbt ab, sondern der Körper des Tieres zerfällt in zwei nahezu gleiche Stücke, die dem Muttertiere vollkommen ähnlich sind, wie dieses weiter leben und sich später, wie dieses, wieder in zwei Hälften teilen. Erst mit der Entstehung der vielzelligen Organismen aus den einzelligen wurden ganz andere Verhältnisse geschaffen. Fortpflanzungs- und Körperzellen trennten sich voneinander; die Körperzellen paßten sich, dem Prinzip der Arbeitsteilung entsprechend, unter fortschreitender histologischer Differenzierung immer vollkommener, aber auch immer einseitiger den mannigfachen Leistungen an, und je mehr dies geschah, um so mehr ging ihnen die Fähigkeit verloren, größere Stücke des Organismus zu reproduzieren, und um so mehr konzentrierte sich das Vermögen der Fortpflanzung des Gesamtindividuums in den Keimzellen. Jene, die Körperzellen, verloren aber nicht nur die Fähigkeit zur Hervorbringung des ganzen Organismus, sondern auch die, sich selbst unbegrenzt zu vermehren. Ihr Vermögen, sich selbst durch Teilung fortzupflanzen, wurde auf eine bestimmte Anzahl von Zellgenerationen beschränkt, haben sie diese hervorgebracht, so erlischt ihre Reproduktionskraft. Das aber bedeutet den „Tod“ des Soma, des Individuums, der bei den vielzelligen Organismen letzten Endes darauf beruht, daß der normale Ersatz der während des Lebens fortwährend und massenhaft zugrunde gehenden, abgenutzten, morphologischen Elemente stockt. Warum aber verloren die Körperzellen die Fähigkeit unbegrenzter Vermehrung? Auch dies erklärt Weismann aus dem Gesichtspunkt des Nutzens, der Zweckmäßigkeit für die Art. Von diesem Gesichtspunkt aus ist das Soma, das Individuum wertlos, wenn es der Aufgabe der Fortpflanzung und gegebenenfalls der Brutpflege genügt hat, ja, die unbegrenzte Lebensdauer aller Individuen würde sogar schädlich für die Art sein, denn sie würde, da alle Organismen durch die Berührung mit der Außenwelt fortgesetzt Schädigungen ihres Körpers ausgesetzt sind, sehr bald zu dem Vorhandensein einer Unmenge krüppelhafter Individuen führen, die den anderen nur den Platz wegnehmen würden. So war es also nicht nur möglich, sondern sogar nützlich und geboten, die Produktivität der Körperzellen auf eine bestimmte Zahl von Zellgenerationen zu normieren und damit die Lebensdauer des Soma zu beschränken, d. h. den 
physiologischen Tod einzuführen. Auch der Tod ist eine Anpassungserscheinung, eine Konzession an die äußeren Lebensbedingungen. Nur den Fortpflanzungszellen durfte die Fähigkeit unbegrenzter Vermehrung nicht verloren gehen, wenn anders die Art erhalten bleiben sollte. Sie besitzen wie die Einzelligen potentielle Unsterblichkeit, bilden den unsterblichen Kern innerhalb des sterblichen Soma. Die Frage endlich, wodurch jene Beschränkung der Vermehrung der Körperzellen auf eine bestimmte festgesetzte Anzahl von Generationen $\mathrm{zu}$ denken sei, beantwortet Weismann dahin, daß der Grund dafür in den Zellen selbst liege, denen schon vom Keime her nur eine beträchtliche Vermehrungsfähigkeit mitgegeben wird. Es geht also damit, wie mit Entwicklungsvorgängen: sie sind letzten Endes auf innere Verhältnisse der Keimzelle zurückzuführen. Die Entwicklungstendenzen, die von hier aus den einzelnen Zellen mitgegeben werden, hören mit der äußeren Fertigstellung des Embryo nicht auf, sondern bleiben wirksam bis ins späte Alter, beherrschen die Lebensvorgänge und bedingen das Ende derselben - den Tod.

In diesen Gedankengängen, auf die Weismann später mehrfach zurückgekommen ist, liegt nicht nur ein abermaliges überzeugtes Bekenntnis zu dem wichtigsten Grundprinzip des Darwinismus, sondern auch der Keim zu ganz neuen eigenen Vorstellungen. Sie zeigen die Anwendbarkeit des Selektionsprinzipes auf Erscheinungen, in denen man sein Wirken zunächst nicht erwartet hätte, - des Selektionsprinzipes, das Weismann in der Folgezeit bis an die äußersten Grenzen seiner Leistungsfähigkeit verfolgt hat, und dem er bis an sein Lebensende bemüht blieb, die beherrschende Rolle bei allem organischen Geschehen und für alle Lebenseinheiten, die größten wie die kleinsten, zuzuweisen; sie stellen ferner bereits den scharfen Gegensatz zwischen Somaund Keimzellen auf, auf dem die ganze Weismannsche Vererbungshypothese beruht, und sie verlegen endlich die wichtigsten bestimmenden Faktoren für die Entwicklung wie für die zellulären Vorgänge bis ans Ende des Lebens in die Keimzelle. Damit aber errichten sie die hauptsächlichsten Fundamente für die Vererbung slehre, die Weis mann nunmehr als selbständiges Problem in Angriff nahm und einige Jahre später vollendete. 
Vierter Abschnitt.

\section{Die Kontinuität des Keimplasmas als Grundlage der Weismannschen Vererbungslehre. Die Vererbung erworbener Eigenschaften.}

I. Vererbung: Bedeutung, Begriff, stoffliche Bedingtheit. Darwins Pangenesishypothese. - 2. Die Kontinuität des Keimplasmas. - 3. Die Vererbung erworbener Eigenschaften. Das Problem. Somatogene und blastogene Eigenschaften. - Angebliche Vererbung von Verletzungen und Verstümmelungen. Angebliche Vererbung von funktionellen Abänderungen. - Harmonische Anpassung (Koadaptation). - Die Anpassungen der Ameisen-Neutra. - Anpassungen der bloß „passiv wirksamen" Teile und Merkmale. - Instinkte. - Geistige Fähigkeiten, spezifische Talente. Der Musiksiun. - Zusammenfassung. - Vererbung von Veränderungen, die durch das Medium bedingt sind. - Ergebnisse. Übertragung derselben auf die Einzelligen. - Die Mnemetheorie von Semon; Weismanns Stellung zu derselben.

\section{r. Vererbung: Bedeutung, Begriff, stoffliche Bedingtheit. Darwins Pangenesishypothese.}

,Von der Vererbung möchte ich reden, diesem Grundpfeiler alles Beharrungsvermögens der organischen Formen, dem unbefangenen Laien so selbstverständlich und keiner besonderen Erklärung bedürftig, der Reflexion so verwirrend durch die unendliche Mannigfaltigkeit ihrer Äußerungen, und so rätselvoll ihrem eigentlichen Wesen nach" - mit diesen Worten beginnt die berühmte Rede, die Weismann am 2I. Juni I883 bei Übernahme des Prorektorates der Universität Freiburg in der Aula derselben hielt. Sie ist zum größten Teil der Behandlung einer bestimmten Frage aus dem Vererbungsproblem, der Frage nach der Vererbung erworbener Eigenschaften gewidmet, legt aber zugleich schon in großen Zügen die allgemeine Grundlage fest, von der aus, nach 
Weismanns Úberzeugung, alle Fragen dieses großen Problemes behandelt werden müssen: die Lehre von der sogenannten Kontinuität des Keimplasmas.

Auch die früheren Veröffentlichungen Weismanns hatten die Erscheinungen dér Vererbung berücksichtigen mïssen. In allen Betrachtungen über die Deszendenztheorie spielt sie naturgemäß eine Rolle, und insbesondere die Erörterungen über die Bedeutung direkter Mediumeinflüsse auf die Umwandlung der Formen, die an die Schmetterlingsexperimente anknüpfen, gehen aus von der Annahme, daß diese Wirkungen erblich sind. Anfangs konnte eben auch Weismann nicht anders, als sich auf den Standpunkt Darwins zu stellen, der die Fähigkeit, die eigenen Eigenschaften auf die Nachkommen weiter zu geben, geradezu als eine gegebene Grundeigenschaft der Organismen annahm und daraufhin die Übertragbarkeit der am Einzelindividuum aus irgendeinem Grunde neu auftretenden Besonderheiten als sicher betrachtete. „Nicht-erbliche Abänderungen sind für uns ohne Bedeutung“ - so fängt ein Abschnitt in Darwins ,Entstehung der Arten“ an, an dessen Schlusse es heißt: , Ja vielleicht wäre die richtigste Art die Sache anzusehen die, daß man jedweden Charakter als erblich und die Nichtvererbung als Anomalie betrachtete“ $\left.{ }^{26}\right)$. Damit war zwar zugegeben, daß es auch nicht-erbliche Abänderungen gibt, für weitaus die meisten Merkmale aber, mögen sie groß oder klein sein, wurde ihre Vererbbarkeit von vornherein vorausgesetzt. Eine eingehendere theoretische Erörterung des Vorganges lag Darwin ferne, seine noch $\mathrm{zu}$ besprechende Theorie der Pangenesis hat er selbst nur als eine ,provisorische Hypothese“ bezeichnet.

Dagegen erkannte Weismann allerdings bald, was er in den oben angeführten Worten ausspricht, daß die Erscheinung der Vererbung, so selbstverständlich sie für die naive Betrachtung sein mag, der genaueren Überlegung eine Menge unbeantworteter Fragen stellt. Auf eine derselben versuchte er auch schon in der Rede von I868 eine Antwort zu geben. Im Gegensatz zu der gewöhnlichen Definition, die unter Vererbungsfähigkeit die Fähigkeit der Organismen versteht, ihre Eigenschaften auf die Nachkommen zu übertragen, erklärt er diese Fähigkeit dahin, daß dem Keim des Organismus durch die Mischung seiner Bestandteile eine ganz bestimmte Entwicklungsrichtung mitgeteilt wird, dieselbe Ent- 
wicklungsrichtung, wie sie der elterliche Organismus zu Anfang besessen hat, so daß also unter absolut gleichen äußeren Einflüssen auch absolut gleiche Entwicklungsstadien vom kindlichen wie vom elterlichen Organismus durchlaufen werden müssen. Die gleiche zunächst mehr physiologische Auffassung der Vererbung hat er wiederholt ausgesprochen; ihr entsprechend erblickt er als Folge der sexuellen Fortpflanzung ,,eine Vermischung der Merkmale (genauer: Entwicklungsrichtungen) zweier gleichzeitig lebender Individuen in einem Keime" (1876) und definiert die Variabilität als ,die Resultate aus der ererbten Entwicklungsrichtung und den äußeren Einflüssen“ (I868) und ebenso, einige Jahre später (I880) als ,,eine durch ungleiche äußere Einflüsse bedingte Ablenkung der durch die Vererbung vorgezeichneten Entwicklungsrichtung" ${ }^{17}$ ). Von dieser Auffassung aus konnte dann die Frage nach den Ursachen, der stofflichen Bedingtheit der Gleichartigkeit in der Entwicklungsrichtung des kindlichen und des elterlichen Organismus in Angriff genommen werden.

$\mathrm{Da} B$ die Erscheinungen der Vererbung an die Fortpflanzung geknüpft sind, und $d a ß$ somit bei der weitaus häufigsten Form der letzteren, der $Z$ weielternzeugung oder geschlechtlichen Fortpflanzung, in der Befruchtung des Eies durch die Samenzelle der Vorgang zu sehen ist, an den die Vererbung der elterlichen Eigenschaften auf den Nachkommen geknüpft ist, - von dieser Voraussetzung konnte Weismann schon bei der Inangriffnahme des Problemes ausgehen. Daraufhin formulierte er denn auch die zwei großen Fragen des letzteren: I. wie kommt eine einzelne Zelle des Körpers dazu, die sämtlichen Vererbungstendenzen des gesamten Organismus in sich zu vereinigen? und 2. durch welche Kräfte, welchen Mechanismus kommen diese Tendenzen beim Aufbau des neuen Organismus zur Entfaltung? $\left.{ }^{18}\right)$.

Nur ganz allgemein hatte Darwin versucht, beide Fragen zu beantworten: in der schon genannten Theorie der Pangenesis, die er aber selbst nur als eine provisorische Hypothese oder Spekulation bezeichnet. Der Name drückt aus, ,daß die ganze Organisation, und zwar in dem Sinne, daß hiermit jedes einzelne Atom oder jede Einheit gemeint wird, sich reproduziert". Das sollte in der Weise geschehen, daß von allen Zellen des Körpers während des Lebens Keimchen abgegeben werden, im Körper kreisen und 
schlieBlich in den Geschlechtszellen zur Ablagerung kommen, um dann bei der Entstehung wieder Teile entstehen zu lassen, denen ähnlich, von denen sie selbst stammten. Durch diese Annahme wäre auch, wie Darwin erörtert, für die ,Vererbung erworbener Eigenschaften " eine verhältnismäßig einfache Erklärung gegeben gewesen: die Keimchen mußten ja auch Träger aller Veränderungen sein, die die betreffenden Zellen durch irgendwelche Einflüsse betrafen. Daß sich die Dinge in Wirklichkeit so verhielten, war freilich schwer zu glauben; besondere auf den Nachweis der Keimchen gerichtete Versuche ergaben denn auch ein negatives Resultat, und von verschiedenen Seiten war die Pangenesistheorie bestritten oder doch stark umgewandelt worden. Und doch ist auch Weismann später, nach anfänglichen Versuchen in anderer Richtung, wieder zu der Annahme kleinster materieller Teilchen als Träger der Vererbung zurückgekehrt, freilich unter bestimmter Ablehnung der Vorstellung, da $B$ diese Teilchen etwa von den Körperzellen abstammten und durch den Körper zu den Keimzellen transportiert würden. Damit aber hat er einen Hauptgedanken der Darwinschen Pangenesishypothese zu neuem Leben erweckt.

\section{Die Kontinuität des Keimplasmas.}

Weismann griff auch dieses Problem historisch an, er suchte die Vererbungserscheinungen von ihrer Wurzel aus zu verstehen, und diese Betrachtung führte ihn zu der Aufstellung des Gedankens, der als Lehre von der Kontinuität des Keimplasmas mit seinem Namen für alle Zeiten verbunden bleiben wird. Mit Recht, denn wenn es auch richtig und von Weismann selbst rückhaltlos anerkannt worden ist, daß schon vor ihm andere Forscher (Galton, Jäger, Nußbaum u. a.) zur Aufstellung der gleichen Anschauung gelangt waren, so ist es doch auch unbestreitbar, daB erst Weismann seine volle Bedeutung erkannt, ihn auf seine Leistungsfähigkeit nach allen Richtungen durchgearbeitet und ihn in seiner Tragweite der Wissenschaft zum Bewußtsein gebracht hat.

Weismann geht, wie gesagt, bei der Betrachtung der Vererbungserscheinungen aus von ihren Anfängen bei den niedersten Lebewesen. Hier, bei den Einzelligen, liegen die Dinge noch verhältnismäßig einfach und leichter verständlich. Wenn wir aus einer Amöbe durch Teilung zwei durchaus gleiche Tochterindi- 
viduen entstehen sehen, so begreifen wir bis $\mathrm{zu}$ einem gewissen Grade, da $B$ diese Tochterindividuen der Mutter in ihrem Aussehen, ihren Lebensäußerungen und Fähigkeiten gleichen, - setzen sie doch den Körper derselben nur in einer neuen Form fort. So muß sich denn auch bei jeder von ihnen die Fähigkeit fortsetzen, Nahrung aufzunehmen, auf Kosten derselben die eigene Lebenssubstanz zu vermehren, um sich dann ebenfalls wieder zu teilen. Und so fort durch ungezählte Generationen: die stoffliche Kontinuität bildet hier die Grundlage der Vererbungserscheinungen. (Diese Überlegung hat später (I89I), wie wir sehen werden, eine geringe Abänderung erfahren, indem Weismann sie ,um eine Stufe weiter gegen den Anfang des Lebens hin" zurückschiebt, d. h. nur noch für die niedersten Organismen gelten läßt, bei denen noch keine Differenzierung in Kern und Zellkörper eingetreten ist.)

Eine ganz gleiche stoffliche Kontinuität nimmt nun Weisınann auch für das Keimplasma, d. i. die Vererbungssubstanz, in den Keimzellen (Ei und Samenfaden) bei den Vielzelligen an. Für die Entstehung der letzteren lagen von vornherein drei Hauptmöglichkeiten vor: I. es könnte, wie es in der Darwinschen Pangenesistheorie zum Ausdruck kommt, die Keimzelle gewissermaßen als Extrakt des ganzen Körpers immer neu gebildet werden, oder 2. die Substanz der elterlichen Keimzelle könnte die Fähigkeit besitzen, einen Kreislauf von Veränderungen durchzumachen, welche durch den Aufbau des neuen Individuums hindurch wieder zu identischen Keimzellen führt, oder endlich 3. die Keimzellen entstehen in ihrer wesentlichen und bestimmenden Substanz überhaupt nicht aus dem Körper des Individuums, sondern unmittelbar aus der elterlichen Keimzelle. Diese letztere Ansicht hält Weisman n für richtig. Seiner Ansicht nach wird das Material der Keimzelle nicht erst während des Lebens gebildet und mit den Fähigkeiten zur Erzeugung eines neuen, dem alten ähnlichen Organismus ausgestattet, sondern es stammt unmittelbar von dem Keimplasma $\mathrm{ab}$, aus dem der Träger der Keimzelle selbst hervorging, ist geradezu nur ein unverbrauchter Teil desselben. Wenn die befruchtete Eizelle, so folgert Weismann, sich anschickt, einen neuen Organismus aus sich hervorgehen zu lassen, so wird von vornherein eine gewisse Menge ihrer maßgebenden Substanz, ihres Keimplasmas, reserviert, wird nicht in der Ontogenese aufgebraucht, sondern 
als unveränderter Rest in die Keimzellen des neuen Individuums gebracht und dort abgelagert. Ist dann an eine dieser Zellen die Reihe gekommen, ein neues Geschöpf entstehen zu lassen - gegebenenfalls nach Vereinigung mit der Keimzelle eines anderen Individuums - so muß dieser neue Organismus notwendigerweise seinem Elterorganismus gleichen, da das ihn erzeugende Keimplasma nur ein Teil dessen ist, das jenen entstehen lieB. So geht es fort durch ungezählte Generationen hindurch; nur Assimilationsfähigkeit, d. h. die Fähigkeit, sich auf Kosten der Nahrung fortwährend zu ergänzen und zu vermehren, müssen wir bei dem Keimplasma voraussetzen, können es aber auch, da diese Fähigkeit eine Elementareigenschaft aller lebenden Substanz ist. (DaB sie für sich eins der schwierigsten organischen Grundprobleme darstellt, wie Roux bemerkt, kommt dabei hier nicht in Frage.) Im übrigen aber besitzt das Keimplasma der Vielzelligen, wie die Einzelligen, potentielle Unsterblichkeit und steht damit den sterblichen Somazellen gegenüber. „Das Keimplasma einer Art wird nie neu erzeugt, sondern es wächst und vermehrt sich nur unaufhörlich, es zieht sich fort von einer Generation zur anderen, wie eine lange, in der Erde fortziehende Wurzel, von der in regelmäßigen Abständen Sprosse emportreiben und zu Pflänzchen werden, zu den Individuen der aufeinander folgenden Generationen." Diese Annahme einer Kontinuität des Keimplasmas war kein bloßes Denkergebnis, sondern konnte sich auf tatsächliche Beobachtungen stützen. Für gewisse Insekten war nachgewiesen, da $B$ die ersten Zellen, die sich bei der Furchung von der übrigen Masse des Eies trennen, eben die Geschlechtszellen sind; bei anderen Formen erfolgt diese Trennung der Geschlechtszellen, wenn auch nicht zu allererst, so doch in sehr frühen Stadien der Ontogenese. $Z u$ besonders wichtigen Ergebnissen in dieser Hinsicht war Weismann selbst durch seine eigenen Untersuchungen über die Entstehung der Sexualzellen bei den Hydromedusen gelangt: die Geschlechtszellen entstehen hier zwar nicht am Anfang der Ontogenese, sondern sehr viel später und bei den verschiedenen Formen an verschiedenen Stellen, aber unter Erscheinungen, die darauf hinweisen, daß nicht jede beliebige Körperzelle zu einer Keimzelle werden kann, sondern daß nur bestimmte Zellen und Zellfolgen Träger des Keimplasmas sind und die Kontinuität desselben durch die Generationen vermitteln. In 
der Folgezeit ist dann bei einer ganzen Anzahl von Tieren die gesamte Zellenfolge, die vom befruchteten Ei bis zu den Keimzellen führt, die sogenannte Keimbahn, verfolgt worden, wobei gewisse histologische Merkmale, die alle diese Keimbahnzellen auszeichnen, den Anhalt abgaben. In diesen Fällen ist also die Kontinuität des Keimplasmas eigentlich keine Hypothese mehr, sondern eine sich unmittelbar aufdrängende Deutung der Beobachtungen. Damit aber ist für die Annahme, daß bei jeder Ontogenese ein Teil des Keimplasmas unverändert in die Keimzellen des neuen Individuums transportiert und dort abgelagert wird, ein genügend sicherer Tatsachenboden gegeben.

Auf Grundlage der Kontinuität des Keimplasmas verstehen wir es, daß das Kind seinem Erzeuger ähnlich ist und daß es bei Zweielternzeugung, wo die Keimplasmen zweier Individuen sich vermischen, Charaktere von beiden Eltern in sich vereinigen kann. Wir haben also eine erste Grundlage für das Verständnis der Vererbungserscheinungen. Diese Annahme von der Kontinuität des Keimplasmas ist die wichtigste Grundlage von Weismanns Vererbungslehre; sie steht im Gegensatz zu der Darwinschen Vorstellung, da $B$ das Keimplasma erst im Individuum durch Teilchen, die von den Körperzellen desselben abgegeben werden, neu gebildet wird, und lehnt auch die andere Auffassung ab, daß das Keimplasma in der Ontogenese einen Kreislauf durchmachen, d. h. da $B$ es in den Kernen der verschiedenen Körperzellen bestimmte gesetzmäBige Veränderungen erleide, um schließlich in den Keimzellen wieder zu Keimplasma rückverwandelt zu werden.

Unter den Fragen, die sich im Anschluß hieran aufdrängen müssen, ist wohl die nächstliegende die, in welchem Bestandteil der Keimzellen jene wichtigste Substanz, das Keimplasma, zu sehen ist. Auch diese Frage, die Frage nach der eigentlichen Vererbungssubstanz, lag damals gewissermaßen in der Luft, und so kann es nicht Wunder nehmen, daß sie fast gleichzeitig von drei Forschern beantwortet wurde: von E. Strasburger, O. Hertwig und A. Weismann. Alle drei kamen zu dem Schluß, daß jene Substanz in der Kernsubstanz und zwar besonders in der chromatischen Substanz des Kernes zu sehen sei. Die Vorgänge bei der Zellteilung und bei der Befruchtung, sowie Experimente von NuBbaum und A. Gruber (- die des letzteren auf Weismanns 
Veranlassung im Freiburger zoologischen Institut unternommen -) sprachen vornehmlich in jenem Sinne. Weismann hat denn auch an dieser Auffassung, der Lehre von dem ,Vererbungsmonopol des Kernes", wie sie später bezeichnet wurde, bis an sein Lebensende festgehalten und auf ihr als Grundlage seine Vererbungstheorie weiter ausgebaut. Bevor wir auf diese eingehen können, sind noch einige andere mehr allgemeine Dinge zu behandeln.

Fragen mußten sich ja gegenüber der Lehre von der Keimplasmakontinuität in großer Menge aufdrängen; vom Standpunkt der Deszendenzlehre aus waren die beiden wichtigsten wohl die: I. wie ist überhaupt das Keimplasma des ersten vielzelligen Tieres entstanden? und 2. wie konnte aus diesem Keimplasma der ersten vielzelligen Wesen die vielen tausende Arten verschiedener Keimplasmen entstehen, die den jetzt lebenden Organismen zugrunde liegen?

Die erste Frage behandelt Weismann unter Hinweis auf die koloniebildenden Einzelligen, die eine Mittelstellung zwischen den isoliert lebenden Einzelligen und den echten Vielzelligen einnehmen, gewissermaßen einen Übergang von jenen zu diesen bilden. Unter diesen koloniebildenden Einzelligen gibt es solche, die aus ganz gleichartigen Zellen zusammengesetzt sind, und bei denen die Dinge noch grundsätzlich ebenso liegen, wie bei den isoliert lebenden Einzelligen: jedes Mitglied der Kolonie ist imstande, sich fortzupflanzen, d. h. sich zu teilen und durch wiederholte Teilung, wobei die Tochterzellen immer in enger Aneinanderlagerung verbunden bleiben, eine neue Kolonie entstehen zu lassen. Die Glieder solcher Kolonien, die als Homoplastiden bezeichnet werden, sind also zugleich , Körperzellen" und "Keimzellen" der Kolonie. Anders liegen die Dinge bei jenen Kolonien, die als Heteroplastiden bezeichnet werden. Hier, z. B. bei der Gattung Volvox, ist eine Arbeitsteilung eingetreten, eine scharfe Trennung von Körper- und Fortpflanzungszellen. Kleinen, zu vielen Hunderten vorhandenen Geißelzellen, die aber auch allen übrigen Funktionen der Lebenserhaltung (Ernährung, Sekretion, Exkretion usw.) dienen, stehen viel weniger zahlreiche große Keimzellen gegenüber, die allein die Fähigkeit bewahrt haben, die Kolonie fortzupflanzen. Jene, die kleinen Geißelzellen, stellen das sterbliche Soma der Kolonie dar: sie können durch Teilung nur ihresgleichen erzeugen, gehen aber dann einmal 
zugrunde; die Keimzellen aber vermögen durch Teilung eine neue Volvoxkolonie hervorzubringen, also nicht nur ihresgleichen, sondern auch die somatischen Zellen. Wie ist dieser Zustand der heteroplastiden Kolonien an den der homoplastiden anzuschließen? Die Antwort, die Weismann darauf gibt, lautet kurz etwa folgendermaßen. Unter irgendwelchen Einflüssen muß einmal die Struktur des Plasmas von Zellen homoplastider Kolonien sich derart geändert haben, daß die Kolonie, die nunmehr durch Teilung aus ihnen hervorging, nicht mehr, wie bisher, aus identischen, sondern aus zweierlei verschiedenen Zellenarten bestand, von denen nur die eine Art die Fähigkeit zur Neuerzeugung einer Kolonie beibehielt, die andere aber die somatischen Funktionen übernahm und durch Teilung nur noch ihresgleichen hervorzubringen vermochte. In die erste Art, die Keimzellen, wurde dabei eine gewisse Menge dieses veränderten Keimplasmas eingeschlossen, um dann auch weiterhin von Generation zu Generation weitergegeben $\mathrm{zu}$ werden und Kolonien gleicher Art zu erzeugen. Der springende Punkt dabei ist also, daß die Besonderheit, die der ausgebildete Organismus zeigt, - hier zunächst die Zusammensetzung aus zweierlei verschiedenen Zellenarten - die Folge ist von einer primären Veränderung des Keimplasmas. Diesen Vorgang haben wir uns nun im Laufe der Generationen fortgesetzt $z u$ denken. Auf primäre Variationen des Keimplasmas ist es zurückzuführen, daß die Zellen der Kolonien im Laufe der Stammesgeschichte noch weiter ungleich wurden, daß eine große Menge sehr verschiedenartiger Elemente, Muskel-, Nerven-, Drüsenzellen usw. entstand, die sich in die verschiedenen Funktionen des Somas teilten. Diese Arbeitsteilung erfolgte also in der Stammesgeschichte nicht an den entwickelten Organismen und wurde von diesen aus durch die Keimzellen den Nachkommen übergeben, sondern umgekehrt: sie war zuerst im Keimplasma vorgebildet, bedingt durch gewisse Veränderungen desselben, und wurde auf Grund der Kontinuität des Keimplasmas weiter vererbt. So entstanden die vielzelligen Organismen, und so konnten sie sich im Laufe der Generationen auch allmählich verändern, immer auf der Grundlage primärer Keimesvariationen. Damit ist auf die zweite der oben gestellten Fragen eine wenigstens vorläufige Antwort gegeben; eine genauere Erörterung des Zustandekommens solcher primärer Keimes- 
variation brachte erst sehr viel später, I895, die Lehre von der Germinalselektion. Daß aber auf der Grundlage primärer Keimesvariationen $z$ weckmäßige Gestaltungen zustande kamen, Organismen, die in der mannigfaltigsten Weise den äußeren Bedingungen angepaßt sind, das beruht auf der Zuchtwahl im Kampf ums Dasein. Durch sie wurden die jeweiligen unzweckmäßigen Varietäten ausgemerzt, aus dem Stammbaum der Art entfernt, die zweckmäßigen erhalten.

Das sind wohl die wesentlichsten Grundgedanken der Weismannschen Vorstellung.

\section{Die Vererbung erworbener Eigenschaften.}

Das Problem.

Unter den weiteren Fragen, die sich an diese Vorstellung anschließen, steht im Vordergrunde die nach den Beziehungen zwischen den Körperzellen und den Keimzellen, insbesondere die, ob Veränderungen des Keimplasmas durch Einwirkung der Körperzellen hervorgerufen werden können, und vor allem, ob Veränderungen der Körperzellen, des Soma, sich so den Keimzellen mitteilen können, daß an den Nachkommen entsprechende Veränderungen auftreten. Es ist kurz gesagt, die Frage, die gewöhnlich, wenn auch nicht zweckmäßig, als die nach der Möglichkeit einer Vererbung erworbener Eigenschaften bezeichnet wird. Daß Weismann diese Möglichkeit überhaupt verneint, ist heutzutage wohl jedem bekannt, der überhaupt Weismanns Namen kennt. Und man mag über die Richtigkeit seines Standpunktes denken wie man wolle, - das Verdienst zum mindesten wird ihm wohl niemand abstreiten, da $B$ erst durch ihn die ganze Frage dem Bereiche einer mehr laienhaften Behandlung entzogen und wirklich wissenschaftlicher Analyse zugeführt worden ist.

Als Weismann an die Behandlung der Frage herantrat, wurde dieselbe - das Lamarcksche Prinzip, wie gewöhnlich gesagt zu werden pflegt - sehr allgemein bejaht. Es ist aber klar, da $B$, wenn sie wirklich durch Beobachtungen einwandfrei bewiesen wäre, das ganze Vererbungsproblem bei den Vielzelligen erheblich schwieriger und rätselhafter würde. Denn dann müßte wohl ein dauerndes geheimnisvolles Abhängigkeitsverhältnis zwischen dem 
Soma und den in seiner Hut befindlichen, in ihm eingeschlossenen Keimzellen angenommen werden. Darwin, der das Prinzip des Lamarckismus für die Umbildung der Arten nicht entbehren zu können glaubte, hatte in seiner schon besprochenen Pangenesistheorie gezeigt, wie man sich rein formal jenes Abhängigkeitsverhältnis denken könne; wenn die Keimzellen erst intra vitam gebildet und mit Keimchen von allen Körperzellen beladen werden, so werden die Zellen, die sie später mit Hilfe dieser Keimchen produzieren, auch die Einzelheiten der Zellen zeigen, von denen die Keimchen stammten. Das war wenigstens, mit Hilfe sonst geläufiger biologischer Vorstellungen, einigermaßen verständlich. Für Weismann aber, für den es feststand, daß die Keimzellen der vielzelligen Organismen nicht erst während des Lebens des Individuums sich bilden und mit all den Kräften ausgestattet werden, die sie zur Hervorbringung des neuen Geschöpfes befähigen, - daß sie vielmehr in gerader Linie von der befruchteten Eizelle, aus der das Individuum selbst hervorgegangen war, abstammten, mußten sich aus der Vererbung erworbener Eigenschaften, falls sie wirklich vorkam, recht beträchtliche Schwierigkeiten ergeben. Denn um sie verständlich zu machen, bedurfte es nicht nur eines dauernden Zusammenhanges zwischen Körper- und Keimzellen, der ja schließlich in Blutgefäßen, Nerven und Protoplasmabrücken zwischen den Zellen gegeben ist, sondern, was viel wichtiger und viel schwieriger vorstellbar ist, auf dem Wege dieser Bahnen müßte es erreicht werden, daß irgendwelche Veränderungen des Körpers sich so dem Keimplasma mitteilten, und dieses so veränderten, daß später, bei der Entwicklung, am Körper des neuen Geschöpfes genau an der gleichen Stelle genau die gleiche Veränderung auftritt. Das ist der springende Punkt des ganzen Problemes. Weismann hat durchaus nicht, wie manchmal oberflächlich behauptet wird, jede Beeinflußbarkeit des Keimplasmas durch den Körper bestritten, diese Möglichkeit sogar schon in dem Aufsatz über Vererbung (I883) ausdrücklich zugegeben und erörtert; nur die Möglichkeit einer Beeinflußbarkeit in der erwähnten ganz spezifischen Weise hat er abgelehnt. Welche große Schwierigkeiten eine solche Annahme in der Tat bietet, und wie viele komplizierte Vorgänge dabei anzunehmen waren, hat unlängst (IgII) W. Roux aufs eingehendste auseinandergesetzt ${ }^{19}$ ). So gelangte denn Weismann 
zunächst theoretisch dazu, das Bestehen einer ,Vererbung erworbener Eigenschaften" anzuzweifeln, und eine Prüfung des Tatsachenbestandes führte ihn dann auch zu einer entschiedenen $\mathrm{Ab}$ lehnung der ganzen Annahme und zu der Überzeugung, daß die konkreten Fälle, in denen man die Vererbung einer erworbenen Eigenschaft festgestellt zu haben glaubte, ungenügend und kritiklos beobachtet waren, und daß ferner die Einrichtungen der Organismen, die man nach dem Prinzip des Lamarckismus als erblich gewordene direkte Wirkungen der äußeren Einflüsse und der Funktion zu erklären geneigt war, auf Grund anderer Faktoren erklärt werden müssen. Als solchen anderen Faktor sprach er zunächst und durch eine Reihe von Jahren ausschließlich die indirekte Wirkung der Lebensbedingungen, vermittelt durch Ausleseprozesse, an; später, von $1895 \mathrm{ab}$, gesellte er dieser als zweiten Faktor eine selbständige innere Gestaltungskraft, die Germinalselektion, zur Ergänzung und Unterstützung hinzu.

Wir wenden uns zunächst der Betrachtung der empirischen Tatsachen und ihrer Auffassung durch Weismann zu; die rein theoretischen Erörterungen werden im Anschluß an die Determinantentheorie zu besprechen sein.

\section{Somatogene und blastogene Eigenschaften.}

Vor allem war es nötig, den Begriff ,,erworbene Eigenschaft" genauer zu definieren. Die Diskussion, die sich im Anschluß an Weismanns Arbeiten erhob, zeigte nämlich sehr bald, daß dieser Begriff auch bei Fachleuten durchaus nicht klar war. Weismann hat daher (I888) die Begriffe "somatogene" und „blastogene" Eigenschaften geprägt und damit außerordentlich zur Klärung der Frage beigetragen. Soma t og ene, im eigentlichen Sinne erw or be ne Eigenschaften sind solche, die nicht als Anlagen sch on im Keime vorhanden sind, sondern erst durch besondere Einwirkungen, die den Körper oder einzelne Teile desselben treffen, als Reaktionen der letzteren auf die äußeren Einwirkungen entstehen; blastogene Eigenschaften sind solche, die ihre alleinige Wurzel in den Keimesanlagen haben. Auch diese Eigenschaften können bei einem Individuum neu auftreten; eine ,neu auftretende“ Eigenschaft ist nicht dasselbe wie eine erworbene. Ebenso ist es keine Vererbung erworbener Eigenschaften, wenn durch Infektion des Keimes eine 
Krankheit von dem Elternorganismus auf den kindlichen Organismus übertragen wird, wie die Pebrine der Seidenraupe, oder wenn auf Grund gleicher schwächlicher Anlage, gleicher abnormer Disposition, das Kind wie der Vater an Tuberkulose erkrankt. Hier ist es die gleiche Disposition, die vererbt wurde, und diese beruht auf der Keimesbeschaffenheit. Als solche aber ist sie erblich.

Von einer wirklichen ,Vererbung einer erworbenen Eigenschaft" kann nach Weismanns Auffassung nur gesprochen werden, wenn eine Eigenschaft zunächst als somatogene bei einem Individuum auftritt und dann erst sekundär, ohne daß die Ursache, durch die sie hervorgerufen wurde, von sich aus auf den Keim wirken konnte, rein vom Soma aus auf den Keim übertragen wird und in diesem eine adäquate Veränderung hervorruft. Dieser hypothetische Vorgang wird neuerdings (von Detto) als somatische Induktion bezeichnet.

\section{Angebliche Vererbung von Verletzungen und Verstümme- lungen.}

Unter den wirklich erworbenen somatogenen Eigenschaften, für die eine Vererbbarkeit vielfach behauptet worden ist, bilden eine erste Gruppe die Verletzungen und Verstümmelungen. Die hornlos geborenen Kälber, deren Hornlosigkeit damit erklärt wurde, daß ihr Vater oder ihre Mutter ihr Horn durch einen Unglücksfall verloren hatten, - die schwanzlosen Kätzchen und Hündchen, deren Schwanzlosigkeit daher rühren sollte, daß einem der Eltertiere der Schwanz kupiert worden war, spielten seinerzeit selbst in der wissenschaftlichen Literatur eine Rolle. Weismann hat mit ihnen gründlich aufgeräumt und überzeugend gezeigt, wie wenig diese und ähnliche Erzählungen Beweiskraft zugunsten einer Vererbbarkeit erworbener Eigenschaften beanspruchen können. Viele Fälle können wegen der ganz ungenauen Angaben von vornherein gar nicht weiter in Frage kommen, andere erklären sich auf andere sehr einfache Weise. Namentlich bezüglich der schwanzlosen oder richtiger stummelschwänzigen Kätzchen konnte Weismann darauf hinweisen, daß angeborene Stummelschwänzigkeit bei Katzen schon lange als gar nicht seltenes Vorkommnis beobachtet wird, und daß z. B. auf der Insel Man, aber auch in Japan, schwanzlose Rassen von Katzen zu Hause sind und gezüchtet werden. Sollte 
also der Schluß, daß die Stummelschwänzigkeit eines Kätzchens mit der künstlichen Schwanzverstümmelung der Mutter in ursächlichem Zusammenhang stehe, berechtigt sein, so müßte zunächst ausgeschlossen werden, daß einer der beiden Katzeneltern oder einer der früheren Aszendenten die Stummelschwänzigkeit als angeborene Eigentümlichkeit besaß. Das aber war in keinem der beschriebenen Fälle beobachtet und geprüft worden. Die Schwanzwirbelsäule der Katzen und Hunde ist überhaupt, wie genauere Untersuchungen gezeigt haben, ein Körperteil, der eine große Neigung zum Rudimentärwerden zeigt, und die spontan auftretenden Stummelschwänze sind als verkrüppelte, nicht aber als verkürzte Schwänze aufzufassen. Daß diese Überlegung durchaus begründet ist, lehren die Erfahrungen an anderen Tieren. So wird bei einer bestimmten Schafrasse schon seit mehr als Ioo Jahren der Schwanz aus bestimmten Gründen gestutzt, aber trotzdem ist noch niemals die Geburt eines schwanzlosen oder stummelschwänzigen Schafes in dieser Rasse beobachtet worden. Das wiegt um so schwerer, als bei anderen Schafrassen Fehlen des Schwanzes einen Rassencharakter bildet.

Ähnlich steht die Sache mit einem Beispiel aus der menschlichen Anatomie: der kleinen Zehe. Die kleine Zehe des Menschen ist in Rückbildung begriffen; diese Rückbildung ist aber nicht etwa als erbliche Wirkung des Schuhdruckes aufzufassen, denn sie findet sich auch bei barfuß gehenden Völkern.

Andererseits hat sich von den mancherlei Verstümmelungen, die von vielen Völkern schon seit langer Zeit absichtlich geübt werden, der Beschneidung, der Durchbohrung von Lippen, Nase, Ohren, dem Ausschlagen der Zähne usw. noch niemals eine erbliche Wirkung sicher feststellen lassen.

Endlich haben auch zielbewußt angestellte Versuche keine Beweise für die Vererbbarkeit von Verstümmelungen ergeben. Weismann selbst hat bei Mäusen, bei denen natürliche Stummelschwänzigkeit nicht vorkommt, durch 22 Generationen hindurch immer wieder die Schwänze kupiert, aber bei den 1592 Jungen, die von entschwänzten Eltern geboren wurden, niemals einen Defekt des Schwanzes beobachten können. -

So darf wenigstens diese Frage als geklärt, und die Vererbbarkeit von Verletzungen und Verstümmelungen in das Reich der 
Fabel verwiesen werden. Wie allgemein das jetzt anerkannt ist, geht daraus hervor, daß heutzutage gelegentlich die Meinung geäußert wird, es sei unbegreiflich, wie Weismann auf eine so selbstverständliche Sache so viel Zeit und Kraft habe verwenden können. Ein Blick in die Literatur zeigt, daß die Frage durchaus nicht so selbstverständlich war; und wenn sie heute so bezeichnet werden kann, ist das eben das Verdienst Weismanns.

\section{Angebliche Vererbung von funktionellen Abänderungen.}

Eine zweite Gruppe erworbener Eigenschaften, für die eine Vererbbarkeit behauptet worden ist, bilden die funktionellen Veränderungen, die Wirkungen des Gebrauches und des Nichtgebrauches. Sie sind es, die in der Entwicklungslehre Lamarcks eine so große Rolle spielen. Das ist auch verständlich genug. Daß die Muskeln durch Turnen gekräftigt werden, das Gedächtnis durch Übung gestärkt wird, Fähigkeiten der verschiedensten Art durch Übung ausgebildet und gesteigert werden können, ist eine alltägliche Erfahrung, ebenso wie die andere, daß manchmal durch Generationen hindurch gewisse Talente und Fähigkeiten vererbt werden. Was liegt da näher, als die Annahme, daß die innigen Anpassungen, die die Organe an ihre Funktion, und die Organismen an ihre Lebensbedingungen zeigen, dadurch zu erklären seien, daß die Übungsresultate, die in einer Generation erreicht werden, der nachfolgenden zugute kommen, daß eine Fertigkeit, die der Vater sich während seines Lebens erwirbt, eine entsprechende günstige Ausstattung des Sohnes bedingt? Vielleicht noch zwingender erscheint es, das Rudimentärwerden nutzloser und daher nicht mehr gebrauchter Organe als erbliche Folge des Nichtgebrauches, als erbliche Inaktivitätsatrophie aufzufassen. Wenn die Augen von Höhlentieren verkümmert gefunden werden, so drängt sich gewiß der Schluß auf, da $B$ diese Verkümmerung bei den Individuen intra vitam als unmittelbare Folge des Nichtgebrauches auftrat und, nachdem sie sich durch Generationen immer wiederholt hatte, allmählich zu einer erblichen Eigenschaft der Art wurde.

Aber so nahe auch diese Überlegungen liegen, so läßt sich, nach Weismanns Auffassung, doch kein Fall nachweisen, in dem sie wirklich zwingend wären. Nach Weismann bleiben alle die Wirkungen des Gebrauches und des Nichtgebrauches auf das In- 
dividuum beschränkt, und die Fälle, in denen sie scheinbar auf die Nachkommen übertragen werden, müssen auf andere Weise erklärt werden: durch Naturzüchtung (Personalselektion, in Verbindung mit Germinalselektion). Das gilt sowohl für die allmähliche stammesgeschichtliche Steigerung der Ausbildung und Leistungsfähigkeit eines viel gebrauchten Organes, wie für die allmähliche Rückbildung eines solchen, das nutzlos geworden ist und daher nicht mehr gebraucht wird. Wir werden später, bei Besprechung der Personalselektion und der Germinalselektion, genauer zu besprechen haben, welche Vorgänge Weismann dabei als wirksam annimmt.

\section{Harmonische Anpassung (Koadaptation).}

Die Auffassung von der Nichtvererbung funktioneller Anpassung ist unter allen Lehren Weismanns die, die den bestimmtesten Widerspruch hervorgerufen hat, am schärfsten und nachhaltigsten bekämpft worden ist. Namentlich war es der englische Philosoph Herbert Spencer, mit dem Weismann deswegen in eine lebhafte Fehde geriet. Unter den Einwürfen, durch die Spencer die Annahme einer Vererbung funktioneller Abänderungen als notwendig beweisen wollte, spielt wohl die Hauptrolle der Hinweis auf die Korrelationen, die zwischen den einzelnen Teilen des Organismus bestehen, und die vielfach so eng und unmittelbar sind,

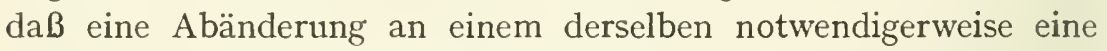
solche an anderen im Gefolge haben muß. Dies ist besonders immer da der Fall, wo mehrere an sich verschiedenartige Teile doch auf gemeinsames Funktionieren angewiesen sind und daher immer in einem bestimmten Verhältnis zu einander stehen müssen. Sehr leicht ist diese harmonische Anpassung oder Koadaptation erkennbar in dem von Spencer angeführten Beispiel des eiszeitlichen Riesenhirsches der irischen Torfmoore mit seinem riesigen Geweih. Ein solches hätte sich gar nicht für sich allein ausbilden können, sondern erforderte zugleich eine Zunahme der Dicke und Festigkeit der Schädeldecke, eine Verstärkung des Nackenbandes sowie der Hals- und Rückenmuskulatur und der Wirbeldornfortsätze, von denen die Muskeln entspringen, ferner der zugehörigen Nerven und Gefäße, der vorderen Extremitäten, ja, der ganzen Vorderhälfte des Tieres. Ohne diese begleitenden Veränderungen 
hätte das riesige Geweih für das Tier nicht nur keinen Wert, sondern es könnte ihm geradezu verderblich werden. Tatsächlich waren denn auch die genannten Veränderungen, soweit sich das aus dem Skelett entnehmen läßt, beim Torfhirsch wirklich ausgebildet.

Vom Standpunkt des Lamarckismus aus läßt sich das alles sehr einfach erklären: jene Veränderungen erscheinen dann als unmittelbare vererbte Folgen des stärkeren Gebrauches, als sekundäre Folge der Vergrößerung des Geweihes. Dagegen ist es in der Tat, wie H. Spencer betont, recht schwierig, sie ohne das La ma rcksche Prinzip, etwa durch Züchtungsprozesse, zu erklären. Denn die Grundlage für diese bilden die kleinen individuellen Abweichungen, die die Individuen einer Art zeigen, und es müßten somit in jenen Fällen ,harmonischer Anpassung" gleichzeitig an allen den genannten Teilen die entsprechenden Veränderungen, unabhängig voneinander, aufgetreten und durch Naturzüchtung erhalten und gesteigert worden sein. So viele Züchtungsprozesse zugleich seien aber nicht vorstellbar, und andererseits: wenn die Veränderungen nicht gleichzeitig erfolgten, so nützte die Abänderung des einzelnen Teiles nichts.

\section{Anpassungen der Ameisenneutra.}

Diesen in der Tat sehr bestechenden Gedankengängen gegenüber konnte Weismann auf ein Beispiel hinweisen, in dem eine solche harmonische Anpassung verschiedener Organe schlechterdings nicht auf dem Wege der Vererbung funktioneller Abänderungen entstanden sein kann, da sie sich bei Formen herausgebildet hat, die steril sind, die also gar nichts auf Nachkommen vererben können.

Der Fall, der von Weismann wiederholt behandelt worden ist, betrifft die Neutra oder Arbeiterinnen der staatenbildenden Insekten, vor allem der Ameisen und Termiten. Die Fortpflanzungsorgane derselben bleiben klein und sind in vielen Fällen geradezu verkümmert zu nennen; eine Fortpflanzung kommt höchstens noch ausnahmsweise vor. Sie sind somit außerstande, irgend eine Besonderheit ihres Baues auf Nachkommen zu übertragen, und eine Vererbung funktioneller Erwerbungen kommt bei ihnen nicht in Betracht. Trotzdem aber weichen sie von ihren Eltern, den Männchen und Weibchen, in einer ganzen Anzahl von Merkmalen in sehr 
charakteristischer Weise ab, und diese Abweichungen erscheinen als Anpassungen an ihre besonderen Aufgaben, stehen untereinander in harmonischem Zusammenhang und machen somit ganz wie die vorhin erwähnten des Torfhirsches den Eindruck, als ob sie unter dem Einfluß des Gebrauches und des Nichtgebrauches, unter Vererbung der Wirkungen beider, entstanden seien.

Phyletisch sind die Arbeiterinnen durch Umgestaltungen fruchtbarer Weibchen entstanden; die Umbildungen aber sind ihrer Art nach teils Rückbildungen, teils Vorwärtsbildungen. Rückgebildet sind, bei den einzelnen Arten in verschiedenem Grade, die Geschlechtsorgane, und damit hängt eben ihre Sterilität zusammen, rückgebildet sind aber auch die Augen und Flügel, und in Zusammenhang mit den letzteren die beiden Abschnitte des Thorax, an denen sonst die Flügel sitzen, dazu die Muskeln der Flügel. Das steht in inniger Beziehung zu den Aufgaben der Tiere innerhalb des Ameisenstaates: der Aufzucht der Blattläuse, Herbeischaffung der Nahrung, Sorge für die Puppen u. a. Durch diese Aufgabe werden die Tiere genötigt, am Boden und auch viel im Dunkeln zu leben und zu arbeiten, - wodurch die Flügel und die Augen überflüssig werden. Auf der anderen Seite werden durch dieselben Aufgaben größere Intelligenz und vielseitigere Instinkte von ihnen verlangt, und damit steht die stärkere Entwicklung des Gehirnes in Zusammenhang. Bei gewissen Arten ist dann noch eine besondere Kaste der Arbeiterinnen als Soldaten ausgebildet und mit der Verteidigung der Kolonie betraut, und diese sind ausgezeichnet durch ganz besonders kräftige Kiefer, mächtige Kiefermuskeln und einen dementsprechend riesigen Kopf. Sie zeigen also ganz ähnliche harmonische Abänderungen, wie wir sie beim Torfhirsch fanden, nur in geringeren absoluten Massen.

Alle diese Veränderungen müssen sich im Laufe der phyletischen Entwicklung bis zu dem jetzigen Grade der Vollkommenheit allmählich ausgebildet haben, in engster Beziehung zu den Aufgaben der Arbeiterinnen im Ameisenstaat. Und doch kann die unmittelbare Wirkung der Funktion als umwandelnder Faktor hier nicht in Frage kommen, da diese Wirkungen bei der Sterilität der Tiere gar nicht übertragbar waren. Die Arbeiterinnen pflanzen sich nicht selbst fort, sondern werden von Männchen und Weibchen der Ameisen immer neu erzeugt. Das Prinzip des Lamarckismus versagt also 
hier durchaus. Das ist ganz besonders von Wichtigkeit im Hinblick auf die harmonische Anpassung, aller zum Kieferapparat gehörigen Teile bei den Soldaten: wir sehen, es kann eine solche harmonische Anpassung sehr verschiedenartiger Teile auch erfolgen ohne eine Vererbung funktioneller Abänderungen. Was aber bei den Ameisen möglich war, mußte wohl bei dem Torfhirsch auch möglich gewesen sein. Auf welchem Wege, - das ist dann freilich eine neue Frage. Solange Weismann nur mit der Alternative „Lamarckismus oder Selektion“ rechnete, konnte auch hier nur die letztere für ihn in Betracht kommen; die Bedenken an der ausreichenden Leistungsfähigkeit dieses Prinzipes ließen ihn dann später noch die Germinalselektion zu Hilfe nehmen. Darauf wird später zurückzukommen sein.

Man mag wie immer über die Selektionstheorie denken, an einem kann wohl nicht gezweifelt werden: daß durch die weitgehenden Anpassungen, die die Arbeiterinnen der Ameisen trotz ihrer Sterilität zeigen, das Prinzip des Lamarckismus einen sehr schweren Stoß erleidet. Der daraus notwendig zu ziehende Schluß, daß weitgehende harmonische Veränderungen einer ganzen Anzahl von Teilen im Laufe der Stammesgeschichte erfolgen können, ohne daß dabei die Vererbung der Gebrauchswirkungen mitspielte, also ohne daß die Organismen selbst dabei mithalfen, indem sie durch Annahme und Ausübung neuer Gewohnheiten die morphologischen Veränderungen einleiteten und weiterhin steigerten, dieser Schluß muß für alle vergleichend-anatomischen Spekulationen von der allergrößten Bedeutung sein. Wer sich nicht damit begnügen will, die Skeletteile oder irgend welche sonstigen anatomischen Einrichtungen verschiedener Formen rein morphologisch $\mathrm{zu}$ vergleichen, wer sich vielmehr bewußt bleibt, daß die Umwandlungen der Formen und die damit so vielfach verbundenen Änderungen in der Funktion einzelner Teile sich nicht an trockenen Sammlungsskeletten oder „Spirituskonserven“, wic Max Weber einmal sagt, abgespielt haben, sondern an lebenden Wesen, und daß alle Einrichtungen zu jeder Zeit gebrauchsfähig sein mußten, der wird freilich oft genug glauben, ohne das Prinzip des Lamarckismus nicht auskommen zu können. Um an eins der größten Probleme aus der Wirbeltiermorphologie, vielleicht das größte, schwerste und bedeutungsvollste zu erinnern: die Überführung von Teilen des Kieferapparates der 
Nichtsäuger in den Dienst des Gehörorganes (als Hammer und Amboß) und die damit verbundene Ausbildung des neuen Kiefergelenkes bei den Säugern - welch eine Menge verschiedenartiger Veränderungen, die doch alle ineinander greifen, $\mathrm{zu}$ jeder Zeit ein harmonisches leistungsfähiges Ganzes bilden müssen, wird dabei vorausgesetzt! Um sie sich verständlicher zu machen, kann man kaum anders, als die lange Reihe von Generationen sich gewissermaßen nur als ein einziges Individuum, aber mit unendlich verlängerter Lebensdauer und stets gleichbleibender jugendlicher Anpassungsfähigkeit zu denken und sich an diesem die morphologischen Umwandlungen in stetem Zusammenhang mit der Funktion, als Folge der sich ändernden Gewohnheiten vorzustellen. Nach La marckscher Vorstellung wäre die Vererbung somatogener Veränderungen das wundertätige Bindemittel, das eine lange Kette auseinander hervorgehender Einzelindividuen zu einem großen Stammesindividuum vereinigte; in dem Beispiel der sterilen Ameisenarbeiterinnen aber fällt dieses Bindemittel fort und damit die Möglichkeit, jenes Bild auch nur als Bild beizubehalten.

\section{Anpassungen der bloß „passiv wirksamen" Teile und Merkmale.}

Außer den Anpassungen der Ameisenneutra gibt es, wie Weismann wiederholt hervorgehoben hat, noch eine zweite Gruppe von Erscheinungen, die den Glauben an eine Vererbung funktioneller Abänderungen $\mathrm{zu}$ erschüttern geeignet sind oder doch jedenfalls zeigen, daß eine solche Annahme nicht nötig ist, um die stammesgeschichtliche Verbesserung oder Verschlechterung eines Teiles zu erklären: die große Menge der Einrichtungen und Merkmale, die nur durch ihre bloße Anwesenheit, ihr Dasein wirken, dem stärkenden Einfluß des Gebrauches und dem schwächenden des Nichtgebrauches aber entzogen sind. Weismann faßt sie als passiv wirkende zusammen und rechnet zu ihnen: die Färbungen der Tiere, die Chitinskelette der Gliedertiere, die mannigfaltigen Schutzvorrichtungen bei Pflanzen, wie Dornen, Borsten, Haare, Schalen der Nüsse, ferner die Flugvorrichtungen der Samen und vieles andere. Man sieht, es sind recht verschiedenartige Dinge, deren Wirkungsart demnach auch sehr verschieden sein wird. Ihre Zusammenfassung als ,passiv wirkende“ Teile ist somit mehr ein 
Notbehelf und nicht ein besonders glücklicher, da die Bezeichnung "passiv funktionierende" Gewebe und Organe von Roux bereits für etwas ganz Bestimmtes, nämlich für die Gewebe der Stützsubstanzgruppe und die aus ihnen gebildeten Organe gebraucht wird. Etwas besser wäre schon ,passiv wirksam“. Für einige der genannten Einrichtungen liegt die Richtigkeit der Weismannschen Überlegungen wohl klar zutage. So für Färbungen: eine Schutzfärbung z. B. wird nicht besser dadurch, daß sie häufig ihre Aufgabe, das Tier zu verbergen, erfüllt. Das gleiche würde übrigens auch für manche Formbesonderheiten gelten, durch die Ähnlichkeiten irgendwelcher Art geschaffen oder verstärkt werden, wie bei den Blattheuschrecken. Hier handelt es sich um Merkmale, die tatsächlich nur eine ,Daseins"-Wirkung haben, selbst aber durchaus untätig und jedem Einfluß des Gebrauches entzogen sind. Man könnte sie vielleicht untätige oder apraktische Merkmale nennen (selbständige ,Teile“ sind es gar nicht) ${ }^{20}$ ). Ihre stammesgeschichtliche Ausbildung zu hoher Vollkommenheit kann nicht als erbliche Wirkung der Funktion erklärt werden, da eine eigentliche „Funktion" gar nicht ausgeübt wird. Hier muß also eine andere Kraft die Ursache der hohen Ausbildung gewesen sein: nach Weismann die Naturzüchtung, die die zufällig aufgetretenen und als nützlich bewährten Variationen auswählte und steigerte.

Am nächsten stehen ihnen die verschiedenen passiven Schutzvorrichtungen, die aus irgend einem festen Material gebildet sind, so die Dornen und Stacheln der Pflanzen und ähnliches. Sehr drastisch bemerkt Weismann: ,Eine mit Dornen über und über bewaffnete Akazie kommt selten in den Fall, ihre Waffen überhaupt nur einmal anzuwenden, und wenn einmal irgend ein hungriger Wiederkäuer sich an den Dornen sticht, so sind es doch immer nur wenige der Dornen, die ,geübt' werden, diej übrigen bleiben unberührt." Für die Flugvorrichtungen der Samen gilt gleiches. Bei den Chitinskeletten der Arthropoden, auf die Weismann auch großen Wert in diesem Zusammenhange legt, würde dagegen wohl genauer zu unterscheiden sein, zu welchem Zweck die Chitinteile Verwendung finden. Weismanns allgemeine Überlegung geht dahin: Die Chitinteile werden als weiche Massen von der unter ihnen gelegenen Hypodermis abgeschieden, treten aber erst in Gebrauch, wenn sie an der Luft vollkommen erhärtet sind. Alsdann 
aber sind sie unveränderlich, nicht mehr plastisch; sie können weder durch Muskelzug, noch sonstwie durch den Gebrauch weiter verdickt, sondern höchstens abgerieben, verdünnt oder gar verstümmelt werden. Soll etwas Neues an ihnen auftreten, so wird es bei der nächsten Häutung von der unterliegenden Hypodermis produziert; es entsteht vor dem Abwerfen der alten Chitinhaut, unter dem Schutze derselben, und tritt erst in Gebrauch, nachdem es fertig gebildet ist. So sei es auch in der Stammesgeschichte gewesen: nicht durch allmähliche Umwandlung während des Gebrauches, sondern durch plötzliche geringfügige Modifizierung vor dem Gebrauch haben sich die Teile des Chitinskelettes entwickelt. Von dieser allgemeinen Erwägung aus erfahren dann die Besonderheiten derselben ihre Deutung: sie sind nicht auf die Funktion, sondern auf Selektionsprozesse zurückzuführen. Dies gilt zunächst für die verschiedene Dicke an den einzelnen Körperteilen. Nirgends am ganzen Körper des Gliedertieres kann die Anpassung des Skelettes in bezug auf Dicke und Widerstandskraft durch die Funktion selbst geregelt worden sein, sondern überall erfolgt das "nur durch Selektionsprozesse, die jeder Stelle desselben die Dicke zusprachen, die sie braucht, damit der Teil leistungsfähig sei, mag es sich nun um den Widerstand gegen Muskelzug, oder um Biegsamkeit einer Gelenkfaite, um Härte zum Zerbeißen der Nahrung, oder zum Bohren in Holz oder Erde handeln, oder etwa um bloßen Schutz gegen äußere Schädlichkeiten". Dasselbe gilt weiterhin für die mannigfachen, zum Teil sehr komplizierten Apparate zum Singen, Schreien, Reinigen der Fühler u. a., bei denen zudem immer Veränderungen an zahlreichen Teilen stattfinden mußten, die also sehr schöne Beispiele von Koadaptation abgeben. Endlich gilt es auch für die Verkü mmerung chitinöser Teile, wenn sie überflüssig, bedeutungslos werden. Derartige Verkümmerungen kommen am Hinterleib solcher Krebse und Insekten vor, die denselben durch ein Gehäuse schützen (bei Einsiedlerkrebsen, die den Hinterleib in Schneckenschalen verbergen, bei den Larven der Köcherfliegen, die ihn in einem aus Pflanzenteilen selbst gefertigten Gehäuse verstecken $u$. a.). Nach Weismanns Auffassung kann auch diese Verkümmerung des Chitinpanzers an den geschützten Körperabschnitten nicht durch das Prinzip des Lamarckismus, also nicht als erbliche Folge des Nichtgebrauches erklärt werden, da ja die geringe Inanspruch- 
nahme der geschïtzten Chitinteile gerade umgekehrt, im Sinne einer Schonung hätte wirken müssen. So bliebe auch hier nur die Naturzüchtung als Erklärungsprinzip übrig.

Diesen Auffassungen Weismanns ist entgegengehalten worden, daß unter der abgesonderten Chitinschicht die Hypodermis liegt, d. h. die Zellschicht, der das Chitin seine Entstehung verdankt, und daß diese Hypodermis auf Reize der verschiedensten Art reagieren, somit auch auf stärkere funktionelle Beanspruchung mit verstärkter Chitinproduktion antworten könne. Dieser Einwand ist gewiß im allgemeinen berechtigt. Indessen muß doch wohl, wenn es sich um die Frage nach der Vererbbarkeit funktioneller Veränderungen handelt, weniger Wert darauf gelegt werden, ob die Chitinskeletteile oder sonstwelche Hartgebilde sich funktionell anzupassen imstande sind, als vielmehr darauf, ob auf Grund ihrer besonderen Verwendung dieses Vermögen auch wirklich so ausgiebig in Anspruch genommen wird, daß sich dadurch - die Vererbung der Anpassungen vorausgesetzt - eine stammesgeschichtliche Verbesserung erklären ließe. Wo es sich um bloße Schutzteile handelt, dürfte letzteres doch oft sehr schwer sein; es werden hier vielfach ähnliche Erwägungen Geltung haben, wie sie Weismann bezüglich der Dornen der Akazie und ihrer funktionellen Beanspruchung äußert. Weismann selbst weist mit entsprechenden Überlegungen auf die Flügeldecken der Käfer hin, in denen gar keine Muskeln liegen, und die doch bei vielen Arten die dicksten und härtesten Stellen des ganzen Hautpanzers sind. „,Der Grund liegt nahe; sie schützen die darunter verborgenen Flügel und die weiche Haut des Rückens, und an diese setzen sich die Muskeln an! ein Verhalten, welches nur durch seine Zweckmäßigkeit, nicht aber durch irgend welche direkte Wirkungen zu erklären ist." Auch die Verkümmerung des Panzers an dem geschützten Hinterleib der Einsiedlerkrebse und Köcherfliegenlarven hängt doch wohl mit dem Geschütztsein des Hinterleibes, nicht mit dem Fortfall funktioneller Inanspruchnahme des Panzers zusammen. Der durch den Schutz bedingte Fortfall der allgemeinen Außenweltsreize, die sonst die Hypodermis treffen, würde weniger in das Kapitel des Lamarckismus im engeren Sinne, als in das der direkten Mediumwirkungen gehören ${ }^{21}$ ). 


\section{$-9^{6}-$}

\section{Instinkte.}

Eine Gruppe von Erscheinungen, für die von jeher das Prinzip des Lamarckismus ganz besonders als durchaus notwendig zur Erklärung angesehen wurde und vielfach auch jetzt noch angesehen wird, bilden die Instinkte. GewiB liegt es am nächsten, sie entstanden $z u$ denken aus Handlungen, die anfangs zweckbewußt ausgeführt, dann aber durch fortgesetzte Wiederholung im Laufe der Generationen und durch Vererbung der Übungsresultate zu fixierten Mechanismen geworden sind. Aber auch hier konnte Weismann auf Fälle hinweisen, bei denen diese Überlegung versagt: auf die zahlreichen Instinkte, die überhaupt nur einmal im Leben zur Ausführung gelangen, bei denen also von erblicher Wirkung der Übung nicht die Rede sein kann. Hierher gehören der Hochzeitsflug der Bienenkönigin mit seinen vielen und komplizierten Instinkten und Reflexmechanismen, ferner die Eiablage, die sich bei manchen Insekten unter Ausübung der kompliziertesten Instinkthandlungen vollzieht, die Anfertigung von Schutzhüllen bei der Verpuppung zahlreicher Insekten, wie des höchst kunstvollen Gespinnstes des Nachtpfauenauges $u$. a. Ist aber bei diesen nur einmal im Leben ausgeführten Instinkthandlungen die Erklärung durch Annahme einer Vererbung von Übungsresultaten unmöglich, und ein anderer Mechanismus dafür verantwortlich zu machen, so liegt kein Grund vor, bei anderen Instinkten etwas anderes vorauszusetzen.

\section{Geistige Fähigkeiten, spezifische Talente. \\ Der Musiksinn.}

In diesem Zusammenhang sind dann endlich auch noch die verschiedenen geistigen Fähigkeiten des Menschen und besonders die spezifischen Talente, für Musik, bildende Künste, Dichtkunst, Mathematik usw. zu nennen, deren hohe Ausbildung beim Kulturmenschen sicherlich auch am leichtesten und bequemsten auf eine Summierung der durch Generationen in jedem Einzelleben erlangten Übungsresultate erklärt würden. Wiederholt hat sich Weismann mit diesen Erscheinungen beschäftigt; namentlich die Frage nach der Herkunft und Ausbildung des Musiksinnes mußte ihn, der selbst ein trefflicher Musiker war, ganz besonders zum Nachdenken anregen. Ihr ist denn auch ein besonderer viel 
besprochener Aufsatz vom Jahre I889 gewidmet, in dem sich ein feines Musikverständnis, Kenntnis der historischen Entwicklung der Musik und anderer kultureller Gebiete mit den scharfsinnigen Erwägungen des kenntnis- und gedankenreichen Naturforschers vereinen.

Hier, wie in dem Vortrag über die Vererbung, von 1883 , der zum ersten Male die erwähnten Erscheinungen berührt, sieht sich Weismann zur Erklärung derselben lediglich auf die Alternative: ,LLamarckismus oder Personalselektion als Naturzüchtung bzw. sexuelle Züchtung“" angewiesen; eine selbsttätige innere Steigerungskraft, wie er sie später in der Germinalselektion annahm, kam für ihn damals noch nicht in Frage. Für die allgemeinen geistigen Fähigkeiten, hohe Intelligenz, Phantasie, Gedankenreichtum, gutes Gedächtnis, Erfindungsgabe, dazu aber auch Fleiß, Ausdauer, Selbstvertrauen, Willenskraft und Tatendrang, läßt sich ja nun cine Steigerung durch den Kampf ums Dasein im Laufe der Menschheitsgeschichte recht wohl verstehen, dagegen kann das nicht gelten für die spezifischen Talente. Naturzüchtung kann sie nicht gesteigert haben, da von ihrem Vorhandensein weder das Leben abhängt, noch durch sie die Aussicht auf Fortpflanzung vergrößert wird. Sexuelle Züchtung aber, durch die Darwin nicht nur die musikalischen Fähigkeiten der Zikaden und der Vögel, sondern auch den primitiven Gesang des Urmenschen und die Steigerung der musikalischen Begabung bei der Menschheit erklären wollte, könnte vielleicht in einzelnen Individuen und Familien eine Verbesserung des Talentes über den Durchschnitt bedingen, würde aber nicht imstande sein, die ungeheure Steigerung der Musikanlage zu erklären, die bis heute stattgefunden haben müßte, wenn wirklich in den ältesten Tagen des Urmenschen zuerst dic Grundlage des Musiksinnes gelegt worden wäre. Praktisch hat eine Auslese, auf Grund des musikalischen oder sonst eines Talentes, in größerem Umfange jedenfalls nicht stattgefunden. Im Gegenteil, gerade unsere größten Musiker haben mit den bittersten Entbehrungen gekämpft. So könnte es scheinen, als ob hoch entwickelte spezifische Talente doch nur als Ergebnis einer durch Generationen fortgesetzten Übung erklärt werden könnten. Indessen läßt sich auch hiergegen manches einwenden, so vor allem das gar nicht seltene scheinbar plötzliche Auftreten einer hohen spezifischen Be- 
gabung in einer Familie, in der die entsprechenden Anlagen zwar vorhanden gewesen sein mögen, aber jedenfalls nicht durch besondere Übung gesteigert wurden. Gauß, Händel, Tizian werden von Weismann als Beispiele hierfür genannt. So stellt er denn eine neue Erklärung für die fraglichen Erscheinungen auf. Sie geht davon aus, daß alle Talente, streng genommen, gar nicht etwas eigentlich Spezifisches, überhaupt nichts einfaches sind, daß sie nicht auf einem einheitlichen Besitz, etwa dem eines besonderen Gehirnteiles, beruhen, sondern auf glücklicher Kombination verschiedener Anlagen, die an sich in jedem Gehirn vorhanden, bei dem Talent aber besonders und einseitig gesteigert und mit anderen in glücklicher Weise gemischt sind. Diese Mischung aber ist zurückzuführen auf Kreuzung elterlicher Anlagen, entsprechend dem so oft zitierten Ausspruch, in dem Goethe seine eigene Begabung in ihre einzelnen Komponenten auflöst und diese als Erbteile seiner verschiedenen Aszendenten anspricht: „Vom Vater hab' ich die Statur, Des Lebens ernstes Führen, Von Mütterchen die Frohnatur, Und Lust zu fabulieren" usw. Die häufige Vereinigung mehrerer Talente in einer Person, das Auftreten verschiedener Talente in einer Familie (z. B. Mendelssohn, Feuerbach), sowie das gehäufte Auftreten eines bestimmten Talentes nach der allgemeinen Geistesströmung der Zeit, reden dieser Auffassung das Wort. Alle jene oben genannten geistigen Besitztümer, hohe Intelligenz, Phantasie usw., für deren Steigerung Naturzüchtung recht wohl verantwortlich gemacht werden kann, bilden gemeinsam eine universelle Begabung, die auf verschiedenen Gebieten Bedeutendes zu leisten vermöchte. In welcher Richtung und wie weit sie zur Betätigung kommt, wird vielfach vom Zufall, von den Einflüssen der Umgebung abhängen; die großartigsten Schöpfungen aber, die von großen Talenten hervorgebracht wurden, wären nicht möglich gewesen ohne Hinzukommen noch anderer Umstände: der äußeren Anregung, Begünstigung und Lenkung durch Erzichung und Umgebung, der Tradition und der hoch entwickelten fein fühlenden menschlichen Seele. Für ein Talent wie das musikalische würde noch etwas Besonderes hinzukommen müssen, was aber, genau betrachtet, doch im Grunde auch nur ein allgemein menschlicher Besitz, wenn auch in hoher Ausbildung, ist: ein hoch entwickeltes Gehörorgan nebst entsprechend ausgebildeten dazu ge 
hörigen Gehirnteilen. Der Musiksinn ist nach Weismann ein Nebenprodukt, eine unbcabsichtigte Nebenleistung des Gehörorgans, wie es etwa eine Nebenleistung unserer Hand ist, Klavier zu spielen. Ganz ähnlich verhält es sich mit dem Kunstsinn überhaupt. Den hoch entwickelten Gehörapparat aber haben schon die Vorfahren des Menschen erworben; im Kampfe ums Dasein ist er durch Naturzüchtung allmählich zu der Höhe gesteigert worden, in der er seit den Tagen des Urmenschen gemeinsamer Besitz aller Menschen ist, wofern nicht wieder ein Absinken, eine Rückbildung, stattgefunden hat. Das wäre bei Unmusikalischen anzunehmen. Eine Steigerung dieses schon beim Urmenschen anzunehmenden Musiksinnes hat im Laufe der Menschheitsgeschichte gar nicht stattgefunden; die ungeheuere Steigerung seiner Leistungen aber, von seiner primitiven Betätigung bei den Naturvölkern an bis zu seinen höchsten Offenbarungen etwa in H-Moll-Messe und Matthaeuspassion, in Beethovens neuen Symphonien oder Mozarts Opern, hat sich allmählich vollzogen wie der Fortschritt in der Geschichte der Wissenschaften. Stufe um Stufe hat sich die Menschheit erklommen, indem eine Generation an die Errungenschaften der anderen anschloß, kraft der Tradition, der die Steigerung aller geistigen Errungenschaften zu verdanken ist. Der neuzeitliche Kulturmensch, der in der Lage ist, sich diese Tradition zunutze zu machen, und auf den ihre Erzeugnisse anregend einwirken, wird dadurch von vornherein auf eine ganz andere Stute gestellt und zu ganz anderen Leistungen befähigt, als der Naturmensch oder der Mensch des Altertums. Ein Rückschluß auf die musikalische Begabung der letzteren ist dadurch aber nicht ermöglicht. Und auch der Besitz dieser spezifisch musikalischen Tradition bei hoher musikalischer Veranlagung würde den Australier oder Neger noch nicht zu den Leistungen eines Beethoven befähigen, da ihnen die reiche, große Seele dazu fehlen würde, die allgemeine Höhe des geistigen Lebens, die die Kulturmenschheit erreicht hat.

So wäre also auch gegenüber den hohen geistigen Gaben und den spezifischen Talenten des Míenschen recht wohl ohne die Annahme einer Vererbung von Fähigkeiten, die durch Übung erworben und gesteigert wurden, auszukommen.

$\mathrm{Zu}$ einer ähnlichen Auffassung der Frage nach der ,,spezifischen" Natur des Musiktalentes wie der hier entwickelten hat 
sich vor nicht langer Zeit einer der bekanntesten modernen Geiger, Bronislaw Hubermann, bekannt, dagegen ist ihr von einem der erfolgreichsten Forscher auf dem Gebiete der Vererbungslehre, $\mathrm{Paul} \mathrm{Kammerer,} \mathrm{fast} \mathrm{in} \mathrm{allen} \mathrm{Punkten} \mathrm{widersprochen} \mathrm{worden}{ }^{22}$ ). Weismann selbst hat sie, wie schon angedeutet wurde, später (in den Vorträgen über Deszendenztheorie) nicht mehr ganz unverändert beibehalten, sondern nunmehr den Musiksinn doch mehr als etwas Besonderes hingestellt, was zwar mit dem Gehörapparat irgendwie in Verbindung steht, aber doch die Annahme besonderer „Musikdeterminanten" rechtfertigt, wenn auch nach wie vor daran festzuhalten ist, daß die Begabung etwa eines Sebastian Bach oder Beethoven nicht lediglich auf dem hoch entwickelten Musiksinn beruht, sondern eine Kombination desselben mit vielen anderen hoch entwickelten geistigen Gaben zur Voraussetzung hat. Eine besonders hohe Ausbildung des Musiksinnes führt Weismann nunmehr auf das Wirken der im Organismus selbst tätigen Kraft zurück, die er von I894 an, an Stelle des aufgegebenen Lamarckschen Übungsprinzipes, anzunehmen genötigt war: der Germinalselektion.

\section{Zusammenfassung.}

So gelangt Weisman $n$ also dazu, eine Vererbung funktioneller Erwerbungen des Individuums auf die Nachkommen abzulehnen. Außer den theoretischen Schwierigkeiten, die ihm die Annahme eines solchen Vorganges bereitet, findet er, daß für keine der beobachteten Erscheinungen jene Annahme notwendig ist, daB es dagegen eine ganze Anzahl von Erscheinungen gibt, in denen der Vorgang, so nahe seine Annahme auf den ersten Blick liegt, doch mit Sicherheit ausgeschlossen werden kann. Die allgemeine daraus gezogene Schlußfolgerung lautet: wenn überhaupt Anpassungen der verschiedensten und kompliziertesten Art, Vervollkommnungen und Rückbildungen von Teilen im Laufe der Stammesgeschichte erfolgen konnten, ohne daß Vererbung funktioneller Abänderung dabei im Spiele war, so liegt keine Notwendigkeit vor, mit letzterem Vorgang, der noch dazu so große theoretische Schwierigkeiten macht, iiberhaupt noch zu rechnen.

Es würde hier viel zu weit führen, alle die Einwendungen auch nur anzudeuten, die gegen diesen Standpunkt erhoben worden 
sind, oder die Anhänger der gleichen Anschauung wic ihre Gegner auch nur mit Namen anzuführen. Die Tatsache, daß sich in beiden Heerlagern führende Forscher finden, zeigt zur Genüge die außerordentliche Schwierigkeit der Frage. An eingehenden vortrefflichen Darstellungen derselben ist überdies zur Zeit kein Mangel. Eins ist sicher: der ungeheuere Einfluß, den Weismanns Anschauung seit Jahrzehnten ausgeübt hat und noch ausübt. W. Roux drückte nur die Empfindung vieler aus, als er schrieb: „Für denjenigen, der sich die Größe des Rätsels der angeblichen Übertragung von Veränderungen des Personalteiles auf den Germinalteil vorgestellt hat, ist die von Weismann sorgfältig begründete und neben ihm auch von Owen, Bütschli, Galton, M. NuBbaum, Jul. Sachs u. a. angebahnte Theorie von der Kontinuität des Keimplasma die Erlösung von einem auf unserem Erkenntnisvermögen lastenden $\left.\mathrm{Alp}^{\text {“ }}{ }^{23}\right)$.

\section{Vererbung von Veränderungen, die durch das Medium bedingt sind.}

An der Überzeugung, daß Verletzungen und Verstümmelungen, sowie angebliche und wirkliche funktionelle Abänderungen nicht vererbt werden, sondern mit dem Individuum vergehen, d. h. passante Veränderungen darstellen, hat Weismann bis an sein Lebensende festgehalten. Ganz anders hat er dagegen von vornherein eine Reihe von Erscheinungen betrachtet, die gewöhnlich auch, wenn auch nicht ganz mit Recht, unter den Begriff des Lamarckismus untergeordnet werden, und die jedenfalls, im Sinne der Weismannschen Bezeichnungen, den Eindruck einer Vererbung erworbener somatogener Eigenschaften machen: die Erblichkeit von Abänderungen, die als direkte Wirkung von veränderten äußeren Bedingungen (Medium, Ernährung, Klima) erscheinen, insbesondere die Vererbung klimatischer Abänderungen. Auf diesem Gebiet hatten sich We is m a n n s erste experimentelle Untersuchungen zur Deszendenztheorie, die Versuche ïber den Saisondimorphismus der Schmetterlinge (1875) bewegt: sie hatten ihn zu dem Schlusse geführt, daß Abänderungen, die unter dem direkten Einfluß des Klimas entstanden sind, im Laufe der Generationen erblich werden. Auch noch I879, in den Betrachtungen über dic Entstehung zyklischer Fortpflanzungsarten, deutet Weismann die Vererbung 
der durch Klimaeinflüsse bedingten Abänderungen in dem Sinne, daß hier ein Fall vorliege, wo die Abänderung des Tieres selbst eine sekundäre Abänderung der Keimzelle nach sich ziche, oder, mit anderen Worten, wo die Abänderung der Keimzelle (- die die Voraussetzung für die Vererbung der Abänderung auf den Nachkommen ist -) durch die Abänderung des Tieres selbst bedingt ist. Und auch in dem Vortrag über die Vererbung, von I883, gesteht er, für die erblichen klimatischen Variationen der Schmetterlinge keine andere Erklärung als durch die Annahme einer Vererbung somatogener Abänderungen finden zu können. Aber die eingehendere Beschäftigung mit dem Vererbungsproblem ließ ihm einen solch€n Vorgang doch als höchst unwahrscheinlich vorkommen, und neue Untersuchungen, die er zur Lösung der Frage mit dem kleinen Feuerfalter (Polyommatus Phlaeas) anstellte, führten ihn denn auch zu einer anderen Auffassung des Sachverhaltes. Die Darstellung und Erklärung findet sich in dem "Keimplasma“ (I892) und im zweiten Bande der ,Vorträge über Deszendenztheorie", kurz auch in der Besprechung von Semons "Mneme"-Theorie (rgo6). Der genannte Falter kommt in zwei verschiedenen Färbungen vor: im hohen Norden und in Deutschland ist er auf der Oberseite rotgolden, im Süden Europas fast ganz schwarz. WVeismann zog nun aus Eiern der Neapler (dunklen) Form Puppen, die er gleich nach der Verpuppung niederer Temperatur aussetzte, und erhielt so Schmetterlinge, die weniger schwarz als die Neapler, wenn auch nicht so rotgolden wie die deutschen war. Umgekehrt ergaben. deutsche Puppen, höherer Wärme ausgesetzt, Falter, die schwärzer waren als die deutschen, aber freilich nie so dunkel, wie die dunkelsten südlichen Exemplare. Daraus mußte geschlossen werden, daß die dunkle Färbung der südlichen Varietät als direkte Folge der erhöhten Temperatur entstanden ist und sich im Laufe der Generationen erblich fixiert hat. So scheint auch hier in der Tat Vererbung einer erworbenen Eigenschaft vorzuliegen: man könnte schließen, daß unter dem direkten Einflusse des Klimas zuerst die Abänderung am Soma entstand, und daß diese sich dann sekundär den Keimzellen auf irgend einem Wege mitteilte, also durch ,somatische Induktion“, wie man jetzt sagen würde. Indessen zeigte Weismann, daß auch noch eine andere Deutung der Versuche denkbar ist, in dem Sinne, wie er es als allgemein 
möglich schon früher (I883, in dem Vortrag über Vererbung; I886 in dem über die sexuelle Fortpflanzung) ausgesprochen hatte. durch die abnorme Temperatur konnten Körper und Keimzellen in gleicher Weise verändert worden sein, d. h. es wurden sowohl die Flügelanlagen beeinflußt, die in der Puppe zur Entwicklung bereit waren, als auch die, die noch im Keimplasma der Keimzellen sich in Ruhe befanden. Der gleiche Reiz - die abnorme Temperatur - verändert diese wie jene in entsprechender Weise, und wenn nun in der nächsten Generation die gleiche Abänderung wieder auftritt, ohne daB aufs neue eine gleiche Einwirkung stattgefunden hat, so ist es nicht die somatische Abänderung selbst, die sich vererbt hct, sondern die ihr entsprechende, durch denselben äußeren Einfluß hervorgerufene Abänderung der Anlagen im Keimplasma. Der gleiche Reiz hat gleichzeitig und in ähnlicher Weise die entsprechenden Anlagen zweier folgender Generationen verändert, oder, anders ausgedrückt: er hat gleichzeitig eine Veränderung des Personalteiles und des Germinalteiles hervorgerufen. $\mathrm{DaB}$ diese letztere aber vererbt wird, ist nicht weiter wunderbar.

Dieser Betrachtungsweise haben sich viele Forscher angeschlossen; sie ist auch angewendet worden zur Erklärung der Ergebnisse, die StandfuB, Merifield, E. Fischer durch Einwirkung abnorm nieảriger Temperaturen (bis $\mathrm{zu}-8^{\circ} \mathrm{C}$ ) auf frische Puppen verschiedener Schmetterlinge erhielten. Die so behandelten Puppen lieferten Falter, die in bezug auf Färbung und Zeichnung abnorm waren, und diese ,Kälteaberrationen“ traten vielfach auch bei den Nachkommen wieder auf, ohne daß die betreffenden Puppen aufs neue der Kälte ausgesetzt wurden. Auch hier lautet Weismanns Erklärung dahin, daß die Kälte gleichzeitig und in entsprechender Weise das bereits in der Entwicklung begriffene Soma des Schmetterlings wie das in ihm eingeschlossene Keimplasma verändert habe. Dieser Vorgang der gleichzeitigen korrespondierenden Beeinflussung des Soma und der Keimzellen durch dieselben Faktoren ist neuerdings (von Detto) als ,Parallelinduktion" oder auch als Beeinflussung von Soma und Keimzellen durch „Simultanreize“ (Plate) bezeichnet worden. Die hypothetischen Prozesse, die dabei im Keimplasma anzunehmen sind, hat Weismann selbst später genauer behandelt und als 
,induzierte Germinalselektion" bezeichnet. Wir werden auf sie zurückkommen müssen.

Ob man hier von „Vererbung erworbener Eigenschaften“ reden soll, oder nicht, würde schlieBlich auf einen Wortstreit herauskommen. Gewiß liegt hier der Fall vor, daß eine Abänderung, die in der ersten Generation als somatischer Erwerb sich bemerkbar macht, in der zweiten als Keimbesitz auftritt, aber Weismanns Deutung zufolge hat eben der Keim diesen Besitz vollständig erworben, während der Erwerb des Personalteils mit diesem zugrunde gegangen ist. Auch im sozialen Leben würde man einen Besitz, den der Sohn selbständig erworben hat, nicht als ,ererbt" bezeichnen, weil der Vater gleichzeitig einen entsprechenden Erwerb gemacht hatte. Natürlich läßt sich gegen diese Betrachtungsweise auch manches einwenden. Der Fortschritt der Kenntnisse und Erfahrungen hat eben hier gezeigt, daß die alte Formel ,Vererbung erworbener Eigenschaften" nicht genügt, um allen - tatsächlich beobachteten oder hypothetisch angenommenen - Vorkommnissen gerecht zu werden, und macht es notwendig, die Dinge schärfer und bestimmter zu bezeichnen.

Weis mann hat den hier besprochenen Erscheinungen: der Entstehung erblicher Veränderungen unter dem direkten Einfluß der äußeren Bedingungen, für den Artumwandlungsprozeß keine sehr große Bedeutung beigemessen; aus welchen Grïnden, bleibt später, bei Erörterung seiner Stellung zur Selektionstheorie, zu betrachten. Hier ist nur die Tatsache von Wichtigkeit, daß er die Möglichkeit ihres Vorkommens jedenfalls anerkannt hat.

\section{Ergebnisse. Übertragung derselben auf die Einzelligen.}

Somit lehnt also Weismann die Vorstellung ab, daß Eigenschaften irgendwelcher Art, die der Organismus an seinem Soma erwirbt, von diesem aus auf den Keim übertragen werden können und am Nachkommen wieder zum Vorschein kommen. Das gilt in gleicher Weise für Verletzungen und Verstümmelungen, wie für die Wirkungen des Gebrauches und Nichtgebrauches, die Resultate der Übung, mag es sich um solche des Körpers oder des Geistes (- Instinkte, geistige Fähigkeiten -) handeln. Auch die Wirkungen direkter Einflüsse des Mediums haben für sich nur die Bedeutung, von passanten Veränderungen, die mit ihrem 
Träger zugrunde gehen; der Schein einer Vererbung von solchen kann aber zustande kommen dadurch, daß ein und derselbe Einfluß sowohl das Soma als die in ihm eingeschlossenen Keimzellen in gleicher Weise verändert. Oder, unter Verwendung moderner Begriffe: erblich sind nur Eigenschaften, die auf Besonderheiten des Keimplasmas beruhen; eine spezifische Abänderung desselben auf dem Wege somatischer Induktion ist nicht möglich, wohl aber kann auf dem Wege von Parallelinduktion das Soma wie das Keimplasma in gleicher Weise verändert werden.

Diese Auffassungen, in denen der Gegensatz zwischen dem Soma und der Keimsubstanz ganz besonders scharf zum Ausdruck kommt, waren zunächst für die vielzelligen Organismen entwickelt worden, bei denen es sich also um einen Gegensatz von Körperund Keimzellen handelt. Dagegen hatte Weismann, wie wir sahen, für die Einzelligen zunächst ganz allgemein gefolgert, daß hier Körper und Keim identisch seien, und daß Veränderungen, die das einzellige Wesen durch die Wirkung der äußeren Bedingungen erfährt, auf die aus ihm durch Teilung hervorgehenden Tochterindividuen übertragen werden müssen, da diese ja das Muttertier geradezu fortsetzen. Diese Auffassung mußte eine Änderung erfahren von dem Augenblick an, wo die Kernsubstanz als alleinige Vererbungssubstanz angesprochen wurde. Denn daraus ergab sich der Schluß, daß auch schon bei den kernhaltigen Einzelligen ein Unterschied zu machen sei zwischen dem Zellkörper, der dem ,,Soma“ der Vielzelligen entspricht, und der Kernsubstanz, die dem „Keim“ derselben zu vergleichen ist. Dementsprechend ergab sich auch eine Änderung in der Betrachtung der Vererbungserscheinungen; die für die Vielzelligen entwickelten Gesichtspunkte mußten mutatis mutandis auch auf die Einzelligen übertragen werden. Das heißt: auch für diese ist anzunehmen, daß alle Variationen, welche infolge äußerer Einflüsse an ihnen auftreten, ,nur dann auf die Teilsprößlinge übertragen werden können, wenn sie von korrespondierenden Abänderungen der Kernsubstanz begleitet sind, oder mit anderen Worten: wir gewinnen die Überzeugung, daß auch hier eine Vererbung ,,somatogener" Abänderungen im allgemeinen nicht stattfindet, nämlich eben nur dann, wenn dieselben von entsprechenden blastogenen Veränderungen begleitet sind" (I 89I, in dem Aufsatz über Amphimixis, S. I29). Das muß Geltung haben ebenso für 
Verstümmelungen wie für direkte Mediumwirkungen und für Veränderungen, die durch Gebrauch und Nichtgebrauch etwa gesetzt werden können, und die ja wenigstens bei den höher organisierten „Einzelligen“ als tatsächlich vorkommend anzunehmen sind. Als Wesen, bei denen alle Variationen, die einmal entstanden sind, cinerlei aus welcher Ursache, auch vererbt werden, würden dann nur sclche niedersten Organismen anzusprechen s?in. welche noch keine Differenzierung in Kern und Zellkörper besitzen.

\section{Die Mnemetheorie von Semon; Weismanns Stellung zu derselben.}

An dieser Auffassung hat Weismann bis an sein Ende festgehalten allen Theorien gegenüber, die die gegenteilige Auffassung, die Möglichkeit einer direkten Übertragung somatogener Veränderungen auf das Keimplasma und damit auf die Nachkommen, vertreten. Auch der bedeutungsvollste Versuch, der in allerjüngster Zeit unternommen worden ist, um den Lamarckismus auf eine neue wissenschaftliche Grundlage zu stellen, Semons Mnemetheorie, hat ihn in dieser Stellungnahme nicht beeinflussen können, und in einem besonderen Aufsatz hat er die Schwächen dieser Theorie beleuchtet und seine Auffassung ihr gegenüber verteidigt. Es ist der schon I870 von Ewald Hering geäußerte Gedanke von dem Gedächtnis als einer allgemeinen Funktion der organisierten Materie, an den anknüpfend Semon die Vererbungserscheinungen verständlich zu machen sucht, - im schärfsten Gegensatz zu der Auffassung Weismanns ${ }^{24}$ ). Erblickt dieser die Wurzel aller Abänderungen in der Keimsubstanz, so sieht Semon sie im Soma. Von diesem aus, von allen Körperzellen her, gelangen im Laufe des Lebens Reize - auf dem Wege der Nervenbahnen oder, bei Organismen ohne Nervensystem, von Zelle zu Zelle fortgeleitet -, zu der Keimsubstanz, bewirken unter günstigen Umständen in diesen Veränderungen und füllen sie so mit Erinnerungsbildern, „Engrammen“, durch die dann die Reaktionsnormen der Nachkommen verändert werden können, und zwar in der Richtung der Veränderungen, die bei den Eltern jenen Reiz bewirkten. Aber, so wirft Weismann ein, die Nerven sind keine Schienengeleise, auf denen alle möglichen Reize weitertransportiert und irgendwo abgeladen werden können, sondern sie sind selbst reizbare Substanz, deren Reizung 
Nervenströme erzeugt, - wie sollten sie da ganz spezifische Reize immer zu ganz bestimmten Anlagen der Keimsubstanz leiten und in diesen bestimmte Engramme erzeugen? Die von Semon vorgebrachten Beweise dafür, daß eine Vererbung somatogener Eigenschaften wirklich vorkommt, sind, Weismanns Ansicht zufolge, nicht stichhaltig, während es andererseits zahlreiche Charaktere gibt, die in ihrer Entstehung und Ausbildung schlechterdings nur auf primäre Keimesabänderungen zurückgeführt werden können, wie viele Instinkte und die vielen bloß durch ihr Dasein nützlichen Teile. Läßt sich aber eine so große Anzahl von Charakteren in ihrer Entstehung und zweckmäßigen Ausgestaltung nur durch primäre Veränderung der Keimsubstanz erklären, so haben wir keinen Grund, für andere nach einem anderen Erklärungsprinzip zu suchen. 
Fünfter Abschnitt.

\section{Befruchtung und Keimzellenreifung.}

I. Vererbung und Zweielternzeugung. - 2. Befruchtung. Ältere Auffassung. Entwicklung der Tatsachenkenntnisse. - Befruchtung und Konjugation als Amphimixis und als Quelle erblicher Variation. - 3. Reifung der Keimzellen. Bildung und Bedeutung der Richtungskörperchen, erste Deutung. - Das Reduktionsproblem. Frühere Auffassung Weismanns. - Spätere Auffassung der Reduktionsvorgänge. - Beziehungen zu den Mendelschen Vererbungserscheinungen. - 4. Reifung und Befruchtung als Quellen erblicher Variation.

\section{Vererbung und $Z_{\text {weielternzeugung. }}$}

Bei der Inangriffnahme des Vererbungsproblemes war Weismann ausgegangen von den Fortpflanzungserscheinungen, - ganz naturgemäß, denn die erbliche Übertragung elterlicher Eigenschaften auf die Nachkommen erfolgt durch die Fortpflanzung. Und es geschah weiter auch ganz bewußt, daß er an die Betrachtung der Verhältnisse bei den Einzelligen sofort die der Fortpflanzung durch Keimzellen bei den Mehrzelligen anschloß, die verschiedenen anderen Formen aber, die Vermehrung durch Knospung und Teilung, zunächst beiseite ließ. Er folgte dabei der Auffassung, daß diese letzteren Fortpflanzungsarten für die Vielzelligen, wo sie vorkommen, nicht ursprüngliche, sondern spätere Einrichtungen bedeuten, und daß das Ursprüngliche für diese Formen die Fortpflanzung durch Keimzellen ist. Diese Fortpflanzung durch Keimzellen erfolgt nun aber, wie bekannt, bei weitaus den meisten Formen auf dem Wege der sogenannten, ,sexuellen Fortpflanzung“ oder, um den besseren Haeckelschen Ausdruck zu gebrauchen: der Amphigonie (Zweielternzeugung). Die Bedeutung dieser für die 
Vererbung im besonderen zu untersuchen, war um so notwendiger und selbstverständlicher, als gerade damals die zellulären Vorgänge bei der Befruchtung durch glänzende Arbeiten von O. Hertwig, van Beneden u. a. bekannt worden waren. Hatten doch auch gerade diese Geschehnisse in erster Linie einen Rückschluß auf die Natur der Vererbungssubstanz möglich gemacht. Den Vorgängen der Befruchtung und, im Anschluß daran, denen der Entwicklung der Keimzellen selbst, namentlich den letzten Stadien derselben, den Reifungserscheinungen, hat daher Weismann schon früh bcsondere Beachtung geschenkt, und die Auffassung beider Vorgänge ist durch ihn wesentlich gefördert worden. Allerdings war er gerade in diesen Fragen zu einer mehrfachen Änderung seiner Auffassung genötigt.

\section{Befruchtung.}

\section{Ältere Auffassung. Entwicklung der Tatsachenkenntnisse.}

Der Vorgang der Befruchtung ${ }^{25}$ ) erschien früher innig und untrennbar mit der Fortpflanzung verbunden, nur einen durchaus notwendigen Teilvorgang derselben auszumachen. Der Laienerfahrung entsprechend, die in dem Begattungsakt die eigentliche „,Zeugung" sieht, werden auch die wissenschaftlichen Befruchtungstheorien früherer Zeiten durch den Grundgedanken beherrscht, daß bei der geschlechtlichen Fortpflanzung gerade die Befruchtung die Hauptsache sei; durch sie sollten die in dem Ei schlummernden Kräfte zum Leben und zur Betätigung erweckt werden, sollte eine „Belebung“ des Eies erfolgen. Daß dabei, wie aus dem Ergebnis zu ersehen war, auch eine Vermischung der männlichen und weiblichen Vererbungstendenzen erfolgte, trat demgegenüber zurück und erschien wie eine gewissermaßen unvermeidliche Nebenwirkung der Befruchtung, neben der dynamischen Hauptwirkung.

Erst um die Mitte des vorigen Jahrhunderts vollzog sich, angebahnt durch Kölliker (I842), der Fortschritt, durch den ein Verständnis für das eigentliche Wesen des Befruchtungsprozesses ermöglicht wurde: die 1677 von Lee uwenhoeks Schüler Ham entdeckten Samenfäden (Spermien), die man im I8. Jahrhundert und auch noch im Anfang des I9. für Parasiten des Samens gehalten hatte, wurden in ihrer Bedeutung als umgewandelte Zellen, bestehend aus einem Kern- und cinem Plasmaanteil, und 
somit als don weiblichen Eiern gleichwertige Gebilde erkannt. An der Festigung dieser Erkenntnis hat Weismann durch seine Arbeit über die Samenzellen der Daphniden (I880), die die eigentïmlichen zum Teil sehr großen und durchaus zellenähnlichen Samenkörper dieser Tiergruppe und ihre Entstehung aus den Hodenzellen kennen lehrte, tätigen Anteil genommen. Die feineren Vorgänge bei der Befruchtung beobachtete 1875 Oskar Hertwig an durchsichtigen Seeigeleiern: er sah als Erster das Eindringen eines - und nur eines - Samenfadens in das Ei sowie die, wenigstens scheinbare, Verschmelzung von Ei- und Samenkern, und gelangte so zu der Auffassung, daB die Befruchtung in einer Kopulation zweier Kerne beruhe. Nach zwei Richtungen gewann diese Entdeckung, die bald von verschiedenen Seiten (van Beneden, Fol, $\mathrm{NuBbaum} \mathrm{u.} \mathrm{a.)} \mathrm{bestätigt} \mathrm{wurde,} \mathrm{grundlegende} \mathrm{Bedeutung:} \mathrm{für}$ die Vererbungslehre, insbesondere zur Schaffung einer Vorstellung über die Substanz, an die die Vererbungstendenzen geknüpft sind, und für die Auffassung der eigentlichen Bedeutung der Befruchtung. In ersterer Hinsicht wies sie darauf hin, da $B$ als jener Träger der Vererbungstendenzen, als eigentliche Erbsubstanz, der Kern anzusprechen sei. Weismanns eigene Beobachtungen an Daphniden (I880), daß bei der Befruchtung nicht nur der Kern der Samenzelle, sondern auch das gesamte reichlich vorhandene Protoplasma derselben sich mit der Eizelle vereinigt, mußte in dieser Richtung an - Bedeutung zurücktreten gegenüber van Benedens glänzender Entdeckung am Pferdespulwurm, Ascaris megalocephala, daß bei der Befruchtung der Ei- wie der Samenkern die gleiche Anzahl von Kernschleifen oder Chromosomen bilden und zu der ersten Teilungsspindel zusammentreten lassen (I884). Denn damit war ein theoretisches Postulat erfüllt, das sich aus den alltäglichen Vererbungserscheinungen ergab: da diese lehren, daß an der Herstellung des Kindes beide Eltern den gleichen Anteil haben, so mußte wohl gefordert werden, daß auch von beiden Seiten die gleichen Mengen Erbsubstanz beigetragen werden und bei der Befruchtung zur Vereinigung kommen. Beobachtung und Überlegung sprachen so in gleicher Weise dafür, daß diese Erbsubstanz in den chromatischen Bestandteilen des Kernes gesucht werden müsse, und diese Schlußfolgerung wurde denn auch, wie wir schon sahen, in den Jahren I 884 und 1885 von E. Strasburger, O. Hertwig 
und Weismann selbständig ausgesprochen. - Auch für die Auffassung des Befruchtungsvorganges war damit eine neue GrundJage geschaffen. Die alte Auffassung der Befruchtung als eines Lebensweckers $\mathrm{zu}$ erschüttern, wäre freilich, wie Weismann in seiner historischen Übersicht (I89I) ganz richtig bemerkt, schon viel früher eine wichtige Tatsache geeignet gewesen: die durch Siebold und Le uckart in der zweiten Hälfte der fünfziger Jahre entdeckte Parthenogonie (Parthenogenese)*). „Als man erkannt hatte, daß ein Ei unter Umständen sich auch ohne Befruchtung zum neuen Organismus entwickeln kann, so hätte dies allein wohl schon genügen können, um zu schließen, daß ,Belebung des Keimes nicht der ,Zweck' der Befruchtung, ich meine der Grund ihrer Einführung in die Lebenserscheinungen sein kann." Allein teils war die Tatsache der Parthenogonie überhaupt nur langsam und schwer anerkannt worden, teils hatte man versucht, sie doch mit der alten Lehre in Einklang zu bringen. In den nebenher gehenden Forschungen über die Konjugation der Einzelligen erhielt diese Lehre sogar noch neue Nahrung. Schon seit geraumer Zeit war in dem genannten Vorgang, der Verschmelzung zweier einzelliger Wesen, eine der Befruchtung bei den Vielzelligen entsprechende Erscheinung gesehen worden, und da gewisse Beobachtungen dafür zu sprechen schienen, daß die normale Vermehrung der Einzelligen durch Zweiteilung nicht unbegrenzt andauern könne, wenn nicht von Zeit zu Zeit Konjugation stattfindet, so erhielt die alte Belebungstheorie eine neue Fassung: die Konjugation erschien als ein Verjüngungsprozeß, der von Zeit zu Zeit die im Verlöschen begriffene Fähigkeit der Zweiteilung wieder anfachen müsse. Die eingehenden erneuten Untersuchungen von Bütschli, denen sich in der Folge die von Balbiani, Engelmann, A. Gruber, R. Hertwig, Maupas anschlossen, lehrten dann aber auch bei der Konjugation der Einzelligen eine Kopulation der Kerne als wichtigsten Vorgang kennen und führten damit nicht nur zu einer vollen Bestätigung der Auffassung, daß die Konjugation bei den Einzelligen und die Befruchtung bei den Vielzelligen die gleichen Vorgänge sind, sondern ließen auch aufs neue die Frage nach der tieferen Bedeutung der Kernverschmelzung aufwerfen. -

*) S. Anm. 15 . 


\section{Befruchtung und Konjugation als Amphimixis und als Quelle erblicher Variation.}

Noch bevor die volle Übereinstimmung der Konjugation und der Befruchtung voll erkannt war, hatte Weismann (I886) als einer der ersten den Gedanken entwickelt, daß der wichtigste Vorgang bei der sogenannten sexuellen Fortpflanzung die Vermischung zweier Vererbungstendenzen ist. Durch diese aber werden, so schloß er weiter, die elterlichen individuellen Verschiedenheiten zu immer neuen Kombinationen vereinigt und damit immer neue individuelle Unterschiede geschaffen, die das Material, die notwendige Voraussetzung, für die Selektionsprozesse abgeben. Die gleiche Auffassung wurde dann bald (I89I) auch auf den Vorläufer der Befruchtung, die Konjugation der Einzelligen, übertragen. Die tiefere Bedeutung der Konjugation der Einzelligen wie der Befruchtung bei den Vielzelligen liegt darnach also in der Amphimixis, der Vermischung der Vererbungssubstanzen zweier Individuen zu einem neuen. Diese aber ist die Quelle der erblichen individuellen Variabilität, sie hat das Material zu schaffen, mittelst dessen Selektion neue Arten hervorbringt. Dabei mußte allerdings angenommen werden, daß überhaupt erst einmal individuelle Unterschiede vorhanden waren: diese allererste Wurzel der Variabilität sucht Weismann, wie noch zu besprechen bleibt, bei den allerniedersten, kernlosen Lebewesen, die noch durch direkte Einwirkung äußerer Einflüsse erblich veränderlich sind.

In der sogenannten, ,geschlechtlichen Fortpflanzung" sind somit zwei ganz verschiedene Vorgänge miteinander verbunden: die Amphimixis und die Fortpflanzung. Daß dieselben in der Tat ursprünglich nichts miteinander zu tun haben, lehren die Einzelligen, bei denen die Amphimixis (Konjugation) durchaus nicht immer eine Fortpflanzung, d. h. Vermehrung der Individuenzahl durch Teilung, zur Folge hat - Amphimixis ohne Fortpflanzung -; und daß beide Vorgänge auch bei den höheren Formen nicht immer notwendig aneinander gebunden sind, lehren die Erscheinungen der Parthenogonie - : Fortpflanzung durch Keimzellen ohne Amphimixis. Für viele Eier allerdings, namentlich bei den höheren Tieren und Pflanzen, ist die Befruchtung eine unerläßliche Vorbedingung für das Ingangkommen der Entwicklung, aber sie ist nicht eine 
fundamentale Ursache derselben und war nicht von vornherein mit ihr verbunden; vielmehr stellt sie cinen Vorgang sui generis dar, dessen erste und hauptsächlichste Bedeutung in seinen Beziehungen zu den Vererbungserscheinungen erblickt werden muß.

\section{Reifung der Keimzellen.}

Bildung und Bedeutung der Richtungskörperchen, erste Deutung.

Diese Auffassung von der Bedeutung der Befruchtung als einer Vermischung zweier Vererbungstendenzen führte auch zu einer neuen Betrachtung der Vorgänge, die der Befruchtung vorausgehen: der Reifungserscheinungen der Geschlechtszellen. Schon bei der ersten Ausarbeitung der ,Kontinuität des Keimplasmas" (I885) hatte Weismann der Eireifung sein Interesse zugewandt und in der Ausstoßung der sogenannten Richtungskörperchen eine Stütze mancher seiner Ansichten zu finden geglaubt. Über die morphologische Natur dieser zwei kleinen, schon seit längerer Zeit bekannten Körperchen, die bei der Eireifung auftreten, war in der zweiten Hälfte der siebziger Jahre, zunächst durch Bütschli und O. Hertwig, Klarheit geschaffen worden. Es hatte sich gezeigt, daß sie als ,,erster" und ,zweiter" von dem Ei durch eine zweimalige Teilung, die das Plasma wie den Kern betrifft, abgeschnürt werden, daß zwar ihr plasmatischer Anteil sehr gering ist im Verhältnis zu dem des Eies, weshalb sie eben als kleine Knospen und nicht als gleichwertige Schwesterzellen desselben erscheinen, daß aber der Kernanteil, den ein jedes von dem Keimbläschen des Eies erhält, genau so groß ist wie der Schwesterkern, der im Ei zurückbleibt. Auch eine nochmalige Teilung des ersten Richtungskörperchens war manchmal beobachtet worden, - in welchen Fällen dann also im ganzen drei kleine Richtungskörperchen neben dem Ei liegen.

An einer befriedigenden physiologischen Deutung dieser bei aller Kleinheit so konstanten Gebilde mangelte es noch, als Weismann sich der Frage zuwandte. Er versuchte eine solche Deutung zunächst (I885) vom Standpunkte der Vorstellung aus, daß der Kern die ganze Zelle beherrsche, ihre Gestalt und ihr Leben bestimme, daß also jede histologisch differenzierte Zelle auch ein spezifisches Kernplasma enthalten müsse. Diese Vorstellung führte 
ihn zu dem Schlusse, daß im Kern der Eizelle zwei verschiedene Substanzen enthalten seien: das eigentliche Keimplasma und außerdem ein histogenes (ovogenes) Plasma, das allen den besonderen Lebensvorgängen des sich entwickelnden Eies, seinem Wachstum, der Anhäufung von Dottersubstanzen usw. vorstehe. Dieses histogene Plasma müsse dann, wenn die genannten Vorgänge abgeschlossen seien, ausgestoßen werden, damit das Keimplasma rein zurückbleıbt und in die Befruchtung und die Entwicklung eintreten könne. In diesem Sinne, als Träger des ovogenen Kernplasmas, faßte Weismann anfangs beide Richtungskörperchen auf. Er stellte diese Ansicht der damals vielfach angenommenen gegenüber, daß die Richtungskörperchen den „männlichen Anı̀il“ darstellten, dessen sich die anfangs zweigeschlechtliche Eizelle entledige, $\mathbf{u m}$ nun, rein weiblich geworden, durch das männliche Spermium befruchtet werden zu können. Auch glückte ihm ein Fund, der gegen die letztere Ansicht und zugunsten seiner eigenen sprach: der Nachweis, daß auch bei parthenogonisch sich entwickelnden Eiern Richtungskörperchen gebildet werden. Denn wenn die letzteren wirklich ein „männliches Prinzip“ waren, das zur Ermöglichung der nachfolgenden Befruchtung aus dem Ei entfernt werden mußte, so durften pathenogonisch sich entwickelnde Eier - bei denen also eine Befruchtung unterbleibt - keine Richtungskörper bilden. War dagegen die Weismannsche Auffassung richtig, so mußten natürlich auch bei parthenogonischen Eiern Richtungskörper austreten. Weismann fand nun einen Richtungskörper (I885) bei parthenogonischen Eiern einer Daphnide, Polyphemus oculus und bald darauf in Verbindung mit seinem Schüler Ischikawa (I888a) bei verschiedenen anderen Daphniden-Arten, sowie bei pathenogonischen Eiern von Ostracoden und Rotatorien. Diese Untersuchungen, die durch gleichzeitige von Blochmann eine Bestätıgung und wertvolle Ergänzung erfuhren, lenkten aber zugleich die Aufmerksamkeit auf eine merkwürdige Tatsache: es erschien als Regel, daß parthenogonisch sich entwickelnde Eier nur einen Richtungskörper bilden, nicht zwei, wie befruchtungsbedürftige Eier. Durch ausgedehnte, mit Ischikawa unternommene Untersuchungen an Eiern der letzteren Art (I 888c) erhielt dieses ,Zahlengesetz der Richtungskörper" eine Bestätigung. Daraus zog dann Weismann, in Abänderung seiner ersten Hypothese, I887 
in einer besonderen Schrift die Folgerung, daß nur der erste Richtungskörper das ovogene Kernplasma enthalte, der zweite aber eine engere Beziehung zu der Befruchtung haben müss: Der Fortfall der letzteren erkläre sein Fehlen bei parthenogonisch sich entwickelnden Eiern. Welches diese Beziehungen sind, findet sich ebenfalls zum ersten Male in der genannten Schrift auseinandergesetzt, der somit eine besondere Bedeutung zukommt, indem sie das Problem aufrollt, das seitdem so vielfach behandelt worden ist und, wie so manches andere, mit Weismanns Namen verknüpft bleiben wird: das Reduktionsproblem.

\section{Das Reduktionsproblem. Frühere Auffassung Weismanns.}

Die Erwägungen, die hier maßgebend werden, sind folgende. Wenn der Befruchtungsprozeß eine Vermischung zweier Keimplasma, eines väterlichen und eines mütterlichen, zur Folge hat, so müssen, vorausgesetzt, daß er von jeher ohne Störung verlaufen ist, in dem Keimplasma eines jeden jetzt erzeugten Individuums zahlreiche Ahnenplasmen oder Ide, wie Weismann sie nennt, vorhanden sein. Nehmen wir zwei Keimplasmen a und b, so werden diese durch ihre Vermischung bei der Befruchtung das Keimplasma $\mathrm{a}+\mathrm{b}$ bilden. Nach der Kontinuitätslehre wird nun von diesem Keimplasma $\mathrm{a}+\mathrm{b}$ ein Rest in den Keimzellen des neuen Individuums reserviert. Es wird sich dann bei der nächsten Befruchtung verbinden mit einem Keimplasma, das, in entsprechender Weise entstanden, vielleicht die Zusammensetzung $c+d$ hat. So entsteht das neue Keimplasma $\mathrm{a}+\mathrm{b}+\mathrm{c}+\mathrm{d}$, und so wird bei jeder neuen Befruchtung eine weitere Verdoppelung erfolgen, das Keimplasma wird immer zusammengesetzter werden, immer mehr Ahnenplasmen in sich aufspeichern müssen. Dadurch würden sich manche Besonderheiten der Vererbungserscheinungen erklären: das oft so zusammengesetzte Bild, das ein Kind seinen Eigenschaften nach darbietet, die Rückschläge auf weit zurückliegende Vorfahren, aber auch die Verschiedenheiten, die die Kinder desselben Elternpaares zeigen. Man wird sich dabei nur vorstellen müssen, daß diese verschiedenen Ahnenplasmen sich bei der Entwicklung eines jeden Individuums in verschiedener Weise zur Geltung bringen können.

Die gleiche Überlegung führt aber auch zu dem Schluß, daß die Zahl der in jedem Keimplasma angehäuften Ahnenplasmen 
allmählich in's Ungeheure steigen müßte, wenn das nicht durch irgend einen anderen Vorgang verhindert würde. Und als solche Gegenmaßregel gegen die Folgen der immer wiederholten Befruchtung sprach nun Weismann von I887 an die Bildung der Richtungskörperchen an, zunächst nur die des zweiten ( - dem ersten ließ er noch die Bedeutung als ovogenes Kernplasma -), bald aber (I89I) die von allen beiden. (Von dem ,ovogenen“ Kernplasma, oder der ovogenen „Determinante“, wie er später sagte, ist dann anzunehmen, daß sie im Verlaufe der Ausbildung des Eies aufgebraucht wird.) Die Bildung der Richtungskörperchen hat nach dieser neuen Auffassung zum Zweck: eine Reduktion des Keimplasmas, nicht bloß an Masse, sondern vor allem an Komplikation der Zusammensetzung. Es sollte dadurch die Hälfte der Ahnenplasmen aus dem Ei entfernt, und so eine übermäßige Anhäufung verschiedenartiger Ahnenplasmen verhindert werden, die sonst notwendig, wie oben gezeigt, durch die Befruchtung stattfinden müßte. Somit handelte es sich um eine Vorbereitung für die Befruchtung: aus dem Ei würde zunächst die gleiche Anzahl von Ahnenplasmen entfernt, die nachher bei der Befruchtung selbst durch das Spermium wieder eingeführt wird.

Diese Vorstellung führte zunächst zu zwei wichtigen theoretischen Voraussagungen, die in der Folge durch die Beobachtungen bestätigt wurden.

Zunächst ergab sich der Schluß, daß jener Reduktionsvorgang nicht aut dem Wege der gewöhnlichen Kernteilung vor sich gehen könne. Das Wesentliche bei dieser ist ja, daß zunächst jedes Chromosom sich der Länge nach in zwei spaltet, und dann die beiden so entstandenen Geschwisterchromosomen sich trennen, indem das eine in den einen, das andere in den anderen Tochterkern wandert, so da $B$ jeder Tochterkern wieder die gleiche Anzahl Chromosomen besitzt wie der Mutterkern. Auf Grund der eben angestellten theoretischen Überlegung sind nun, - und diese Vorstellung ist von Weismann lange Zeit festgehalten worden -, die Chromosomen aus sehr vielen einzelnen Ahnenplasmen oder Iden zusammengesetzt zu denken, die innerhalb eines jeden Chromosoms in Form linear angeordneter Chromatinkörper, der vielfach beobacliteten Mikrosomen, liegen, und von denen jedes einzelne die Anlage eines ganzen Individuums darstellt. Bei dieser Anordnung 
aber müßten durch eine Längsspaltung des ganzen Chromosoms, wie sie der gewöhnlichen Zellteilung vorausgeht, auch die einzelne Ide zunächst halbiert, ihre Zahl also verdoppelt werden, und jeder Tochterkern würde von einem jeden Id ein Teilstück, also in summa genau so viel Ide erhalten, als der Mutterkern besaß. Auf diese Weise wäre also die gewünschte Reduktion der Id- oder Ahnenplasmenzahl nicht zu erreichen. Es muB demnach, so folgerte Weismann weiter, neben dieser gewöhnlichen Teilung, die er als Äquationsteilung bezeichnete, noch eine zweite, eine Reduktionsteilung, geben, bei der die Längsspaltung der Chromosomen unterbleibt, und einfach die Zahl der vorhandenen Chromosomen zu gleichen Teilen auf die beiden Tochterkerne verteilt wird. Die Forschung der folgenden Jahre hat das Vorhandensein einer solchen Teilung bestätigt. Die Bildung des ersten Richtungskörperchens erfolgt nach dem gewöhnlichen Schema: die Zahl der Chromosomen wird zuerst durch Längsspaltung der einzelnen verdoppelt und dann durch die Teilung halbiert, so daß in dem ersten Richtungskörperchen wie in dem Ei, von dem es sich abschnürte, die ursprüngliche Zahl von Chromosomen vorhanden ist; bei der Bildung des zweiten Richtungskörperchens wird aber von diesen letzteren einfach die Hälfte mit dem Richtungskörperchen herausgeschafft, so daß das zurückbleibende ,Reifei" nun tatsächlich auch nur die Hälfte der ursprünglichen Chromosomenzahl behält.

Eine weitere Konsequenz der Anschauung von der Notwendigkeit der Halbierung der Zahl der Ahnenplasmen vor der Befruchtung war das Postulat einer solchen Reduktionsteilung auch für die Samenzellen, und auch dieses wurde durch die Untersuchungen über die Reifung der Samenzellen, zunächst von O. Hertwig, als richtig nachgewiesen. Nur daß durch die zwei Reifeteilungen des Eies vier ungleiche Teilungsprodukte entstehen, nämlich drei kleine Richtungskörperchen und ein großes Reifei, während bei der Samen reife alle vier Teilungsprodukte gleich groß sind und funktionsfähige Samenfäden geben. Auch die Art, wie Weismann diesen Unterschied betrachtet, ist jetzt Gemeingut geworden: auch für die Eizelle ist von einem früheren Zustand auszugehen, wodurch ihre zweimalige Teilung vier funktions-, d. h. befruchtungs- und entwicklungsfähige Eier entstanden; erst im Laufe der phylogenetischen Entwicklung hat sich der jetzige Zustand herausgebildet, 
wo drei der Teilungsprodukte verkümmern, und nur eins zur vollen kräftigen Ausbildung gelangt und das zum Aufbau des Embryo nötige Nahrungsmaterial in sich aufspeichert. Der Gedanke ist dann noch weiter nach der physiologischen Seite hin verfolgt worden: die Besonderheiten von Ei und Samenzelle sind der Ausdruck der Arbeitsteilung zwischen beiden; das Ei ist der ruhende, passive Teil der Befruchtungselemente, betraut mit der Aufspeicherung des Materials, dessen der Embryo zu seiner Bildung bedarf, die Samenzelle ist das aktive, aufsuchende Element. Darauf beruhen die Unterschiede beider und auch die Unterschiede ihrer Bildung. Ihrem wichtigsten Bestandteile, der in den Chromosomen gegebenen Erbmasse nach aber verhalten sie sich gleich: das reife $\mathrm{Ei}$ wie die reife Samenzelle enthalten gleichviel Chromosomen, und zwar der Zahl nach halb so viel als sie im unreifen Zustand besaßen. Durch ihre Vereinigung bei der Befruchtung wird in dem befruchteten Ei die ursprüngliche Zahl der Chromosomen wieder hergestellt, und von dem letzteren aus wird sie allen Körperzellen mitgegeben. Das gleiche gilt natürlich für die in den Chromosomen enthaltenen Ahnenplasmen: auch deren Zahl, die in den beiderlei Geschlechtszellen durch die Reifeteilungen halbiert worden war, wird durch die Befruchtung wieder auf den früheren Stand gebracht. -

Mit der bloßen Halbierung der Zahl der Ahnenplasmen und der dadurch erzielten Verhinderung einer übermäßigen Anhäutung von solchen im Keimplasma ist aber, Weismanns damaliger Anschauung zufolge, die Bedeutung der Reifeteilungen - des Eies wie der Samenzellen - nicht erschöpft. Die weitere theoretische Analyse der Geschehnisse ließ in den Reifeteilungen auch eine neue wichtige Quelle für individuelle Variation erkennen, für die Erscheinung, daß auch Kinder desselben Elternpaares, also Erzeugnisse der Keimzellen derselben Geschlechtsdrüsen, - wofern es sich nicht um den Sonderfall, ,identischer Zwillinge" handelt —, niemals einander ganz ähnlich sind, ja, unter Umständen recht große Verschiedenheiten aufweisen. Zu dieser Auffassung führte die Überlegung, daß jene Halbicrung der Chromosomenzahl in sehr verschiedener Weise vor sich gehen kann, und daß demnach auch aus den zahlreichen Keimzellen eines und desselben Individuums bei den Reifevorgängen gan $z$ verschicdene Ahnenplasmen entfernt werden können. So würde z. B. bei einer 
Form, deren Eikern vor der Bildung des zweiten Richtungskörperchens nur vier Chromosomen (a, b, c, d) bildet, zwar bei der Reduktionsteilung eine Zerlegung in zwei Gruppen von je zwei Chromosomen erfolgen, aber diese Gruppen könnten in den verschiedenen Zellen schon sechserlei verschiedene Zusammensetzung haben: $(a+b), \quad(a+c), \quad(a+d), \quad(b+c), \quad(b+d), \quad(c+d) . \quad$ Bei acht Chromosomen wären schon 70 , bei I6 schon 12870 Kombinationen möglich; entsprechend der angenommenen Zusammensetzung der Chromosomen aus einer großen Menge von Iden (Anlagekomplexen, Ahnenplasmen) heißt das in der Sprache der Theorie: die reifen Keimzellen auch desselben Individuums werden in bezug auf ihre Zusammensetzung aus einzelnen Ahnenplasmen qualitativ nicht identisch sein; in der einen werden sich andere Ahnenplasmen zusammenfinden als in der anderen. Das gilt für die Keimzellen beider Geschlechter. Da nun bei der Befruchtung stets von beiden Seiten her die gleiche Anzahl von Chromosomen zusammentrifft, so wird die Zahl der Keimplasmavariationen, welche ein Elternpaar möglicherweise zu liefern imstande ist, eine ganz ungeheure sein müssen, da sie sich durch Multiplikation der väterlichen mit der mütterlichen Kombinationszahl ergibt. Damit wäre die theoretische Grundlage für das Verständnis der großen individuellen Verschiedenheiten gegeben, die auch Kinder eines und desselben Elternpaares zeigen. Bei der großen Zahl verschiedener Idkombinationen in den reifen Keimzellen eines Individuums ist auch bei mehrmaliger Amphimixis desselben Elternpaares nicht anzunehmen, daß sich jemals die gleichen Kombinationen zusammenfinden werden, und so ergibt sich die stets wechselnde Kombination elterlicher und vorelterlicher Eigenschaften, wie sie das Charakteristische der geschlechtlichen Fortpflanzung ist. Nur wo aus demselben befruchteten Ei zwei Individuen entstehen, wird völlige Gleichheit zu erwarten sein - identische (,eineiige“) Zwillinge.

Darnach schaffen also die Reifeteilungen fortwährend eine "Neotaxis" oder Neukombinierung der Keimplasmaelemente, und dieser Proze $B$ der Umkombinierung der Ide setzt sich dann bei der Amphimixis fort. Reifeteilungen und Befruchtung bewirken so eine fast unendliche Zahl von Keimplasmamischungen und vermitteln damit ein Verständnis für die Verschiedenheit der Kinder auch desselben Elternpaares, wie überhaupt für das mosaik- 
artig aus Zügen väterlicher und mütterlicher Herkunft zusammengesetzte Bild, das ein Individuum darbieten kann. Ihre Bedeutung für die Entwicklung des Organismenreiches aber sieht Weismann darin, da $\beta$ sie Individuen in den verschiedensten Kombinationen individueller Unterschiede der Naturzüchtung zur Verfügung stellen.

\section{Spätere Auffassung der Reduktionsvorgänge; Beziehungen zu den Mendelschen Vererbungserscheinungen.}

In Weismanns Theoriengebäude wie überhaupt in der Vererbungslehre spielen die Reduktionsteilungen vom Jahre I887 ab eine große Rolle, um so mehr, als ganz entsprechende Vorgänge als Vorbereitung für die Befruchtung auch bei Einzelligen und Pflanzen nachgewiesen worden sind, und damit als sicher gelten kann, daß ihnen eine wichtige biologische Bedeutung zukommt. Weismanns Gedankengänge, die die Reduktionsteilungen zu den Vererbungserscheinungen in Beziehung brachten, haben dabei die Richtung gewiesen, in der diese Bedeutung zu suchen ist. Im einzelnen freilich haben sich die Anschauungen darüber nicht unerheblich geändert, und auch Weismann selbst hat in der letzten Auflage seiner „Vorträge" (I9I3) sich eine andere Betrachtung der Vorgänge zu eigen gemacht. Sie geht von einer veränderten Voraussetzung, einer etwas anderen Vorstellung von der Natur der Chromosomen aus und sucht den Erscheinungen gerecht zu werden, die am Anfang dieses Jahrhunderts einen gewaltigen Aufschwung der ganzen Vererbungsforschung angebahnt und auch dem Interesse für das Reduktionsproblem einen neuen Impuls gegeben haben: den schon in der zweiten Hälfte des vorigen Jahrhuncierts durch den Augustinermönch Gregor Mendel ${ }^{26}$ ) gefundenen, damals aber unbeachtet gebliebenen und erst zu Beginn unseres Jahrhunderts von Tschermak, de Vries und Correns aufs neue entdeckten Gesetzmäßigkeiten in den Vererbungserscheinungen bei Bastarden. Der theoretisch konstruierte Zusammenhang zwischen ihnen und dem Reduktionsproblem wird am raschesten verständlich an den durch Correns bekannt gewordenen Erscheinungen bei der Kreuzung der rot (tiefrosa) blühenden Mirabilis Jalapa mit der weiß blühenden. Hier zeigt die erste Nachkommengeneration (erste Filialgeneration, $\mathrm{F}_{1}$ ) die Mischung des mütterlichen und des 
väterlichen Merkmals durch die hellrosa Färbung der Blüten auch äußerlich sichtbar an, aber schon die von diesen rosa blühenden Pflanzen durch Selbstbefruchtung gewonnene zweite Nachkommengeneration $\left(\mathrm{F}_{2}\right)$ zeigt die charakteristische ,,Spaltung der Merkmale" der ,Mendel-Bastarde“: nur zwei Viertel der Nachkommen bietet wieder die hellrosa Blütenfarbe, ein Viertel dagegen blüht rein rot (tiefrosa), das letzte Viertel rein weiß. Und diese roten und weißen Individuen bewahren nun auch, durch Selbstbefruchtung weiter gezüchtet, die rote und die weiße Blütenfarbe dauernd bei: die elterlichen Merkmale sind bei ihnen wieder rein zur Geltung gekommen, rein ,abgespalten“. Der gleiche Spaltungsprozeß wiederholt sich bei den zwei Viertel rosa blühenden Individuen der zweiten Nachkommengeneration: auch sie, durch Selbstbefruchtung weiter gezüchtet, geben wieder ein Viertel rot, ein Viertel weiß, und zwei Viertel rosa blühende Individuen. So geht es weiter; jede neue Generation, die aus rosa blühenden Individuen gezüchtet wird, zeigt wieder die drei Farben in dem Verhältnis I:I:2. Für diese Erscheinungen gab Mendel selbst schon die Erklärung: in den Keimzellen oder Gameten (Ei- und Samenzellen), die von den rosa blühenden Bastarden gebildet werden, werden die Merkmale „,rot" und ,weiß“" gespalten, d. h. die einen Keimzellen erhalten nur die Anlage für das Merkmal ,rot“, die anderen nur die für das Merkmal „,wei $B^{\prime \prime}$. Werden nun diese Keimzellen zur gegenseitigen Befruchtung gebracht, so werden sich finden können: ",rote" männliche und ",rote" weibliche Keimzelle; oder: ,weiße" männliche und ,weiße" weibliche, oder: ,rote" männliche und ,weiße" weibliche oder endlich ,weiße" männliche und ,rote" weibliche. In den beiden letzten Fällen wird das Ergebnis gleich sein: rosa Blüten; in den beiden ersten Fällen entstehen rein und dauernd rote oder rein und dauernd weiße. So erfährt das empirisch festgestellte Verhältnis I: I: 2 seine theoretische Erklärung: die zwei Viertel hellrosa Individuen sind Heterozygoten, d. h. durch Vermischung verschiedener Merkmalsanlagen (rot und weiß) entstanden; die ein Viertel rot oder tiefrosa gefärbten sind ebenso wie die ein Viertel weißen Homozygoten, d. h. in ihnen haben sich von beiden Seiten her die gleichen Merkmalsanlagen gefunden, in der roten die roten, in der weißen die weißen. 
Es liegt nahe, die Herstellung dieser in bezug auf bestimmte Merkmale „reinen Gameten", die aus den Beobachtungen erschlossen werden, in Verbindung zu bringen mit den Reifeteilungen, durch die ja ein Teil der Chromosomen, also der Erbmasse, aus der Keimzelle herausgeschafft wird. Für die Durchführung des Gedankens im einzelnen ist freilich die frühere Weismannsche Vorstellung, daß jedes Chromosom die Gesamtanlagen für eine sehr große Anzahl von Einzelindividuen enthält, nicht besonders geeignet; um so mehr die andere, hauptsächlich durch Boveri begründete, nach der in jedem Chromosom die Anlagen nur für bestimmte Teile eines Individuums enthalten sind. Diese aus gewissen direkten Beobachtungen und experimentellen Ergebnissen erschlossene Auffassung von der Ungleichwertigkeit der Chromosomen ist denn auch in die dritte Auflage von Weismanns Vorträgen über Deszendenztheorie ïbergegangen und an die Stelle der früheren Anschauung getreten, nach der die Chromosomen gleichwertige und nur durch die individuelle Färbung ihrer Ahnenplasmen unterschiedene Gebilde seien. So lautet die jetzige Annahme dahin, da $B$ in jeder befruchteten Eizelle - und demnach auch in jeder Keimzelle vor den Reifeteilungen - die Anlagen für ein ganzes Individuum nur zweimal vorhanden sind: einmal vom Vater und einmal von der Mutter her. Diese Anlagen sind so auf sämtliche Chromosomen verteilt, daß die eine Hälfte die väterlichen, die andere Hälfte die mütterlichen Anlagekomplexe darstellt. Das Einzelchromosom enthält darnach nicht eine große Menge von Ahnenplasmen oder Iden (,,Volliden“), ja nicht einmal ein einziges, sondern nur eine beschränkte Anzahl von Anlagen für ganz bestimmte Teile des Individuums, und erst die ganze Menge der Chromosomen repräsentiert zwei „Vollide“, d. h. die Anlagen für zwei ganze Individuen. Einem jeden väterlichen (vom Vater stammenden) Chromosom entspricht ein mütterliches; diese beiden „,homologen“ Chromosomen enthalten immer den gleichen Anlagekomplex. Auf der Grundlage dieser Anschauung erfahren dann auch dic beiden Reifeteilungen der Keimzellen eine neue Deutung, und die Ergebnisse der auf diesem Gebiete ungemein tätigen und ertolgreichen Forschung, namentlich die Bildung der sogenannten ,Vierergruppen“, gibt die Handhabe zu einer Deutung, die die Reifungsteilıngen zu den eben kurz berührten Mendelschen 
Vererbungserscheinungen in engere Beziehung bringt. Sie kommt in ihrem Endergebnis darauf hinaus, in jenen Vorgängen das Mittel zu sehen, um die Gesamtzahl der Chromosomen zunächst zu verdoppeln - wonach also dann die Anlagenkomplexe für vier Individuen in der Keimzelle liegen würden, zwei aus väterlichen, zwei aus mütterlichen Chromosomen bestehend, - und die so gewonnene Chromosomenzahl alsdann auf vier Zellen (- beim männlichen Geschlecht: auf vier Samenzellen, beim weiblichen: auf ein Reifei und drei Richtungskörperchen -) in der Weise zu verteilen, daß eine jede Zelle den ganzen für ein Individuum erforderlichen Chromosomensatz nur einmal enthält, aber in der verschiedensten, dem Zufall überlassenen Mischung väterlicher und mütterlicher Elemente. Durch die Befruchtung werden dann zwei solcher Chromosomensätze zusammengebracht; diese beiden setzen die Kernsubstanz des befruchteten Eies zusammen und beherrschen weiterhin die ganze Ontogenese, wie noch zu besprechen sein wird.

Damit wäre, auch vom Standpunkt der neuen Auffassung der Chromosomen aus, eine Grundlage gegeben für die Verschiedenheiten der Kinder auch eines und desselben Elternpaares, ferner für das zusammengesetzte Bild, das ein jedes Individuum darbietet, endlich aber auch für die eigentümliche Merkmalsspaltung, die die Mendel-Bastarcie in der zweiten und den folgenden Bastardgenerationen zeigen. Denn durch die Reifeteilungen bekommt, dem Gesagten zufolge, eine jede Keimzelle die Anlage für jedes Merkmal nur einmal, entweder vom Vater oder von der Mutter - eingeschlossen in ein Chromosom väterlicher oder mütterlicher Herkunft - , und damit wäre die von Mendel selbst geforderte Reinheit der Gameten oder Keimzellen in bezug auf ein bestimmtes Merkmal erreicht. Freilich ergeben sich dabei auch manche Schwierigkeiten, die Weismann selbst auch anerkannt hat, so besonders aus der bei manchen Formen sehr geringen Zahl von Chromosomen. Denn die Bastardierungsversuche mit Formen, die sich nicht nur durch ein, sondern durch zwei, drei und mehr Merkmale unterscheiden (Di-, Tri-, Polyhybriden), haben ja ergeben, daß diese Merkmale in den Bastardgencrationen sich selbständig verhalten, aus dem Zusammenhang, in dem sie sich bei den Elternformen fanden, gelöst werden, und sich in allen möglichen neuen Kombinationen wieder zusammenfinden können, und 
es wird angenommen, daß das ganz allgemein für alle Merkmale gilt. Die Unmöglichkeit, das mit der meist nur geringen Zahl der Chromosomen in Einklang zu bringen, liegt auf der Hand; sie macht es. verständlich, da B man sogar an einen Austausch von Determinanten (Merkmalsanlagen) zwischen den homologen Chromosomen väterlicher und mütterlicher Herkunft - die sich vorübergehend eng aneinander legen - gedacht hat. Hier ist also noch sehr vieles unklar. Indessen muB ein genaueres Eingehen auf die $\mathrm{Be}_{-}$ ziehungen der Mendel-Forschung zu den Weismannschen Vorstellungen hier unterbleiben. -

\section{Reifung und Befruchtung als Quelle erblicher Variation.}

Durch diese Änderung im einzelnen wird die ursprüngliche allgemeine Auffassung von der Bedeutung der Reifungserscheinungen und der Amphimixis nicht berührt. Auch nach der neuen Auffassung erscheinen diese beiden Vorgänge als eine unaufhörlich fließende Quelle individueller Variation. Die Bedeutung derselben ist freilich eine Zeitlang von Weismann, wie er selbst bald erkannte, überschätzt worden. Was die Vermischung der Individuen in Verbindung mit den ihr vorausgehenden Reifungserscheinungen der Keimzellen leisten kann, ist ja immer nur eine neue Kombination der auf beiden Seiten gegebenen verschiedenen Anlagen, die Schaffung neuer Anlagenkomplexe; die Elemente dieser Komplexe aber, die Anlagen selbst, bleiben dadurch unverändert. Der Zuchtwahl gegenüber werden freilich auch diese Komplexe sehr verschiedenwertig sein: die einen brauchbar und der Erhaltung wert, die anderen minderwertig und $\mathrm{zu}$ verwerfen. Aber wenn dadurch auch das individuelle Bild der Vertreter einer gegebenen Art verändert werden kann, so wird das doch eben nur innerhalb der Grenzen des Artbildes möglich sein; in bezug auf die Elemente aber würde nichts völlig Neues dadurch zustande kommen. Hierfür ist die Annahme einer besonderen Kraft nötig, die wirkliche Veränderungen der Teile, d. h. im Sinne der Determinantentheorie: Veränderungen der Determinanten hervorruft. Weismann stellte als diese Kraft später die Germinalselektion auf.

Indessen ist die umordnende Bedeutung der Amphimixis einschließlich der vorhergehenden Reifungserscheinungen nicht zu unterschätzen und auch im Menschenleben spielt sie eine sehr 
große Rolle. Das Individuum ist eine Kombination, ein Mosaik aus einer sehr großen Anzahl von Anlagen verschiedener Herkunft, über die seine Ahnentafel Auskunft gibt, und auch die hervorstechendsten menschlichen Erscheinungen, Talente und Genies, sind vor allem als zufällige glückliche $\mathrm{K}$ ombinationen günstiger Anlagen zu betrachten. Diese schon von Goethe in seinem bekannten Verse ausgesprochene, von Weismann in seinem bereits oben eingehend behandelten Aufsatz über die Musik und dann in den Vorträgen über Deszendenztheorie näher ausgeführte Auffassung wird auch von der modernen Vererbungsforschung immer mehr als zu Recht bestehend anerkannt. 


\title{
Weiterer Ausbau der Keimplasmatheorie: die Determinantentheorie.
}

\begin{abstract}
„Das Keimplasma. Eine Theorie der Vererbung." - Fragestellung. - I. Der Bau des Keimplasmas. - Vererbungssubstanz; die Chromosomen als Träger der Vererbungstendenzen. - Nägelis Idioplasma, Ungestaltung des Idioplasmabegriffes durch Weismann. Biophoren und Determinanten. - Die Ide. Wechsel der Anschauung Weismanns hinsichtlich der Natur der Chromosomen. - 2. Die Betätigung des Keimplasmas in der Ontogenese. - Das Problem. - Ontogenetische Zerlegung des Keimplasmas. - Kampf der homologen Determinanten untereinander; Bedeutung für die Vererbungserscheinungen; alternierende Vererbung (Mendel). - Beeinflussung der Entwicklung durch äußere Einwirkungen. - Neben- (Reserve-, Regenerations-) Idioplasma. - Erbgleiche und erbungleiche Teilung. - 3. Allgemeine Betrachtung der Determinantentheorie. Die Determinantentheorie als Theorie der Vererbung. - Die Determinantentheorie als Theorie der Entwicklung. - Hypothetischer Charakter der Theorie.
\end{abstract}

\section{"Das Keimplasma. Eine Theorie der Vererbung."}

Die Bausteine, die Weismann von verschiedenen Seiten her zur Vererbungslehre herbeigeschafft hatte, fügte er I892 zum ersten Male zu dem Gebäude einer Theorie zusammen. ,Das Keimplasma. Eine Theorie der Vererbung" ist der Titel des Werkes, das Rudolf Le uckart gewidmet ist. Die Theorie erscheint hier in ihrer ersten Form, an der Weismann später mancherlei geändert hat.

\section{Fragestellung.}

$\mathrm{Zu}$ der schon oben kurz berührten ersten Hauptfrage des Vererbungsproblemes: wie kommt eine einzelne Zelle des Körpers dazu, die sämtlichen Vererbungstendenzen des gesamten Organismus in sich zu vereinigen? - gesellt sich hier die zweite: durch welche Kräfte, durch welchen Mechanismus kommen diese Tendenzen beim 
Aufbau des neuen Organismus zur Entfaltung? Die Beantwortung beider wird gegeben auf Grund einer im einzelnen durchgearbeiteten Vorstellung vom Bau der Vererbungssubstanz: ihrer Zusammen setzung aus einzelnen Bestimmungsstücken oder Determinanten.

\section{r. Der Bau des Keimplasmas.}

\section{Vererbungssubstanz. Die Chromosomen als Träger der Ver- erbungstendenzen.}

Schon in seiner ersten Schrift über die Vererbung, von I883, hatte Weismann eine ganz bestimmte Vererbungssubstanz, einen materiellen Träger der Vererbungstendenzen, angenommen und, wie auch schon I882 in der Schrift über die Dauer des Lebens, die Überzeugung vertreten, daß in der befruchteten Eizelle selbst die Faktoren liegen, die über die Art ihrer Entwicklung entscheiden. Diese Annahme konnte durch Versuche von Pflüger (I883), nach denen die äußeren Bedingungen einen ausschlaggebenden Einfluß bei der Entwicklung zu haben schienen, als gefährdet erscheinen, erhielt aber durch Experimente von Roux (I844), die das Pflügersche Ergebnis als unrichtig nachwiesen, eine sehr wichtige Bestätigung.

Zunächst galt es nun, diese Vererbungssubstanz, für die Weismann die kurze Bezeichnung Keimplasma eingeführt hat, ihrem Sitze und ihrem Wesen nach genauer zu bestimmen.

Den Sitz des Keimplasmas verlegt Weismann in den Kern der Keimzellen, und insbesondere nimmt er die chromatische Substanz desselben als Träger der Vererbungstendenzen in Anspruch, d. h. die Substanz, die zur Zeit der Zellteilung in Form der stäbchenoder schleifenartigen Chromosomen erscheint. Die hohe Bedeutung des Kernes für das Leben der Zelle, und im besonderen seine Bedeutung als Vererbungssubstanz war von der Mitte der siebziger Jahre des vorigen Jahrhunderts an immer deutlicher und klarer hervorgetreten. Die eigentümlichen Erscheinungen, die sich bei der indirekten Zellteilung am Kerne abspielen (,Karyokinese“), und die zuerst von A. Schneider und Auerbach beobachtet, dann von Bütschli, Flemming u. a. aufs genaueste studiert worden waren, hatten schon die große wichtige Rolle, die die chromatische Substanz des Kernes bei der Zellteilung spielt, erkennen 
lassen; die gleichzeitig daneben herlaufenden Untersuchungen über die Befruchtungserscheinungen (O. Hertwig, Fol, van Beneden, E. Strasburger u. a.) hatten noch bestimmter darauf hingewiesen, daß die chromatischen Substanzen des Kernes die Träger der Vererbungstendenzen seien. Endlich zeigten Versuche über künstliche Teilbarkeit der Infusorien (M. NuBbaum, A. Gruber; - die Experimente des letzteren sind auf Veranlassung von Weismann im Freiburger zooløgischen Institut ausgeführt worden -), daß der Kern die Wiederherstellung des verstümmelten Tieres leitet, $\mathrm{da} B$ in ihm also etwas enthalten sein muß, was den Organismus mit seinen Einzelheiten bestimmt. Die Schlußfolgerung aus alle dem, die Lehre vom „Vererbungsmonopol des Kernes“, wie man sie später genannt hat, wurde denn auch ziemlich gleichzeitig, in den Jahren $\mathrm{r} 884$ und $\mathrm{I} 885$, von E. Strasburger, O. Hertwig und A. Weismann, von letzterem in der ,Kontinuität des Keimplasmas", I 885, ausgesprochen ${ }^{27}$ ). Unter den Beobachtungen, auf die sie sich stützte, waren von der allergrößten Bedeutung die von E. van Beneden (1884; an Ascaris megalocephala angestellt), daß bei der Befruchtung der Ei- wie der Samenkern die gleiche Anzahl von Kernschleifen oder Chromosomen bilden, daß die Kernschleifen väterlicher und mütterlicher Herkunft getrennt bleiben, eine jede sich spaltet, und bei der Teilung des Eies eine jede Furchungszelle gleichviele väterliche und mütterliche Spalthälften erhält. Daraus mußte geschlossen werden, daß auch jede Zelle des Körpers zur Hälfte väterliche und zur Hälfte mütterliche Kernschleifen bekommt - ein Schluß, der für das Verständnis der Vererbungserscheinungen von größter Bedeutung sein mußte. Zugleich aber forderten diese Beobachtungen dazu auf, die Formel, daß der Kern der Träger der Vererbungstendenzen sei, bestimmter dahin zu fassen, daß die Chromosomen die Vererbungssubstanz repräsentieren. Eine wesentliche Stütze fand diese Auffassung in der zuerst (I884) von Rabl aufgestellten, darauf besonders von Boveri begründeten und vielfach, wenn auch nicht allgemein, angenommenen Hypothese, daß die Chromosomen oder Kernschleifen nicht vergängliche, sondern konstante Gebilde sind, die während des sogenannten Ruhestadiums des Kernes zwar äußerlich nicht gegen einander abgegrenzt werden können, aber doch ihre Individualität bewahren. In Einklang mit dieser Vorstellung steht, 
daß die Zahl der Chromosomen, die sich bei der Kernteilung bilden, für jede Organismenform konstant, d. h. in allen Zellen derselben gleich ist (Boveri I89o).

Alle die hier kurz berührten Vorstellungen und Tatsachen hat Weismann in seiner Vererbungstheorie verwertet, die sich somit ganz auf der Lehre aufbaut, da $B$ die Vererbungssubstan $z$ lediglich in den Chromosomen des Kernes enthalten ist. Daß diese Grundannahme heute vielfach angezweifelt, und von vielen Forschern auch dem Plasma der Keimzellen - namentlich des Eies eine wichtige Rolle bei der erblichen Übertragung und bei der Bestimmung der Ontogenese zugewiesen wird, sei nur kurz erwähnt.

\section{Nägelis Idioplasma, Umgestaltung des Idioplasmabegriffes durch Weismann. Biophoren und Determinanten.}

Für den weiteren Ausbau der Weismannschen Keimplasmatheorie wurden von gröBter Bedeutung die theoretischen Erörterungen, die der Münchener Botaniker Carl von Nägeli in seinem I 884 erschienenen Werk: , Mechanisch-physiologische Theorie der Abstammungslehre" aufstellte. Mit den hier niedergelegten Anschauungen berühren sich die von Weis ma $n \mathrm{n}$ in manchen Punkten, in anderen aber weichen sie sehr bestimmt ab. Für den Ausbau der Vererbungslehre von besonderer Wichtigkeit ist der Begriff des Idioplasmas geworden, den Nägeli eingeführt hat. Das Idioplasma

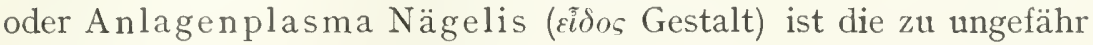
gleichen Teilen vom Vater und von der Mutter stammende Vererbungssubstanz, die den ganzen Organismus des Nachkommen durchsetzt und, obschon in sehr viel geringerer Menge als die übrige lebende Substanz des Körpers, das Ernährungsplasma, vorhanden, dennoch diesen in seiner Gestaltung bestimmt. Weismann übernahm den Nägelischen Begriff des Idioplasmas, verwendete ihn aber etwas anders als Nägeli selbst, indem er ihn - wie das auch von O. Hertwig geschehen war - auf die Chromatinsubstanz des Kernes übertrug, entsprechend eben der Auffassung, da $B$ in der Tat diese Kernsubstanz bestimmend für den morphologischen und physiologischen Charakter der Zelle ist. Jede Zelle enthält nach Weismann in dem Chromatin ihres Kernes ein spezifisches Idioplasma, das der Zelle, in der es liegt, den Stempel aufdrückt, sie beherrscht. Diese Beherrschung der Zelle 
durch den Kern dachte sich Weismann anfangs (1885), im Anschluß an E. Strasburger, in der Weise, daß von dem Kern(Idio-)plasma, das in jeder Zelle eine ganz spezifische Molekularstruktur habe, sich molekulare Erregungen in das umgebende Zellplasma fortpflanzen und hier in spezifischer Weise beim Stoffwechsel und Wachstum wirksam werden. Unter Zugrundelegung dieser Anschauung versuchte Weismann anfangs auch eine Keimplasmatheorie aufzustellen (I 885, in der ,Kontinuität des Keimplasmas"). An ihre Stelle trat aber dann später eine andere, die den Schwerpunkt von der Struktur auf die Substanz verlegte: die Lehre von den Determinanten. Darnach denkt sich Weismann nunmehr, wie auch andere Forscher, alle lebende Substanz, also auch das Kern- und das Zellplasma, aus kleinsten lebendigen Einheiten, zusammengesetzt, denen er den Namen Biophoren gibt. Es sind die kleinsten Molekülgruppen, die noch assimilieren, wachsen und sich vermehren können, also die niedersten Lebenseinheiten überhaupt. Es muß unzählige Biophoren-Arten in all den verschiedenen Teilen der Millionen von Lebensformen geben, die heute auf der Erde leben; die Biophoren der Muskelzellen sind anderer Art als die der Nerven-, Drüsenzellen usw.; nur ein Grundschema des Baues, an das ihre Lebensfähigkeit geknüpft ist, dürfte ihnen gemeinsam sein. Im Anschluß an eine Vorstellung von de Vries betrachtet dann Weismann den Kern (das Idioplasma) einer differenzierten Zelle als ein Magazin der Biophoren-Arten, die den spezifischen Zellcharakter, aber auch Größe, Lebenskraft, Vermehrungsdauer usw. der Zelle bestimmen sollen; in diesem Magazin liegen sie aber nicht lose durcheinander, sondern in festem Verbande, vereinigt zu lebendigen Einheiten höherer Ordnung, den sogenannten „,Determinanten“ (Bestimmungsstücken der Zelle), in passivem Zustand; sie werden aktiv und erfüllen ihre Aufgabe, indem sie nach Auflösung der Determinanten, durch die Kernmembran hindurch in den Zellkörper austreten und denselben - das genauere „Wie“ entzieht sich bisher unserer Vorstellung - in ihrem Sinne umgestalten. Da nun letzten Endes jede Zelle des Organismus aus der befruchteten Eizelle, jeder Zellkern aus dem Keimkern hervorgegangen ist, so müssen auch die Determinanten aller Kerne ursprünglich aus dem Kern der befruchteten Eizelle, d. h. aus dem Keimplasma, stammen: das Keimplasma muß alle die verschieden- 
artigen Determinantensorten für den ganzen Organismus enthalten. Dabei ist freilich nicht anzunehmen, daß jede einzelne Körper zelle im Keimplasma durch eine besondere Determinante vertreten ist; das würde bei den Milliarden von Zellen, die den vielzelligen Organismus aufbauen, eine ungeheuerliche Annahme sein. Sie ist aber auch gar nicht nötig, denn da die Determinanten lebendige Einheiten sind, so muß ihnen die Fähigkeit der Assimilierung und Vermehrung zugesprochen werden, und so können wohl die Determinanten von tausenden von Blut- oder Muskelzellen von einer einzigen Determinante oder doch von deren wenigen im Keimplasma abstammen. Daß indessen andererseits auch nicht etwa alle gleichartigen Gewebszellen nur von einer einzigen Keimplasmadeterminante abstammen können, lehren die Vererbungserscheinungen. Von deren Standpunkt aus betrachtet, müssen die einzelnen Determinanten im Keimplasma nicht bloß ganz allgemein Muskel-, Nervennusw. Determinanten sein, sondern eine nach Spezies, ja nach Individuen eigenartige Natur besitzen. Von den elterlichen Keimplasmen stammend, sollen sie die Eigenheiten der elterlichen Organismen auch im kindlichen Organismus wieder zum Ausdruck bringen. Dazu aber ist nötig, daß jeder selbständig und erblich veränderliche Teil des Körpers durch ein besonderes Teilchen, eine besondere Determinante, im Keimplasma vertreten ist. Wenn eine kleine individuelle Besonderheit beim Menschen, die sich nur auf eine beschränkte Stelle eines Körperteiles bezieht (- ein Grübchen der Haut, eine besonders gefärbte Haarlocke u. a. -) durch mehrere Generationen hindurch in einer Familie vererbt wird, so erfordert das die Annahme, daß für diesen Teil schon im Keim ein besonderes Bestimmungsstück vorhanden ist, dessen Variieren eben jene Variation des Individuums nach sich zog. Die Milliarden von Blutzellen dürften möglicherweise von einer einzigen Determinante des Keimplasmas bestimmt werden; die Muskel-, Haut-, Drüsenund manche anderen Zellen werden vermutlich gruppenweise durch eine Determinante bestimmt.

Dadurch wird die Zahl der im Keimplasma anzunehmenden Determinanten wesentlich verkleinert. Auf der anderen Seite aber gibt es eine Anzahl von Erscheinungen, die dafür sprechen, daß vielfach für denselben Teil mehrere etwas verschiedene Determinanten vorhanden sind - wodurch die Zahl der anzunehmenden 
Determinanten wieder vergrößert wird. Hierauf ist unten, bei Betrachtung der ,Ide“, zurückzukommen.

Die Determinanten des Keimplasmas sind also lebendige Teilchen, Anlagestücke für bestimmte Teile des Organismus, die durch sie in ihrer Existenz wie in allen ihren Besonderheiten (also nicht bloß in der histologischen Zelldifferenzierung, sondern auch in ihrer Größe usw.) bestimmt werden. Die durch sie bestimmten Teile des fertigen Organismus nennt Weismann Determinaten, Vererbungsstücke. Es müssen im Keimplasma mindestens so viel Determinanten enthalten sein, als es selbständig und erblich variable Bezirke am fertigen Organismus gibt, seine sämtlichen Entwicklungsstadien mit eingeschlossen.

In der gleichen Weise wie es eben für die Keimzellen der Vielzelligen besprochen worden ist, ist auch schon bei den mit einem Kern versehenen Einzelligen die gesamte Individualität des Tieres in dieser Kernsubstanz als Anlage- oder Vererbungssubstanz enthalten. Daher leitet bei Verstümmelung von Infusorien der Kern die Wiederherstellung des verstümmelten Tieres. Der Kern der Einzelligen kann der Keimsubstanz, der Zellkörper dem Soma der Vielzelligen verglichen werden. (Von dieser Grundlage aus sind ja auch, wie im vorigen Abschnitt besprochen wurde, die Vererbungserscheinungen bei den Einzelligen in gleicher Weise zu betrachten wie die bei den Vielzelligen.)

\section{Die Ide. Wechsel der Anschauung Weismanns hinsichtlich der Natur der Chromosomen.}

Ein Begriff, der in Weismanns Theorie eine große Rolle spielt und daher wiederholt in seinen Schriften angewendet wird, ist: ,,das Id“. Die Bedeutung dieses Begriffes hat aber gewechselt; in der letzten Auflage der ,Vorträge" ist er in anderem Sinne gebraucht als früher, woraus sich eine Schwierigkeit bei dem Vergleich dieser letzten Darstellung der Theorie mit den früheren ergibt. Anfangs bedeutete ein ,Id“: den gesamten Determinantenkomplex, der die Anlagen für ein ganzes Individuum in bestimmter gesetzmäBiger Anordnung enthält. Die anfängliche Fassung der Theorie nimmt nun an, daß in jedem Keimplasma, d. h. in dem Kern einer jeden Keimzelle, eine sehr große Anzahl solcher Ide (,Vollide“) enthalten sei, die 
alle, von verschiedenen Aszendenten stammend und somit Ahnenplasmen darstellend, eine etwas verschiedene individuelle Färbung besäßen. Als diese Ide wurden die Mikrosomen angesprochen, d. h. die kleinen Körnchen, die bei den höheren Formen eine jede Kernschleife (jedes Chromosom) in linearer Aneinanderreihung zusammensetzen. Letztere, die Chromosomen, erhielten daraufhin den Namen Idanten. Das Keimplasma erschien so zusammengesetzt aus drei Stufen von Lebenseinheiten: die erste, niederste, bilden die Biophoren, die zweite die Determinanten, die dritte die Ide.

Diese Vorstellung, daß das Keimplasma einer jeden Keimzelle die Anlagenkomplexe für eine sehr große Anzahl von Individuen enthält, aus einer großen Menge von Ahnenplasmen zusammengesetzt ist, gründete sich auf die Überlegung, daß bei jeder Befruchtung zwei Keimplasmen miteinander vereinigt werden. Das wurde schon oben bei Besprechung der Befruchtung genauer auseinandergesetzt, und zugleich wurden die Konsequenzen erörtert, die sich daran knüpften. Aus der Überlegung, daß nach jener Auffassung durch die Befruchtung schon nach wenigen Generationen eine ganz ungeheure Anhäufung von Anlagekomplexen im Keimplasma entstehen müßte, ergab sich die Notwendigkeit eines Vorganges, durch den die Zahl der Anlagenkomplexe oder Ide vor der Befruchtung auf die Hälfte verkleinert, und dadurch die Keimzellen für die nachfolgende Befruchtung vorbereitet würde. Hierfür konnte aber vom Standpunkt der Weismannschen Vorstellung aus eine gewöhnliche Kernteilung nicht in Betracht kommen. Denn wenn die Ahnenplasmen oder Ide sich in den Chromosomen in linearer Anordnung (in Form der Mikrosomen) befinden, so müßte eine Längsspaltung der Chromosomen, wie sie bei jeder gewöhnlichen Zellteilung erfolgt, auch eine Halbierung eines jeden Ids bewirken, und jedes der beiden Tochterchromosomen würde je eines der zusammengehörigen Tochteride, der Zahl nach also genau so viel Ide erhalten wie das Mutterchromosomen. So ergab sich zunächst theoretisch clie Forderung, daß neben dieser Äquationsteilung noch ein anderer Teilungsmodus, eine Reduktionsteilung, vorkommt, und die zweite Reifeteilung der Keimzellen gestattete tatsächlich eine Auffassung in diesem Sinne: denn hier unterbleibt die vorherige Längsspaltung der Chromosomen, und es wird einfach die 
Zahl derselben auf zwei Zellen verteilt. Damit würde also auch die Zahl der Ide oder Ahnenplasmen halbiert werden, und erst durch die nachfolgende Befruchtung, d. h. die Vereinigung je eines in dieser Weise präparierten Eies und Spermiums würde in dem befruchteten Ei die ursprïngliche Idzahl wiederhergestellt. Die Schlüsse, die Weismann auf der Grundlage dieser Auffassung hinsichtlich der Bedeutung der Reifeteilungen und der Befruchtung zog, wurden schon besprochen.

Diese lange Zeit festgehaltene Vorstellung von der Zusammensetzung des Keimplasmas aus einer sehr großen Anzahl von Ahnenplasmen oder Volliden hat Weismann, wie ebenfalls schon berührt wurde, in der dritten Auflage seiner Vorträge (I9I3) fallen gelassen. Veranlassung dazu boten mehrere Umstände. Zunächst mag wohl auch Weismann selbst den vielfach erhobenen Einwand, daß jene Annahme dem Vorstellungsvermögen etwas zu viel zumutet, als nicht unberechtigt empfunden haben. Schon die einzelnen Kernstäbchen oder Kernschleifen sind mikroskopisch kleine Gebilde, die Mikrosomen sind noch viel kleiner. Und ein jedes von diesen sollte nun noch die vielen Tausende von Determinanten enthalten, die für einen ganzen Organismus bestimmt waren! Dabei mußte sich die einzelne Determinante allerdings völlig ins Wesenlose verflüchtigen. Aber zu dieser Erwägung kamen auch verschiedene Beobachtungstatsachen. Einmal gewisse von verschiedenen Seiten crhobene Befunde, die bei manchen Formen eine Verschiedenheit der einzelnen Chromosomen eines Kernes, nach Form und Größe, kennen lehrten, dann gewisse Versuche von Boveri, endlich, und wohl nicht zum mindesten, die Mendelschen Vererbungserscheinungen, die zwar schon in der zweiten Hälfte des vorigen Jahrhunderts erkannt worden waren, aber erst zu Beginn dieses Jahrhunderts aufs neue entdeckt wurden und die Vererbungsforschung auf eine ganz neue wissenschaftliche Grundlage stellten. Für den wichtigsten Grundgedanken seiner Theorie, die Vorstellung, daß das Keimplasma aus zahlreichen verschiedenen materiellen Teilchen - Bestimmungsstücken oder Determinanten - bestehe, durfte Veismann allerdings gerade in den Mendelschen Vererbungsregeln eine willkommene Bestätigung sehen: die Selbständigkeit, die in den Mendelschen Bastardierungsversuchen die einzelnen Merkmale der Bastardeltern zeigten, konnte wohl als Hinweis 
darauf aufgefaßt werden, daß diesen Merkmalen auch selbständige materielle Vererbungsstücke entsprechen, die zugleich die substantielle Grundlage für die auch von der modernen Vererbungslehre angenommenen ,Faktoren“ bilden, von denen die Ausbildung eines Merkmals abhängig gedacht wird; aber jene Anschauung von der Vielheit von Volliden im Keimplasma war mit den Mendelschen Vererbungserscheinungen schwer in Einklang zu bringen, und die anderen oben angeführten Gründe sprachen ebenfalls für eine andere Auffassung der Chromosomen. So bekennt sich denn Weismann in der letzten Auflage der ,Vorträge“ zu der von Boveri begründeten Anschauung von der qualitativen Ungleichwertigkeit der einzelnen, in einem Kcimzellenkern enthaltenen Chromosomen und schreibt einem jeden derselben nur die Bedeutung eines Teil- odes Partialides zu, d. h. eines Komplexes einer großen Anzahl ganz bestimmter Determinanten. Die ,Teilide“ sind qualitativ untereinander ungleich und enthalten nur die Determinanten für bestimmte Teile des Körpers. Noch ein weiteres Ergebnis der modernen Zellforschung, zu dem ebenfalls Boveri, nebst anderen Forschern (Montgomery, Sutton) gelangt war, ist von Weismann nunmehr anerkannt und verwertet worden: der tür verschiedene Formen geführte Nachweis, daß immer je zwei Chromosomen sich in ihrer Form und Größe entsprechen, was dahin gedeutet werden konnte, daß immer je zwei gleich große und gleich beschaffene Chromosomen die entsprechenden homologen Gebilde von väterlicher und mütterlicher Seite her seien ${ }^{28}$ ).

So lautet nun die neue Deutung dahin, daß, wenigstens bei den höheren Tieren und Pflanzen, die Gesamtsumme aller Chromosomen der unreifen Keimzelle nur zweimal die Anlage eines vollen Individuums ausmacht. Nur zweimal sind der Regel nach die Gesamtanlagen für den ganzen Organismus im Kern der unreifen Keimzelle enthalten, einmal vom Vater und einmal von der Mutter her; diese Gesamtanlagen sind auf die ganze Menge der Chromosomen so verteilt, daß immer je zwei Chromosomen die entsprechenden (homologe, korrespondierende) Determinantenkomplexe enthalten: je einem väterlichen Komplex entspricht ein mütterlicher. Somit wäre auch die für jedes Merkmal notwendige Determinante stets zweimal vorhanden, einmal vom Vater, einmal von der Mutter. Dies würde wenigstens als Regel bei den höheren Organismen zu 
gelten haben. Doch dürften auch bei diesen manchmal Ausnahmen vorkommen: so weisen die Erscheinungen des Polymorphismus bei den sozialen Hymenopteren darauf hin, daß hier neben den Teiliden noch Vollide in den Kernen der Geschlechtszellen vorkommen. Bei niederen Organismen liegen die Dinge wahrscheinlich vielfach anders: so scheinen bei den Radiolarien die, nach Haecker in der Zahl von Hundert bis Tausend vorhandenen Chromosomen die Bedeutung von Volliden zu besitzen, d. h. ein jedes dürfte den ganzen Determinantenkomplex enthalten, der für ein ganzes Individuum notwendig ist. Man darf annehmen, daß die Chromosomen sich in der Stammesgeschichte erst allmählich differenziert haben, aus Volliden zu Partialiden geworden sind ${ }^{29}$ ).

Bei dieser gänzlich veränderten Sachlage wäre es vielleicht das beste gewesen, den Ausdruck „I d“ ganz fallen zu lassen. Weismann hat das nicht getan; er hat den Begriff beibehalten und ihm nur eine ganz allgemeine Bedeutung gegeben: die einer selbständigen, in sich geschlossenen Determinantengruppe, mag diese die ganze Erbmasse der Art einschließen, oder nur einen Teil davon. Die uns sichtbare Form dieser Determinantengruppen sind die Chromosomen; ,,Id“ "und ,Chromosom“ sind darnach jetzt identische Begriffe. Für die höheren Organismen gilt allgemein, daß die als geschlossene Einheiten auftretenden Determinantengruppen, die Chromosomen, Partialide, also Komplexe einer beschränkten Anzahl von Anlagèn darstellen, und somit untereinander ganz ungleichwertig sind, da ein jedes nur bestimmte Determinanten enthält.

Der mancherlei Schwierigkeiten, die sich aus dieser neuen Betrachtungsweise ergeben, und der vielen Unklarheiten, die hier noch bestehen, ist sich Weismann durchaus bewußt gewesen. Es gibt zahlreiche Tatsachen, die, wenn man überhaupt Determinanten gelten läßt, zu der Annahme nötigen, daß vielfach für denselben Teil nicht nur zwei, sondern mehrfache, etwas rerschiedene Determinanten vorhanden sind. So die Erscheinungen des sogenannten Rücksclılags, das Wiederauftreten alter längst verschwundener Ahnencharaktere. Vom Standpunkt der Determinantentheorie erklärt Weismann sie ganz allgemein durch die Annahme, daß vielfach durch Generationen hindurch latente Vorfahrendeterminanten im Keimplasma mitgeführt werden, die von 
der allgemeinen Veränderung, die die Determinanten ihresgleichen im Laufe der Phylogenese erlitten, nicht betroffen wurden und gelegentlich wieder einmal zur Geltung gelangen. Unter Zugrundelegung der ursprünglichen Vorstellung, daß jedes Keimplasma sich aus einer sehr großen Menge von Volliden aufbaut, war das leicht verständlich: in jedem dieser Vollide mußten ja dieselben homologen Determinanten vertreten sein, und man konnte sie sich in jedem Id etwas verschieden denken. Für die netere Fassung der Theorie ergibt sich eine größere Schwierigkeit, da nach derselben die Gesamtsumme aller vorhandenen Determinanten nur die Anlagen für zwei Individuen bilden soll. Einen Ausweg ergibt die schon erwähnte Annahme, daß gelegentlich, bei den sozialen $\mathrm{Hy}-$ menopteren, außer Teiliden noch Vollide vorhanden sind; ein anderer liegt in der Vorstellung, daß wir uns die Determinanten für einen Teil oder ein Merkmal ,wohl meist im Plural zu denken haben“. Darnach brauchen Veränderungen, die im Laufe der Phylogenese an den Determinanten eines Merkmals erfolgen, nicht gleich alle homologen Determinanten dieses Merkmais treffen, sondern können eine mehr oder minder große Anzahl derselben unberührt lassen. Diese können durch Generationen hindurch in latentem Zustand mitgeführt werden, dann aber gelegentlich sich wieder einmal zur Geltung bringen. In weiterer Verfolgung dieses Gedankens von der Mehrheit der Determinanten auch für ein und dasselbe Merkmal hält Weismann es auch für sehr wohl möglich, daß die Zahl der Determinanten, die in zwei homologen Chromosomen für dasselbe Merkmal bestimmt sind, gelegentlich ungleich ist. In dieser Ungleichheit der Zahl könnte der Grund für die Ungleichheit ihrer Stärke liegen, und damit der Grund für die erwähnte Erscheinung: daß die von dem einen Elter stammenden Determinanten eines Merkmals die des anderen Elters unterdrücken. -

Hier bleiben noch manche Fragen ungeklärt. Mit der einfachen Annahme, da $B$ in jeder befruchteten Eizelle die Anlage für jeden Teil zweimal vertreten sei, einmal vom Vater, und einmal von der Mutter her, kommt man nicht aus. Und auch über die Verteilung der Determinanten auf die einzelnen Chromosomen ist höchstens etwas Negatives auszusagen: die Vererbungserscheinungen sprechen dafür, daß zusammengehörige Determinanten, z. B. die der Haare oder Federn, durchaus nicht immer zusammenliegen. Ist doch, 
um gewissen Schwierigkeiten zu begegnen, selbst an einen Austausch von Determinanten zwischen zwei homologen Chromosomen gedacht worden.

Die Änderung in der Auffassung von der Natur und Zusammensetzung der Chromosomen, wie sie in der 3. Auflage der Vorträge durchgeführt ist, erforderte dann auch eine andere Betrachtung der Vorgänge, die sich bei der Reifung der Geschlechtszellen abspielen. Sie kommt, wie schon im fünften Abschnitt erörtert wurde, darauf hinaus, daß durch die Reifeteilungen zunächst die Zahl der Chromosomen oder Determinantenkomplexe verdoppelt wird, und die Komplexe dann auf die vier reifen Keimzellen, die aus der einen unreifen Zelle hervorgehen, verteilt werden, und zwar in der Art, da $B$ jede der vier Zellen einen ganzen Satz von Determinantenkomplexen, wie er zur Erzeugung eines ganzen Individuums nötig ist, erhält. Wobei es dann ganz vom Zufall abhängig ist, wie sich im einzelnen väterliche und mütterliche Chromosomen mischen. Jede reife Keimzelle wird so mit allen für ein ganzes Individuum nötigen Determinanten ausgestattet, die aber zum Teil der Mutter, zum Teil dem Vater des Individuums entstammen, an dem die fragliche Keimzelle zur Reife kommt. Die theoretischen Schlußfolgerungen, die sich daran knüpfen lassen, insbesondere auch die Beziehungen zu den Erscheinungen der alternierenden oder Mí endelschen Vererbungsweise wurden schon oben besprochen. In Ergänzung des dort Gesagten mag hier nur noch besonders betont werden, daß die Bezeichnungen: ,väterliche" und ,mütterliche Chromosomen" cum grano salis zu verstehen sind, und nur bedeuten: Chromosomen, d. h. Determinantenkomplexe (Partialide) aus der väterlichen und aus der mütterlichen Aszendentenreihe. Die Determinantenkomplexe stellen ,Ahnenplasma“ dar, das letzten Endes zurückverfolgbar ist durch die Reihe der Vorfahren hindurch bis auf die ersten Anfänge bestimmender Keimplasmen ïberhaupt. Nur sind sie im Laufe dieser ungeheuer langen Zeit nicht unverändert geblieben, sondern vielfachen Veränderungen unterworfen gewesen. Auf diese wird noch besonders einzugehen sein.

Hat nun auch so die Weismannsche Theorie eine Anpassung an neu bekannt gewordene Tatsachen erfahren, so ist doch ihr wichtigster Hauptgedanke: die Lehre von der Zusammensetzung des Kcimplasmas aus materiellen Bestimmungsstücken, derselbe 
geblieben. Die Keimsubstanz verdankt ihre wunderbare Entwicklungskraft nicht bloß ihrer chemisch-physikalischen Beschaffenheit im ganzen, sondern dem Umstand, daß sie aus zahlreichen und verschiedenartigen ,Anlagen“ besteht, d. h. aus Gruppen lebendiger Einheiten, die mit allen Kräften des Lebens ausgerüstet sind. Sie ist nicht ein einfacher Organismus, sondern ein Bau von sehr verschiedenen Organismen oder Einheiten, ein Mikrokosmus. Von dieser Grundlage aus entwickelt denn auch Weismann seine Theorie der Ontogenese sowie die von der Germinalselektion, d. h. den Vorgängen, durch welche im Laufe der Stammesgeschichte erbliche Abänderungen des Keimplasmas und damit der Formen zustande gekommen sind.

\section{Die Betätigung des Keimplasmas in der Ontogenese.}

\section{Das Problem.}

Eine bestimmte Antwort auf die zweite Frage des Vererbungsproblemes: wie kommen bei der Entwicklung die Vererbungstendenzen zur Entfaltung? ergibt sich aus der Auffassung vom Wesen und Bau des Keimplasmas. Solange Weismann noch der Ansicht war, daß die Wirksamkeit des Idioplasmas, d. h. des Kernplasmas in jeder Zelle, auf seiner molekularen Struktur beruhe, und daß somit auch alle erblichen Merkmale in Besonderheiten der molekularen Struktur des Keimplasmas ihren Grund haben müßten, mußte er auch annehmen, daß während der Ontogenese schrittweise eine Umwandlung dieser Struktur im Sinne einer Vereinfachung erfolge. Nachdem aber diese Strukturhypothese durch die Determinantenhypothese ersetzt worden war, mußte auch die Auffassung vom Wesen der Ontogenese eine andere werden. Aber auch jetzt waren noch zwei Möglichkeiten gegeben: die Annahme einer gesetzmäßig fortschreitenden Zerlegung der in dem Keimplasma enthaltenen Anlagenmasse in immer kleinere Gruppen (Zerlegungstheorie), und die Annahme, daß sämtliche Anlagen zusammenbleiben in allen Zellen des Bion, da $B$ aber jede von ihnen auf einen spezifischen Reiz abgestimmt ist, der sie allein auslöst (Auslösungstheorie). Weismann entschied sich in der Hauptsache für die Zerlegungstheorie, doch mit der Einschränkung, daß für manche $Z$ wecke gewisse Mengen von Keimplasma zunächst 
unzerlegt bleiben (zur Ausstattung der Keimzellen sowie gewisser somatischer Zellen zwecks Erzeugung von Knospen oder zwecks Regeneration), sowie daß auch den auslösenden Reizen eine Bedeutung für das Aktivwerden bestimmter Determinanten in der Ontogenese zukommt.

\section{Ontogenetische Zerlegung des Keimplasmas.}

In der Hauptsache lautet darnach seine Auffassung von der Ontogenese dahin: es muß während derselben eine Zerlegung der Determinantenkomplexe (Chromosomen, Teilide) des Keimplasmas erfolgen; diese Komplexe müssen gesetzmäßig in der Weise aufgeteilt werden, daß die Tausende von Determinanten, die in ihnen vereinigt waren, sich im Laufe der Entwicklung voneinander trennen und schließlich einzeln in die Zellen gelangen, die sie zu bestimmen haben. Vorbedingung für diesen gesetzmäßigen Ablauf der Zerlegung der Chromosomen ist, daß diese selbst eine ganz bestimmte Architektur besitzen, in der den einzelnen Determinanten ganz bestimmte Stellen angewiesen sind; das Mittel, durch das die Zerlegung erreicht wird, sind die Kernteilungen, die den ontogenetischen Zellteilungen vorausgehen. Diese Kernteilungen müssen ,erbungleich" sein, d. h. die beiden Spalthälften, in die sich ein jedes Chromosom teilt, und die dann auseinander rücken, müssen, so sehr sie äußerlich auch gleich erscheinen mögen, doch innerlich ungleich, aus sehr verschiedenen Determinantengruppen zusammengesetzt sein. Es findet also eine Aufteilung der Determinanten im Laufe der Ontogenese statt; die Zahl der Determinantenarten in den Chromosomen vermindert sich mit jeder Zellteilung, so daß schließlich die Kerne hoch differenzierter Zellen nur noch eine Art von Determinanten enthalten. Wenn dabei nicht auch eine entsprechende Abnahme der Masse der Kernsubstanz erfolgt, so ist das so zu erklären, daß die Determinanten, als lebende Einheiten, die Fähigkeit besitzen, zu assimilieren und sich durch Teilung zu vermehren, so daß schließlich im Kern einer hoch differenzierten Zelle zwar lediglich Determinanten einer Art, diese aber in sehr großer Menge, vorhanden sein müssen. Den Vorgang der Entwicklung hat man sich so zu denken, daß ,, bei jedem Zellenschritt der Ontogenese" gewisse Determinanten aktiv werden und die Zelle bestimmen, in der sie sich gerade befinden, während die anderen, 
die ( - infolge ihrer besonderen Lage innerhalb des Ids! - ) noch nicht an der Reihe sind, einstweilen noch latent bleiben, während ihres ganzen Transportes von der Keimzelle bis zu ihrer Endstätte sich gegenüber den beherbergenden Zellen passiv, einflußlos verhalten und erst, wenn sie an ihrem Ziele angelangt sind, heranreifen, sich in ihre Biophoren auflösen, diese in den Zellkörper austreten lassen und so die spezifische Natur desselben bestimmen.

\section{Kampf der homologen Determinanten untereinander; Bedeutung fur die Vererbungserscheinungen: alternierende Vererbung (M endel).}

Für das Verständnis der Vererbungserscheinungen von Bedeutung ist dann besonders der Umstand, daß in dem befruchteten Ei die für den Gesamtorganismus nötigen Determinantenkomplexe zweimal - einmal vom Vater und einmal ron der Nutter her vorhanden sind. An beiden Komplexgruppen müssen sich die gleichen Vorgänge der Auseinanderlegung der Anlagen abspielen: das aus einer befruchteten Eizelle hervorgehende Individuum ist das Ergebnis der Entfaltung nicht eines einzigen Anlagenkomplexes, sondern zweier. Für jedes Organ, jede selbständig variierende Zellgruppe sind also die notwendigen Determinanten in der Zweizahl vorhanden; jede einzelne Zelle erhält zu gleichen Teilen väterliche und mütterliche Chromosomen, und in diesen auch väterliche und mütterliche homologe (korrespondierende) Determinanten oder richtiger woll: Determinantengruppen. Denn es wurde ja schon gesagt, daß die Determinanten die Fähigkeit haben, sich zu vermehren, und daß somit der Begriff ,eine" Determinante nicht immer buchstäblich zu nehmen ist, sondern oft, auch wenn es sich um die Bestimmung nur eines Merkmals handelt, eine Gruppe von Einzeldeterminanten bezeichnen wird. Ein Kampf um die Geltendmachung, wie er zwischen den Individuen in der Natur herrscht, wird sich nun auch hier, während der Ontogenese, im kleinen abspielen. Dabei kann die eine der beiden homologen Determinanten oder Determinantengruppen die andere vollständig unterdrücken und somit bei der Ausbildung der betreffenden Zelle oder Zellgruppe allein maßgebend werden, oder es kann zwischen den beiden gewissermaßen ein Kompromiß zustande kommen. Das wird abhängen von dem Stärkeverhältnis der beiden Gruppen, das wieder, 
nach der schon oben erörterten Hypothese Weismanns, auf der verschiedenen Anzahl gleicher Determinanten in ihnen beruhen dürfte. Im ersteren Fall (völlige Unterdrüickung einer Determinantengruppe durch die andere) erscheint in dem Individuum an der betreffenden Stelle nur das eine der beiden Merkmale, die der väterliche und der mütterliche Organismus darboten, im zweiten Falle (Kompromiß zwischen beiden Gruppen) kommt ein Mittelding zwischen dem väterlichen und dem mütterlichen Merkmal zustande. Da dieser Kampf der Determinanten sich aber erst in den somatischen Zellen abspielt, die von den Determinanten beherrscht werden, und nur in diesen, nicht aber auch zugleich in dem Anteil des Keimplasmas, der in den Keimzellen reserviert ist, so ist es durchaus möglich, daß ein Merkmal, das in einer Generation unterdrückt erscheint, in einer späteren wieder auftaucht: eine Determinantenart, die in einer Ontogenese der ihr entgegenstehenden unterliegt, kann in einer folgenden Generation zur Geltung gelangen, wenn sie durch die Befruchtung mit einer anders gearteten, aber schwächeren, oder gar mit einer gleich gearteten zusammenkommt.

Von diesen Überlegungen aus würden, nach der letzten Fassung der Weismannschen Theorie, viele Erscheinungen der Vererbung zu erklären sein. Zunächst insbesondere die sogenannten Rückschläge. Erste Vorbedingung für dieselben wäre, wie oben gesagt, das Vorhandensein alter Ahnendeterminanten, die von der phyletischen Umwandlung der übrigen homologen Determinanten unberührt blieben und durch die Generationen hindurch fortgeführt wurden, ohne sich gegenüber den übrigen, umgewandelten, zur Geltung bringen zu können; die Bedingung für ihr Wiederhervortreten wäre gegeben, wenn sie durch die Amphimixis mit gleichartigen, ebenfalls unverändert gebliebenen zusammengebracht würden und so das Übergewicht über die modernen, veränderten, erhielten.

Die gleiche Vorstellung von dem Kampfe der homologen Determinanten um die Geltendmachung vermittelt dann auch ein Verständnis für das verschiedene Aussehen der Bastarde bei Kreuzung verschiedener Rassen, wie es Mendel und seine Nachfolger kennen gelehrt haben. Kreuzung der ungebänderten und der gebänderten Gartenschnecke ergab, in den berühmten Versuchen von 
A. Lang, in der ersten Generation stets nur bänderlose, einfach gelbe Nachkommen; das eine Nerkmal, die Bänderung, war also hier unterdrückt oder, wie Mendel selbst es nennt, "rezessiv" das andere, die Bänderlosigkeit, war herrschend, ,dominant". Dagegen ergab die Kreuzung der tiefrosa blühenden Wunderblume (Mirabilis Jalapa) mit der weiß blühenden, nach Correns, in der ersten Generation nur hellrosa gefärbte Nachkommen, ,intermediäre" Bastarde in der Mendel-Terminologie. Diese Terminologie nennt bekanntlich das Vereinigungsprodukt zweier Keimzellen ganz allgemein eine Zygote, und spricht von Homozygoten, wenn dabei gleiche Anlagen (in bezug auf ein oder mehrere Merkmale) zusammenkommen, und von Heterozygoten bei Ungleichheit der Anlagen. Das verschiedene Anssehen der Heterozygoten, wie es sich in den beiden erwähnten Beispielen zeigt, erklärt die Weismannsche Theorie in der angedeuteten Weise durch den Kampf der homologen Determinantengruppen, der in beiden Fällen verschieden ausgeht. In dem Beispiel der Gartenschnecke siegen die Determinanten für Bänderlosigkeit über die für Bänderung, die somit nicht zur Geltung kommen; in dem Beispiel der Mirabilis dagegen würden sich die Determinanten für tiefrosa und die für weiß die Wage halten, und als Ergebnis die hellrosa Färbung der Bastarde herauskommen. DaB, wie Weismann es annimmt, diese Determinantenkämpfe sich nur in den somatischen Zellen abspielen, während in dem Keimplasma die beiderlei Gruppen friedlich nebeneinander bleiben und den Nachkommen übergeben werden, geht aus dem Verhalten der zweiten Bastardgeneration hervor, die durch Inzucht aus den Individuen der ersten erzielt wird: hier treten die Stammerkmale bei einer bestimmten Anzahl der Individuen hervor. In dem Beispiel der Gartenschnecke erscheint also wieder eine Anzahl gebänderter Exemplare: die Determinanten für „Bänderung“ waren also nur in den somatischen Zellen unterdrückt, aber nicht in den Keimzellen.

Diese Auffassung ist im allgemeinen gewiß einleuchtend; für die weitere, daß das Überwiegen einer Determinantengruppe iiber die ihr entgegenstehende homologe auf einer größeren Zahl der Einzeldeterminanten beruht, ergibt sich allerdings eine Schwierigkeit aus der Gesetz mä Bigkeit der oben erörterten Erscheinungen. Die Bastardierungsexperimente haben gelehrt, daß die zwei zu 
cinem Merkmalspaar gehörigen Merkmale, die in den BastardGenerationen wieder auseinandergehen, ,gespalten werden“, sich unter allen Umständen in gleicher Weise zueinander verhalten. Ein bestimmtes Merkmal ist gegenüber einem bestimmten anderen stets (obligatorisch) dominant oder rezessiv oder gleichwertig. Darnach könnten Zufälligkeiten, wie stärkere Vermehrung der einen Determinante, hier keine Rolle spielen.

Die frühere Auffassung Weismanns, die das Keimplasma aus einer sehr großen Anzahl von Ahnenplasmen (Volliden) zusammengesetzt sein ließ, mußte sich natürlich auch den Ablauf der Ontogenese etwas anders denken. Das neu entstehende Individuum erschien dabei als die Resultante aus dem Zusammenwirken aller dieser Ide, die das Keimplasma ausmachen, der Kampf um die Geltendmachung war nicht zwischen nur zwei Gruppen homologer Determinanten auszufechten, sondern zwischen sehr vielen. Und je nach dem Ergebnis dieses Kampfes mußte sich dann auch das individuelle Bild des neuen Individuums gestalten, bald als Mischung väterlicher, mütterlicher und der verschiedensten Ahnencharaktere, bald mehr einseitig dem einen oder dem anderen Aszendenten nachschlagend. Auch damit war ein Verständnis für die große Mannigfaltigkeit in der Mischung des kindlichen Körpers aus väterlichen und mütterlichen Vererbungsstücken, wie auch für die Rückschläge auf frühere Aszendenten gegeben; aber die Gesetzmäßigkeiten in den Vererbungserscheinungen, die die moderne Erblichkeitsforschung namentlich im Anschluß an Mendels grundlegende Versuche, kennen gelehrt hat, waren dadurch nicht zu erklären. Daher ist Weismann von jener älteren Auffassung zurückgekommen.

\section{Beeinflussung der Entwicklung durch äußere Einwirkungen.}

Der gesetzmäßige Ablauf der Ontogenese in der eben angedeuteten Weise setzt freilich eins voraus: normale Entwicklungsbedingungen. So sehr die Weismannsche Theorie den Schwerpunkt auf das Vorhandensein substantieller Anlagestücke und auf ihre ganze bestimmte Anordnung legt, so leugnet sie doch nicht den Einfluß der äußeren Einwirkungen auf den Ablauf der Entwicklung, und angesichts der Ergebnisse der experimentellen entwicklungsmechanischen Forschung hat auch Weismann das Zugeständ- 
nis gemacht, da $B$ Determinanten nicht unter allen Umständen immer nur ein und dasselbe Gebilde hervorbringen müssen, sondern als lebendige Einheiten anch die Fähigkeit haben, auf verschiedene Reize verschieden zu antworten, verschiedenen Einflüssen nachzugeben.

\section{Neben- (Reserve-, Regenerations-) Idioplasma.}

Aber auch unter normalen Bedingungen können sich die Dinge nicht immer in der geschilderten Weise abspielen; nicht jede Kernteilung in der Ontogenese kann eine Abspaltung nur bestimmter Determinantengruppen aus den verschiedenen Iden bedeuten. Innerhalb der Zellenfolge, die vom befruchteten Ei zu den Keimzellen des neuen Individuums führt, muß, der Lehre von der Keimplasmakontinuität entsprechend, ein unveränderter Teil des Keimplasmas in inaktivem, gebundenem Zustand erhalten bleiben, der den Anlagenkomplex des ganzen Individuums (- und zwar zweimal, zur Hälfte aus den väterlichen, zur Hälfte aus den mütterlichen Chromosomen stammend -) enthält. Dieser Rest gelangt in die Urkeimzellen und bildet in denselben den Bestand an Keimplasma, der bei der Vermehrung dieser Zellen sich ebenfalls durch Assimilation vermehren muß, $\mathbf{u m}$ für die Menge der Keimzellen auszureichen. Ein älınlicher Vorgang muß nach Weismanns Auffassung auch angenommen werden zur Erklärung der Knospungsund Regenerationserscheinungen. Wo, wie bei der Knospung der Pflanzen und niederer Tiere, ein neues Individuum von irgend welchen Körperzellen eines Mutterorganismus aus entsteht, da ist anzunehmen, daß diese somatischen Zellen außer den sie selbst bestimmenden Determinanten auch noch ein „Nebenidioplasma“ in gebundenem inaktivem Zustand enthalten, das unter gewissen äußeren oder inneren Einflüssen aktiv wird und die Bildung der Knospe veranlaßt. Ähnlich wie bei der Regeneration: auch in den Körperzellen, von denen aus nach einer Verletzung eine Regeneration eines ganzes Körperteiles erfolgt, müssen außer den spezifischen Determinanten auch noch größere für eben diesen ganzen Körperteil bestimmte Gruppen von Regenerations- oder Nebendeterminanten in aktivem Zustand vorhanden gewesen sein, bereit, unter gewissen Umständen aktiv zu werden und den Teil, den sie bestimmen, aufs neue hervorzubringen. Sie bilden ein Nebenidioplasma, 
das sich schon von dem Keimplasma der befruchteten Eizelle her crhält. Diese Erklärung, zu der Wcismann wohl ganz selbständig gelangt ist, und die sich ihm aus seiner Keimplasmalehre ergab, war gleichwohl nicht ganz neı: in grundsätzlich gleichem Sinne hatte schon I88I Roux die Regenerationsfähigkeit darauf zurückgeführt, daß die fraglichen Zellen ,,nicht durch und durch an ihre spezifische Funktion angepaßt sind, sondern daß jede, sei es im Kern oder im Protoplasma, noch einen Rest wirklichen embryonalen Stoffes enthält, welcher in Tätigkeit tritt, sobald und soweit er nicht mehr durch den Widerstand der physiologischen Umgebung daran verhindert wird“"30). Den fraglichen Stoff nannte Roux später Reserveidioplasma und ließ ihn im Zellkern lokalisiert sein. -

\section{Erbgleiche und erbungleiche Teilung.}

In den hier erörterten Gedankengängen spielt die wichtigste Rolle die Annahme einer erbungleichen oder differentiellen Teilung, die Weismann als Gegensatz zu der gewöhnlichen erbgleichen oder integrellen Kernteilung aufgestellt hat. Die Notwendigkeit, eine solche anzunehmen, hat Weismann schon $r 885$ in der Schrift über die Kontinuität des Keimplasma erörtert: wenn der Kern das Wesen der Zelle bestimmt, so müssen verschieden differenzierte Zellen auch spezifisch verschiedene Kerne enthalten; da es nun aber im Laufe der Entwicklung so und so oft zu beobachten ist, da $B$ aus einer Mutterzelle sehr verschiedenartige Tochtergebilde hervorgehen, so muß angenommen werden, da $B$ in solchen Fällen der Kern der Mutterzelle in zwei qualitativ ungleiche Hälften sich geteilt hat, - so völlig identisch die beiden Tochterkerne und die sie zusammensetzenden Kernschleifen auch äußerlich aussehen. Dieser äußerlichen Gleichheit wird oft genug auch eine innere Wesensgleichheit entsprechen, in vielen anderen Fällen aber wird sie eben nur eine seheinbare sein. Es ist dies gerade ein Punkt der Weismannschen Anschauungen, der besonders oft und bestimmt bestritten worden ist. Auf der Annahme einer ,erbungleichen“ Teilung beruhte auch schon die erste Auffassung Weismanns von den Richtungskörperchen, die in diesen das ,ovogene Kernplasma" sah, das sich von dem eigentlichen Keimplasma abgespalten habe. - 


\section{Allgemeine Betrachtung der Determinantentheorie.}

Weismanns Keimplasmatheorie ist eine Theorie der Vererbung und der Ontogenese.

\section{Die Determinantentheorie als Theorie der Vererbung.}

Als Vererbungstheorie schließt sie sich, mit der Annahme wirklicher materieller Teilchen als Träger der Vererbung, an Darwins Pangenesistheorie an, zu der sie aber in scharfen Gegensatz tritt bezüglich der Auffassung des Verhältnisses dieser Keimchen zu den Körperzellen. Während bei Darwin die Keimchen von den Körperzellen stammen, von diesen abgegeben werden, so daß sie vom Zustand der letzteren in ihrer Natur bestimmt werden, sind bei Weismann umgekehrt die Teilchen das Bestimmende (Determinierende); die Eigenschaften der Körperzellen aber sind das Sekundäre, Bestimmte, Abhängige.

Auf Grund der Determinantenlehre ergeben sich nun auch bestimmtere Vorstellungen in bezug auf das viel umstrittene Problem der Vererbbarkeit somatogener Veränderungen. Schon auf Grund der Prüfung des vorliegenden Beobachtungsmateriales und der Lehre von der Kontinuität des Keimplasmas war Weismann, wie ja ausführlich in Abschnitt IV besprochen wurde, zu den Schlußfolgerungen gekommen: I. da $\beta$ nur Besonderheiten, die im Keimplasma bedingt sind, „,blastogene“ Veränderungen, vererbt werden können; 2. daß somatogene Veränderungen, mögen sie durch Gebrauch und Nichtgebrauch, oder durch direkte Wirkungen äußerer Einflüsse bedingt sein, nicht auf die Nachkommen übertragbar sind, da sie nicht vermögen, das Keimplasma, ganz allgemein gesprochen, in einem entsprechenden Sinne zu beeinflussen; 3. daß direkte Mediumeinflüsse sowohl das Soma wie den Keim in gleichem Sinne zu verändern vermögen, so daß am Soma passante, und am Keim entsprechende vererbbare Veränderungen entstehen, - wodurch der Schein einer Vererbung somatogener Abänderungen zustande kommt. Durch die Annahme, daß das Keimplasma, das früher nur ganz allgemein als eine höchst komplizierte Substanz genommen wurde, aus einer sehr großen Anzahl einzelner Bestimmungsstücke besteht, gewannen alle diese Vorstellungen eine viel bestimmtere Fassung. Der Vorgang einer wirklichen Vererbung einer somatogenen 
Abänderung hätte bei dieser Struktur des Keimplasmas zur Voraussetzung, daß Veränderungen somatischer Zellen, die unter dem Einfluß des Gebrauches und Nichtgebrauches oder direkter Mediumwirkungen entstanden, von sich aus die entsprechenden noch inaktiven Determinanten des Keimplasmas derartig umzuändern vermögen, daß sie bei ihrer Aktivierung auch wieder entsprechend veränderte Determinaten bei dem Nachkommen hervorbringen. Weismann hat die Möglichkeit eines solchen Vorganges ,,somatischer Induktion" durchaus abgelehnt. Andere Forscher sind in dieser Hinsicht anderer Ansicht, ja es ist sogar gesagt worden, daß gerade die Determinantentheorie die Möglichkeit bietet, sich eine Vererbung somatischer, insbesondere funtioneller Abänderungen theoretisch vorzustellen ${ }^{31}$ ). Aber die Schwierigkeit, das muß doch immer wieder hervorgehoben werden, wie es auch von Weismann geschehen ist, liegt nicht darin, sich überhaupt eine Beeinflussung des Keimplasmas durch das Soma zu denken, sondern darin, sich die ganz bestimmte, der peripheren entsprechende Veränderung der Determinanten vorzustellen. Auch der Hinweis auf Blutgefäße, Nerven, Protoplasmabrücken als die tatsächlich vorhandenen Wege, auf denen jene Beeinflussung des Keimplasmas durch das Soma erfolgen kann, gestaltet das Problem nicht leichter. Eine besondere Erörterung der theoretischen Vorgänge, die dabei anzunehmen wären, hat, gerade unter Zugrundelegung eines Determinantenaufbaues des Keimplasmas, Roux vor einiger Zeit gegeben ${ }^{32}$ ). Dagegen ist es leichter denkbar, daß durch denselben äußeren Mediumeinfluß eine gleichsinnige Veränderung sowohl der Determinanten erfolgt, die bereits in den Körperzellen aktiv sind, wie derer, die noch im Keimplasma in inaktivem Zustand verharren. Die Denkbarkeit einer gleichsinnigen Veränderung des Soma und des Keimes durch denselben Einfluß, wie sie Weismann auf Grund seiner Schmetterlingsversuche gefolgert hatte - des Vorganges der „Parallelinduktion“ des Soma und des Keimes - wurde jedenfalls durch die Determinantentheorie nicht beeinträchtigt, im Gegenteil, eher vergrößert. Daß Weismann in der Folge dazu gelangte, sich diese Veränderung der Determinanten nicht als direkte Wirkung der äußeren Einflüsse, sondern als auf dem Umweg über eine Veränderung der Ernährungsbedingungen der Determi- 
nanten zu denken, ist später bei der Lehre von der Germinalselektion genauer zu behandeln.

Überhaupt schloß sich ja an die Determinantenlelıre auch gleich die neue Frage an, auf welchem Wege eine Veränderung der Determinanten überhaupt zustande kommen kann, und unter welchen Einflüssen dies am häufigsten erfolgt: die ganze Frage nach der Herkunft und Entstehung erblicher Abänderungen der Keimsubstanz verlangte vom Standpunkt der Determinantentheorie eine besondere Erwägung. Sie folgte in der im Jahre I895 zuerst entwickelten Theorie der Germinalselektion, mit der die Determinantentheorie erst ihren vollen Abschluß erhielt.

Hinsichtlich der allgemeinen Auffassung der Vererbungserscheinungen kam Weismann durch die Annahme von Determinanten von der ursprünglichen mehr physiologischen Betrachtungsweise zu einer immer mehr morphologischen Behandlung des Problemes, zu der sich die neueste Vererbungsforschung in einen Gegensatz stellt, indem sie, von einer ähnlichen Grundlage wie seinerzeit auch Weismann ausgehend, die morphologischen Merkmale der Organismen als Reaktionen der im Keimplasma gegebenen inneren Konstitution auf die verschiedentlich wechselnden Faktoren des äußeren Milieus, der Lebenslage, auffaßt, von dieser Grundlage aus aber mehr in physiologischer Richtung weiterschreitet und das Vererbungsproblem ,,chemisch-physikalisch-physiologisch“" (Johannsen) behandelt. Indessen scheidet auch bei Weismann die physiologische Betrachtungsweise nicht ganz aus, denn auch seine Determinanten sind nicht schlechtweg Träger der Merkmale und nicht bloße chemische Molekülgruppen, sondern vielmehr lebende Wesen, deren Mitwirkung beim Zustandekommen eines bestimmten Teiles des Organismus nicht entbehrlich ist, und die auch in Wechselwirkung mit den äußeren Entwicklungsbedingungen arbeiten und sich sogar einer abnormen Gestaltung derselben in ihrer Reaktionsart anzupassen vermögen. So ist es wohl nicht berechtigt, Weismanns Behandlung des Vererbungsproblemes als ,ultramorphologisch" zu bezeichnen, wie es gesehehen ist.

\section{Die Determinantentheorie als Theorie der Entwicklung.}

Als Theorie der Entwicklung betrachtet, steht Weismanns Determinantenlehre auf dem Boden der Präformations- oder Evo- 
lutionslehre. Sie ist eine rein evolutionistische Theorie. Freilich sieht sie, genau betrachtet, denn doch recht anders aus als die alte Präformationslehre, die in I7. und I8. Jahrhundert herrschte und sich vor allem an die Namen Malpighi, Swammerdam, Leeuwenhoek im I7., A. v. Haller und Ch. Bonnet im I8. Jahrhundert knüpft. Denn die genannten Forscher nahmen an, daß eine der Keimzellen - nach den einen das Ei, nach den anderen der Samenfaden - bereits den ganzen fertigen Organismus, nur in minimalster Ausführung, als Miniaturmodell, enthielte - wollten doch phantasiebegabte Mikroskopiker im menschlichen Samenfaden den ganzen kleinen Menschen erkannt haben -, und für sie bestand somit die ,Entwicklung“ in der Hauptsache auf einem Wachstum, der bloßen Vergrößerung der bereits gegebenen Teile. Ganz anders Weismann. Nur in dem Grundgedanken, daß im Keim der ganze Embryo präformiert, und zwar substantiell präformiert ist, schließt er sich an jene Vorstellungen an, aber der Keim ist ihm nicht etwa lediglich ein minimales Modell des fertigen Organismus, und die Substanzteile, aus denen er besteht, sind den fertigen Teilen des späteren Organismus nicht im geringsten ähnlich, sie sind auch nicht so zu verstehen, daß aus ihnen etwa durch rein formale Umbildung die definitiven Teile hervorgehen, sondern sie sind „Determinanten“, Bestimmungsstücke, arbeitende Lebensteilchen, die in der Ontogenese innerhalb der Zellkerne durch zahllose Zellgenerationen hindurchgeführt werden, um dann erst, am richtigen Orte angelangt — die einen früher, die anderen später zur Reife zu gelangen und, von den Kernen aus, den Zellen, in denen sie eingeschlossen sind, einen bestimmten Charakter aufzudrücken. So kann, wenn man die Weismannsche Keimplasmatheorie als Präformationstheorie bezeichnet, dies nur dahin verstanden werden, daß auch nach Weismann schon die befruchtete Eizelle ein substantiell außerordentlich zusammengesetztes Gebilde ist, ein Mikrokosmus, bestehend aus einer Unmenge kleinster körperlicher Teilchen, die unter sich durchaus verschieden sind und befähigt, alle die mannigfaltigen Teile des späteren Geschöpfes unter Verwendung der Zellkörper entstehen zu lassen. Roux, der den Unterschied der modernen Entwicklungstheorien gegenüber den älteren zuerst scharf analysiert und in erklärenden Begriffen ausgedrückt hat, bezeichnet Weismanns Theorie als eine neo- 
evolutionistische, womit gesagt ist, daß die ganze Menge der später bei der Entwicklung sichtbar werdenden verschiedenen Teile schon im Keim vorhanden war, aber unsichtbar und in ganz anderer Form, so daß zwar bei der Ontogenese nicht ganz neue Teile gebildet werden, wohl aber die von vornherein vorhandenen eine Umbildung erfahren und nummehr in neuer Form sichtbar werden. Weismanns Keimplasmatheoric ist eine streng neoevolutionistische Theorie ${ }^{33}$ ).

Das war sic nicht von vornherein. Auch Weismanns Gedankengänge bewegten sich anfangs in Vorstellungen, wie sie von Caspar Friedrich Wolff zuerst schon I753 vertreten, freilich erst sehr viel später zu allgemeiner Anerkennung gelangt waren. Der alten grobsinnlichen und doch, an den zu beobachtenden Tatsachen gemessen, rein phantastischen Evolutionslehre konnte Wolff die Lehre von der Epige nese entgegenstellen, die in gewissenhaftem Anschluß an die tatsächlich zu beobachtenden Entwicklungsvorgänge das Ei als ein außerordentlich einfaches Gebilde auffaßte, aus dem erst auf dem lange Wege zahlreicher Um- und Neubildungen der verwickelte Bau des fertigen Geschöpfes hergestellt wird. War mit dieser Hervorhebung des tatsächlich Wahrnehmbaren das unveräußerliche Recht der Beobachtung auf Anerkennung zur Geltung gekommen, so war doch andcrerseits außer acht gelassen - und mußte von Wolff, bei dem damaligen Stande der Dinge auch außer acht gelassen werden - daß das, was unseren Hilfsmitteln einfach erscheint, innerlich doch eine uns unerkennbare Komplikation besitzen kann. Die fortschreitende Forschung mußte dann auch notwendig zu der Erkenntnis kommen, daß es unmöglich ist, eine tatsächlich ,einfache“ Substanz als Ausgang für die Entwicklung irgend eines Lebewesens anzunehmen. Enthält auch die befruchtete Eizelle noch nicht das fertige in minimalsten Maßen ausgeführte Modell des späteren Geschöpfes, so muß sie doch die Anlage zu demselben enthalten und damit die Art des Endproduktes bestimmen, ,determinieren“. Aus dem Hühnerei kann schlechterdings nur ein Huhn, aber kein anderes Tier werden. So ist die Epigenese im alten Wolffschen Sinne ganz ebenso abzulehnen wie die Evolution im alten Sinne. Die ,Epigenesis“ im Sinne Wolffs ist nur ein Ausdruck des Beobachteten, sie bezeichnet, wie Roux es ausdrückt, bloß das von Wolff erwiesene Geschehen, 
„, die sichtbare formale Produktion von Mannigfaltigkeit von sichtbar einfachem Ausgange aus". Aber es war eine andere, an die alte epigenetische Vorstellung anschließende Auffassung von den Entwicklungsvorgängen denkbar, und Weismann hat sich lange bemüht, eine Keimplasmatheorie in diesem Sinne auszudenken. Sie ging aus von der Überzeugung, daß in der befruchteten Eizelle der ganze gesetzmäßige Ablauf der Entwicklung und damit das Endprodukt derselben präformiert sein muß, suchte aber diese Präformation nicht in der Zusammensetzung des Keimplasmas aus unzähligen substantiell verschiedenen und potentiell verschiedenwertigen Teilchen, sondern in seiner besonderen Konstruktion unter Verwendung nur weniger verschiedenartiger Stoffe; sie faßte das Keimplasma also mehr auf als eine kunstvoll gebaute Maschine, einen Präzisionsapparat, bei dem es weniger auf den verwendeten Stoff, als auf die Konstruktion, die Zusammenfügung der Teile ankommt. In diesem Sinne ist noch die ,Kontinuität dis Keimplasmas" geschrieben, in der Weismann versucht, die Entwicklung der Anlagen nicht aus vorgebildeten Keimchen, sondern aus dem molekularen Bau des Keimplasmas herzuleiten. Hier heißt es noch (S. 37I), daß nicht nur die sämtlichen quantitativen und qualitativen Charaktere der Art, sondern auch alle individuellen Variationen, soweit dieselben erblich sind, in der winzigen Quantität von Keimplasma, welches der Kern einer Keimzelle birgt, enthalten sein müssen, ,nicht als vorgebildete Anlagen (Keimchen der Pangenesis) wohl aber als Abweichungen in der Molekularstruktur". Diese Molekulatstruktur tritt bei der Ontogenese in Aktivität und bildet mit Hilfe der plasmatischen Zellbestandteile alle die verschiedenen mannigfaltigen Teile des newen Geschöpfes, sie schafft also tatsächlich neues, vorher nicht dagewesenes. Im Sinne der Rouxschen Terminologie war diese ältere Weismannsche Vorstellung eine Theorie der Neoepigenesis, womit gesagt ist, „daß von wirklich, nicht bloß von sichtbar Einfacherem aus die ganze Mannigfaltigkeit der Formen, Strukturen und chemischen Qualitäten des entwickelten Lebewesens hervorgebracht werde".

Weitere Beschäftigung mit dem Problem führte Weismann indessen zu dem Schlusse, daß es doch nötig sci, auf die Da rwinsche Annahme kleinster Teilchen im Keime zurückzukommen, trotz des Mißverhältnisses zwischen der überaus großen Zahl solcher Teilchen, 
die anzunchmen war, und der geringen Menge von Keimplasma, in dem sie enthalten scin mußten. Was ihn von jenen früheren Versuchen wieder abgebracht, und in der Richtung der Darwinschen Keimchenlehre zu der Determinantentheorie geführt hat, waren die Erscheinungen des Auftretens erblicher Varietäten. Wenn in menschlichen Familien durch Generationen hindurch gewisse körperliche Besonderheiten, - eine eigentümlich gefärbte Haarlocke an bestimmter Stelle, ein Grübchen an einer bestimmten Stelle des Körpers oder dergleichen - vorkommen, so weist das mit Bestimmtheit auf eine Besonderheit des Kieimes hin, die eben zu jener Körperstelle in fester Beziehung steht, ihre Ausbildung beherrscht. Es muß irgend ein materielles Substrat in dem Keimplasma vorhanden sein, das mit diesem vererbbar ist, und dessen von der Norm abweichende Beschaffenheit sich in einer Abnormität des Endproduktes äußert. Diese materiellen Teilchen sind eben We is manns Determinanten. In den Erscheinungen der alternierenden Vererbung, die Mendel kennen gelehrt hat, erfuhr ihre Annahme eine neue Stütze. So sind sie denn auch unter diesem oder jenem Namen in andere Vererbungs- und Entwicklungstheorien übernommen worden.

\section{Hypothetischer Charakter der Theorie.}

An scharfer Gegnerschaft hat es der Determinantentheorie nicht gefehlt. Dieselbe richtet sich gegen die Grundvorstellung, daß die winzige Menge von Keimplasma eine so unfaßbar große Menge von Einzelanlagen in sich enthalten soll, wie auch gegen ihre Durchführung im einzelnen, ja gegen das ganze Unterfangen, sich von der Architektur des Keimplasmas überhaupt eine Vorstellung machen zu wollen. Gewiß ist der Einwand nicht unberechtigt, daß jeder Versuch dieser Art sich von dem Boden der Tatsachen fort und durchaus in das Gebiet der Spekulation begibt, - wenigstens im Augenblick noch, bei unseren jetzigen Kenntnissen. Aber auch Weismann ist sich dessen bewußt gewesen, da $B$ seine Theorie nur einen Versuch bedeutete, rein theoretisch eine Möglichkeit zu erörtern, wie man sich überhaupt die Dinge zurechtlegen könne. Das Bedürfnis nach einer geschlossenen Vorstellung in dieser Hinsicht entsprach seiner Natur, seinem künstlerischen Bedürfnis nach greifbaren anschaulichen Vorstellungen. Daß er im Gegensatz zu 
dem vorsichtigen Darwin, der seine Pangenesistheorie nur eine ,provisorische Hypothese" nannte, oft allzu dogmatisch auftritt, mag dabei zugegeben werden. Seine Lebensarbeit hat die Wissenschaft so vielfach bereichert und ihr — auch durch die Keimplasmatheorie - so mannigfache Anregungen gegeben und zur Klärung der Anschauungen beigetragen, daß man es ihm zugute halten kann, wenn der scharfsinnige und kühl abwägende Denker in ihm den temperamentvollen, lebhaft empfindenden Menschen einmal zu sehr zu Worte kommen läßt. Darin aber, daß die Grundlagen der Theorie sich auch gegenüber den Erscheinungen der alternierenden (Mendelschen) Vererbung als leistungsfähig erwiesen, ja durch diese geradezu gestützt wurden, liegt doch auch ein Beweis für ihren Vert. 


\section{Siebenter Abschnitt.}

\section{Personalselektion: natürliche und geschlechtliche Zuchtwahl.}

Natürliche und geschlechtliche Zuchtwahl, die zwei Formen der Personalselektion. I. Artenzüchtung (Naturzüchtung). Wesen und Begründung der Zuchtwahllehre. - Notwendigkeit ihrer Prüfung. - Übersicht über Weismanns Stellungnahme zu Darwins Zuchtwahllehre. - Prüfung der Zuchtwahllehre im einzelnen. I. Aufgabe 2. Möglichkeit und Wahrscheinlichkeit der Naturzïchtungsvorgänge. a) Einfluß der Isolierung auf die Artbildung. b) Selektionswert der Anfangs- und Steigerungsstufen der Abänderungen. Abänderung in kleinen Schritten. Variationen „unter der Grenze von Gut und Schlecht". c) Freiwillig gewählte Änderungen in den Lebensbedingungen. Divergente Entwicklung auf demselben Gebiete. d) Die natürlichen Beschränkungen in der Wirksamkeit der Naturzüchtungsvorgänge. Beschränkungen, die aus dem Wesen der Naturzüchtung selbst folgern: Naturzüchtung arbeitet mit gegebenen Abänderungen, arbeitet langsam, schafft nur relativ Vollkommenes. - Beschränkungen der Naturzüchtung, die in den Organismen liegen. - Beschränkungen der Naturzüchtung, die in den Verhältnissen der Umwelt liegen. - 3. Leistungsfähigkeit der Selektionstheorie für die Erklärung der phyletischen Entwicklung der Organismen. a) Fragestellung. b) Zuchtwahl oder inneres Vervollkommnungsprinzip? Nägelis Theorie der direkten Bewirkung. Die Organismen als Anpassungskomplexe. Regeneration als Anpassungserscheinung. Die Schicksale der Arten als Anpassungserscheinungen. Mutationstheorie. c) Zuchtwahl oder direkte Bewirkung durch äußere Einflüsse und Funktion? $\alpha$ ) Direkt umwandelnder Einfluß der äußeren Bedingungen. $\beta$ ) Direkte Anpassung durch Gebrauch und Nichtgebrauch. - Phyletische Vervollkommnung eines Teiles durch Personalselektion. Phyletische Verkümmerung nutzloser Teile als Folge von Personalselektion; Panmixie. - Beweise gegen den Lamarckismus (phyletische Vervollkommnung und Verkümmerung von Teilen bei sterilen Formen, phyletische Anpassungen apraktischer Merkmale, einmal ausgeübte Instinkte). - Funktionelle Anpassung (Roux). Partialauslese. - 4. Ergebnis der Prüfung der Zuchtwahllehre: Neo-Darwinismus. - II. Sexuelle Züchtung (geschlechtliche Zuchtwahl). - III. Ergänzungsbedürftigkeit der DarwinWallaceschen Zuchtwabllehre. 


\section{Natürliche und geschlechtliche Zuchtwahl, die zwei Formen der Personalselektion.}

Das Neue, was der Darwinismus gebracht, zugleich das, was ihm seinen ungeheueren Erfolg verschafft und der Abstammungslehre zu ihrem Siegeslaufe verholfen hatte, war die Lehre von der Naturzüchtung oder natürlichen Zuchtwahl. Mit ihr war durch Darwin und seinen großen Landsmann Wallace das Selektionsprinzip in die Naturbetrachtung eingeführt worden, das Selektionsprinzip, das dann ganz besonders von Weismann und Roux in seiner Leistungsfähigkeit verfolgt und von dem engeren Gebiet, für das es aufgestellt worden war, dem der Personen, auf alle Lebenseinheiten, die größten wie die kleinsten, übertragen worden ist. Neben die ,natürliche“ Zuchtwahl oder ,Artenzüchtung", wie Weismann zu sagen vorschlägt, hat dann Darwin noch die ,geschlechtliche" Zuchtwahl gestellt; auch sie betrifft die Individuen, die Personen. Artenzüchtung und sexuelle Züchtung sind somit zwei besondere Formen der Personalselektion. Beide Formen verlangen eine besondere Betrachtung.

\section{Artenzüchtung (natürliche Zuchtwahl, Naturzüchtung).}

Wesen und Begrundung der Zuchtwahllehre.

Notwendigkeit ihrer Prufung.

Die Artenzüchtung (natürliche Zuchtwahl, Naturzüchtung kurzweg) arbeitet, wie früher gewöhnlich gesagt zu werden pflegte, und wie es auch Weismann meist ausdrückt, mit drei Erscheinungen: dem Auftreten individueller Varietäten, der Erblichkeit derselben und der Auslese der passendsten von ihnen durch den Kampf ums Dasein. Besser ist es wohl, nur von zwei Faktoren zu sprechen: dem Auftreten erblicher Varietäten und der Auslese. Es wird damit von vornherein dem Umstancl Rechnung getragen, daß es auch nichterbliche Varietäten gibt (siehe Abschnitt VIII). Durch das Zusammenwirken der genannten Formen soll im Laufe der Generationen eine Umänderung der Formen erfolgen, die verbunden ist mit einer Anpassung an dic Lebensbedingungen, also nicht eine Umänderung schlechtweg, sondern eine solche, die, um mit Roux zu reden, die Dauerfähigkeit 
der Organismen erhöht. Die Lebensbedingungen selbst sind es, die die Auslese treffen, und die die zunächst nur kleinen günstigen oder wie Roux sagt, dauerfähigen, ,,in den äußeren Verhältnissen sich bewährenden" Varietäten sich häufen lassen. Die Anpassung auf diesem Wege betrifft die Art und erfolgt im Laufe vieler Generationen, im Gegensatz zu der direkten Anpassung, wie Lamarck und Geoffroy-St.-Hilaire sie lehrten: der zweckmäßigen Veränderung der Individuen durch die Funktion und durch direkte Einwirkung der äuBeren Bedingungen, unter erblicher Übertragung der so bedingten Veränderungen auf die Nachkommen. Nach der Zuchtwahllehre hat also die Umbildung der Formen in engster Fühlung mit den Lebensbedingungen, in inniger fortgesetzter Wechselwirkung mit derselben stattgefunden, aber auf dem Umwege der Konkurrenz und des „Überlebens des Passendsten". Sie setzt von vornherein überall Anpassungen, überall Nützliches voraus und gibt eine Erklärung für diese $Z$ weckmäßigkeiten der Organismen, ohne die außernatürlich wirkende Kraft eines Schöpfers oder irgend ein in den Organismen selbst wirksames teleologisches Prinzip annehmen zu müssen.

Was Darwin seinerzeit zur Aufstellung der Lehre von der natürlichen Züchtung veranlaßt hat, waren, wie bekannt, wesentlich zwei Dinge: einmal die Tatsache, daß bei allen Arten fortwährend sehr viel mehr Individuen geboren werden, als am Leben bleiben und zur Nachzucht kommen, und zweitens die Erfolge der künstlichen Tier- und Pflanzenzucht. Diese beiden Haupttatsachen boten wohl genügende Berechtigung, um den Gedanken von der natürlichen Züchtung zu erwägen und von ihm aus eine Theorie von der stammesgeschichtlichen Entwicklung der Organismen zu versuchen. Daß diese Theorie auf Grund allgemeiner und bekannter Tatsachen logisch richtig entwickelt war, ist wohl kaum angezweifelt worden, aber doch konnten ihr manche Einwände gemacht werden, und unter ihnen der wichtigste: daß sich nämlich die Hauptvoraussetzung, von der sie ausgeht, nicht beweisen lasse. Man konnte, so drückt es Weismann (Igoga) aus, in keinem Falle der unzähligen Anpassungen, die wir an den Organismen beobachten, nachweisen, daß schon ihre ersten und kleinsten Anfänge von Vorteil für ihren Träger waren, von solchem Vorteil nämlich, wie wir ihn mit dem Wort ,selektionswertig“ be- 
zcichnen, daß sie somit Vorteile darstellten, deren Besitz oder Nichtbesitz unter Umständen über Leben und Tod ihres Trägers entscheiden, jedenfalls sein Überleben in Nachkommen vereiteln können. Die höchste Prüfungsinstanz naturwissenschaftlicher Theorien, die Beobachtung, versagte gegenüber dem wichtigsten Faktor, mit dem die Zuchtwahllehre operiert, der Auslese im Kampfe ums Dasein. Diese, das „Überleben des Passendsten“, wie Darwin es, nicht gerade glücklich, nennt, ist unmittelbarer Beobachtung nicht zugänglich, und so konnte die Richtigkeit der Selektionstheorie nicht unmittelbar bewiesen, sondern nur immer wieder auf dem Wege logischen Denkens und an den Tatsachen auf ihre Wahrscheinlichkeit und auf die Grenzen ihrer Leistungsfähigkeit geprüft werden. Das hat keiner der nächsten Nachfolger Darwins so eingehend getan wie Weismann. Nicht blinder vorgefaßter Glaube an ein Dogma, sondern Fragen und Zweifel bilden den Ausgang für seine Betrachtungen. „Niemand wird glauben“ — so heißt es in dem Vorwort zu der Abhandlung über den Einfluß der räumlichen Isolierung auf die Artbildung (I872) — , daB mit der Darwin-Wallaceschen Lehre von der natürlichen Züchtung die Forschung in dieser Richtung abgeschlossen sei, ich meine im Gegenteil, daß sie damit erst begonnen hat. So unzweifelhaft richtig mir auch das Prinzip scheint, welches durch diese Lehre zur Geltung gebracht wird, so sind wir doch noch sehr weit davon entfernt, die Grenze auch nur einigermaßen bestimmt ziehen zu können, bis $\mathrm{zu}$ welcher es wirkt. Daß aber eine solche Grenze besteht, daß nicht alle Charaktere organischer Wesen ihre Erklärung in diesem Prinzip finden, daß somit natürliche Züchtung nicht der einzige Faktor der Artbildung, das scheint mir ebenso unzweifelhaft als daß natürliche Züchtung einer und zwar einer der wichtigsten dieser Faktoren ist, und dies ist ja auch von Darwin selbst anerkannt worden. Ganz abgesehen von den Momenten, welche in der physischen Konstitution der Organismen selbst liegen und welche die dunkelsten von allen sind, können die äußeren Lebensbedingungen noch in mancherlei anderer Richtung und Weise auf den ProzeB der Artentwicklung einwirken, als durch jenes Überleben des Passendsten, welches Darwin mit dem Namen der natürlichen Züchtung belegt hat." Und in der Untersuchung über die Zeichnungen der Sphingidenraupen ist mit aller Bestimmtheit aus- 
gesprochen, daß der Verfasser nicht zu denjenigen gezählt werden will, ,welche sich von vornherein zur Allmacht der Naturzüchtung bekennen, wie zu einem Glaubensartikel oder einem wissenschaftlichen Axiom". Der Begriff der ,Allmacht der Naturzüchtung“" erscheint hier wohl zum ersten Male in Weismanns Schriften; der Zusammenhang, in dem es geschieht, verdient alle Beachtung.

\section{Ưbersicht uber Weismanns Stellung zu Darwins Zuchtwahllehre.}

Eine vorläufige Ükersicht über Weismanns Stellungnahme zu Darwins Zuchtwahllehre läßt drei Perioden unterscheiden.

Als den im Anfange der Dreißiger Stehenden die Rücksicht auf seine Augen auf eine mehr theoretische Gedankenarbeit verwies, und sich ihm für eine solche die Darwinsche Theorie als dankbares Gebiet darbot, da konnte er gar nicht anders, als sich auf den Darwinschen Standpunkt stellen, d. h. neben der Selektion noch den Lamarckismus gelten lassen. Diese Voraussetzung beherrscht somit die erste Periode, von ihr ging Weismanns kritische Prüfung der Zuchtwahllehre aus. Ihre erste Frucht war die Abhandlung über den Einfluß der Isolierung auf die Artbildung, die 1872 erschien. Ihr folgten, von der gleichen Absicht eingegeben, die schon besprochenen Studien über Deszendenztheorie, insbesondere die Versuche über den Einfluß der Temperatur auf die Schmetterlingspuppen, sowie die Untersuchungen über die Zeichnungen der Sphingidenraupen, die zu dem überraschenden Ergebnis führten, daß diese Zeichnungen recht wohl als zweckmäßige Anpassungen aufgefaßt und durch Naturzüchtung erklärt werden können. Eine neue Unterstuitzung erhielt dieses Ergebnis durch die Arbeiten ïber die Generationszyklen der Daphnoiden, deren Besonderheiten sich ebenfalls in überraschender Weise als Anpassungen an die Lebensbedingungen verstehen und damit auf Zuchtwahlprozesse zurückführen ließen. Angesichts dieser Ergebnisse mußten wohl die Zweifel an der Leistungsfähigkeit des Zuchtwahlprinzips immer mehr verstummen, und es konnte sich die Frage aufdrängen, ob es überhaupt nötig und berechtigt sei, neben demselben noch das der direkten Anpassung gelten zu lassen. Die Beantwortung der Frage ergab sich aus den Schlußfolgerungen, zu denen Weismann inbetreff der ,,Vererbung erworbener Eigenschaften“ gelangte. Mit 
der Ablehnung der Vorstellung, daß funktionelle Abänderungen, die Wirkungen des Gebrauches und des Nichtgebrauches, vererbt werden können, fiel auch die Annahme, daß die im Einzelleben erworbenen funktionellen Anpassungen irgend welche Bedeutung für die phyletische Umbildung der Formen gehabt haben. So gelangte Weismann dazu, in der Bewertung der Naturzüchtungslehre als Erklärungsprinzip noch über Darwin hinauszugehen, indem er ihr auch Erscheinungen unterordnete, für deren Erklärung dieser noch das Lamarcksche Prinzip der Vererbung funktioneller Abänderungen hatte gelten lassen. Das gänzliche Fallenlassen dieses Prinzipes kennzeichnet die von Weismann seitdem vertretene Richtung, den Neo-Darwinismus, wie man sie genannt hat; es ist auch das, was ihm ganz besonders als einseitige Übertreibung angerechnet worden ist.

Diese entschiedene Absage an den Lamarckismus im engeren Sinne - die Bedeutung direkter Mediumwirkungen hat Weismann, wenn auch in engen Grenzen, stets zugegeben - erfolgte mit der Rede über die Vererbung im Jahre I883; sie schließt die erste Periode $a b$ und eröffnet eine zweite, die die nächsten I2 Jahre umfaßt und unter dem Zeichen des begeistertsten rückhaltlosen Eintretens für die Darwin-Wallacesche Lehre steht. "Ich halte", so lautet nunmehr Weismanns Bekenntnis im Jahre I893, ,die Entdeckung der Naturzüchtung für eine der fundamentalsten, die auf dem Gebiete des Lebens jemals gemacht worden ist, eine Entdeckung, die allein genügt, den Namen Charles Darwin und Alfred Wallace die Unsterblichkeit zu sichern, und wenn meine Gegner mich als ,Ultra-Darwinisten' hinstellen, der das Prinzip des großen Forschers ins Einseitige übertreibt, so macht das vielleicht auf manche ängstliche Gemüter Eindruck, welche das ,juste-milieu' überall schon im voraus für das Richtige halten, allein mir scheint, daß man niemals schon a priori sagen kann, wie weit ein Erklärungsprinzip reicht, es muß erst versucht werden, und diesen Versuch gemacht zu haben, das ist mein Verbrechen oder mein Verdienst" (I893, S. 63). Indessen, auch in dieser Periode, in der sogar das Wort von der ,Allmacht der Naturzüchtung" als Titel einer besonderen Streitschrift erscheint - das Wort, das später so oft und gern gegen seinen Urheber ausgespielt worden ist - , hat Weismann mit der ruhigen 
sachlichen Prüfung der Naturzüchtungslehre nicht aufgehört. Das Ergebnis war denn auch die Erkenntnis der mancherlei Beschränkungen, dessen die Zuchtwahl als umbildender Faktor unterworfen ist, eine Erkenntnis, dic schließlich in der Anerkennung einer selbständigen, den Organismen innewohnenden Umbildungskraft ihren Ausdruck findet. In der dritten Periode, die die letzten 20 Jahre, von I895 an, umfaßt, steht somit in Weismanns theoretischen Vorstellungen neben dem Prinzip der natürlichen Zuchtwahl der Personen ein anderes: das Prinzip der Germinalselektion, durch das zwar dem Selektionsprinzip an sich ein größerer Geltungsbereich zugesprochen wird, die DarwinWallacesche Zuchtwahllehre aber eine sehr erhebliche Einschränkung erfährt. -

\section{Prufung der Zuchtwahl im einzelnen.}

Im nachfolgenden soll nun versucht werden, Weismanns Stellung zu den Fragen der Zuchtwahllehre im einzelnen etwas genauer klarzulegen.

\section{A ufgabe.}

Wenn von „Zuchtwahl“", „Naturzüchtung“, „Selektion“ und dergleichen schlechtweg gesprochen wird, so geschieht das, wie schon manchmal gerügt worden ist, bald in dem einen, bald in dem anderen Sinne: entweder werden darunter die natürlichen, von der Theorie vorausgesetzten Vorgänge verstanden, oder aber die Theorie als solche ${ }^{34}$ ). Beides ist auseinanderzuhalten, nach beiden Richtungen hin hat sich eine Prüfung zu erstrecken, und nach beiden Richtungen hat denn Weismann auch tatsächlich eine solche vorgenommen. Es galt also: einmal die als „Naturzüchtung“ zusammengefaßten angenommenen Vorgänge selbst auf ihre Möglichkeit und Wahrscheinlichkeit nach allen Richtungen, zugleich unter Berücksichtigung der verschiedentlich gemachten Einwände, zu durchdenken und im AnschluB daran zu erörtern, was denn füglich von ihnen erwartet werden dürfe, und worin ihre natürlichen Hemmnisse liegen; zweitens aber: die Frage nach der Leistungsfähigkeit der auf jenen Vorgängen aufgebauten Zuchtwahllehre als Erklärungsprinzip zu prüfen, der Frage also, wie weit die gegebenen Erscheinungen der Lebewesen, ihr Bau, ihre Lebens- 
erscheinungen und ihre Geschichte, durch die Zuchtwahllehre erklärbar sind, ob nicht andere Erklärungsprinzipien an ihre Stelle gesetzt oder neben ihr als wirksam anerkannt werden müssen.

2. Möglichkeit und Wahrscheinlichkeit der Natur$z$ üc ht ungsvorgänge.

\section{a) Einfluß der Isolierung auf die Artbildung.}

Einen wichtigen Beitrag in der ersten der beiden genannten Richtungen, zur Prüfung der Richtigkeit der Darwinschen Gedankengänge, gibt gleich die erste, I872 erschienene theoretische Schrift, über den Einfluß der Isolierung auf die Artbildung; sie hat für die Klärung einer wichtigen, mit der Lehre von der Artumbildung in Verbindung stehenden Frage grundlegende Bedeutung gehabt. Es handelt sich in ihr, wie der Titel sagt, um den Einfluß, den die räumlich geographische Isolierung bei der Entstehung einer neuen Art, auf Grund individueller Varietäten einer bereits vorhandenen, besitzt. Diese letzteren werden als gegeben vorausgesetzt. Moritz Wagner war durch vieljährige, auf Reisen gewonnene Beobachtungen über die geographischen Besonderheiten der Tierformen zu der Auffassung gelangt, daß räumliche Isolierung einen unerläßlichen Faktor bei der Artbildung darstellt, nicht nur, weil durch Versetzung in ein anderes Gebiet neue Lebensbedingungen gegeben werden, durch die die individuelle Veränderlichkeit der Organismen eine gesteigerte Anregung erhalten müsse, sondern vor allem, weil durch sie eine Rückkreuzung der abgeänderten Individuen mit der Stammform verhindert werde. Ohne eine solche Verhinderung aber sei eine Fixation und Steigerung der Abänderungen, kurzum die Bildung einer neuen Art, nicht möglich. Durch das ,Migrationsgesetz der Organismen“, das die freiwilligen und die passiven Wanderungen der Organismen in den Vordergrund rückt, glaubte Wagner zunächst eine wesentliche Lücke in Darwins Transmutationstheorie ausfüllen und das Prinzip der natürlichen Zuchtwahl durch ein weiteres ergänzen zu können, um dann später in der ,Separationstheorie“ noch entschiedener den Faktor der räumlichen Isolierung an die Stelle der natürlichen Zuchtwahl zu setzen, - wenigstens für die höheren Formen mit getrennten Geschlechtern. Gegen eine solche übertriebene Bewertung der räumlichen Isolation wandte sich Weismann, indem 
er einerseits den Wag ne rschen Satz, daß Umbildung der Organismen ohne räumliche Isolierung nicht möglich sei, durch einwandfreie Beispiele und Überlegungen als irrig nachwies, andererseits die zweifellos vorhandene Bedeutung der letzteren für die Entstehung neuer Arten genauer untersuchte. Diese Bedeutung erkannte er, in verschiedentlicher Berührung mit Wagners Gedankengängen, einmal darin, daß die räumliche Isolierung die Kreuzung der isolierten Individuen mit denen des Stammgebietes verhindert (,A mixi e“, oder Kreuzungsverhinderung), - dies betrifft aber nur „rein morphologische" Charaktere ohne nachweisbaren biologischen Nutzen - , andererseits darin, daß die Versetzung in beinahe immer veränderte Lebensbedingungen die Tätigkeit der natürlichen Züchtung anregen muß. So begünstigt die Isolierung in mehrfacher Weise die Entstehung neuer Arten, aber sie ist nicht eine notwendige Vorbedingung für eine solche. Vielmehr ist zweifellos, daß auch auf einem und demselben Wohngebiet, ohne alle Beihilfe räumlicher Isolierung, eine Art sich in zwei Formen spalten kann, unter Bedingungen, wo eine Kreuzung mit der unveränderten Form notwendigerweise fortgesetzt stattfinden muß. Einen Beweis dafür liefert der sexuelle Dimorphismus ${ }^{35}$ ), d. h. die verschiedene Gestaltung der Männchen und Weibchen einer und derselben Art, der sich ja doch trotz der fortwährenden Kreuzung der beiderlei Formen herausgebildet hat und erhält. So ist anzunehmen, daß auch die natürliche Zuchtwahl durchaus imstande ist, auf demselben Wohngebiet eine Art umzuwandeln, und aus der Paläontologie konnte Weismann ein schönes Beispiel anführen, das als Beleg für diese Auffassung gelten kann: die mannigfaltige Umwandlung der Tellerschnecke in dem beschränkten Gebiete des kleinen Steinheimer Seegrundes auf der Rauhen Alb.

An dieser Auffassung, die für die ganze Frage nach der Bedeutung der räumlichen Isolierung für die Artbildung grundlegend geworden ist, hat Weismann festgehalten; auch der 33. Vortrag im zweiten Bande der ,Vorträge über Deszendenztheorie“, der sich mit dem Problem befaßt, geht von ihr aus. Welche Wichtigkeit der ganzen Frage und den sich anschließenden uber sonstige Arten der Isolation für die Beurteilung der Darwinschen Selektionstheorie zukommt, dafür mag auf das betreffende Kapitel in Plates 
vortrefflichem Handbuch des Darwinismus (Selektionsprinzip und Probleme der Artbildung) verwiesen werden.

\section{b) Selektionswert der Anfangs- und Steigerungsstufen der Abände- rungen. Abänderung in kleinen Schritten.}

Neben dem Einwand, daß ohne räumliche Isolierung eine Weiterzüchtung einmal aufgetretener Varietäten nicht möglich sei, ist einer der wichtigsten von denen, die der Zuchtwahllehre gemacht worden sind, der, daß es schwer denkbar sei, wie die geringen individuellen Abweichungen, die nach Darwin das Material für die natürliche Züchtung abgeben sollen, ausschlaggebend im Kampfe ums Dasein werden sollen. Auch diese Frage nach dem „,Selektionswert der Anfangs- und Steigerungsstufen“ ist nicht dirch direkte Beobachtung zu beantworten, volle Klarheit über sie wäre nur durch den genauesten Einblick in die verwickelten Lebensbedingungen der Formen, in ihre Abhängigkeit von Klima, unbelebter und belebter Umgebung $\mathrm{zu}$ erlangen. Dieser Einblick aber ist zur Zeit noch recht lückenhaft. Bei der gewiß vorhandenen Schwierigkeit, geringen individuellen Abänderungen eine ausschlaggebende Bedeutung im Wettbewerb der Individuen zuzuschreiben, kann es nicht Wunder nehmen, daß wiederholt die Ansicht geäußert worden ist, nicht an die geringen individuellen Variationen, sondern an die hin und wieder plötzlich auftretenden Abänderungen stärkeren Grades sei die Umbildung der Formen geknüpft. Diese Abänderungen stärkeren Grades waren auch Darwin bekannt gewesen, und einige Fälle, in denen solche ,,single variations" oder ,sports", wie er sie nannte, den Ausgang für die künstliche Züchtung neuer Rassen abgegeben haben, sind auch von ihm behandelt worden; doch schrieb er diesen „sprungartigen“" Abänderungen oder ,,diskontinuierlichen Variationen“, wie sie auch bezeichnet worden sind, schon wegen der Seltenheit ihres Vorkommens eine nennenswerte Bedeutung für die Umbildung der Formen nicht zu und hielt daran fest, da $B$ es die kleinen erblichen Variationen sind, die für die Zuchtwahl das nötige Auslesematerial liefern. Viel wichtiger indessen als diese Meinungsverschiedenheit ist eine andere daran anknüpfende: die Anschauung, daß die Umwandlung der Formen nicht allmählich in kleinen Schritten, sondern mehr "sprungartig" vor sich gegangen sei, ist verschiedentlich 
verbunden worden mit einer völligen Ablehnung der Selektionstheorie und Ersatz derselben durch Annahme einer gesetzmäßigen Entwicklung aus inneren Ursachen. So geschah es von Kölliker in der „Theorie der heterogenen Zeugung“, deren Grundgedanke der war, daß unter dem Einflusse eines allgemeinen Entwicklungsgesetzes die Geschöpfe aus von ihnen gezeugten Keimen andere, abweichende hervorbringen ${ }^{36}$ ); auch Eduard von Hartmann trat für ähnliche Vorstellungen ein.

Weismann hat auch zu dieser Frage sich vielfach geäußert, zuerst wohl 1872 in dem eben besprochenen Aufsatz über den Einfluß der Isolierung auf die Artbildung, dann 1876 in dem über die mechanische Auffassung der Natur, im zweiten Bande der Studien zur Deszendenztheorie, und später noch wiederholt, besonders in den Vorträgen über Deszendenztheorie sowie (I909) in der Schrift über die Selektionstheorie, die in der Festschrift der Universität Cambridge zum Gedächtnis Darwins erschienen ist. Gegen die Annahme einer gesetzmäßigen inneren Entwicklungskraft hat er, wie noch $\mathrm{zu}$ besprechen sein wird, immer geltend gemacht, daß dadurch die Anpassungen der Organismen an die Lebensbedingungen nicht erklärt werden; aber auch die ganze Grundvorstellung einer diskontinuierlichen, in größeren Sprüngen erfolgten Entwicklung der Formen - bei gleichzeitiger Wirksamkeit der Naturzüichtung - hat er abgelehnt. Es ist ja auch von anderen Seiten vieles dagegen vorgebracht worden: vor allem die Erfahrung, daß Abweichungen größeren Betrages, die plötzlich und sprungweise auftreten, im ganzen recht selten sind und somit für die Artbildung schon aus diesem Grunde kaum eine große Bedeutung besitzen können; - und die weitere, daB sie - z. B. bei Pflanzen - sich in freier Natur nicht zu halten und zu ausdauernden Lebensformen zu werden pflegen. Uberall vielmehr, wo a usdauernde Lebensformen entstanden sind, finden sich auch Spuren einer allmählichen, schrittweise erfolgten Entstehung, auch da, wo man anfänglich eine sprunghafte vor sich zu sehen glaubte ${ }^{37}$ ). Eine solche allmähliche Entstehung unter Auslese der kleinen nützlichen Abänderungen ist auch allein imstande, die Anpassungen zu erklären. Allerdings gibt Weismann unumwunden zu, da $B$ auch ein entschiedener Anhänger der Selektionstheorie den Selektionswert der Anfangsund Steigerungsstufen nur annehmen, aber in keinem einzigen 
bestimmten Falle beweisen kann. Aber wenn sich auch nicht nachweisen läßt, daß die unbedeutenden Abweichungen, die wir als individuelle Variationen kennen, wirklich darüber $\mathrm{zu}$ entscheiden imstande sind, wer untergehen und wer überleben soll, so läßt sich doch in genug Fällen der Selektionswert auch kleiner Abweichungen sehr wahrscheinlich machen; es konnte ferner auf Versuche von Cesnola und Poulton hingewiesen werden, die den Selektionswert der fertigen Anpassungen deutlich zeigten, und endlich lieB sich auf einem ganz verwandten Gebiete, dem der sexuellen Züchtung, der Nutzen auch kleiner individueller Unterschiede sehr einleuchtend zeigen.

So hat Weismann durchaus an der Darwinschen Auffassung festgehalten: in kleinen Schritten, auf dem Wege der individuellen erblichen Variation, durch Häufung kleiner Abweichungen, hat die Umwandlung der Formen stattgefunden. Dagegen räumt er auf dem Gebiete der sexuellen Zuchtwahl allerdings den Spielvariationen eine größere Bedeutung ein, wie sich noch zeigen wird.

\section{Variationen unter der Grenze von Gut und Schlecht.}

Bestimmter und eingehender als Darwin hat aber Weismann einen Gedanken verfolgt, der bei seinem großen Vorgänger mehr im Vorübergehen geäußert wird: daß nämlich Abänderungen, die selektionswertig sein sollen, nicht ganz ,,minimal“ sein dürfen, sondern einen gewissen Betrag besitzen müssen, und daß es auch Abänderungen gibt, die ihrer Quantität nach ,,unter der Grenze von Gut und Schlecht" liegen, denen gegenüber somit die Zuchtwahl noch nicht Anlaß hat, einzuschreiten. Die weitere Verfolgung dieses Gedankens führte ihn dann dazu, nach einer Kraft zu suchen, die auch solche minimale Abänderungen bis zum Selektionswert zu steigern vermöchte. Es war das eine der Überlegungen, die ihn zur Aufstellung der Lehre von der "Germinalselektion“ führten. Bei dieser werden wir jenen ,,jenseits von Gut und Schlecht" gelegenen Merkmalen wieder begegnen ${ }^{38}$ ).

c) Freiwillig gewähIte Änderungen in den Lebensbedingungen. Divergente Entwicklung auf demselben Gebiete.

Aus den vielen Einzelerörterungen zu der Frage der Naturzüchtung, die sich in Weismanns Schriften finden, mag noch 
eine besonders herausgegriffen werden, weil sie einen Punkt behandelt, der recht oft nicht genügend beachtet wird. Sie findet sich in dem Aufsatz , über den Rückschritt in der Natur " ${ }^{39}$ ).

Die Formel, daß die Umbildung der Formen im Anschluß an die Veränderungen der Lebensbedingungen vor sich gegangen sei, wird gewöhnlich dahin ausgelegt, daß die Veränderung der Lebensbedingungen als das Primäre, die Anpassung der Organismen an die Veränderungen aber als das Sekundäre hingestellt wird: die veränderten Lebensbedingungen ,zwingen“ die Organismen, sich ihnen anzupassen, indem die Varietäten, die ihnen genügen, erhalten bleiben, die unbrauchbaren zugrunde gehen. Dabei erscheinen die Organismen rein passiv. So liegen die Dinge aber doch wohl nicht immer, wenigstens nicht für die tierischen Organismen. Weismann hat wiederholt darauf hingewiesen, daß die Naturzüchtung sehr langsam arbeitet und daß rasch und plötzlich einsetzende Veränderungen der Lebensbedingungen zum Aussterben vieler Arten führen, weil diese den Veränderungen nicht so rasch in ihren Anpassungen zu folgen vermögen. Er hat aber auch (in dem erwähnten Aufsatz) sehr einleuchtend auseinandergesetzt, daß die Veränderungen der „Lebensbedingungen“ von einer Art auch gewissermaßen freiwillig gesucht werden können, ohne daß die natürliche Umgebung sich irgendwie zu verändern braucht. ,Wenn ein Vogel, der bisher seine Nahrung auf Büschen und Bäumen suchte, am Boden des Waldes so reichlich Nahrung entdcckt, daß er davon allein besser als früher leben kann, so wird er sich jetzt mehr und mehr an das Leben auf dem Boden gewöhnen und immer weniger mehr auf Büsche und Bäume fliegen. Dadurch allein schon wird er unter ganz andere Lebensbedingungen versetzt sein, als die waren, unter denen er früher lebte; er wird nun das Fliegen nicht mehr nötig haben, wird deshalb zuerst weniger als früher und in späteren Generationen gar nicht mehr fliegen. Dabei braucht sich der Wald, in dem er lebt, das Klima, die Tierwelt, die ihn umgibt, nicht geändert zu haben, es genügt, daß er selbst eine neue Gewohnheit angenommen hat." Ähnlich klar liegen die Dinge bei der Entstehung der Höhlen- oder Tiefseefauna. Die Einwanderung in diese Gebiete hat langsam und allmählich von den Gebietsgrenzen aus stattgefunden, und allmählich haben sich die Organismen den neuen Bedingungen angepaßt. Wir können hinzufügen: und auch hier 
wird die Einwanderung nicht unter einem besonderen Zwange, sondern mehr freiwillig, höchstens unter den allgemeineren Bedürfnissen nach Nahrungserwerb, Schutz vor Feinden usw. erfolgt sein. Das Gebiet stand offen für alle Formen, die in seiner Nähe lebten, auf die Dauer benutzbar war es aber nur für die, deren Organisation dafür irgendwie günstige Einrichtungen bot. Die, bei denen das nicht der Fall war, gingen entweder wieder hinaus oder, wenn das aus einem unglücklichen Grunde nicht möglich war, zugrunde. Dies Prinzip der freiwillig, selbst gewählten Änderung der Lebensbedingungen unter Ausnutzung der eigenen Fähigkeiten und aller vorhandenen natürlichen Möglichkeiten sollte meines Erachtens viel mehr betont werden, als es geschieht. Wo Bäume waren, war auch immer die Bedingung zur Entstehung von Kletterund Flugtieren gegeben, und einer besonderen Aufforderung, davon Gebrauch $z u$ machen, bedurfte es nicht; wo Wasser war, lag fortgesetzt für die Bewohner der angrenzenden Ufer die Möglichkeit zur Einwanderung und allmählichen Anpassung vor; eine Verschiebung der Land- und Wassergrenze durch langsames Vordringen des Meeres veränderte im Laufe langer Zeiten die Lebensbedingungen in einem gegebenen Gebiet, konnte aber für die Einzelindividuen der einzelnen Generationen nicht eine besondere Aufforderung zum Einwandern abgeben. Man braucht sich die Organismen durchaus nicht als rein passiv, als bloß, ,geschoben“ vorzustellen, - wie das der Zuchtwahllehre zum Vorwurf gemacht worden ist - sondern kann, ja muß ihrer eigenen Betätigung (wenigstens bei den Tieren) eine größere Bedeutung für die Umbildung zuerkennen, auch ohne dabei die Vererbung funktioneller Abänderungen annehmen zu müssen ${ }^{40}$ ). Denn wenn eine Form mit einer selbstgewählten neuen Gewohnheit oder an einem selbstgewählten neuen Aufenthaltsort Erfolg hat, so setzt das eine gewisse günstige Veranlagung in bestimmter Richtung voraus, und diese wird sich weiter vererben und steigern können, lediglich nach dem Zuchtwahlprinzip. An dem Tisch der Natur ist kein Platz unbesetzt, sind alle Existenzbedingungen ausgenutzt; innerhalb der Organismen andererseits sehen wir denselben funktionellen $Z$ weck auf die verschiedenste Weise, durch morphologisch ganz verschiedene Einrichtungen erreicht, und sehen alle morphologischen Charaktere in verschiedensten Graden der Entwicklung, - kaum einen, der 
nicht irgendeine Form in ganz exzessiver Weise ausgebildet besäße, der nicht in all seiner Verwendungsmöglichkeit ausgenutzt wäre. Diese unendliche Mannigfaltigkeit, diese Ausnutzung aller gegebenen äußeren und inneren, in der Umwelt wie in der Bildsamkeit der Organismen gegebenen Bedingungen wird viel verständlicher, wenn man die Organismen sich eben nicht als bloß ,,geschoben“ vorstellt, sondern davon ausgeht, da $B$ auch sie das ihrige zu dieser Ausnutzung aller Bedingungen getan haben, unbewußt, unter dem allgemeinen Zwange von Hunger und Liebe, und zwar schon ,,bei Zeiten", nicht erst dann, wenn eine durchgreifende Veränderung der Umwelt die Bedingungen ganz wesentlich umgestaltete. Denn dann dürfte es gewöhnlich schon zu spät gewesen sein ${ }^{41}$ ).

Abgesehen von dem Vorhandensein eines gewissen Selbstbestimmungsrechtes, wenigstens bei den tierischen Organismen, lehrt diese Betrachtung auch noch ein anderes: die Möglichkeit zur Züchtung neuer Charaktere und damit zur Abänderung einer Art, auch ohne da $B$ die natürlichen Verhältnisse des Gebietes tiefgreifende Veränderungen erfahren. Es ergibt sich daraus, daß die auf Darwin zurückzuführende und auch von Weismann oft gebrauchte Formel vom Überleben des „Passendsten“ nicht sehr glücklich ist; der Superlativ erweckt die Vorstellung, als ob unter irgendwo gegebenen Bedingungen stets nur eine ganz bestimmte Organisation dauerfähig sei, während doch auch unter gleichen oder ähnlichen Bedingungen divergente Entwicklung auf Grund und unter Ausnutzung ganz verschiedener Vorzüge denkbar ist und wohl auch vielfach stattgefunden hat. Gute Beispiele bieten die Sinnesorgane, die unter erschwerten Funktionsverhältnissen entweder aufgegeben oder bis zur höchsten Leistungsfähigkeit vervollkommnet werden (Verkümmern der Augen in lichtlosen Grotten, - Ausbildung von Leuchtorganen an den Augen bei Tiefseefischen).

\section{d) Die natürlichen Beschränkungen in der Wirksamkeit der Natur- züchtungsvorgänge.}

Kehren wir zu Weismann zurück. Immer mehr befestigte sich diesem im Verlaufe seiner Beschäftigung mit der Selektionstheorie die Überzeugung, daß die von Darwin angenommenen Vorgänge der natürlichen Zuchtwahl nicht nur in den Erfahrungen der künstlichen Züchter eine feste Stütze finden und aus richtigen 
Voraussetzungen logisch gefolgert, sondern auch tatsächlich imstande sind, Umänderungen der Formen mit gleichzeitiger Anpassung an die Lebensbedingungen zu bewirken und damit eine große Anzahl sonst unverständlicher Tatsachen zu erklären. Trat so die Richtigkeit des Prinzipes immer mehr hervor, so ergab sich auch unmittelbar die Frage: was können wir von diesen Vorgängen der Naturzüchtung, wenn wir sie als tatsächlich wirksam annehmen, füglich erwarten? Und oft genug, vom ersten Augenblick seiner Beschäftigung mit dem Darwinismus an, hat er darauf geantwortet: gewiß nicht alles und jedes, nicht unbegrenzte Möglichkeiten; es gibt für sie auch Beschränkungen und Unmöglichkeiten. Sie sind begründet in dem Wesen der Naturzüchtung selbst, in den Organismen und in den Bedingungen der Umwelt.

\section{Beschränkungen, die aus dem Wesen der Naturzüchtung selbst folgen.}

Aus dem Wesen der Naturzüchtung selbst, wie wir es mit Darwin annehmen, müssen sich mehrere Beschränkungen ergeben. Diesem ihrem Wesen nach ist die Naturzüchtung nicht imstande, selbst lebende Substanz oder die Variationen derselben zu schaffen; sie kann nur an das Gegebene anknüpfen, d. h. an die Variationen, die ihr von den Organismen dargeboten werden, und kann nur wirken, indem sie die ungünstigsten dieser Variationen verwirft, ebenso wie der Züchter die Träger nichtgewollter Merkmale von der Nachzucht ausschließt. Aber indem sie das eine verwirft, erhält sie das andere, die nützlichen Varietäten, und macht sie allmählich zum Gemeinbesitz der Art. Fußend auf den Erfahrungen der künstlichen Züchtung nimmt die Zuchtwahllehre aber auch an, daß durch die natürliche Züchtung im Laufe der Generationen eine Steigerung eines Merkmals möglich sei. Fast alle Teile der Hühner und Tauben sind durch die künstliche Züch . tung nachweislich bis zum ExzeB verändert worden, unzählige Charaktere künstlich gezüchteter Rassen zeigen die Steigerungsfähigkeit eines Merkmals durch zielbewußt fortgesetzte Auslese, und wenn wir all die zahllosen, weitgehenden, im einzelnen durchgearbeiteten Anpassungen, die wir an den Organismen sehen, im Darwinschen Sinne erklären, nehmen wir auch eine Summation und Steigerung von anfangs geringfügigen Variationen an. Auf 
diese Weise schafft die Naturzüchtung Neues. Aber freilich: bei dem einzigen Mittel, das ihr zu Gebote steht, dem Ausmerzen des Nichtgewollten, ist sie darauf angewiesen, daß eine andere Kraft ihr in die Hände arbeitet, ihr das Rohmaterial liefert, und nicht nur immer wieder neues, sondern auch das bereits als brauchbar Gefundene in weiterer Steigerung. Also auch die Steigerung eines Merkmals durch Naturzüchtung setzt das Walten noch einer anderen Kraft voraus; Personalselektion ist nur die große Baumeisterin, die die brauchbaren Steine auswählt und in neuen Kombinationen zusammenfügt. Die unendliche Mannigfaltigkeit der Formen lehrt, wieviel "Neues" sie trotzdem zu schaffen vermag.

Dieses ihr Schaffen aber braucht Zeit, und darin liegt eine zweite Beschränkung, die unter Umständen einmal den Organismen verhängnisvoll werden kann. Naturzüchtung arbeitet langsam, und so kann es geschehen, daß sie einmal bei einem rasch vor sich gehenden Wechsel in den Lebensbedingungen einer Form, wozu auch das Auftreten eines neuen mächtigen Feindes, wie des Menschen, gehört, nicht zu folgen vermag und damit diese Form dem Untergang ausliefert. Nicht Starrheit der Form, nicht Unfähigkeit zur Hervorbringung und Fixierung nützlicher Abänderungen war in diesen Fällen der Grund des Aussterbens, sondern die Langsamkeit des Zuchtwahlprozesses, der die Umformung nur in kleinen Schritten vornimmt.

Und nun endlich eine letzte Beschränkung, die nicht wie die eben genannten nur in Ausnahmefällen in Kraft treten wird, sondern die überall, bei allen Zuchtwahlprozessen Geltung hat, und die sich die Naturzüchtung selbst setzt, da sie ganz besonders zu ihrem innersten Wesen gehört: die Relativität der Anpassungen. Das innerste Wesen der Naturzüchtung ist ja, daß sie die Einrichtungen der Organismen in Einklang mit den Lebensbedingungen zu bringen strebt. Ihr Ziel ist also ein durchaus relatives, bestimmt durch die Lebensbedingungen. Ist die Harmonie mit diesen erreicht, so hat die Naturzüchtung ihre Arbeit getan, ganz gleichgültig, ob das erlangte Ergebnis, vom menschlichen Standpunkt aus betrachtet, nun wirklich als die höchste Steigerung der betreffenden Entwicklungsrichtung anzusehen ist. Am deutlichsten wird das aus der Betrachtung der verschiedenen Fälle von „Nachahmung“, auf die Weismann wiederholt in diesem Zusammenhang hin- 
gewiesen hat. Die Blattähnlichkeit auch der blattähnlichsten Schmetterlinge ist nur so groß als nötig ist, um die Vögel zu täuschen ; darüber hinaus kann Naturzüchtung nicht wirken, da die Bevorzugung besserer Variationen von dem Augenblick an aufhört, wo diese Verbesserungen nicht mehr nötig sind, weil die Existenz der Art von dieser Seite her nicht mehr stärker zu sichern ist, d. h. weil weitere Variationen in der bisher befolgten Richtung keine Verbesserungen mehr sind, auch wenn sie uns als solche erscheinen mögen. Das Wesen der Naturzüchtung steckt also der Vervollkommnung der Organismen gewisse Grenzen, macht die „Vollkommenheit" zu einem ganz relativen Begriffe. Sehr schön kommt diese Auffassung zur Geltung in dem wie ein Glaubensbekenntnis anmutenden Ausspruch, mit dem Weismann einen Aufsatz über das Sehen der Insekten (I895) schließt: ,,So finden wir auf diesem Gebiete des Sehens wie auf allen anderen Gebieten tierischer Tätigkeit immer wieder von Neuem die Wahrheit bestätigt, daß die Höhe der Leistungsfähigkeit eines Organs niemals größer ist, als durchaus notwendig für die Existenzfähigkeit der betreffenden Art, daß sie aber auch nie geringer ist, da $B$ also das Organ immer genau so vortrefflich ist, als es sein muß, damit alle Lebenstätigkeiten der Art erfüllt und ausgeübt werden können. Der Bau einer Art ist genau so fein und so hoch ausgebildet, als es sein muß, damit sie bestehen kann. Und so ist es in dem ganzen Gebiete des Lebens, ja der ganzen Natur: die Welt ist genau so vortrefflich, als sie sein muß, damit sie Bestand habe."

\section{Beschränkungen der Naturzüchtung, die in den Organismen liegen.}

Eine zweite Quelle für Beschränkung der Naturzüchtung liegt in den Organismen selbst; - die Objekte, mit denen und für die sie arbeitet, bilden zugleich eine Instanz, von der sie bis zu einem gewissen Grade abhängig ist. Schon in seiner Antrittsvorlesung von $\mathrm{I} 868$ hat Weismann, wie wir bereits wissen, ganz bestimmt ausgesprochen, da $\beta$ die Variabilität der Organismen nicht regel- und ziellos, sondern durch die physische Konstitution des letzteren gewissen Beschränkungen unterworfen ist, so daß das Varietätenmaterial, an dem die Ausleseprozesse wirksam werden sollen, nicht unbeschränkt, sondern für jede Form begrenzt ist. Schon einmal wurden seine Worte angeführt: „Es beruht auf ein- 
seitiger Übertreibung der Darwinschen Lehre, wenn oft behauptet wird, die Organismen könnten nach allen möglichen Richtungen hin variieren. Freilich nach allen möglichen, aber auch nur nach den möglichen, womit zugestanden wird, daß es auch unmögliche gibt." Aus einem Käfer kann, wie es später einmal heißt, nicht ein neues Wirbeltier werden, nicht einmal ein beliebiges anderes Insekt, sondern zunächst nur immer wieder ein Käfer, und zwar der gleichen Familie und Gattung. Das Neue kann nur an das schon Gegebene anknüpfen. Diese „physische Konstitution“ ist aber nicht Ausfluß einer selbständigen inneren Bildungskraft, sondern das Ergebnis des historischen Entwicklungsganges, den eine jede Form durchgemacht hat; in der Lehre von der Germinalselektion fand sie und die durch sie bedingte Beschränkung der Variationsmöglichkeit eine genauere Analyse vom Standpunkt der Determinantentheorie aus. Diese Beschränkung der Variationsmöglichkeit bedingt einerseits die Beibehaltung bestimmter Entwicklungsrichtungen bei der phyletischen Entwicklung und kann andererseits unter Umständen auch einmal zum Untergang einer Art führen, indem die gegebenen Variationsmöglichkeiten nicht genügen, um eine Art veränderten Lebensbedingungen anzupassen.

Noch nach einer anderen Richtung macht sich die Natur der Organismen selbst bei der Umwandlung der Formen geltend. Alle Teile stehen in einem bestimmten Zusammenhang, und keiner kann für sich abändern, ohne die Abänderung eines anderen nach sich zu ziehen. Das ist das Gesetz der Korrelation, dessen Bedeutung schon von Darwin scharf hervorgehoben worden ist. Auch Weismann ist hier und da darauf $\mathrm{zu}$ sprechen gekommen und hat seine Wichtigkeit behandelt. Für die natürliche Auslese kann sich aus ihm eine gewisse Beschränkung ergeben. Gesetzt, dieselbe richtet ihr Augenmerk auf die Steigerung eines bestimmten nützlichen Charakters, so wird ja, dem Gesetz der Korrelation entsprechend, auch irgend ein anderer Charakter eine Abänderung erfahren. Solange diese zweite, begleitende Abänderung ihrer Art oder ihrem Grade nach gleichgültig ist, wird sie ungestört vor sich gehen können, sowie sie aber nach irgend einer Richtung schädlich wird, werden die betreffenden Individuen gegenüber den anderen benachteiligt und ausgemerzt werden, und damit würde denn auch die Steigerung jener primären, nützlichen Abänderung zum Ende 
gekommen sein. Bildlich ausgedrückt: die Naturzüchtung wird zwar ihr Hauptaugenmerk gewöhnlich auf ein bestimmtes Merkmal richten, muß dabei aber auch auf den ganzen übrigen Organismus ein wachsames Auge haben, um sich im gegebenen Augenblicke selbst ein Halt zuzurufen, eine Beschränkung aufzuerlegen.

\section{Beschränkungen der Naturzüchtung, die in den Verhältnissen der Umwelt liegen.}

Endlich kann aber auch, Weismanns Auffassung zufolge, in den Verhältnissen der Umwelt gelegentlich einmal das Walten der Naturzüchtung eine Grenze finden. Wenigstens ist der Fall denkbar, daß unter dem direkten Einflusse der äußeren Verhältnisse eine Art in allen Individuen so ungünstig verändert wird, daß der Naturzüchtung, mangels günstiger Variationen, keine Möglichkeit geboten ist, ihr aufzuhelfen. Wir werden hierauf noch einmal zurückkommen müssen (in dem Abschnitt über die Germinalselektion).

Somit ist auch Weismann durchaus der Ansicht, daß die Vorgänge der Naturzüchtung ihrer Natur nach nicht imstande sein können, jede beliebige Form in jeder beliebigen Weise umzubilden, jedes beliebige Merkmal bis zu jedem beliebig hohen Grade zu steigern oder jede Art unter allen Umständen zu erhalten und vor dem Verderben zu schützen. Die Naturzüchtung, als personifizierte Kraft genommen, ist nach vielen Richtungen hin beschränkt. Das bedeutet aber nicht, daß die Naturzüchtungslehre als Erklärungsprinzip versage. Auch der Arten tod bedeutet nicht etwa, wie gesagt worden ist, einen Bankerott der Selektionstheorie; im Gegenteil, er findet gerade in ihr, in den von ihr angenommenen Kräften, seine zureichende Erklärung. Die Selektionsthe orie darf nicht verwechselt werden mit den $\mathrm{Kräften,} \mathrm{mit} \mathrm{denen} \mathrm{sie} \mathrm{rechnet.}$

3. Leistungfähigkeit der Selektionstheorie für die Erklärung der phyletischen Entwicklung der Organismen.

\section{a) Fragestellung.}

Wie weit die Zuchtwahllehre als Erklärungsprinzip im Reiche des Organischen Geltung hat, wie weit also durch die Vorgänge der Naturzüchtung die tatsächlich zu beobachtenden Erscheinungen der Lebewesen, ihr Bau, ihre Lebensäußerungen 
und auch ihre Geschichte - ihr Aufkommen, ihre Entfaltung und ihr Wiederverschwinden von der Erdoberfläche - ihre Erklärung finden, das ist die zweite große Frage, die sich erhebt, und die auch Weismann immer wieder behandelt hat. Reicht für das Verständnis jener Erscheinungen Naturzüchtung in der Form der Personalauslese als Erklärungsprinzip aus, oder müssen statt ihrer oder wenigstens neben ihr andere Umwandlungsprinzipien anerkannt werden, und welche? Auch Darwin hatte sich diese Frage vorgelegt, hatte zur Erklärung einer ganzen Anzahl von Merkmalen das Prinzip der sexuellen Auslese neben das der natürlichen Zuchtwahl gestellt, daneben die Vererbung von direkten Mediumwirkungen und von funktionellen Abänderungen angenommen und damit diesen beiden Faktoren eine gewisse Rolle bei der Umwandlung der Formen zugewiesen, endlich auch die korrelative Abänderung bei der letzteren in Rechnung gestellt. Unter den von anderer Seite vertretenen Anschauungen waren die wichtigsten die Annahme einer inneren zielstrebig arbeitenden Entwicklungskraft, eines großen Gestaltungsgesetzes, demzufolge sich die ganze Organismenreihe unter einem inneren $Z$ wange entwickelt habe und ebenso entwickelt haben würde, auch wenn die äußeren Bedingungen ganz andere gewesen wären, sowie Rouxs Lehre von dem züchtenden Kampf der Teile im Organismus, die neben die Personalauslese die Partiala uslese innerhalb des Organismus stellte und auf diese die inneren ZweckmäBigkeiten der Organismen zurückführte. Mit diesen und anderen Anschauungen galt es sich abzufinden, und auch hierbei konnte, da der Vorgang der Naturzüchtung nicht unmittelbar zu beobachten ist, die Behandlung immer nur darauf ausgehen, zu zeigen, einmal wie weit die gegebenen Tatsachen sich jenem Erklärungsprinzip fügen, und ferner, daß die von anderer Seite vertretenen Prinzipien unzulänglich oder zum mindesten überflüssig sind.

\section{b) Zuchtwahl oder inneres Vervollkommnungsprinzip? Nägelis Theorie der direkten Bewirkung.}

Die Auffassung, daß nicht Nützlichkeit und Zufall, wie es die Darwinsche Theorie annimmt, den Werdegang der Organismen beherrschten, sondern eine innere bestimmt gerichtete Entwicklungskraft, ist vielfach vertreten worden. Sie spielt eine besondere Rolle in der Theorie der direkten Bewirkung von Carl von Nägeli, 
dem genialsten, bedeutendsten Forscher, zu dem Weismann Stellung zu nehmen hatte, und dessen gedankenreichem und in klassischer Einfachheit und Klarheit geschriebenen Werke über die Abstammungslehre (I884) cr selbst vielfache Anregung verdankte. Schon I 865 war der berühmte Münchener Botaniker in grundsätzlich wichtigen Punkten der Darwinschen Theorie gegenübergetreten und hatte sich für die Annahme eines besonderen inneren Vervollkommnungsprinzipes ausgesprochen; in seinem großen Werke über die mechanische-physiologische Theorie der Abstammungslehre von 1884 hatte er den gleichen Gedanken im Zusammenhang mit seiner Idioplasmatheorie, der ersten im einzelnen durchgearbeiteten Vererbungstheorie, ausführlicher behandelt. Ein scharf ausgesprochener Dualismus beherrscht die Auffassung Nägelis, soweit sie sich auf die Entwicklung der Organismen bezieht. In zwei Gruppen werden zunächst die Merkmale derselben eingeteilt: in Organisationsmerkmale und in Anpassungsmerkmale. Die Organisationsmerkmale, auch als ,rein morphologische“, das soll heißen: biologisch bedeutungslose, bezeichnet, bedingen das Wesentliche der Organisation, auf ihnen beruht die ganze Gliederung der Organismen, in Arten, Gattungen, Familien, Ordnungen usw.; die nützlichen Anpassungen bedeuten an dem Gebäude nur die Ausführung im einzelnen, die ,Verzierung“. Alle Merkmale sind der Ausdruck einer bestimmten Beschaffenheit des Idioplasmas, das den ganzen Organismus durchsetzt; auf Veränder ungen des Idioplasmas beruhen somit die erblichen Veränderungen der Organismen, beruht die Entwicklung der organischen Reiche. Die Ursachen für diese erblichen Veränderungen des Idioplasmas sind, entsprechend jenen beiden Gruppen von Merkmalen, ebenfalls zweierlei Art: innere und ä ußere. Die inneren, in der molekularen Zusammensetzung des Idioplasmas beruhend, sind die wichtigeren. Sie bedingen eine fortschreitende gesetzmäßige Veränderung des Idioplasmas im Sinne einer mannigfaltigeren Gliederung desselben und dementsprechend eine stete Veränderung der Organismen im Sinne einer zusammengesetzteren Organisation und Funktion. Mit innerer Notwendigkeit entstehen periodisch neue „Organisations-“ oder ,Vervollkommnungsanlagen“ und dadurch auch eine stetige in bestimmter Bahn fortschreitende Entwicklung der Formen, eine stetige Vervollkommnung der Organisation. Den äußeren Ein- 
flüssen bleibt es dann nur vorbehalten, die „Verzierung“, d. h. die nützlichen Anpassungen an die Außenwelt und damit die Mannigfaltigkeit und spezielle Beschaffenheit der Gestaltung zu bilden. Die Wirkung der Außenwelt ist aber nicht im Darwinschen Sinne auf dem Umwege der Konkurrenz und Verdrängung zu denken, sondern als ,unmittelbares Bewirken“, in der Weise, daß unter lange dauernder - durch Generationen sich wiederholender - Beeinflussung durch äußere Reize das Idioplasma, das den ganzen Körper durchsetzt, zweckentsprechend verändert wird, und diese primären Idioplasmaveränderungen dann als nützliche Anpassungsmerkmale an den entwickelten Organismen bemerkbar werden. Wie mit innerer Notwendigkeit aus inneren Ursachen in dem Idioplasma periodisch neue Organisations- oder Vervollkommnungsanlagen entfaltungsfähig werden, so schaffen die äußeren Einflüsse, ebenfalls zwingend, neue Anpassungsanlagen, und auf dem Zusammenwirken beider Kräfte, des inneren Vervollkommnungsprinzipes und der direkten Wirkung der äußeren Einflüsse, beruht die Umwandlung der Formen. Diese Umwandlung ist also von beiden Seiten her eine ganz bestimmt gerichtete (,Theorie der direkten Bewirkung“); die Selektion erscheint dabei zwar nicht ganz ausgeschaltet, aber sie übt keinen richtenden, ordnenden Einfluß aus, sondern kann höchstens das weniger Existenzfähige beseitigen; auch ohne Konkurrenz würden sich alle Organismen, die wir jetzt kennen, gebildet haben.

Das sind grundsätzliche Unterschiede gegenüber der Anschauung von Darwin. Dieser hatte, wie Plate es einmal ausdrückt, „die ganze Evolution unter dem Gesichtswinkel der Anpassungen“ betrachtet ${ }^{42}$ ); für Nägeli dagegen erschienen die Anpassungen nur als Verzierungen, während die viel bedeutungsvolleren Organisationsmerkmale, ihrem inneren Ursprung entsprechend, sich gegenüber den äußeren Verhältnissen gleichgültig verhalten sollten. Für Darwin waren ferner die ersten Abänderungsstufen der Organismen richtungs- und regellos, und erst die äußeren Einflüsse trafen aus ihnen die Auswahl und bestimmten damit die Richtung der Entwicklung; für Nägeli war die Entwicklung von vornherein bestimmt gerichtet. In bezug auf die Ursachen der Umbildung besteht eine gewisse Fühlung zwischen Nägeli und Lamarck, der auch ein 
inneres Umwandlungsprinzip und die äußeren Einflüsse in diesem Sinne in Anspruch genommen hat, doch tritt bei Nägeli jenes innere von Darwin ganz abgelehnte Prinzip, der innere Vervollkommnungstrieb, viel beherrschender in den Vordergrund.

In den Bahnen Nägelis wandelten viele Forscher, teils bewußt, teils unbewußt. Mit Bestimmtheit vertrat Kölliker die Auffassung, da $B$ der Entstehung der gesamten organischen Natur ein großer Entwicklungsplan, mit anderen Worten, allgemeine Naturgesetze zugrunde liegen, daß bei der Umbildung der Formen nicht der Gesichtspunkt der Nützlichkeit, gewissermaßen von Fall zu Fall, die Entscheidung über die Art und Richtung getroffen, sondern da $\beta$ sich diese Umbildung mit derselben Gesetzmäßigkeit vollzogen habe, wie die Entwicklung des Eies. Askenasy und der Philosoph Eduard von Hartmann äußerten ähnliche Auffassungen, deren weite Verbreitung im übrigen auch aus der Fassung, in der die "Darwinsche" Theorie oft dargestellt wird, erhellt. Paßt die oft gehörte Formel, daß bei der Umbildung der Organismen zwei Prinzipien wirksam gewesen seien, ein konservatives, die Vererbung, und ein fortschrittliches, die Anpassung, nicht eigentlich viel besser auf die Nägelische Vorstellung, als auf die Darwinsche? Von dieser aus müßten als Umwandlungsprinzipien genannt werden: Anpassung - vor allem auf Grund erblicher zunächst richtungsloser Variationen, zum kleineren Teil auf Grund direkter Mediumwirkungen und funktioneller Veränderungen -, Vererbung dieser Anpassungen und Hinzukommen neuer. Die ganze Organisation ist nach Darwin Anpassung.

\section{Die Organismen als Anpassungskomplexe.}

Der Frage, wie weit ein innerer Vervollkommnungstrieb - eine phyletische Lebenskraft, wie Weismann zu sagen vorschlägt - die Umbildung der Organismen bestimmt habe, sind die ersten deszendenztheoretischen Arbeiten des jungen Freiburger Forschers gewidmet. Schon die Antrittsrede von 1868 stellt das Problem scharf und bestimmt hin: „Es wäre denkbar, daß den Organismen eine Kraft innewohne, mittelst welcher sie im Laufe zahlreicher Generationen ihre Gestalt änderten und sich zu einer neuen Art umwandelten. Es müßte dann mit Notwendigkeit aus einer bestimmten Art nach Ablauf einer gewissen Zeit eine oder mehrere neue, eben- 
falls ganz fest bestimmte Arten hervorgehen, und das gesamte Tier- und Pflanzenreich müßte mit Notwendigkeit sich gerade zu der Gestalt aus den niedersten Organismen entwickelt haben, in welcher es uns faktisch entgegentritt; die Organismenwelt hätte so wenig anders ausfallen können, als aus dem Ei einer Taube etwas anderes kommen kann als eine Taube!" Aber sofort folgt auch die Antwort: „Eine solche Vorstellung ist unstatthaft, da sie im Widerspruch mit Tatsachen steht. Der Mensch vermag nach seiner Willkür durch künstliche Züchtung neue Rassen hervorzubringen, mit anderen Worten: er vermag die Organismenwelt umzugestalten, wenn auch nur innerhalb enger Grenzen; dies könnte aber nicht der Fall sein, wenn nur diese organische Welt möglich gewesen wäre, die wir tatsächlich beobachten! Ohnehin ist es nicht erlaubt, eine unbekannte Kraft anzunehmen, wo wir mit den bekannten Kräften zur Erklärung der Erscheinungen ausreichen oder doch hoffen dürfen, nach weiteren Forschungen einst auszureichen."

Daß unter diesen ,,bekannten Kräften“ vor allem die Faktoren der Selektionsvorgänge zu verstehen sind, lehren die Arbeiten der nächsten Jahre, die immer wieder darauf hinzielen, die allerverschiedensten Einrichtungen und Lebenserscheinungen der Organismen als nützliche „Anpassungen“ verständlich zu machen. Denn diese Vorfrage war allerdings zuerst $\mathrm{zu}$ erledigen: sind in der Tat, wie Nägeli meinte, die wichtigsten Merkmale der Organismen, die die Höhe der Organisation bestimmen, biologisch bedeutungslos, rein morphologisch, oder sind sie nützliche Einrichtungen? Nur in letzterem Falle konnte die Erklärung durch das Selektionsprinzip für sie in Anwendung kommen.

Die hier vorliegende Aufgabe entsprach der angeborenen Begabung Weismanns zur denkenden Naturbeobachtung, seiner Freude an den Organismen und ihren Lebensäußerungen, die ihn von Jugend auf beseelt hatte. Aber an die Stelle der naiven Freude des Knaben, der Pflanzen, Käfer, Schmetterlinge gesammelt und Raupen gezüchtet hatte, trat nun die überlegende Betrachtung des gereiften Mannes, der nach Sinn und Zweck der Einrichtungen der Lebewesen fragte. Ihm erschloß sich die Erkenntnis, die bestimmend wurde für seine Stellungnahme gegenüber dem Darwinismus: die Überzeugung von der tatsächlich vorhandenen, bis ins kleinste 
gehenden Zweckmäßigkeit der Organismen, ihrer genauesten Anpassung an die Lebensbedingungen. Er hat selbst oft hervorgehoben, daß gerade dem die Natur beobachtenden Zoologen diese Anpassungen viel richtiger und bedeutungsvoller erscheinen müssen, als dem Botaniker, da die Anpassungen der Pflanzen nicht so leicht erkennbar sind, und hat darauf vor allem es zurückgeführt, da $B$ er in dieser Frage zu einer ganz anderen Auffassung gelangte als Nägeli ${ }^{43}$ ). Die vier Abhandlungen des zweiten Bandes der ,Studien zur Deszendenztheorie" vom Jahre I876 sind der Erörterung der Frage nach dem Vorhandensein einer phyletischen Lebenskraft gewidmet; wir sahen schon, daß das Ergebnis dieser Prüfung durchaus negativ war. Die Zeichnungen der Sphingidenraupen ließen sich als Anpassungen nach dem Selektionsprinzip erklären; ebenso führte die Betrachtung der selbständigen Abänderungen von Raupen und Schmetterlingen sowie die der Verwandlung des mexikanischen Axolotl zu der Ablehnung einer solchen inneren Entwicklungskraft. Weitere bedeutungsvolle Prüfungen der Leistungsfähigkeit des Selektionsprinzipes an zwei ganz verschiedenartigen Gruppen von Erscheinungen folgten wenige Jahre später: I880 konnte Weismann zeigen, daß die eigentümlichen Verschiedenheiten in den Fortpflanzungserscheinungen der Daphnoiden sich als Anpassungen an die Lebensbedingungen verstehen lassen, und die Untersuchungen über die Dauer des Lebens und über Leben und Tod lehrten ebenso die Lebensdauer der Arten wie den natürlichen Tod unter dem gleichen Gesichtspunkt betrachten. So kam auch Weismann dazu, als konsequenter Jünger Darwins, ,die ganze Evolution unter dem Gesichtswinkel der Anpassungen“ zu betrachten und - ebenfalls in Übereinstimmung mit Darwin - als rein morphologisch, biologisch bedeutungslos nur wenige Merkmale gelten zu lassen. A bgelehnt hat er das Vorhandensein solcher durchaus nicht - schon der Vortrag von 1868 rechnet mit ihnen und sucht sie zu erklären, in den ,Studien zur Deszendenztheorie“ spielen sie eine große Rolle, und in der ,Germinalselektion“ gab er später eine Erklärung für sie vom Boden der Determinantentheorie aus - aber er hat doch wie Darwin zur Vorsicht gemahnt und davor gewarnt, eine biologische Bedeutung, eine ZweckmäBigkeit überall da zu leugnen, wo sie bisher nicht bekannt ist. Mit Recht konnte er darauf hinweisen, wie durch die fortschreitende Forschung immer wieder 
nicht nur auf ticrischem, sondern auch auf dem in dieser Hinsicht schwierigeren pflanzlichen Gebiete Merkmale, die man früher als bedeutungslos betrachtete, als wichtig erkannt und aus der Reihe der ,rein morphologischen" Merkmale in die der "Anpassungen“" versetzt wurden. Alle Formen, das ist seine oft ausgesprochene Uberzeugung, sind in erster Linie Komplexe von Anpassungen, und auch die meisten sogenannten Organisationsmerkmale müssen als Anpassungen entstanden gedacht werden. Freilich darf man - eine gewiß sehr beherzigenswerte Warnung - nicht nur das als Anpassung gelten lassen, was bei der Art, die man gerade ins Auge faßt, neu erworben wurde. Denn wir setzen doch eine Entwicklung voraus; die Anpassungen von heute vollziehen sich unter Beibehaltung einer gegebenen Grundlage, die aber ihrerseits einmal als Anpassung sich ausbildete: sie schließen sich an die Anpassungen von gestern und von der Urzeit her an. Die Bedeutung dieser alten Anpassungen würde bei den Formen zu prüfen sein, bei denen sie zum ersten Male auftraten. Hier harrt noch ein großes Arbeitsgebiet der systematischen Inangriffnahme. Von vielen, an sich längst bekannten und in allen Lehrbüchern aufgeführten Merkmalen wissen wir noch nicht, welche biologische Bedeutung ihnen zukommt, aber es hat sich auch noch niemand die Mühe genommen, ernstlich darnach zu fragen und unter Berücksichtigung des von Weismann so klar hervorgehobenen historischen Gesichtspunktes darnach zu forschen. Daß ein Fortschritt auf diesem Gebiete vor allem von der liebevollen Versenkung in die Lebenserscheinungen kleinerer Gruppen von Organismen und ihre Beziehungen zur belebten und unbelebten Umwelt zu erwarten sein wird, ist ein Gedanke, dem Weismann besonders in dem Vorwort zu der ,Internationalen Revue der gesamten Hydrobiologie und Hydrographie" Ausdruck gegeben hat, und aus dem er eine wichtige Aufgabe der hydrobiologischen Forschung herleitet.

Diesen Standpunkt immer wieder zu begründen, ist Weismann nicht müde geworden, und seine ungewöhnlich ausgedehnte Erfahrung und Kenntnis von Einzeltatsachen setzten ihn in den Stand, immer neue Beispiele zu seinen Gunsten anzuführen. Welche Fülle von Stoff ist in dieser Hinsicht in den Vorträgen über Deszendenztheorie zusammengetragen, nicht nur aus dem Gebiete der Zoologie, sondern auch aus dem der Botanik, dem ja Weismann 
ebenfalls von Jugend auf seine Neigung zugewandt hatte. Die mannigfachen mechanischen und chemischen Schutzvorrichtungen der Pflanzen gegen große und kleine Tiere, die wunderbaren Anpassungen der fleischfressenden Pflanzen, - die Einrichtungen zur Bestäubung der Blumen, die gegenseitigen Anpassungen zwischen diesen und den Insekten, Einrichtungen so zweckmäßiger Natur, daß sich der Ausspruch rechtfertigt, die Pflanzen seien aus lauter Anpassungen entstanden und zusammengesetzt, - dann weiter die Instinkte der Tiere, die mancherlei Färbungen und Zeichnungen derselben, die als ,sympathische" Färbungen das Tier mit seiner Umgebung in Einklang bringen, oder als Schreckmittel wirken, und unter ihnen wieder besonders die schützenden nachahmenden Färbungen: die Blattschmetterlinge und Blattheuschrecken, die Spannerraupen, die wie kleine Zweigchen aussehen, und vor allem die echten Mimikrifälle: die Beispiele von Nachahmung einer durch ihren widrigen Geschmack geschützten Tierform durch eine andere - es ist ein reiches Gebiet von Tatsachen, bei denen der Charakter der zweckmäßigen Anpassungen teils ohne weiteres in die Augen springt, teils der genaueren Forschung sich erschlossen hat. Sie konnten wohl zu der Auffassung führen, daß auch die sogenannten „Organisationsmerkmale" der Arten, Gattungen, Familien, Ordnungen, Klassen ursprünglich adaptive Bedeutung hatten, wenn sich dieselbe auch jetzt nicht mehr immer erkennen läßt. Und doch gibt es unter den Tieren Gruppen, bei denen auch das ganz gut möglich ist. Ein Lieblingsbeispiel dieser Art, auf das Weismann oft zurückgekommen ist, bilden die Wale: in ihrem Organismus ist alles, was als charakteristisch für die Ordnung gilt, als Anpassung an das Wasserleben aufzufassen, und nach Wegnahme dieser Anpassungen bleibt überhaupt nur das allgemeine Schema des Säugetieres übrig. Aber auch die Vögel, die Fledermäuse und die verschiedenen Familien der parasitischen Krebse sind solche Gruppen, deren Hauptcharaktere als Anpassungen erkennbar sind.

Wenn aber die Organismen in erster Linie Anpassungskomplexe sind, - kann dann noch der Glaube an ein inneres Vervollkommnungsprinzip, an eine phyletische Lebenskraft, die ganz gesetzmäßig die einzelnen Formen auseinander hervorbrachte, aufrecht erhalten werden? Wohl kaum. Auch Nägcli hatte die Schaffung 
von Anpassungen seinem „Vervollkommnungsprinzip“ nicht zugeschrieben, und in der Tat wäre es schwer, sie auf ein solches zurückzuführen. Denn Anpassungen, so folgert Weismann, sind Veränderungen, die den Organismus in Übereinstimmung mit den Lebensbedingungen setzen; es handelt sich also nicht darum, zu erklären, wie es kommt, daß überhaupt die Arten sich von Zeit zu Zeit umwandeln, sondern es ist zu erklären, daß sie sich gerade in der Weise umwandeln, wie es für die Bedingungen, unter denen sie zu existieren haben, zweckmäßig ist. Unter Hinweis auf die Wale, deren eben gedacht wurde, wird die Frage gestellt: gesetzt auch, man ließe die Annahme gelten, daß die charakteristischen Eigenschaften eines Organismus alle durch eine innere Entwicklungskraft ins Dasein gerufen seien, wie solle man es verstehen, daß ein nur für ganz bestimmte Lebensbedingungen berechneter und unter anderen Bedingungen gar nicht existenzfähiger Organismus gerade an der Stelle der Erde auftrat und zu der Zeit der Erdentwicklung, welche die geeigneten Existenzbedingungen darbot? Die Anhänger einer inneren Entwicklungskraft sind, nach Weismanns Ansicht, genötigt, eine Hilfspypothese anzunehmen: eine Art von prästabilierter Harmonie im Sinne von Leibniz, die es mit sich bringt, daß die Veränderungen in der Organismenwelt Schritt für Schritt parallel gehen mit den Veränderungen der Erdrinde und der Lebensbedingungen auf ihr. Und selbst das würde noch nicht genügen, weil nicht bloß die Zeit, sondern auch der Ort in Betracht kommt, und weil es einem Wal nichts nützt, wenn er auf dem Trocknen entsteht. Es gibt sogar unzählige Fälle, wo ein Organismus ausschließlich einem ganz bestimmten Fleckchen der Erde genau angepaßt ist und nirgends anders gedeihen könnte, so besonders die zahlreichen Fälle von Nachäffung, in denen ein Insekt ein anderes, das durch einen schlechten Geschmack geschützt ist, kopiert, oder ein Blatt, eine bestimmte Baumrinde nachahmt. Das läßt sich nicht durch eine innere zielstrebige Umwandlungskraft erklären. Und wie passen zu der Annahme eines nach aufwärts drängenden Entwicklungsprinzipes die Fälle von Rückbildung von Organen, wie sie im größten Umfang bei schmarotzenden Formen zu beobachten sind! Dem Darwinschen Erklärungsprinzip fügen sich dagegen auch diese Erscheinungen ohne jeden Zwang. Sie zeigen, wie Weismann es einmal in einem besonderen Aufsatz 
über den Rückschritt in der Natur (I886) ausdrückt, die Kehrscite der Naturzüchtung, zeigen, daß im Interesse des ganzen Tieres und seiner Anpassung an gegebene Lebensbedingungen einzelne Organe unter Umständen sich rückbilden müssen, weil ihnen unter diesen Bedingungen keine Aufgabe zu erfüllen bleibt. Durch Beseitigung des entbehrlichen Organes wird das volle Gleichgewicht zwischen dem Bau des Körpers und seinen Leistungen wieder hergestellt, - der Rückschritt ist ein Teil des Fortschrittes.

Auch noch eine andere Erscheinung wird gerade vom Standpunkt des Selektionsprinzipes aus erst recht verständlich : die scheinbare Unvollkommenheit mancher Einrichtungen und Merkmale, die schon oben unter den Beschränkungen der Naturzüchtungsvorgänge erwähnt wurde. Die Zeichnungen der Sphingidenraupen, die Weismann genauer untersuchte, zeigen ja, genau betrachtet, außerordentlich unvollkommene Ähnlichkeit mit Blattzeichnungen, aber sie genügen, um die Tiere inmitten der Blätter leichter zu verstecken, für spähende Feindesaugen schwer erkennbar zu machen; ebenso fehlt auch den schönsten Blattschmetterlingen, wie der Kallima, zur wirklichen Kopie eines Blattes noch sehr viel, aber gerade darin liegt eben ein Beweis für den Ursprung dieser Zeichnungen aus Selektionsprozessen, „denn nicht ein botanisch genaues Bild des Blattes konnte auf diese Weise entstehen, sondern nur eine Fixierung solcher Einzelheiten, welche die Täuschung erhöhten" $\left.{ }^{44}\right)$. Der auslesende Faktor war eben nicht der Naturforscher, der Blatt und Schmetterling nebeneinander vor sich legt und vergleicht, sondern das Auge des Vogels, der im Fluge sich schwerlich jedes ihm als Blatt erscheinende Gebilde ganz genau darauf ansehen wird, ob es auch wirklich ganz genau geformt und gezeichnet ist. Und so ist es auch mit den echten mimetischen Anpassungen: sie genügen gerade zur Täuschung des Feindes. Aber auch sonst lehrt eine genaue Betrachtung der Organismen und ihrer Einrichtungen immer wieder eine nur , ,relative Vollkommenheit" derselben. Das ist ohne weiteres verständlich, wenn man sie auf Selektionsprozesse bezicht: der Natur der sie bewirkenden Ursachen nach können sie nur relativ vollkommen sein, weil die Naturzüchtung, wie wir schon sahen, nur so lange wirkt, als eine weitere Verbesserung des betreffenden Charakters noch von Vorteil für die Existenz der Art ist. Gerade diese Unvollkommenheiten der Anpassungen 
sprechen dafür, daß dic letzteren durch Selektionsprozesse entstanden sind.

\section{Regeneration als Anpassungserscheinung.}

Als Anpassungen, die durch Naturzüchtung ausgebildet worden sind, nimmt Weismann auch die Erscheinungen der Regeneration in Anspruch. Schon 1892 in dem Werke über das Keimplasma findet sich diese Auffassung entwickelt, die dann I899 noch in einem besonderen Aufsatz verteidigt und in den ,Vorträgen“" behandelt ist. Die theoretischen Erörterungen erfahren eine Ergänzung durch Versuche, die sich auf die Regeneration innerer Organe bei Tritonen beziehen und außer an den genannten Stellen noch in einer kurzen selbständigen Mitteilung von I903 besprochen worden sind. Nach Weismanns Auffassung ist das Regenerationsvermögen nicht eine primäre Eigenschaft der lebenden Substanz, sondern eine erst nachträglich geschaffene ,Einrichtung“, eine Anpassung des Organismus an bestimmte Forderungen der Lebensbedingungen. Das wird gefolgert aus den Verschiedenheiten des Regenerationsvermögens bei den einzelnen Tierformen und den einzelnen Organen. Die beiden Bedingungen, die den züchtenden Einfluß ausgeübt haben, sind die Verlusthäufigkeit und die Höhe des Verlustschadens, der sich aus der biologischen Bedeutung der Organe ergibt. Das heißt: Regenerationsfähigkeit ist bei solchen Teilen eingerichtet oder beibehalten, die von häufigerem Verluste bedroht und für das Tier von wichtiger biologischer Bedeutung sind. Eine ganze Anzahl von Beispielen, die Weismann gesammelt hat, konnte im Sinne dieser Betrachtungsweise gedeutet werden. So regenerieren sich die Beine der Tritonen sehr rasch und sogar zu wiederholten Malen, wenn sie abgeschnitten werden, während die Beine des Olm erst nach I $1 / 2$ Jahren wiedergebildet werden. Aber diese sind auch normalerweise schwach, rudimentär, und zudem lebt der Olm geschützt vor Gefahren in dunklen Höhlen, während die Tritonen viel mehr auf ihre kräftigen Beine angewiesen und dazu viel mehr Gefahren ausgesetzt sind. Bei Vögeln, deren Regenerationsvermögen sehr gering ist, regeneriert sich doch die Schnabelspitze, die bei den Kämpfen, namentlich der Männchen, häufig abgebrochen wird. Eigene und von Schülern Weismanns angestellte Versuche zeigten ferner, daß innere Teile (Lungen, Ei- 
und Samenleiter) bei Tritonen nicht regeneriert werden, - auch das konnte in dem Sinne gedeutet werden, daß dieselben in der Natur keinen häufigeren Verletzungen ausgesetzt sind und daß somit bei ihnen das Regenerationsvermögen nicht angezüchtet wurde. Die substantielle Grundlage der Regenerationserscheinungen sieht Weismann, wie schon erwähnt wurde, in einem Nebenidioplasma mit Ersatz- oder Regenerationsdeterminanten, das vom Keimplasma stammend, bestimmten Zellen beigegeben ist, in den Kernen derselben in inaktivem Zustand verharrt, um unter gewissen Umständen aktiv zu werden und den Teil, den es bestimmt, von neuem hervorzubringen.

Die Auffassung, daß die Größe des Regenerationsvermögens in einem direkten Verhältnis zu der Verletzlichkeit der Teile stehe, war nicht neu, sondern ist schon früher, bereits im I8. Jahrhundert (von Réaumur, Bonnet), ausgesprochen worden, doch erst Weismann hat den Gedanken konsequent durchgeführt und im weiteren Verfolg die Regenerationserscheinungen der Selektionstheorie untergeordnet. Von vielen Seiten hat er darin Zustimmung erfahren; groß aber freilich ist auch die Zahl derer, die sich dagegen ausgesprochen haben, und in der Tat fügen sich viele Tatsachen der Weismannschen Betrachtungsweise nicht. So ist sie gerade von den Forschern, die auf dem Gebiete der Regenerationserscheinungen speziell gearbeitet haben, als unbefriedigend abgelehnt worden, wenigstens soweit es sich um die Auffassung handelt, daß das Regenerationsvermögen überhaupt erst sekundär angezüchtet worden sei. Doch läßt sich ein vermittelnder Standpunkt verteidigen, nach dem die Regeneration an sich eine Fundamentalerscheinung der Organismen darstellt, aber durch Zuchtwahlprozesse vielfach beeinflußt worden ist, teils im Sinne einer Steigerung, teils in dem einer Rückbildung. Auch Weismann selbst hat einer derartigen vermittelnden Auffassung vorgearbeitet, indem er I892 seine Ansicht in der ,Vermutung“ zusammenfaßt: ,,es möchte die allgemeine Regenerationsfähigkeit sämtlicher Teile eine durch Selektion herbeigeführte Errungenschaft niederer und einfacherer Tierformen sein, die im Laufe der Phylogenese und der steigenden Kompliziertheit des Baues zwar allmählich mehr und mehr von ihrer ursprünglichen Höhe herabsinkt, die aber auf jeder Stufe ihrer Rückbildung in bezug auf bestimmte, biologisch wichtige und zugleich häufigem 
Verlust ausgesetzte Teile durch speziell auf diese Teile gerichtete Selektionsprozesse wieder gesteigert werden konnte.

\section{Die Schicksale der Arten als Anpassungserscheinungen.}

Die Unterordnung der Regenerationserscheinungen unter das Selektionsprinzip bedeutet ein weiteres Fortschreiten auf dem Wege, den Weismann seinerzeit in den Erörterungen über den Tod und die Dauer des Lebens beschritten hatte, einen weiteren Versuch, nicht nur die morphologischen Merkmale der Formen, sondern auch physiologische Erscheinungen als Anpassungen, entstanden durch Personalselektion, zu erklären. Da $B$ Weismann dieselbe Betrachtungsweise auch auf die wechselvollen Geschicke anwandte, die die Arten im Laufe der Stammesgeschichte durchmachen, und daß er auch hier das Walten einer, ,phyletischen Lebenskraft" ableugnete, bedarf kaum noch einer besonderen Erwähnung. Es ist, seiner Ansicht nach, nur ein ,,Spielen mit Begriffen", wenn man den Arten Geburt, Aufbliihen, Stillstand, Niedergang und Tod zuspricht, anders als in figürlichem Sinne. Gäbe es eine innere Entwicklungskraft, so könnte die Möglichkeit in der Lebensdauer der Arten keine so ganz maßlose sein; gäbe es ein ,Greisenalter" und einen ,natürlichen Tod" der Arten, so könnten beispielsweise nicht die meisten Nautiliden auf die Silurzeit beschränkt sein, einige aber bis heute leben, und gäbe es eine „,Tendenz", immer weiter zu variieren, so könnten solche uralte und primitive Cephalopodenformen wie die Nautilus-Arten sich überhaupt nicht bis auf unsere Tage erhalten haben, sondern müßten längst in höhere Formen umgewandelt sein. Dem Selektionsprinzipe fügen sich dagegen alle diese Erscheinungen ohne Mühe. Solange die Formen ihren Lebensbedingungen voll angepaßt waren, blieben sie erhalten und hatten auch keine Veranlassung, sich umzuwandeln; bei einem merklichen Wechsel dieser Bedingungen aber konnten nur die Arten erhalten bleiben, die unter den veränderten Lebensbedingungen dauerfähig waren, die anderen gingen zugrunde. Die mancherlei Gründe für die Unfähigkeit, sich anzupassen, wurden schon erörtert: sie können im Wesen der Naturzüchtungsvorgänge selbst, in den Organismen und in der Umwelt liegen.

So ist die phyletische Entwicklung der Organismen nicht nach einem von vornherein feststehenden Naturgesetz, auf Grund 
einer ihnen innewohnenden Entwicklungskraft, erfolgt, sondern auf Grund der erblichen individuellen Variationen, unter Auswahl der für die jeweiligen Existenzbedingungen nützlichen. Nicht aus inneren Gründen ist die Art geschaffen, sondern sie ist ,,in erster Linie ein Komplex von Anpassungen, von modernen, eben erst erworbenen, und von ererbten altüberkommenen, ein Komplex, der sehr wohl auch anders hätte sein könne $\mathbf{n}$, und der anders hätte sein müsse $\mathbf{n}$, falls er unter dem Einfluß anderer Lebensbedingungen entstanden wäre". Nur in geringem Umfang ist die Art zugleich ein Variationskomplex, d. h. nur gering an Zahl sind die Merkmale, für die der Charakter als „Anpassungen" nicht nachweisbar ist. Sie können nicht durch Personalselektion herausgebildet worden sein, sondern erfordern eine andere Erklärung. Sie ist später zu geben.

\section{Mutationstheorie.}

Bei dieser scharfen Betonung der Abhängigkeit der Artenentwicklung von den Lebensbedingungen, mußte Weismann sich auch gegenüber der Mutationstheorie, der neuen Form, die der holländische Botaniker de Vries, auf Grund langjähriger ausgedehnter Versuche an Pflanzen, der Selektionstheorie gegeben hatte, ablehnend verhalten. Auch die Mutationstheorie läßt die natürliche Zuchtwahl bis zu einem gewissen Grade gelten, legt aber besonderen Wert darauf, daß nicht, wie Darwin und Weismann annehmen, die fortwährend an den Organismen auftretenden individuellen, ,fluktuierenden“" Variationen das Material liefern, das erst von den Ausleseprozessen zur bleibenden Umbildung der Formen verwertet wird, sondern daß die neuen Formen bereits fix und fertig aus den alten auf Grund innerer Entwicklungskräfte entstehen und sich so gewissermaßen der Naturzüchtung zur Begutachtung darbieten. Die fluktuierenden Variationen sind nach de Vries nicht erblich-konstant, Züchtungen auf Grund derselben rönnten somit niemals einen dauernden Erfolg haben, vielmehr würcie nach Aufhören der Züchtung sehr bald wieder ein Rückschlag zur Ausgangsform erfolgen. Ihnen stellt er die erbbeständigen Variationen als ,M utationen“ gegenüber. Es sind Abänderungen kleineren, manchmal aber auch größeren Betrages, die aus inneren Ursachen nur $\mathrm{ab}$ und $\mathrm{zu}$, plötzlich, auftreten und, was eben für ihn das wichtigste ist, von vornherein erbbeständig sind. Die Muta- 
tionen größeren Betrages entsprechen den , single variations" oder „,sports" Darwins, den ,sprungartigen“ oder ,diskontinuierlichen" Variationen vieler Autoren (s. oben, S. I64). Im Leben der Art wechseln Perioden der Konstanz mit „Mutationsperioden“ ab; in den letzteren erfolgt das Auftreten newer ,elementarer Arten“" d. h. eine plötzliche Spaltung der Art in mehrere neue, die von vornherein erbbeständig, ihrer Natur nach aber teils nützlich, teils schädlich, teils indifferent sind. Die Aufgabe der Selektion ist es nur, die schädlichen bald wieder zu vernichten. So hat sich nach dieser Auffassung die phyletische Entwicklung der Formen nicht ganz allmählich, schrittweise, in Übergängen und im Laufe sehr langer Zeiträume vollzogen, sondern sprung- oder stoßweise durch plötzliche Umänderungen, periodisch.

Von verschiedenen Seiten, so besonders von L. Plate, ist hervorgehoben worden, daß der Gegensatz der Mutationstheorie zu der alten Darwinschen Selektionstheorie im Grunde gar nicht so groß ist, wie es vielfach angenommen wird, und $\mathrm{da} B$ insbesondere die „Mutationen“ von de Vries unter den Begriff der ,fluktuierenden Variationen“ Darwins fallen. Es sind eben die ,erblichen“ Variationen, auf denen natürlich allein die Umbildung der Formen beruhen kann. Auch Weismann hat, bei rückhaltloser Bewunderung des an Tatsachen und Gedanken reichen de Vriesschen Werkes doch die Schlußfolgerungen desselben nicht als bindend erachtet und manche Bedenken dagegen erhoben. Den Hauptwert legt seine Kritik darauf, daß auch die Mutationstheorie für die Erklärung der die ganze Organismenwelt beherrschenden Anpassung nicht ausreicht. Die Anpassungen können nicht entstanden gedacht werden im Anschluß an Abänderungen, die aus rein inneren Gründen, nur selten und in einem kleinen Prozentsatz der Individuen, dazu völlig richtungslos auftreten, sondern nur auf Grund der fortwährend auftretenden kleinen individuellen Variationen. Diese sind auch ihrem Wesen nach gar nicht verschieden von den „Mutationen"; vor allem sind auch sie erblich, und wenn auch eine auf sie begründete künstliche Züchtung nicht gleich eine „rein züchtende", konstant bleibende neue Rasse ergibt, so muß doch damit gerechnet werden, daß dies im Laufe länger fortgesetzter Züchtung endlich erfolgt. 


\section{c) Zuchtwahl oder direkte Bewirkung durch äußere Einflüsse und Funktion?}

Schärfer und hartnäckiger als der Kampf gegen alle Vorstellungen, die mit einer inneren, zwangsmäßig schaffenden Bildungskraft rechneten, war aber doch der, den Weismann gegen den Lamarckismus und alle Theorien, die an ihn anknüpfen, zu führen hatte. Die von ihm vertretene Auffassung, da $B$ die Organismen in erster Linie und zum gröBten Betrage Anpassungskomplexe sind, sagt ja an sich noch nichts über das Wie der Entstehung dieser Anpassungen. Daß er sich darüber ganz klar war, ist selbstverständlich, wenn er es auch nicht in jedem Einzelfalle wieder ausdrücklich hervorhebt. Für ihn selbst war die Frage entschieden : eine andere Möglichkeit für die Entstehung zweckmäßiger Anpassungen als auf dem Wege von Personalausleseprozessen sah er nicht. Das spricht sich deutlich in seiner Ausdrucksweise aus. Die Kennzeichnung einer Einrichtung als einer „Anpassung“ bedeutet bei ihm nicht nur das fertige Ergebnis eines Vorganges, sondern auch den in ganz bestimmter Weise gedachten Vorgang selbst: bedeutet nicht nur, da $B$ es sich hier um eine Einrichtung handelt, die, um mit Roux zu reden, die Dauerfähigkeit des Besitzers erhöht, sondern auch, daß diese Einrichtung durch Naturzüchtung auf dem Wege der Personalauslese zustande gekommen ist, d. h. als indirekte Anpassung. Der Doppelsinn, der in dem Worte „Anpassung“ wie in manchen ähnlichen Wortbildungen liegt, erleichterte diese kurze Ausdrucksweise.

An einer Begründung und Verteidigung dieser Ansicht hat er es freilich nicht fehlen lassen: die Fragen nach dem direkt umändernden Einfluß der äußeren Bedingungen wie nach der Umwandlung durch die Funktion, sind von ihm oft genug behandelt worden. Seine Stellungnahme zu ihnen war vor allem bestimmt durch die ablehnende Antwort, zu der er hinsichtlich der wichtigsten Vorbedingung für die Anerkennung jener Einflüsse kam: ihrer Erblichkeit.

a) Direkt umwandelnder Einfluß der äußeren Bedingungen.

In der Frage nach dem direkt umwandelnden Einfluß der äuberen Bedingungen ist Weismann von einer hohen Bewertung dieses Einflusses ausgegangen. Die Rede von 1868 
führt das Auftreten erblicher Varietäten auf die Wechselwirkung zwischen den äußeren Bedingungen und der physischen Natur der Organısmen zurück. Damit war den äußeren Bedingungen schon eine ziemlich große Bedeutung zugewiesen, immerhin verblieb doch noch dem Kampfe der Individuen die Auslese und damit die Fixierung der besten jener Varietäten. Die Schrift über den Saisondimorphismus der Schmetterlinge, von 1875, geht erheblich weiter: sie versucht den Nachweis, „daß allein schon durch äußere Einflüsse, wenn sie viele Generationen hindurch in gleicher Weise auf eine Art einwirken, mehr oder weniger bedeutende Umwandlungen der Form entstehen können". (So ist das Ergebnis in dem Vorwort zum zweiten Heft der Studien zur Deszendenztheorie, I876, ausgedrückt.) Mit der Vorstellung von der Kontinuität des Keimplasmas und der Nichterblichkeit somatogener Abänderungen wurde dies später, wie schon erörtert, in Einklang gebracht durch die Annahme, daß durch direkte Umweltwirkungen eine korrespondierende Beeinflussung sowohl des Soma wie des Keimplasmas erfolgen kann. Indessen kam Weismann in der Folge dazu, diesen an sich möglichen Vorgang als ein nur seltenes Vorkommnis und als wenig bedeutungsvoll für die Artumwandlung gelten zu lassen. In ersterer Hinsicht konnte er auf gewisse von anderer Seite angestellte Versuche hinweisen, aus denen hervorging, daß bei Pflanzen unter veränderten Lebensbedingungen sehr starke Veränderungen des Körpers erfolgen können, die aber bei Rückversetzung der Nachkommen in die alten Verhältnisse bald wieder rückgängig werden, also keine bemerkbare dauernde Abänderung des Keimplasmas hervorrufen; für eine nur geringe Bedeutung der direkten Mediumwirkungen aber in bezug auf die Artenumwandlung sprachen theoretische Erwägungen. In erster Linie die, daß Abänderungen an sich noch keine Anpassungen darstellen, daß es also schwer ist einzusehen, wie durch direkte Wirkungen zweckmäBige Abänderungen zustande kommen sollen. Wo wir zweckmäßige Abänderungen als Wirkung veränderter Lebensbedingungen sich ausbilden sehen, da ist viel mehr daran $\mathrm{zu}$ denken, daß hier indirekte Wirkung vorliegt, d. h. Auslese, natürliche oder künstliche Züchtung. So fehlt es an Beweisen dafür, daß die Veränderung der Behaarung bei Ziegen, Schafen, Rindern, Katzen, Schäferhunden durch das Klima mancher Hochländer, wie Tibet und Angora, direkt erzeugt sei und nicht 
vielmehr durch natürliche oder künstliche Züchtung. Gleiches gilt für die Beurteilung des Pelzes der Polartiere, der als direkte Wirkung der Kälte angesprochen worden ist, oder für die starke Entwicklung des Unterhautfettgewebes bei Wassersäugern. Es ist wenig wahrscheinlich, daß die zahllosen zweckmäßigen Einrichtungen der Organismen durch direkte Einwirkung von Umweltfaktoren, Klima, Nahrung usw. entstanden seien. Andererseits ist zu beachten, - was sich schon aus den Versuchen über den Saisondimorphismus der Schmetterlinge 1875 ergeben hatte - , daß durch direkte Mediumeinflüsse, wenn sie überhaupt erbliche Abänderungen hervorbringen und Generationen hindurch anhalten, alle Individuen einer Art in gleicher Weise verändert werden müßten. Das aber könnte für die Art leicht verhängnisvoll werden. Nur solange jene Abänderungen qualitativ oder quantitativ indifferent wären, würden sie ohne Schaden in den Merkmalsbestand der Art aufgenommen werden können; sobald sie aber irgendwie schädlich würden, würde Selektion zwar einsetzen und wenigstens versuchen, durch Ausmerzung der am empfindlichsten auf den Mediumreiz reagierenden Individuen die Abänderung einzudämmen, aber es könnte sich dabei leicht der Fall ergeben, daß die Gewalt der äußeren Einflüsse zu stark ist und der Art durch weitere Steigerung der schädlichen Abänderungen den Untergang bereitet. Auf diese Weise sind vielleicht manche Tierformen, als Opfer der äußeren Einwirkungen, ausgestorben.

Aus diesen Erwägungen kann gefolgert werden, daß ganz besonders sogenannte rein morphologische, biologisch bedeutungslose Merkmale auf die direkte Einwirkung der äußeren Verhältnisse $\mathrm{zu}$ beziehen sein werden, daß aber im allgemeinen solchen direkten Einwirkungen kein großer Spielraum bei der Umwandlung der Arten eingeräumt ist. Es wäre das auch nicht im Interesse der Arten gewesen.

Hat somit Weismann dem direkt umwandelnden Einfluß der äußeren Bedingungen keine sehr große Bedeutung bei der Herausbildung der Formen zuerkannt, so muß doch gegenüber unrichtigen Darstellungen betont werden, daß er einen solchen Einfluß durchaus zugegeben hat. Sogar so weit, daß er das Aussterben von Tierformen unter dem direkt umändernden Einfluß von Mediumwirkungen für möglich hält — somit dem Prinzip der direkten Be- 
wirkung als Erklärungsprinzip für gewisse Fälle den Vorrang läßt gegenüber dem Selektionsprinzip. Bei der Lehre von der Germinalselektion wird auf diese Frage zurückzukommen sein (s. Abschnitt VIII).

Die angeführten Erwägungen begründen den Gegensatz gegenüber Nägelis oben schon kurz angedeuteter Auffassung dieser Frage. In einem Punkte besteht zwischen beiden Forschern Übereinstimmung: in der geringen Bewertung der klimatischen und Ernährungseinflüsse. Auch Nägeli betrachtet die unmittelbaren and ersichtlichen Wirkungen dieser Einflüsse nur als vorübergehend, nicht als erblich und bleibend. Aber er erkennt an, daß durch äußere Einwirkungen, die durch Generationen anhalten, Reize hervorgerufen werden, die als Reaktionen in dem Idioplasma erbliche Veränderungen erzeugen. Diese erblichen Veränderungen haben den Charakter von „Anpassungsanlagen“; die auf ihnen beruhenden Merkmale, die an den Organismen sichtbar hervortreten, ,,befriedigen ein Bedürfnis“, sind nützlich. „Den Schutz, den die Tiere kalter Klimate in ihrer dicken Behaarung, und diejenigen weniger kalter Gegenden in ihrem Winterpelz finden, hat ihnen die Einwirkung der Kälte auf das Hautorgan gegeben. Die verschiedenen Waffen zur Abwehr und zum Angriff, die die Tiere in den Hörnern, Krallen, Stoßzähnen usw. besitzen, sind durch den Reiz, der beim Angriff oder bei der Verteidigung auf bestimmte Stellen der Körperoberfläche ausgeübt wurde, nach und nach entstanden und größer geworden." Weismann lehnt diese Vorstellung ab: Abänderungen sind noch keine Anpassungen, und es ist nicht ersichtlich, wie durch direkte Wirkungen äußerer Einflüsse mit Regelmäßigkeit nützliche Abänderungen im Keimplasma hervorgebracht werden sollen. Zufällig könnte das natürlich einmal der Fall sein; die Verwertung einer solchen nützlichen Einrichtung und ihre Erhebung zum Gemeinbesitz der Art würde aber immer der Selektion zufallen.

\section{B) Direkte Anpassung durch Gebrauch und Nichtgebrauch.}

Eine ganz andere, durchaus ablehnende, Haltung nahm er dagegen von I883 an gegenüber der Vorstellung ein, daß auch die Wirkungen des Gebrauches und des Nichtgebrauches erbliche Veränderungen herbeiführen könnten, und daB Zweckmäßigkeiten, 
die an einer Form ererbt auftreten, auf funktionelle Abänderungen der Vorfahren zurückzuführen seien. Diese funktionellen Abänderungen hat er von jenem Jahre ab stets nur als ,"passant", als auf das Individuum beschränkt betrachtet; alle für das Gegenteil ins Feld geführten Beweisgründe beruhen nach ihm entweder auf mangelhafter Beobachtung oder sind auf andere Weise, und zwar eben durch Personalselektion, zu erklären. Letzteres würde in gleicher Weise betreffen die allmähliche Steigerung eines viel gebrauchten Organes im Laufe der Stammesgeschichte, wie die allmähliche stammesgeschichtliche Rückbildung eines nutzlos gewordenen, nicht mehr gebrauchten Organes. Die Anwendbarkeit des Selektionsprinzipes gegenüber diesen Erscheinungen, die scheinbar auf der Vererbung der Wirkungen des Gebrauches und Nichtgebrauches beruhen, ergibt sich aus folgender Überlegung.

\section{Phyletische Vervollkommnung eines Teiles durch Personalselektion.}

Ein Organ, das von besonderer Wichtigkeit im Kampfe ums Dasein ist, wird naturgemäß von seinem Besitzer durch Übung in seiner Leistungsfähigkeit gesteigert werden. Diese Steigerung der Leistungsfähigkeit besitzt aber Grenzen, die für jedes Individuum in der natürlichen Veranlagung festgesetzt sind. Die Fähigkeiten eines nach irgend einer Richtung mangelhaft veranlagten Individuums können auch durch die größte Anstrengung in dieser Richtung nicht ins Riesenhafte gesteigert werden. So wird der Grad der Leistungsfähigkeit auf irgend einem Gebiete, der schließlich von den einzelnen Individuen erreicht wird, letzten Endes von der natürlichen Anlage, also von einer gegebenen Keimesbeschaffenheit abhängen. Und wenn dann im Kampfe ums Dasein immer oder doch hauptsächlich die leistungsfähigsten Individuen erhalten bleiben und zur Fortpflanzung gelangen, die minder leistungsfähigen aber ausgemerzt werden, so wird schließlich ein höherer Gesam tdurchschnitt der Leistungsfähigkeit der Individuen erreicht werden, - scheinbar als Folge des Gebrauches, tatsächlich als Folge der Auslese der besseren Anlagen. Der AusleseprozeB betrifft also letzten Endes nicht das Plus oder Minus stattgehabter Übung, sondern die verschiedenen Anlagen, d. h. die verschiedenen Keimesvarietäten, die als solche natürlich erblich sind. Das englische Vollblutpferd, das in seinem ganzen Körperbau sich weit von den 
Begründern der Rasse - drei orientalische Hengste - unterscheidet, hat seine Besonderheiten nicht durch fortdauernde Übung auf der Rennbahn erworben, sondern dadurch, daß 200 Jahre lang die für das Rennen vorteilhaftesten Variationen von den Züchtern zielbewußt ausgewählt und durch Züchtung gesteigert worden sind. Und so beruht überall die Steigerung, die ein Organ im Laufe der Generationen erkennen läßt, nicht auf einer Summierung der Übungsresultate des Einzellebens, sondern auf der Summierung günstiger Keimesanlagen. -

Daß diese Wirkungen der Naturzüchtung nicht unmittelbar beobachtet werden können, hat auch Weismann immer wieder ausgesprochen, aber wie sein großer Vorgänger Darwin konnte auch er immer wieder zur Begründung seiner Überzeugung die Erfolge der Pflanzen- und Tierzüchter heranziehen, über die er sich durch das Studium darauf bezüglicher Werke und durch den persönlichen Umgang mit praktischen Züchtern auf dem Laufenden zu halten suchte. Freilich kam er dabei gelegentlich in die eigentümliche Lage, die Erfolge der Züchter gewissermaßen gegen diese selbst verteidigen, und als Ergebnis zielbewußter Auslese in Anspruch nehmen zu müssen, was von züchterischer Seite als Ergebnis fortdauernder Übung in bestimmter Richtung, also im Sinne des Lamarckismus, gedeutet wurde (I893).

\section{Phyletische Verkümmerung nutzloser Teile als Folge von Personal- selektion.}

Aber auch die phyletische Verkümmerung eines nutzlos gewordenen, außer Gebrauch gesetzten Organes läßt sich auf der Grundlage der Selektionstheorie verstehen.

Zunächst kann, wie das schon von Darwin geschehen, in einer Anzahl von Fällen gezeigt werden, daß die Verkümmerung gewisser Organe unter Umständen sogar einen Nutzen gewährt: die Verkümmerung der Flügel bei vielen Käfern ozeanischer Inseln erscheint als nützlich, da sie für die Tiere die Gefahr, durch die Winde ins Meer geweht zu werden, vermindert; das Verschwinden der Beine bei den Schlangen kann als eine Erleichterung des Kriechens durch enge Löcher und Spalten angesehen werden, u. dgl.

In anderen Fällen ist ein ausgesprochener Vorteil aus der Verkümmerung eines Organes nicht zu ersehen. Hier kommt aber 
dann ein anderes Moment in Frage, das vor Weismann schon von Romanes hervorgehoben worden, dann aber in Vergessenheit geraten war, und auf das erst Weismann wieder mit Nachdruck hingewiesen hat: der Fortfall der erhaltenden Kraft der Naturzüchtung und die sogenannte Panmixie. Wenn ein Organ aus irgend einem Grunde an Bedeutung für die Art verliert, - wie etwa das Auge bei Tieren, die in Höhlen einwandern -, so werden auch die Ausleseprozesse, die es bisher auf seiner Höhe gehalten haben, in Wegfall kommen. Da seine gute oder weniger gute Leistungsfähigkeit jetzt für die Existenz des Individuums und somit auch für die Erhaltung der Art gleichgültig ist, so werden nunmehr auch die Individuen, die es in mangelhafter Ausbildung besitzen, zur Fortpflanzung kommen, und die fortgesetzte Kreuzung guter und schlechter Anlagen muß schließlich eine Verschlechterung des Organes zur Folge haben. Dieses Nachlassen der konservierenden Wirkung der Naturzüchtung hat Weismann eben als Panmixie bezeichnet, insofern dabei alle Individuen zur Fortpflanzung gelangen, sich miteinander vermischen, und nicht bloß die im ganzen oder in bezug auf ein Organ Bestausgestatteten. Auf Grund dieses Prinzipes, des Mangels einer Kontrolle durch Naturzüchtung, wäre auch z. B. die Kurzsichtigkeit des zivilisierten Menschen zu erklären. Allerdings hat die Leistungsfähigkeit des Prinzipes ihre Grenzen: es macht zwar die Verschlechterung eines Organes im Laufe der Generationen verständlich, kann aber nicht den völligen Schwund desselben erklären, wie er tatsächlich in vielen Fällen als erfolgt anzunehmen ist. So ergab sich auch von hier aus bei näherem $\mathrm{Zu}$ sehen die Notwendigkeit, neben der Personalselektion noch ein anderes Umbildungsprinzip als wirksam anzuerkennen, wie es denn auch später als Germinalselektion von Weismann aufgestellt worden ist.

\section{Beweise gegen den Lamarckismus.}

Aus dem Gesagten erhellt die Möglichkeit, die phyletische Steigerung oder Verkümmerung eines Organes durch Personalauslese zu erklären. Von größerer Bedeutung für die Stellungnahme gegenüber der Frage: Selektion oder direkte Anpassung? ist es, daß Weismann auf eine Anzahl von Tatsachen hinweisen konnte, die zwar auf den ersten Blick den Eindruck machen, als lägen in 
ihnen vererbtc Wirkungen des Gebrauches und des Nichtgebrauches vor, für die aber, bei genauerem Zusehen, das La ma rcksche Prinzip schlechterdings nicht in Frage kommen kann. Da diese Beispiele schon im vierten Abschnitt, bei Besprechung des Problemes der Vererbung funktioneller Abänderungen eingehender behandelt wurden, so genügt hier ein kurzer Hinweis. Es sind wesentlich dreierlei Erscheinungen: die phyletische Steigerung und Verkümmerung von Organen bei sterilen Formen, ferner die gleichen Vorgänge bei funktionslosen Merkmalen, und endlich die nur einmal im Leben ausgeübten Instinkte.

Geradezu als Musterbeispiele für weitgehende Anpassung aller Teile an die Funktion erscheinen die ,Arbeiter" der Ameisen. Einige Teile - die Geschlechtsorgane, die Augen, die Flügel, die Abschnitte des Thorax, an denen die letzteren sitzen sollten, nebst den Flügelmuskeln — sind rückgebildet, andere - vor allem das Gehirn und bei der Kaste der Soldaten auch die Kiefer, die Kiefermuskeln und in Zusammenhang damit der ganze Kopf - haben eine außerordentlich hohe Entwicklung erfahren. Alles das steht in innigster Beziehung zu der Funktion, die Ausbildung des Kieferapparates bietet noch besonders ein vortreffliches Beispiel für harmonische Anpassung mehrerer aufeinander angewiesener Teile, kurz, alles entspricht so unseren Erfahrungen und Vorstellungen von den Wirkungen des Gebrauches, daß es schwer ist, diese Wirkungen und ihre Erblichkeit hier ganz auszuschließen. Und doch müssen sie ausgeschlossen werden, denn die Arbeiter der Ameisen, an denen sich alle jene Einrichtungen finden, sind steril und somit gar nicht imstande, irgend etwas auf Nachkommen zu übertragen! Damit entscheidet sich die Alternative Selektion oder Lamarckismus? zugunsten der ersteren ,- wenigstens soweit es die erblichen Grundlagen jener Veränderungen anlangt: für die hohe Ausbildung im Einzelindividuum dürften Gebrauch und Nichtgebrauch immerhin noch von wichtiger Bedeutung sein. Sind aber so weit gehende ineinander greifende Anpassungen durch Naturzüchtung überhaupt möglich, so sind wir - so folgert Weismann -- zum mindesten berechtigt, sie in allen Fällen nach diesem Prinzip zu erklären. Zugleich zeigt das Beispiel sehr deutlich, daß die Naturzüchtung nur scheinbar mit den Merkmalen der fertigen Organismen, in Wahrheit aber mit den in den Keimzellen verborgenen Anlagen dieser 
Merkmale operiert. Denn in jenem Falle sind nicht die best angepaßten Arbeiter selbst ausgewählt worden, sondern die Männchen und Weibchen, die das beste Arbeiterkeimplasma produzierten, und das auslesende Prinzip war der Nutzen, den die Kolonie von der Erzeugung besonders gut organisierter Arbeiter hatte. Alle Zuchtwahl beruht auf der Auswahl von Keimesvariationen, oder, in der Sprache der Determinantenlehre ausgedrückt, auf der Auswahl günstiger Variationsrichtungen der Determinanten.

In gleicher Weise sprechen zugunsten des Selektionsprinzipes und gegen den Lamarckismus die allmähliche stammesgeschichtliche Steigerung oder Rückbildung ,,apraktischer“, untätiger Teile, die nur durch ihr Dasein bedeutungsvoll, einer Beeinflussung durch Ubung aber gar nicht unterworfen sind. Welcher Art sollte die Übung gewesen sein, die es bewirkte, daß gewisse Schmetterlinge im Sitzen aufs täuschendste trocknen Blättern gleichen? Hier bleibt nur Naturzüchtung, Personalselektion zur Erklärung übrig: die Individuen, die die größere Blattähnlichkeit zeigten, hatten auch die größere Aussicht, ihren Feinden zu entgehen und sich fortzupflanzen, und so konnte sich jene nützliche Eigenschaft vererben und immer mehr steigern. Umgekehrt: die Verkümmerung des Chitinskelettes bei den Einsiedlerkrebsen und den Larven der Köcherfliegen, die ihren Hinterleib durch ein Gehäuse schützen, kann nicht im Sinne einer vererbten ,Atrophie infolge von Nichtgebrauch“ erklärt werden, da der Chitinpanzer zu den Teilen gehört, bei denen funktionelle Anpassung gar nicht mehr wirksam ist, die also durch den Gebrauch nur abgenutzt, durch Nichtgebrauch aber im Gegenteil vielmehr geschont, also erhalten werden. So ist auch hier zunächst Personalselektion zur Erklärung heranzuziehen: der Panzer wurde überflüssig, als sich bei den Einsiedlerkrebsen der Instinkt ausbildete, den Hinterleib in einem schützenden Schneckengehäuse zu verbergen, und nunmehr konnte durch Panmixie seine Rückbildung verfolgen, die dann durch die noch zu besprechenden Vorgänge der ,"Germinalselektion“ bis zum völligen Schwund gesteigert wurde.

Was aber für die funktionslosen Teile gilt, warum sollte das für die aktiv oder passiv funktionierenden nicht auch gelten? Kommt bei jenen das Lamarcksche Prinzip nicht in Frage, so liegt zum mindesten keine Notwendigkcit vor, es für diese gelten 
zu lassen, und wenn durch Selektion die Schwanzfedern der Hähne außerordentlich verlängert werden konnten, bei denen doch eine „Übung" und dadurch bedingte Steigerung ganz fortfällt, so dürfte wohl auch in dem englischen Rennpferd mit seinen mancherlei geschätzten Eigenschaften lediglich das Ergebnis der tatsächlich durch Generationen hindurch stattgehabten Auslese, und nur scheinbar cin Erfolg der wiederholten Übung auf der Rennbahn zu sehen sein.

Und so ist denn endlich, nach Weismanns Überzeugung, auch für die Ausbildung der Instinkte Personalselektion verantwortlich zu machen. Das klingt freilich unglaubwürdig genug und ist denn auch bis in die neueste Zeit mit manchen guten Beobachtungen bekämpft worden. Aber so nahe es liegt, gerade in den oft so komplizierten Instinkthandlungen die erblich fixierten Resultate einer durch Generationen fortgesetzten Wiederholung von Handlungen zu sehen, dic ursprünglich einmal zweckbewußt ausgeführt wurden, so sprechen die von Weismann hervorgehobenen Fälle der nur ein mal im Leben ausgeführten Instinkte wieder entschieden gegen das Lamarcksche Prinzip und zugunsten des Selektionsprinzipes. Als solche wurden schon genannt der Hochzeitsflug der Bienenkönigin, mit seinen vielen Reflexmechanismen, die Eiablage, die oft von höchst komplizierten Instinkthandlungen begleitet ist, dic Herstellung von Schutzhüllen bei der Verpuppung. Hier ist von einer Übung überhaupt nicht die Rede, und es bleibt, wenn man nicht auf eine Erklärung überhaupt verzichten will, von allen zur Verfügung stehenden Erklärungsprinzipien nur das der Naturzüchtung übrig. Auf Naturzüchtung müssen dann auch die von Weismann in einem besonderen kleinen Aufsatz behandelten Fälle zurückgeführt werden, in denen sich bestimmte Instinkthandlungen zu bestimmten Färbungen hinzugesellen und mit diesen zu besonders wirkungsvollen Schutzmitteln vereinen. So die ,Trutzstellung" des Abendpfanenauges, die das bedrohte Tier dadurch zustande bringt, daß es statt wegzufliegen plötzlich die Augenflecke zeigt und wippende Bewegungen des Rumpfes ausführt, die, dem Stoßen eines Bockes ähnlich, einen bevorstehenden Angriff auf den Gegner vortäuschen. Für die schützende Bedeutung dieser Trutzstellung gegenüber angreifenden Vögeln haben Versuche von Standfuß den vollen Beweis erbracht. Das Interessante in diesem und ähnlichen Fällen ist die Häufung einer ganzen Anzahl nütz- 
licher Besonderheiten, teils rein somatischer, wie der Augenflecke, teils funktioneller, wic der komplizierten Bewegungen, und der Unterdrückung des Fluchttriebes, die sich dem Nervensystem des Tieres so fest eingeprägt haben, daß sie auf einen Reiz stets in derselben gesetzmäßigen Reihenfolge ablaufen. Sie alle sind als durch Naturzüchtung entstanden $z \mathfrak{u}$ denken.

Auf diese wären dann auch die hoch entwickelten geistigen Eigenschaften allgemeiner Natur bei dem Kulturmenschen - hohe Intelligenz, Phantasie, gutes Gedächtnis, Willenskraft, Fleiß usw. zurückzuführen, während sie für die Erklärung der spezifischen Talente, wie im vierten Abschnitte gezeigt wurde, nicht ausreicht. Diese erfordern vielmehr außer der auf die Steigerung der allgemeinen Geisteskräfte gerichteten Tätigkeit der Personalselektion noch die selbständig steigernde Wirkung der Germinalselektion und die Amphimixis, die die an sich guten Anlagen zu glücklicher Mischung vereinigt.

\section{Funktionelle Anpassung (Roux). Partialauslese.}

In der ablehnenden Haltung gegen den Lamarckismus ist Weismann auch nicht wankend geworden durch die ganz neue vertiefte Behandlung, die die Lehre von den Wirkungen des Gebrauches und des Nichtgebrauches als Lehre von der ,funktionellen Anpassung" durch Wilhelm Roux erfahren hat, eine Behandlung, die allerdings geeignet erscheinen konnte, für den Lamarckismus eine wertvolle Stütze zu bilden, und die anfangs wenigstens auch von ihrem Urheber selbst in diesem Sinne gedacht war. Eingehend erörtert wurde sie von Roux zuerst I88I in dem „Kampf der Teile im Organismus“, dem Epoche machenden Werke, das Darwin selbst als eine der bedeutungsvollsten Erscheinungen auf dem Gebiete der Entwicklung bezeichnet hat; in zahlreichen Schriften hat Roux ihre maßgebenden Gedanken auch späterhin verfolgt und an Tatsachen auf ihre Leistungsfähigkeit geprüft ${ }^{45}$ ).

Gleich die erste Erwägung, von der Roux ausgeht, richtet sich gegen die Darwin-Wallacesche Zuchtwahllehre: sie legt als unbestreitbare Tatsache fest, daB diese Lehre, die mit einer Auslese der Personen rechnet, zwar imstande ist, die gröberen Anpassungen der Organismen an die äußeren Bedingungen verständlich $\mathrm{zu}$ machen, nicht aber die feineren und feinsten zweckmäßigen 
Einrichtungen im Innern, die zweckmäßigen Strukturen der Organe, Gewebe und Zellen. Die aufs genaueste der Funktion, d. h. der Beanspruchung angepaßte Anordnung der Knochenblättchen in der Spongiosa der Knochen oder der Bindegewebsfasern des Trommelfelles und so viele andere Bildungen im Knochen-, Binde-, Muskelgewebe usw. können nicht durch Personalauslese auf Grund zufälliger Einzelvariationen entstanden sein, da ja schon Tausende derartig zweckmäßig angeordneter Bälkchen oder Fasern nötig gewesen wären, um für das Individuum einen Vorteil im Kampfe ums Dasein zu bedeuten, der durch Personenauslese hätte gezüchtet werden können. Hier findet also die Darwin-Wallacesche Lehre eine Grenze ihrer Leistungsfähigkeit und verlangt eine Ergänzung durch ein anderes Prinzip, das imstande ist, in direkterer Weise das ZweckmäBige hervorzubringen. Roux sieht dasselbe eben in der direkten Wirkung des Gebrauches und des Nichtgebrauches, oder, wie er dafür kürzer zu sagen vorschlägt: in der funktionellen Anpassung, d. h. der Anpassung an die Funktion durch Ausuibung der Funktion (und an das Ausbleiben der Funktion). Dem neuen Namen, - der übrigens, wie das Wort „Anpassung“ überhaupt, nicht nur für den Vorgang, sondern auch für das Ergebnis desselben verwendbar ist - gesellt sich sofort die neue Betrachtungsweise des Problemes hinzu, eine in die Tiefe dringende Analyse der Geschehnisse, die bis dahin, als aus der alltäglichen Erfahrung ganz geläufig, einfach als gegeben hingenommen und einer solchen genaueren Untersuchung nicht unterworfen worden waren.

Von den Ergebnissen, soweit sie hier in Betracht kommen, ist zunächst das wichtigste, grundlegende die Lehre von der trophischen Wirksamkeit der funktionellen Reize. Die aus der täglichen Erfahrung geläufige Erscheinung, daß der Gebrauch ein Organ kräftigt, der Nichtgebrauch es schwächt, hat darnach ihren Grund nicht, wie man früher meinte, darin, daß zu dem arbeitenden Organ mehr Blut strömt, während das untätige schlechter durchblutet wird, sondern darin, daß die Funktion selbst die in Anspruch genommenen Gewebselemente zur vermehrten Nahrungsaufnahme anregt, ihre Lebensprozesse steigert. Der funktionelle Reiz - oder richtiger: die Vollziehung der Funktion selbst, was aber wenigstens bei den Stützorganen auf eins herauskommt — wirkt als trophischer 
Reiz: die Aktivitätshypertrophie ist eine Folge der Stärkung der Assimilationskraft durch jenen, die zur Überkompensation des Verbrauches führt, wie die Inaktivitätsatrophie eine Folge der Schwächung der Assimilationsfähigkeit, bei Ausbleiben des funktionellen Reizes, darstellt. Damit ist also die erste Gruppe der Erscheinungen, die unter den Begriff der funktionellen Anpassungen fallen: die Veränderung der Größe der Organe unter dem Einfluß gesteigerter oder verringerter Inanspruchnahme - Aktivitätshypertrophie und Inaktivitätsatrophie - als unmittelbare Folge der Wirksamkeit jenes Prinzipes erkannt.

Das gleiche Prinzip erweist sich aber auch als leistungsfähig zur Erklärung der zweiten Gruppe funktioneller Anpassungen: der zweckmäßigen, „f unktionellen“, inneren Strukturen der Organe. Hier schiebt sich aber vermittelnd ein Vorgang des Kampfes, der Konkurrenz, ein. Kennzeichnend für die durch das Maß des Gebrauches regulierte Vergrößerung oder Verkleinerung eines Organes ist es, daß diese nicht in allen Dimensionen erfolgen, sondern nur in den stärker in Anspruch genommenen: es besteht dimensional beschränkte Aktivitätshypertrophie und ebenso dimensional beschränkte Inaktivitätsatrophie. Und so werden auch innerhalb eines Organes, z. B. eines Knochens, die stärker gebrauchten Stellen in den bestimmten stärker beanspruchten Dimensionen stärker vergrößert; die hier gelagerten Elemente nehmen den anderen weniger stark in Anspruch genommenen den funktionellen Reiz mit seiner trophischen Wirkung fort. So besteht in den Organen eine Konkurrenz der sie zusammensetzenden Elemente um den funktionellen Reiz", die zur Herstellung einer zweckmäßigen „,funktionellen“ inneren Struktur des Organes führt. Größe wie funktionelle Struktur eines Organes sind damit in letzter Instanz Wirkungen desselben Prinzipes: der Abhängigkeit der Gewebe von ihren funktionellen Reizen.

Diese Abhängigkeit der Gewebe von ihren funktionellen Reizen ist somit die Voraussetzung für die Vorgänge der funktionellen Anpassung, die im Individuum das Zweckmäßige durch Selbstgestaltung, also auf kürzestem Wege, hervorbringen. Sie ist, Rouxs Auffassung zufolge, in der Phylogenese gezüchtet worden, auf Grund von zufällig - d. h. aus unbekannten Ursachen - aufgetretenen Variationen unter den Zellen desselben Gewebes, aber auch unter 
den lebenstätigen Zellteilen, also jedenfalls unter gleichartigen Lebenseinheiten, die, mit jener glücklichen Qualität ausgestattet, sich zunächst im Kampf der Teile um Nahrung und Raum innerhalb der Einzelindividuen die Alleinherrschaft errangen, alsdann aber eine solche Begünstigung der betreffenden Individuen bedeuteten, daß sie weiterhin im Kampfe der Individuen zum Gemeinbesitz aller Organismen herausgezüchtet wurden. Neben dieser Form des Kamples der Teile innerhalb des Organismus gibt es noch eine andere, so insbesondere die zwischen ungleichartigen Teilen (z. B. verschiedenen Organen), auf deren Bedeutung aber hier nicht einzugehen ist.

Unter der von Roux begründeten Betrachtungsweise erscheint somit das Prinzip der funktionellen Anpassung zwar dem Darwin-Wallaceschen Prinzip der Personalauslese entgegengesetzt, indem es auf einem viel direkteren Wege, durch funktionelle Selbstgestaltung, das Zweckmäßige hervorbringt, aber doch dem großen Prinzip der Auslese überhaupt subsummiert. Auch bei ihm handelt es sich um eine Auslese, doch nicht um eine solche der Personen oder Individuen, sondern um eine solche der feineren und feinsten Teile, um Partial-oder Teilauslese. Durch den züchtenden Kampf um Nahrung und Raum und um den funktionellen Reiz sind innerhalb des Organismus die Teile zur Herrschaft gelangt, die die Fähigkeit besitzen, durch den funktionellen Reiz trophisch erregt zu werden; auf dem Wege der Konkurrenz um den funktionellen Reiz bilden sie dann die einzelnen zweckmäßigen funktionellen Anpassungen. So bringt der Kampf der Teile die Zweckmäßigkeit im Innern der Organismen hervor, der gleichzeitige Kampf der Individuen die Zweckmäßigkeit nach außen, das in den äußeren Existenzbedingungen Dauerfähige. Damit gelangt das Selektionsprinzip, von dessen kritischer Betrachtung die ganze Erörterung ausgegangen war, wieder zu Ehren; nur wird es aus dem Bereiche der Personen, auf dem sich die Grenzen seiner Leistungsfähigkeit herausgestellt hatten, auf die Lebenseinheiten aller Instanzen innerhalb des Organismus übertragen und in dieser neuen Verwendung mit Erfolg zur Erklärung der Erscheinungen in Anspruch genommen, die es bei seiner ursprünglichen Anwendung unerklärt lassen mußte.

Für das Individuum bedeutet die Fähigkeit zur funktionellen 
Anpassung einen Besitz von unschätzbarem Werte: sie ermöglicht es ihm, gleichzeitig in vielen, ja in allen Organsystemen beliebig viele zweckmäßige Einrichtungen in kurzer Zeit hervorzubringen und zwar auch Anpassungen an solche Verhältnisse, die erst während des Individuallebens neu an das Individuum herantreten. Darin aber ist die Partialauslese dem Darwinschen Prinzip der Personenauslese weit überlegen. Ihre Bedeutung für die stammesgeschichtliche Entwicklung der Organismen müßte eine ungeheure sein, wenn ihre Ergebnisse erblich wären. Die Überzeugung, da $B$ sie das sind, ist denn auch von vielen Seiten immer wieder vertreten, ja geradezu als notwendige zwingende Folgerung aus Rouxs Kritik an der Leistungsfähigkeit des Prinzips der Personenauslese, - für die Erklärung der inneren Zweckmäßigkeiten, der funktionellen Strukturen, - ausgesprochen worden.

Auch Weismann hat die große Bedeutung der von Roux angestellten und durch ein reiches Beobachtungsmaterial begründeten Erörterungen rückhaltlos anerkannt; für die phyletische Umbildung der Formen vermochte er indessen den Vorgängen der Partialauslese oder, wie er selbst, nicht gerade sehr glücklich, zu sagen vorschlägt: der Histonalselektion (Gewebsauslese), keinen Einfluß zuzuerkennen, aus dem uns bereits bekannten Grunde, weil er die Ergebnisse dieser Auslese, die funktionellen Anpassungen, nicht für erblich hielt. In letzterer Hinsicht hat auch Roux selbst seine anfängliche, im ,,Kampf der Teile“ vertretene Auffassung geändert: während er damals die Wirkungen der funktionellen Anpassung durch die vorliegenden Beobachtungen für gesichert annahm, ist er später, nachdem die Kritik Weismanns in dieser Hinsicht eingesetzt hatte, zu einer sehr vorsichtigen Stellungnahme gekommen und hat immer wieder die ,Größe des Rätsels der angeblichen Übertragung von Veränderungen des Personalteiles auf den Germinalteil" hervorgehoben, ohne auf der anderen Seite doch die Nichtvererbbarkeit erworbener Eigenschaften bereits als ganz sicher erwiesen zu halten. Für Weismann aber war diese Nichtvererbbarkeit eine sichere Tatsache, und so besitzen auch seiner Ansicht nach die Vorgänge der Partialauslese zwar eine sehr große Bedeutung für das Individuum, für die zweckmäßigen Ausgestaltungen im Inneren desselben, ihre Wirkungen bleiben aber auf dasselbe beschränkt und gehen mit ihm zugrunde. Soweit die zweckmäßigen 
Einrichtungen erblich sind, beruhen sie auf Keimesvariationen und Personalauslese. Und ebenso ist das Substrat, an das die Vorgänge der funktionellen Anpassung geknüpft sind, die Verschiedenheit der histologischen Elemente, ihre Differenzierung nach dem Prinzip der Arbeitsteilung in Muskel-, Nerven-, Drüsenzellen usw. ihre Fähigkeit, auf den adäquaten Reiz mit vermehrter Nahrungsaufnahme und Überkompensation des Verbrauchten $\mathrm{zu}$ reagieren durch Personalselektion gezüchtet. Histonalselektion tritt auf Grund dieses Substrates nur in Wirksamkeit im konkreten Falle, an einer gegebenen Stelle, unter gegebenen Bedingungen.

Daß Personalauslese überhaupt imstande ist, selbst kleinste histologische Elemente in ihrer Ausgestaltung, Zahl und Form zu beeinflussen, wofern damit nur ein wirklicher Nutzen für die Art verbunden ist, dafür konnte $\mathrm{W}$ eismann auf ein besonderes schönes und einleuchtendes Beispiel hinweisen: die von ihm festgestellten und in ihrer Bedeutung zum ersten Male eingehender behandelten Samenzellen der Daphnoiden. Nach Form, Größe und Zahl zeigen diese Elemente bei den einzelnen Arten außerordentlich bedeutende Verschiedenheiten, wobci besonders auffallen muß, daß manchmal Arten, die ganz verschiedenen Familien angehören, sehr ähnliche, und andererseits nahe verwandte Arten sehr verschiedenartige Samenzellen besitzen. Das hängt, wie sich zeigen ließ, damit zusammen, da $B$ die Besonderheiten der Samenzellen aufs zweckmäßigste den Besonderheiten der Begattungsbedingungen entsprechen, diesen angepaßt sind. So sind sie bei manchen Arten sehr klein, aber in ungeheuerer Zahl vorhanden, bei anderen sehr groß und viel weniger zahlreich. Jenes findet sich bei Formen, deren Weibchen einen geräumigen, aber schlecht verschlossenen Brutraum besitzen, bei denen also mit einem bedeutenden Verlust von Samenelementen bei der Begattung gerechnet werden muß; dieses, der Besitz spärlicher großer Samenzellen, zeichnet die Formen mit geschlossenem Brutraum aus. Am größten und am wenigsten zahlreich sind die Samenzellen der Formen, deren Männchen ein Begattungsorgan besitzen, bei denen somit jeder Verlust von Samenzellen ausgeschlossen ist. Die Annahme einer inneren Bildungskraft versagt hier, wenn man nicht hinter ihr geradezu eine bewußt schaffende Intelligenz gelten läßt, aber auch direkte, funktionelle Anpassung der Samenzellen kann nicht in Frage kommen. Es bleibt von den 
bisher aufgestellten Bildungsprinzipien nur das der Selektion, und zwar das der Personena uslese, zur Erklärung brauchbar: nur die Individuen, deren Samenzellen infolge ihrer günstigen Beschaffenheit zur Befruchtung gelangten, hatten Nachkommen und konnten die Art fortführen, die anderen starben ohne Nachkommen ab.

Hat aber Weismann auch so eine Bedeutung der Partialauslese unter den somatischen Elementen für die phyletische Umbildung der Formen abgelehnt, so hat doch gerade er den allgemeinen von Roux zuerst ausgesprochenen und begründeten Gedanken, daß nicht nur zwischen den Personen, sondern zwischen den Lebenseinheiten aller Instanzen ein Kampf besteht, mit besonderer Zustimmung ergriffen und denselben später in der Lehre von der Gèrminalselektion auf die letzten hypothetischen Elemente des Keimplasmas, die Determinanten, ausgedehnt, - bei denen, eben weil es sich um Keimesbestandteile handelt, auch mit einer Vererbbarkeit der Kampfesergebnisse gerechnet werden konnte.

4. Ergebnis der Prüfung der $Z$ uchtwahllehre:

Neo-Darwinismus.

So sind nach Weismann alle zweckmäßigen Einrichtungen der Organismen, alle Anpassungen, alle irgendwie wertvollen Besitztümer der Organisation auf Selektionsprozesse zurückzuführen; das Prinzip der direkten Anpassung im Sinne Lamarcks ist fallen gelassen. Damit ist der "Neo-Darwinismus" gekennzeichnet, als dessen Hauptvertreter Weismann genannt werden muß.

Der Einfluß, den diese scharfe Hervorhebung der Bedeutung der Personalauslese auf das biologische Denken der letzten Dezennien und darüber hinaus auf die Behandlung der verschiedensten Probleme gehabt hat, insbesondere auch auf die Bestrebungen, die auf eine Verbesserung des Menschengeschlechtes hinzielen, kann kaum überschätzt werden. Daß Weismanns Schriften daran einen besonderen Anteil gehabt haben, ist zweifellos; aber es wäre eine Beleidigung zahlreicher ernst und gründlich denkender Männer, anzunehmen, daß dabei die Art der Darstellung, , gewandte Dialektik“, den Ausschlag gegeben hätte. Es war die Kraft der von Weismann vorgebrachten Tatsachen, die diesen Eriolg bedingte. Eine wie große Bedeutung der Ausbaugedanke auf dem Gebiete der zuletzt genannten Bestrebungen der Eugenik oder 
Rassehygiene nachgerade gewonnen, darüber gibt die Literatur über dies Gebiet AufschluB; das bekannte verdienstvolle Werk von Schallmayer zeigt es auf jeder Seite. Mit lebhafter Anteilnahme hat Weismann auch diese Bestrebungen verfolgt; wenn er selbst nicht besonders agitatorisch dafür eingetreten ist, so lag der Grund dieser Zurïckhaltung wohl in seiner ganzen Geistesrichtung, der es mehr auf das Erkennen als auf das praktische Verwerten ankam. Aber es war gewiß voll berechtigt, daß die Gesellschaft für Rassehygiene ihn zu ihrem Ehrenmitgliede ernannte.

\section{Sexuelle Züchtung (geschlechtliche Zuchtwahl).}

Hat sich Weismann mit seiner Ablehnung des La ma rckschen Prinzips von dem erblich verändernden Einfluß des Gebrauches und Nichtgebrauches von Darwin getrennt, so hat er sich diesem dagegen in der Frage der sexuellen Züchtung oder geschlechtlichen Zuchtwahl in allen wesentlichen Punkten angeschlossen. Natürliche Züchtung und sexuelle, geschlechtliche Züchtung bringen beide das Selektionsprinzip zur Geltung; ihre Annahme beruht auf ähnlichen Überlegungen, nur der auslesende Faktor, der angenommene ,Züchter" ist in beiden Fällen verschieden. Bekanntlich hat Darwin in einem besonderen Werke I87I das Prinzip der geschlechtlichen Zuchtwahl neben das der natürlichen gestellt und mit seiner Hilfe zahlreiche Merkmale erklärt, die durch das letztere nicht verstanden werden können, da sie für die Erhaltung der Art bedeutungslos sind: so insbesondere einen Teil der sogenannten sekundären Geschlechtscharaktere, die bei manchen Formen derartig in die Augen springend sind, daß man von einem Geschlechtsdimorphismus sprechen kann. Die hierher gehörigen Merkmale lassen sich in drei Gruppen bringen. Es sind erstens wirkliche Angriffs- oder Verteidigungswaffen für die Kämpfe der Männchen um die Weibchen (Geweihe, Mähnen, Sporn der Hähne), dann Organe zum Aufspüren, Fangen und Festhalten des Weibchens, endlich Schmuckbildungen und sonstige Auszeichnungen verschiedenster Art (prächtige Färbungen, musikalische Fähigkeiten, Düfte und dgl.). Die Merkmale der beiden ersten Gruppen sind, nach dem Darwinschen Prinzip, von unmittelbarem Nutzen für das Männchen zwecks Erreichung der Fortpflanzung; ihre besondere Ausbildung wird dem betreffenden Männchen ein Übergewicht in der Konkurrenz 
mit Rivalen verleihen, während die Weibchen selbst dabei sich passiv verhalten. Anders bei der dritten Gruppe; den Schmuckbildungen, im weitesten Sinne. Diese sollen, nach Darwins Vorstellung, auf das Unterscheidungsvermögen und den Geschmack des begehrten Weibchens wirken und die Wahl desselben auf den Träger der hervorstechendsten Auszeichnung lenken; - bei ihnen wird also ein aktives Eingreifen des Weibchens vorausgesetzt. Alle aber bilden für die Männchen Mittel, um zur Fortpflanzung zu gelangen; je besser sie ausgeführt sind, um so leichter wird ihr Besitzer zum Ziele kommen und damit zugleich seine auszeichnenden Vorzüge auf Nachkommen übertragen. Im Laufe der Generationen muß sich dadurch, wie bei der natürlichen Zuchtwahl, eine Steigerung der Güte der Merkmale ergeben.

So allgemein angenommen die Darwinsche Auffassung von der Bedeutung der wirklichen Kampfwaffen sowie der Spür- und Fangeinrichtungen, so bestritten ist seine Vorstellung von der Gattenwahl durch die Weibchen und der Entstehung von Schmuckfedern, musikalischen Fähigkeiten und ähnlichen auszeichnenden Merkmalen durch geschlechtliche Auslese, und vielfach wird dieselbe durchaus abgelehnt, auch von solchen, die die Naturzüchtung gelten lassen. Weismann hat sich mehrfach zu dieser Frage geäußert, so schon kurze Zeit nach dem Erscheinen des Darwinschen Buches, in seiner Schrift über die Bedeutung der Isolierung für die Artbildung ( 1872, - in der er, wie es scheint, den Begriff ,,sexueller Dimorphismus" eingeführt hat -), in der Arbeit über die Schmuckfarben der Daphnoiden, zusammenfassend endlich in der Gedächtnisschrift für Darwin (Igoga) sowie in einem besonderen Kapitel seiner Vorträge über Deszendenztheorie. Von Anfang an und bis zum Ende ist er für die allgemeine Richtigkeit der Darwinschen Auffassung eingetreten, doch hat er hier und da Abänderungen an ihr angebracht, sie teils erweitert, teils eingeschränkt, besonders auch das Verhältnis der sexuellen Selektion zu der Artselektion, das mannigfache Ineinandergreifen beider erörtert. Es gibt, wie Weismann ausführt, sekundäre Geschlechtsmerkmale, die lediglich durch natürliche Zuchtwahl (Artselektion) erklärt werden müssen, wie die zwerghafte Kleinheit der Männchen mancher schmarotzender Krebse, einiger Würmer und Rädertierchen, andere, bei deren Ausbildung Artselektion und sexuelle Selektion inein- 
andergreifend zu denken sind, wie die wirklichen Waffen, die ja doch auch eine Verbesserung der Art im Kampfe ums Dasein (nicht nur in dem der Männchen untereinander) bedeuten, oder Einrichtungen zum Festhalten der Weibchen bei manchen Formen, - Einrichtungen, ohne deren Vorhandensein die Fortpflanzung der Art übcrhaupt in Frage gestcllt wäre, deren bessere Ausbildung aber doch auch dem einzelnen Männchen einen Vorteil gegenüber seinem Rivalen verleiht -, endlich aber auch musikalische Betätigungen, die vielfach nicht nur Werbemittel der Männchen sind, sondern auch dazu dienen, daß die Artgenossen sich zusammenfinden. Damit schränkt sich die Zahl der Einrichtungen, die rein auf geschlechtliche Auslese zurückgeführt werden müssen, erheblich ein. Unter diesen ist auch wieder eine Anzahl solcher, deren Besitzwert in bezug auf die Fortpflanzung ohne weiteres in die Augen springt, und denen gegenüber die Weibchen sich lediglich passiv verhalten: die besonders gut ausgebildeten Geruchsorgane bei den Männchen vieler Schmetterlinge, Käfer und niederer Krebse, deren Vervollkommnung leicht darauf zurückgeführt werden kann, daß immer die besseren Riecher und Spürer am leichtesten und raschesten das Weibchen zu wittern imstande waren; ferner gewisse Fangorgane, mit denen die Männchen mancher niederen Krebse die Weibchen einfangen und fosthalten. Der Umstand, daß gegenüber dicsen Einrichtungen den Weibchen eine selbständige Wahl nicht zufällt, erleichtert es, hier ähnliche Züchtungsprozesse anzunehmen, wie bei der natürlichen Zuchtwahl — wenigstens für den, der überhaupt an der Wirksamkeit von Selektionsprozessen glaubt. So bleibt denn endlich die Gruppe der reinen Auszeichnungen, „,Ornamente", die nach Darwins Auffassung zunächst anziehend auf die Weibchen wirken und daraufhin bei ihnen die Auswahl cines Gatten anregen sollen: die prächtigen Farben mancher Vogelund Schmetterlingsmännchen, der Gesang der Vogelmännchen und andere musikalische Fähigkeiten, die merkwürdigen Düfte, die manche Schmetterlingsmännchen von ihren Flügeln ausströmen lassen. Weismann hat auch für diese die Darwinsche Erklärung angenommen, freilich mit einer kleinen Abänderung: während Darwin jene Vorzüge auf das ästhctische Empfinden der Weibchen wirken läßt, hält Weismann dafür, daß sie mehr unmittelbar als sexuelle Erregungsmittel in Betracht kommen, manche schon 
an und für sich, wie etwa die Farben und Düfte mancher Schmetterlingsmännchen, andere, indem sie als Äußerungen des erregten männlichen Geschlechtstriebes die gleiche Empfindung beim Weibchen auslösen, wie Locktöne oder die Liebestänze, die das Pfauenmännchen, unter Entfaltung aller seiner Reize, um das Weibchen ausführt. Aus Locktönen, die ursprünglich nur dem Weibchen die Anwesenheit eines Männchens ankündigten, ist durch weitere Steigerung der Vogelgesang entstanden zu denken, der nun die Bedeutung eines Werbe- und Erregungsmittels hat. Ähnlich mag es mit den Düften sein, die manche männliche Tiere zur Brunstzeit ausströmen. Auch sie mögen zuerst nur die Nähe des anderen Geschlechtes angezeigt, dann aber durch Ausleseprozesse eine Steigerung zu einem Erregungsmittel erfahren haben. Unter ihnen haben die an Blumen erinnernden Wohlgerüche, die von manchen männlichen Schmetterlingen ausgehen und nach der Entdeckung von Fritz Müller auf eigentümlichen Duftschuppen beruhen, Weismann ganz besonders beschäftigt und zu Untersuchungen angeregt, die zu dem Nachweis führten, daß der Duftstoff, ein ätherisches Öl, wahrscheinlich von Hautzellen der Flügel (die nach früherer Anschauung zugrunde gehen sollten) erzeugt wird. Nicht vergessen seien auch die Ausführungen Weismanns über die Häufung sekundärer Geschlechtsmerkmale bei manchen Formen, über die Unterschiede der auf sexuelle Zuchtwahl zurückführbaren Färbungen und Zeichnungen gegenüber denen, für die die natürliche Auslese verantwortlich zu machen ist, über die Entstehung komplizierter Farbenmuster auf den Flügeln der Schmetterlinge. Von diesen nimmt er an, daß sie einer wied erholten Farbengebung ihre Entstehung verdanken ${ }^{46}$ ). Denn der Wettbewerb innerhalb eines Geschlechtes hört nie auf, und wenn eine Farbenkombination sich völlig fixiert hat und allen Individuen in fast gleicher Weise zukommt, so wird nur noch eine ganz neue Variation ihrem Träger Vorteil gewähren. Es wird dann gewissermaßen eine „neue Mode“ aufkommen. Der ersten Farbengebung folgte so eine zweite, dritte usw., und durch diesen vielfachen Wechsel der Farben konnten die ungemein feinen und komplizierten Zeichnungen der Schmetterlinge entstehen.

Noch nach manchen anderen Richtungen hat Weismann dic Darwinsche Vorstellung von der Wirksamkeit der sexuellen 
Auslese weiter geführt und zur Erklärung auffallender Erscheinungen verwertet. Die sexuelle Züchtung ist ihm eine wichtige Ergänzung, zugleich aber auch eine Bestätigung der Naturzüchtung, da es in einfachen Fällen möglich ist, den Selektionswert kleiner Verbesserungen eines Merkmals zu verstehen; sie hat aber auch, wie er (in der Arbeit über die Schmuckfarben der Daphnoiden) besonders erörtert und übrigens für manche Fälle auch schon von Darwin selbst angenommen worden ist, vielfach nicht nur zu einer Umgestaltung des einen, und zwar gewöhnlich des männlichen Geschlechtes geführt, sondern auch eine solche der ganzen Art eingeleitet, indem die zunächst bei den Männchen herangezüchteten Charaktere sich mehr oder weniger vollständig auf die Weibchen übertragen. So erfolgte ein ,Aufrücken sekundärer Geschlechtscharaktere zu Artcharakteren". In dem Umstand, daß sie die Art nicht widerstandsfähiger machen im Kampfe ums Dasein, unterscheiden sich diese Merkmale von denen, die auf Naturzüchtung zurückzuführen sind. -

Von allgemeiner Wichtigkeit ist endlich noch der Gedanke, daß sexuelle Abzeichen gelegentlich in sprungweise aufgetretenen Variationen ihre erste Wurzel gehabt haben können. Ein wichtiger Einwand gegen die sexuelle Selektion wird beseitigt, wenn man annimmt, daß die Sexualabzeichen von vornherein als a uffällige Variationen größeren Betrages auftraten.

So hat Weismann die Lehre von der geschlechtlichen Zuchtwahl verschiedentlich weiter geführt und hat auch hier gezeigt, wie es ihm stets darum zu tun war, die Einzeltatsachen unter großen allgemeinen Gesichtspunkten zu verstehen, zugleich aber auch die Theorie immer wieder an den Tatsachen zu prüfen. Diese Prüfung führte ihn dazu, auch die Lehre von der Gattenwahl der Weibchen auf Grund auszeichnender Ornamente für richtig zu halten, - die Lehre, die zur Zeit von vielen Seiten als unmöglich, von anderen als ein Notbehelf hingestellt wird, der lediglich mangels besserer Erklärungen einstweilen beizubehalten ist. Weismann hat sich rückhaltlos zu ihr bekannt und von der weiteren Ausbreitung der Tatsachenkenntnis ihre allgemeinere Anerkennung erwartet. Wie weit er mit diesem Optimismus Recht gehabt, kann erst die Zukunft lehren ${ }^{46}$ a). 


\section{Ergänzungsbedürftigkeit der Darwin-Wallaceschen Zuchtwahllehre.}

Indem Weismann so bestrebt war, die Darwin-Walla ce sche Zuchtwahllehre in ihren beiden Formen, als Art- und sexuelle Selektion, von allen Seiten $\mathrm{zu}$ beleuchten, sie $\mathrm{zu}$ vertiefen und auszubauen, kam er doch auch zu der Erkenntnis, daß nicht alle Erscheinungen, die wir an den Organismen wahrnehmen, durch Naturzüchtung erklärt werden können, und daß der so bezeichnete Vorgang nicht allein in der "Auslese“ (im engeren Sinne) besteht, sondern zunächst das Vorhandensein eines auslesefähigen Materiales zur Voraussetzung hat, das durch irgendeine andere Kraft geschaffen und beeinflußt wird. An die Stelle der Frage nach der Causa summandi (Roux), nach der Ursache der Auslese und Häufung der Variationen, einer Frage, die allein von der Selektionstheorie behandelt worden war, trat nun die nach der wirklichen Bildungsursache, der Causa efficiens. Die Annahme noch eines neben der eigentlichen Auslese wirksamen Entwicklungsprinzipes erwies sich als notwendig. Darwin und nach ihm viele andere Forscher hatten die gleiche Notwendigkeit empfunden und eine Umwandlung der Formen unter dem direkten Einfluß der äuBeren Bedingungen sowie durch den Gebrauch und Nichtgebrauch der Organe gelten lassen. Die letztere lehnte Weismann für die phyletische Entwicklung ab, die erstere gab er nur innerhalb enger Grenzen zu. Damit aber fiel für eine ganze Anzahl von Erscheinungen die Erklärungsmöglichkeit fort, und es war notwendig, irgendein anderes wirkliches Bildungsprinzip an die Stelle des aufgegebenen zu setzen. Es blieb noch die Möglichkeit, dasselbe in inneren Vorgängen zu suchen, und in dieser Richtung fand denn auch Weismann eine Lösung der Frage - freilich anderer Art, als die von Nägeli, Kölliker u. a. gegebene es war.

Die wichtigsten jener von Weismann anerkannten, ein selbständiges inneres Entwicklungsprinzip verratenden Erscheinungen, - auf die zum Teil schon hingedeutet wurde - dürften die folgenden sein.

Wenn Abänderungen, auch nützlicher Art, nur bei vereinzelten Individuen auftreten, so wird, wofern nicht besondere Umstände, wie Isolierung oder sexuelle Züchtung, unterstützend hinzukommen, 
indem sie die Rückkreuzung mit der Stammform erschweren, wenig Aussicht auf ihre Erhaltung sein. So sind wir zu der Annahme genötigt, daß vielfach von Anfang an zahlreiche Individuen die Anfangsstufen der nützlichen Abänderung hervorgebracht haben. Das aber weist darauf hin, daß die Variationen schon bei ihrem ersten Auftreten nicht, wie Darwin meinte, regel- und richtungslos, sondern entweder durch die äußeren Verhältnisse oder durch innere, d. h. in den Organismen selbst gelegene Kräfte bedingt sind ${ }^{47}$ ). Eine solche Abhängigkeit der Variationen von bestimmten Gesetzen, insbesondere das Walten einer Kraft, die ein variierendes Merkmal in der cinmal eingeschlagenen auf- oder absteigenden Variationsrichtung festzuhaiten vermag, ein besonderes ,,Stärkungs" - und ,Schwächungs"-Prinzip, muß dann aber auch, wie schon angedeutet, bei jedem Zuchtwahlproze B angenommen werden. Das ist ja der Sinn der Zuchtwahllehre, daß ein Merkmal, das zuerst in kleinem Betrage auftritt, allmählich gesteigert, daß also das Mittel, um das herum die individuellen Schwankungen stattfinden, alimählich nach aufwärts verschoben wird. Das kann durch ,Auslcse" allein nicht erreicht werden, sondern setzt eine Kraft voraus, die von sich aus eine solche Verschiebung des Mittels bewirkt und der Auslese das betreffende Merkmal in immer höherer Ausbildung anbietet. Diese Steigerungsfähigkeit eines Merkmals, mit der die Lehre von der natürlichen Zuchtwahl rechnet, wird durch die Erfolge der künstlichen Züchtung bewiesen. Durch die im individuellen Leben erfolgende Übung der betreffenden Einrichtung würde eine solche Steigerung leicht zu erklären sein -- wofern man die Wirkungen derselben als erblich ansehen könnte, was Weismann aber ablehnte. Zudem könnte auch dieses Prinzip nicht überall in Frage kommen; es scheidet von vornherein aus bei den ,,apraktischen", nur durch ihr Dasein bedeutungsvollen Merkmalen, die nicht eigentlich ,funktionieren“, und bei denen somit auch eine ,funktionelle Anpassung“, deren Wirkungen etwa vererbt werden könnten, gar nicht in Frage kommt. Wenn der japanische Züchter Hähne mit sechs Fuß langen Schwanzfedern züchten konnte, so weist das darauf hin, daß durch irgendeine Kraft die Schwanzfedern sich überhaupt in einer anhaltenden aufwärts gerichteten Variationsbewegung befanden, die vom Züchter ausgenutzt wurde, indem er immer die Tiere mit den am stärksten verlängerten Federn 
zur Nachzucht auswählte. Und doch kann Personalselektion offenbar das Voranschreiten einer Variationsrichtung nicht direkt bewirken, sondern ihr nur freien Lauf lassen, indem sie die Träger entgegenstehender Variationen von der Nachzucht ausschließt. Was war aber dann die eigentliche Ursache dieser Steigerung, dieses Fortschreitens in einer bestimmten Variationsrichtung? Es bleibt auch hier kaum etwas anderes übrig, als die Annahme einer inneren Kraft, die den Variationen bestimmte Richtungen vorschreibt.

Ist das schon zur Ergänzung der Ausleseprozesse notwendig, so wird es in noch höherem Maße gefordert durch die Erscheinungen, bei denen solche Prozesse überhaupt nicht in Frage kommen, also zur Erklärung der notwendig anzunehmenden Steigerungsfähigkeit von Merkmalen, die der Zuchtwahl nicht unterworfen sind, und zwar nach der positiven wie nach der negativen Seite hin. - Abänderungen, die Selektionswert haben sollen, müssen eine gewisse Größe besitzen; bevor sie diese erreicht haben, d. h. solange sie ,unter der Schwelle von Gut und Schlecht" bleiben, haben sie keine Bedeutung für die Zuchtwahl und können somit von dieser auch nicht gesteigert werden. So ergibt sich die Notwendigkeit, nach einer anderen Ursache $\mathrm{zu}$ forschen, die imstande ist, solche noch indifferenten Abänderungen in der gleichen Richtung weiter zu steigern und bis zum Selektionswert emporzuheben.

Diese mehr theoretische Erwägung erfährt eine sehr kräftige Unterstützung durch eine Gruppe von Erscheinungen, die man ganz besonders gern dem Selektionsprinzip entgegengehalten, und denen auch Weisman $\mathrm{n}$ immer ganz besondere Beachtung geschenkt hat: die biologisch wertlosen, rein morphologischen Merkmale. Wir sahen ja schon (S. I76ff.), daß Nägeli und mit und nach ihm viele andere Forscher alle „,Organisationsmerkmale“, also alle für die großen Gruppen des Systems (Klassen, Ordnungen, Familien, Gattungen) maßgebenden Erkennungsmerkmale als solche rein morphologische Merkmale betrachteten und den "Anpassungen“" nur den Wert von „Verzierungen“ zugestanden. Hiergegen hat Weismann freilich immer sehr bestimmt Stellung genommen und die Ansicht vertreten, daß auch die größte Menge der „Organisationsmerkmale" als Anpassungen entstanden sind, aber daß "rein morphologische" Merkmale ohne nachweisbare biologische 
Bedeutung tatsächlich vorkommen, hat er stets zugegeben. Schon seine Antrittsrede von $\mathrm{I}^{8} 6_{5}$ behandelt sie und sucht sie zu erklären, und oft genug ist er später auf sie zurückgekommen. Der im Eifer des Kampfes ihm öfter entschlüpfte Ausruf ,,alles ist Anpassung“ erfährt doch, namentlich in den letzten 20 Jahren seines Lebens, auch immer wieder eine Einschränkung, und in den ,Vorträgen zur Deszendenztheorie“ ist es ganz offen ausgesprochen: „Aber freilich sind die Arten nicht lediglich Anpassungskomplexe, sondern zugleich auch bloße Variationskomplexe, deren einzelne Bestandteile nicht alle Anpassungen sind, nicht alle also die Grenze von Gut und Schlecht erreichen" ${ }^{48}$ ). Freilich ist ihre Zahl nicht sehr groß anzunehmen; das meiste, was die Organismen darbieten, hat Anpassungswert, wenn auch seine jetzige Bedeutung eine andere ist, als die war, auf Grund deren es durch Selektion in den Merkmalbestand der Art aufgenommen wurde. Immerhin gibt es biologisch bedeutungslose Merkmale, die teils mehr individueller Art sind und nur für einige Generationsfolgen beibehalten werden, teils konstante Artmerkmale bilden (z. B. Zahl und Stellung der Blütenblätter bei Pflanzen). Die Formel, daß sie durch die „,Korrelation der Teile“ zu erklären seien, wie Weismann anfangs meinte, konnte auf dic Dauer nicht befriedigen; abgesehen davon, daß solche Korrelationen durchaus nicht immer erkennbar waren, blieb die Formel selbst ja noch erklärungsbedürftig. So verlangten also auch die rein morphologischen Merkmale und die Steigerung in der Ausbildung, die sie in manchen Fällen zeigen, die Annahme eines Entwicklungsprinzipes, das in den Organismen selbst in bestimmter Richtung tätig ist.

Die Notwendigkeit, nach einer solchen inneren Entwicklungskraft zu suchen, ergab sich endlich aus der Unmöglichkeit, das völlige Schwinden funktionslos gewordener Organe durch das Selektionsprinzip zu erklären. Daß ein nutzlos gewordenes Organ von der Höhe seiner Leistungsfähigkeit herabsinkt, war wohl vom Boden der Zuchtwahllehre aus verständlich (durch den Fortfall der konservierenden Kraft der Naturzüchtung, s. S. I96), aber was bewirkte, nachdem es einmal funktionslos geworden war, seinen völligen Schwund? Konnte die dadurch bewirkte Ersparnis an Material und Raum irgendwie nützlich und sogar ausschlaggebend im Kampf ums Dasein sein? Konnte es, wie Herbert Spencer schon gefragt 
hatte, bei den vielen Zentnern, die das Gewicht eines Wales ausmachen, noch von einem Nutzen sein, daB die hinteren Extremitäten vollständig verschwanden, statt etwa auf der Stufe rudimentärer Anhängsel stehen zu bleiben? Auch hier versagt das Prinzip der Personalselektion, und es war nötig, nach einer anderen Erklärung zu suchen.

Alle diese Erwägungen verlangten somit die Annahme noch einer besonderen, neben der natürlichen Zuchtwahl tätigen inneren Bildungskraft. Weismann erkannte sie in der Germinalselektion, in Vorgängen des Kampfes, die er zwischen den Determinanten des Keimplasmas annimmt. Diese im Keimplasma sich abspielenden Vorgänge, die wir in ihrem Wesen noch genauer kennen lernen werden, können - wenn auch vielleicht nicht gerade häufig - angeregt werden durch Mediumeinflüsse und vermitteln so das Auftreten erblicher Abänderungen unter der direkten Einwirkung von Klima, Ernährung usw. Vor allem aber sind sie die Folge von noch nicht genauer anzugebenden Vorgängen innerhalb des Organismus und schaffen, durch diese angefacht, die kleinen individuellen Varietäten, mit denen die Personalselektion arbeitet, und die die ersten Stufen der Umwandlungen darstellen. Ihrer Natur nach haben sie das Bestreben, in der einmal eingeleiteten Richtung weiter zu gehen, somit eine angebahnte Veränderung in gleicher Richtung fortschreiten zu lassen, so lange, bis ihnen durch eine höhere Instanz ein Halt zugerufen wird. Diese höhere Instanz ist aber nach wie vor: Personalselektion. Sie läßt die Germinalselektion gewähren, solange die durch sie beschaffenen Veränderungen für das Wohl des Individuums gleichgültig, ,jenseits von Gut und Schlecht" sind, läßt so die ,,rein morphologischen", biologisch bedeutungslosen Merkmale sich ausbilden, oder Organe zugrunde gehen, wenn dieselben für die Art infolge der augenblicklichen Bedingungen, unter denen dieselbe lebt, wertlos sind; sie greift aber ein, wenn die Abänderungen, die die Germinalselektion schafft, nach der guten oder der schlechten Seite bedeutungsvoll werden, Selektionswert erlangen. Dann merzt sie die ungünstigen Variationen aus, befördert die günstigen, und modelt so die Organismen im Sinne der Anpassung um. So schafft, wie Weismann es einmal ausdrückt, die Germinalselektion die Bausteine, aus denen die Personalselektion ihre Tempel und Paläste aufbaut: die Anpassungen. 
Mit der Aufstellung der Lehre von der Germinalselektion im Jahre I895 schließt für Weismann eine Epoche ab, die Epoche des allzu weit gehenden Glaubens an die Leistungsfähigkeit der Zuchtwahllehre von Darwin und Wallace. Sie war eingeleitet gewesen durch die Absage an den Lamarckismus und gipfelte in dem oft, namentlich oft von Weismanns Gegnern mit überlegener Geste wiederholten Wort von der ,Allmacht der Naturzüchtung". Es war keine glüickliche Stunde, als Weismann dieses Wort zum Titel einer besonderen Streitschrift machte (I893). Schlagworte sind in der Wissenschaft immer miBlich; dic schlagende Wirkung, die von ihnen verlangt wird, kann oft genug nur durch Einseitigkeit und Übertreibung erreicht werden. So ist es hier. Daß Weismann sich dessen durchaus bewußt gewesen ist, geht daraus hervor, daß er selbst jenes Wort später (I909) als ein ,,starkes" bezeichnet und gewissermaßen damit entschuldigt hat, daß er es einem Gegner gegenüber gebrauchte, der von der Unzulänglichkeit (inadequacity) der Naturzüchtung gesprochen hatte. Vor allen Dingen aber hat er durch die Aufstellung der Germinalselektion anerkannt, daß von einer "Allmacht der Naturzüchtung", wenn man das Wort wirklich genau nimmt, nicht gesprochen werden kann. Unumwunden und klarer kann das nicht ausgedrückt werden, als es von We is ma n n selbst geschehen ist in dem Vorwort zu der ersten Auflage der Vorträge über Deszendenztheorie: ,An der Determinantenlehre aber hängt dann weiterhin auch die Germinalselektion, und ohne diese bleibt der große Gedanke der Leitung des Umwandlurigsganges der Lebensformen durch Auslese unter Verwerfung des UnzweckmäBigen und Bevorzugung des Besseren nach meiner Überzeugung ein Torso, ein Baum ohne Wurzel." Das bedeutet eine freimütige Absage an die ,,Allmacht" der Naturzüchtung im Sinne von Darwin und Wallace, von der auch die Gegner Weismanns Kenntnis nehmen sollten ${ }^{49}$ ). 
Achter Abschnitt.

\title{
Herkunft erblicher individueller Variationen. Germinalselektion.
}

\begin{abstract}
Variabilität der Organismen. Erbliche und nichterbliche Abänderungen. - Die erblichen individuellen Variationen, ihre Ursache und Art. - Variabilität als Folge der Wechselwirkung der äußeren Einflüsse und der physischen Natur der Organismen. Variabilität als Folge der Vermischung der Individuen (Amphimixis). - Variabilität als Folge von Germinalselektion. - Die verschiedene Ernährung der Determinanten als Grund für ihre Veränderung. - Beibehaltung der eingeschlagenen Variationsrichtung; Grenzen der Schwankungen; Korrelation der Determinanten. - Wesen der Determinantenveränderungen; Wirkungen auf das Soma (die Determinaten). - Ursachen der Ernährungsschwankungen. Spontane und induzierte Germinalselektion. - Germinalselektion und Personalselektion. - Bedeutung der Lehre von der Germinalselektion. - Erweiterung der Machtsphäre des Selektionsprinzipes durch die Lehre von der Germinalselektion. - Die verschiedenen Formen der Auslese.
\end{abstract}

\section{Variabilităt der Organismen. Erbliche und nichterbliche Ab- ănderungen.}

Der wichtigste Grundpfeiler der Darwinschen Lehre ist die Variabilität der Organismen. Nicht zwei Individuen einer Art gleichen einander völlig, sie alle zeigen gewisse Unterschiede, deren Erblichkeit Darwin als Regel ansah. Nichterbliche Abänderungen ließ er zwar gelten, aber: ,,sie sind für uns ohne Bedeutung“. Neuerdings wird der Unterschied zwischen erblichen Varietäten und nichterblichen oder ,passanten“, wie Weismann sie nennt, schärfer betont, und die erblichen haben durch die Benennung als „,Mutationen“ eine besondere Kennzeichnung erhalten. Nur sie kommen hier in Frage ${ }^{50}$ ). 
Die erblichen individuellen Variationen, ihre Ursache und Art.

Die Tätigkeit der Selektionsprozesse setzt das Vorhandensein solcher erblicher individueller Variationen voraus, diese sind somit die ersten Stufen der Abänderung; sie werden von der Zuchtwahl ausgelesen, kombiniert, gesteigert, aber nicht geschaffen. Ohne sie würde, nach Darwinscher Auffassung, eine Umwandlung der Formen nicht stattgefunden haben und überhaupt nicht stattfinden können. So spitzt sich die Frage nach den Ursachen der Formenumwandlung zu einer solchen nach den Ursachen der individuellen erblichen Variationen zu. Und neben ihr stehen andere: die nach der für die Zuchtwahl notwendigen Größe der Abänderungen, die schon im vorigen Abschnitt besprochen wurde, und vor allem die nach der Art der Variationen. Darwin nahm ihre Richtungs- und Regellosigkeit an; andere Autoren, wie E. v. Hartmann und Askenasy dagegen rechneten mit einer ,, bestimmt gerichteten Variation“, die der Ausfluß einer unbekannten inneren Entwicklungskraft sein sollte. Damit war aber ein metaphysisches Prinzip zugegeben, das in die mechanistische Naturauffassung des Darwinismus nicht hineinpaßte. So gewinnt die Frage nach der Herkunft und der Art derVariationen noch eine allgemeinere Wichtigkeit, die Weismann einmal ausdrückt in den Worten: „Eine theoretische Definition der Variabilität ist es, ohne welche die Selektionslehre allerdings noch immer dem Einschmuggeln einer zwecktätigen Kraft die Türe offen läßt. Eine mechanische Erklärung der Variabilität muß die Grundlage dieser Seite der Selektionstheorie bilden" 51 ).

In klarer Erkenntnis dieser Sachlage hat Weismann die Frage nach der Variabilität in ihren verschiedenen Beziehungen vom ersten Augenblick seiner Beschäftigung mit dem Darwinismus an ins Auge gefaßt, und vielleicht spiegelt nichts so deutlich das allmähliche Werden seiner theoretischen Anschauungen wieder, als die drei Phasen, die seine Stellungnahme zu der Variabilitätslehre durchlaufen hat, und denen man mit kurzen Kennworten etwa die Überschriften geben könnte: Variabilität als Folge der Wechselwirkung der äußeren Einflüsse und der physischen Natur der Organismen, Variabilität als Folge der Vermischung der Individuen (Amphimixis), Variabilität als Folge von Germinalselektion. - 
Variabilităt als Folge der Wechselwirkung der äußeren Einflüsse und der physischen Natur der Organismen.

Schon die Rede von I865 erörtert auch die Variabilitätsfrage und bringt wichtige Gesichtspunkte zu ihr herbei. Die Vererbung, so wird hier geschlossen, bedentet Übertragung einer bestimmten Entwicklungsrichtung, die für den elterlichen Organismus gegolten hat, auf den Keim, der sich zum kindlichen Organismus entfalten soll; die Variabilität kommt dadurch zustande, daß diese Entwicklungsrichtung durch die verschiedenen äußeren Einflüsse bald hierhin, bald dorthin abgelenkt wird; sie ist die Resultante aus der ererbten Entwicklungsrichtung und den äußeren Einflüssen. Dagegen lehnte Weismann damals schon die Vorstellung ab, daß eine innere Ursache - Näg elis ,Vervollkommnungsprinzip“ die Organismen zwinge, im Laufe der Zeit ihre Gestalt gesetzmäßig $z u$ ändern und sich in eine neue Art umzuwandeln. Eingehender, aber in gleichem Sinne, spricht er darüber in dem Aufsatz über die mechanische Auffassung der Natur (I876), der für die allmähliche Entwicklung seiner theoretischen Vorstellungen ein so besonders wertvolles Zeugnis darstellt. Alle Ungleichheit der Organismen, so heißt es hier, muß darauf beruhen, daß im Laufe der Entwicklung der organischen Natur ungleiche änBere Einflüsse die einzelnen Individuen getroffen haben, sie ist der Ausdruck ungleicher Beeinflussung an und für sich gleicher Entwicklungsrichtungen. Dabei ist aber zweierlei auseinanderzuhalten, nämlich einmal die ungleichen Einflüsse, denen die Keime vom ersten Augenblick ihrer Entwicklung an ausgesetzt sind, und zweitens eine schon vorher gegebene Ungleichheit der Keime selbst, die darauf zurückzuführen ist, daß schon die Muttertiere und deren Vorfahren ungleichen äußeren Einflüssen ausgesetzt waren. Ja, es muß sogar als wahrscheinlich gelten, daß das organisehe Leben einmal nicht mit einem Urorganismus begann, sondern daß von vornherein deren mehrere durch Urzeugung entstanden, die dann ebenfalls nicht absolut gleich gedacht werden können, da die Umstände, unter denen sie ins Leben traten, nicht absolut identisch gewesen sein können. Weismann steht bei dieser ganzen Betrachtung noch durchaus auf dem Boden der Annahme einer Vererbung erworbener Eigenschaften, er geht von der Voraussetzung aus, daß die individuellen 
Verschiedenheiten der Vorfahrenreihe, die auf der ungleichen Beeinflussung durch die äußeren Einflüsse beruhen, auch bei ungeschlechtlicher Fortpflanzung Minimalverschiedenheiten der auf das Ei ïbertragenen Entwicklıngsrichtung bedingen müssen. Somit ist die Variabilität nicht ctwas dem Begriff des Organismus Immanentes, sondern: ,die Verschiedenheit der Individuen gleicher Abstammung beruht in letzter Instanz lediglich auf der Ungleichheit der äußeren Einflüsse, und zwar cinerseits dorjenigen, welche die Entwicklung der Vorfahren, andererseits derjenigen, welche das betreffende Individuum selbst von dem eingeschlagenen Wege, d. h. von der durch Vererbung übertragenen Entwicklungsrichtung, um ein Geringes ablenken. Dabei ist weiter damit zı rechnen, daß die individuellen Verschiedenheiten einer und derselben Vorfahrenreihe die erzeugten Keime in vorschiedener Weise beeinflussen werden, so daß auch bei gleicher Vorfahrenreihe eine Ungleichheit der Keime zustande kommt, die nicht erst etwa durch ungleiche Ernährung dieser selbst bedingt ist, sondern auf ungleicher Vererbung der individucllen Verschiedenheiten der Vorfahrenreihe beruht, eine Quelle der Ungleichheit, die bei der geschlechtlichen Fortpflanzung noch ungleich stärker fließen muß, als bei der ungeschlechtlichen. Wie aber hier eine Vermischung der Merkmale (genauer: Entwicklungsrichtungen) zweier gleichzeitig lebender Individuen in einem Kieime stattfindet, so wirả bei jeder Art der Fortpflanzung eine Mischung der Merkmale einer ganzen Sulzession von Individuen (der Ahnenreihe) in demselben Keim zusammentreffen, von denen sich freilich die entferntesten nur selten in merklicher Weise geltend machen." Damit taucht ein Gedanke auf, der dann später bestimmtere Form erhalten sollte: die Anschauung von der Bedeutung der sexuellen Fortpflanzung für die Entstehung von individuellen Varianten.

Durch seine Versuche über den Saisondimorphismus der Schmetterlinge hatte Weismann den direkten abändernden Einfluß der äußeren Bedingungen experimentell nachgewiesen; die Erörterungen über die verschiedenen Formen des Generationswechsels, in seiner Daphnoidenmonographie, gaben ihm AnlaB, diese Tatsache nochmals scharf zu betonen und allgemein zu erklären, daß auch die Keimesänderungen, mit denen die Naturzüchtung operiert, und die die Ursache angeborener erblicher Abänderungen der In- 
dividuen sind, in letzter Instanz auf direkter Wirkung äußerer Einflüsse beruhen ${ }^{52}$ ).

In der Frage nach der Qualität der durch diese Einflüsse bedingten Abänderungen nahm Weismann von vornherein einen von Darwin abweichenden Standpunkt ein. In der Antrittsrede von ${ }^{8} 865$ ist vielleicht der wichtigste eigene Gedanke der, daß ein gegebener Organismus nicht regellos nach allen beliebigen Richtungen hin variieren kann, sondern daß seine spezifische Natur, die eigentümliche chemische und physikalische Zusammensetzung seines Körpers, seiner Variationsfähigkeit Grenzen steckt und bestimmte Richtungen vorschreibt. Zahl und Art der möglichen Variationen sind durch die eigentümliche Natur einer jeden Art fest bestimmt; die Abänderung der Formen ist eng verknüpft auch mit einer Abänderung ihrer Variationsfähigkeit, und je weitläufiger die Verwandtschaft zweier Arten ist, um so verschiedener muß ihre Variationsfähigkeit sein, da ihre gemeinsamen Stammeltern um viele Generationsreihen hinter ihnen zurückliegen, und die Variationsfähigkeit, die jenen eigen war, von den folgenden Generationen in verschiedener Weise abgeändert wurde. Eine Katze variiert anders als ein Hund oder gar als ein Infusorium. So sind denn auch die Bahnen, in denen sich die Entwicklung des Organismenreiches vollzogen hat, nicht regel- und richtungslos, nicht reine Sache des Zufalls gewesen, sondern haben sich mit Notwendigkeit ergeben aus dem Zusammenwirken der äußeren Einflüsse und der physischen Natur der Organismen. Der gleiche Standpunkt wird in dem mehrfach genannten Aufsatz über die mechanische Auffassung der Natur vertreten: letzten Endes sind es immer die äußeren Einflüsse, die die Abänderungen der Organismen hervorrufen, aber die Art, wie die letzteren auf die Abänderungsreize reagieren, ist abhängig von der physischen, historisch gewordenen Konstitution des Organismus, und Organismen verschiedener Art reagieren verschiedenartig, wenn sie von den gleichen Abänderungsreizen getroffen werden. So besteht allerdings eine ,,bestimmt gerichtete Variation", aber nicht im Sinne Askenasys und Hartmanns als Ausfluß eines unbekannten inneren Entwicklungsprinzips, sondern als notwendige Folge der ungleichen physischen Natur der Arten: die Annahme eines Variierens in bestimmter Richtung schließt keineswegs die Anerkennung eines metaphysischen Ent- 
wicklungsprinzipes ein, sondern läßt sich als Resultat der physischen historisch bedingten Zusammensetzung der Organismen sehr wohl begreifen.

Von diesen Überlegungen aus läßt sich auch die Entstehung einer neuen Form, lediglich unter dem direkten Einflusse der äußeren Bedingungen (ohne das Eingreifen von Ausleseprozessen), verstehen. Eine größere Individuengruppe derselben Art, von den gleichen Einflüssen getroffen, wird in nahezu gleicher Weise variieren müssen, und wenn diese Einflüsse Generationen hindurch wirksam sind, so werden sich ihre Wirkungen durch Vererbung häufen und aus jener Individuengruppe eine neue Form schaffen. So könnten klimatische Varietäten ihre Erklärung finden. Freilich, ungleich wirksamer wird die Häufung individueller Abweichungen durch Hinzutreten von Selektionsprozessen zustande kommen, wenn sich also zu der direkten Wirkung der äußeren Einflüsse noch die indirekte hinzugesellt.

Dies der ursprüngliche Standpunkt Weismanns, gekennzeichnet durch eine starke Bewertung der äußeren Einflüsse und Rückführung aller Variabilität auf diese, bei Annahme der Vererbungsmöglichkeit der durch sie bedingten Variationen.

\section{Variabilität als Folge der Vermischung der Individuen (Amphimixis).}

Nun aber folgte die eingehende Inangriffnahme der Vererbungsfrage, wobei die anfangs mehr physiologische Betrachtungsweise der Vererbungsvorgänge - ,Vererbung ist Übertragung gleicher Entwicklungsrichtungen" - einer morphologischen weichen mußte; es folgte die Aufstellung der Lehre von der Kontinuität des Keimplasmas und seiner Zusammensetzung aus Determinanten oder „Bestimmungsstücken“ der einzelnen Merkmale, und damit ergab sich eine bestimmtere Fassung auch der Frage nach dem Wesen der Variation, allerdings auch eine größere Schwierigkeit ihrer Beantwortung. Insbesondere die Voraussetzung einer ,Kontinuität" des Keimplasmas erschwerte die Betrachtung. War das Keimplasma ausschlaggebend und bestimmend für das neue Individuum in allen seinen Einzelheiten, so mußten individuelle Varietäten, wenigstens soweit sie sich als erblich erwiesen, ihren 
Grund in einer gewissen Verschiedenheit der erzeugenden Keimplasmen haben, das Keimplasma einer Art mußte trotz seiner ,,Kontinuität" veränderlich sein. Und ebenso: wenn sich die Formen auseinander entwickelt und doch dabei im Laufe der Generationen umgewandelt haben, so mußte das Keimplasma im Laufe der Zeit erbliche Veränderungen erfahren haben. Die Quelle dieser Veränderungen aufzudecken, war und ist für die Kontinuitätshypothese eine der wichtigsten Aufgaben, vielleicht die allerwichtigste. In den Erörterungen über die Vererbbarkeit erworbener Eigenschaften (I883) kam die Frage aufs neue zur Behandlung, nun aber mit größerem Skeptizismus gegenüber der Bedeutung direkter Einflüsse. Das Ergebnis war eine bestimmte Ablehnung der Vorstellung, daß Verletzungen, Verstümmelungen, funktionelle Veränderungen des ausgebildeten Somas eine adäquate erbliche Veränderung des Keimplasmas bewirken könnten - ein Ergebnis, das durch die spätere Ausführung der Determinantentheorie auch vom rein theoretischen Standpunkte aus nur eine Bekräftigung erfahren konnte. Denn da die Determinanten etwas ganz anderes sind als die Teile selbst, so müßten sie sich auch, falls jener Vorgang möglich wäre, in ganz anderer Weise verändern, als diese sich verändert hatten, etwa wie wenn ein deutsches Telegramm nach China dort gleich in chinesischer Sprache ankäme ${ }^{53}$ ). Auch gegenüber den direkten Einflüissen der äußeren Bedingungen ergab sich nun eine andere Stellungnahme, eine vorsichtigere und zurückhaltendere Beurteilung. Die Ergebnisse der eigenen Schmetterlingsversuche Weismanns blieben freilich zu Recht bestehen: sie zwangen nach wie vor dazu, in direkten Mediumeinflüssen eine Quelle erblicher Abänderungen zu sehen, und dies Ergebnis ließ sich ja auch mit der Kontinuitäts- und Determinantentheorie in Einklang bringen durch die Annahme, daß verschiedenartige äußere Einflüsse nicht nur das fertige oder in Entwicklung begriffene Individuum selbst, sondern auch die in demselben eingeschlossenen Keimzellen treffen und den Determinantenkomplex ihres Keimplasmas verändern können. Indessen konnte diese Quelle erblicher Abänderungen jetzt nicht mehr als sehr wichtig, geschweige denn als ausschließlich erscheinen. Prüfung der Tatsachen, insbesondere auch der auf pflanzlichem Gebiete gemachten Beobachtungen, führten $\mathrm{zu}$ deın Schlusse, daß die äußeren Einflüsse viel häufiger und in erster 
Linie nur passante Veränderungen hervorrufen, die auf das Individuum beschränkt bleiben, aber nicht auf die Nachkommen übergehen, und die immerhin zuzugebenden, auf direkte Mediumeinflüsse zurückzuführenden erblichen Abänderungen mußten bei genauerer Betrachtung viel von ihrer früher angenommenen Bedeutung für die Transmutationsvorgänge einbüßen, auch abgesehen davon, daß sie nur als Ausnahmen in Frage kamen. Denn einerseits könnten sie, so folgerte Weismann jetzt ${ }^{54}$ ), bei dem großen Beharrungsvermögen des Keimplasmas nur sehr langsam und in sehr kleinen Schritten vor sich gehen, und andererseits müßten sie sich bei allen von den Einwirkungen betroffenen Individuen stets in gleichem Sinne äußern. Daraus aber würde folgen, daß sie wohl die Quelle zu allmählicher Abänderung aller Individuen einer Art werden können, wenn dieselben lange Generationsfolgen hindurch von den gleichen verändernden Einflüssen getroffen würden, nicht aber die Quelle der stets hin- und herschwankenden, in tausend und abertausend von Kombinationen wechselnden individuellen Abweichungen, die für die Darwin-Weismannsche Auffassung die unentbehrliche Voraussetzung aller Selektionsprozesse sind. In dieser aber und in dem durch sie vermittelten indirekten Einfluß def äußeren Bedingungen hatten Darwin und Wallace den wichtigsten Faktor für die Umwandlung der Formen kennen gelehrt, dem gegenüber der direkt umwandelnde Einfluß der Umgebung nur eine untergeordnete Rolle beanspruchen konnte, - eine Anschauung, der sich Weismann wenigstens hinsichtlich der höheren Formen von vornherein mit Überzeugung angeschlossen hatte, und die ihm selbst nur immer klarer wurde. So mußte er denn nach einer besonderen Quelle gerade für diese individuelle Variabilität suchen, und er glaubte dieselbe eine Zeitlang in der Amphimixis, der Vermischung der Individuen bei der sexuellen Fortpflanzung (der Befruchtung in Verbindung mit den vorhergehenden Reduktionsteilungen der Keimzelle) gefunden $\mathrm{zu}$ haben. Durch diese sollte eine fortgesetzte Vermischung und Umkombinierung der individuellen Vererbungstendenzen und damit jene "proteusartige" individuelle Variabilität der Formen zustande kommen, die die Voraussetzung aller Selektionsprozesse ist (I89I). Eins war dabei freilich vorausgesetzt: es mußten überhaupt erst einmal individuelle Unterschiede vorhanden, es mußte ein erster 
Anfang für die Variabilität gegeben sein. Diesen „Urquell“ der individuellen Ungleichheit sucht Weismann bei den niedersten Organismen, anfangs (I 886) bei den Einzelligen, dann (von I89r an) noch tiefer, bei den kernlosen Lebewesen, deren Körper noch, wie das an anderer Stelle ausgeführt wurde, durch direkte Wirkung äußerer Einflüsse veränderlich ist und diese Änderungen auf seine Teilsprößlinge unmittelbar zu übertragen vermag, weil Elter und Kind in gewissem Sinne noch ein und dasselbe Wesen sind. Der letzte Urgrund aller erblichen individuellen Unterschiede würde somit allerdings in den äußeren Einflüssen, die den Organismus direkt verändern, zu sehen sein; aber nicht auf jeder Organisationshöhe kann auf diese Weise erbliche Variabilität entstehen, sondern nur auf der allerniedersten. Nachdem aber hier einmal die Ungleichheit der Individuen gegeben war, vererbte sie sich auf die ,,höheren“ Organismen - worunter schon die kernhaltigen Einzelligen sowie die Vielzelligen zu verstehen wären - und wurde bei diesen durch die amphigone Fortpflanzung, der die Konjugation bei den Einzelligen entspricht, erhalten und immer weiter vervielfacht.

Die Jahre von I886-I894 stehen unter dem Zeichen dieser Auffassung, die an anderer Stelle, bei Betrachtung der Befruchtung und ihrer Bedeutung, schon etwas eingehender besprochen wurde.

\section{Variabilität als Folge von Germinalselektion.}

Indessen lie $\beta$ sich die hohe Meinung, die Weismann in dieser Hinsicht von der Amphimixis hegte, auf die Dauer nicht aufrecht erhalten. Gewiß ist in der Halbierung der Chromosomenzahl und der dadurch bedingten Neukombinierung der Chromosomen (Ide, Determinantenkomplexe) bei den Reifeteilungen der Geschlechtszellen, sowie in der folgenden Vereinigung zweier solcher halbierten Keimplasmen, die zwei verschiedenen Individuen entstammen (bei der Befruchtung), eine Quelle individueller Verschiedenheit gegeben, aber doch eben nur so weit, als es sich dabei um eine stets sich wiederholende Umkombinierung der individuell gefärbten homologen Determinanten handelt; eine wirkliche Veränderung der Determinanten kann dadurch niemals erreicht werden. Und doch muß schlechterdings eine solche im Laufe der Zeit stattgefunden haben. Die Determinanten eines Wurmes der Vorwelt könnten nicht unverändert heute das Keimplasma eines Elefanten zusammen- 
setzen, auch wenn es ganz sicher wäre, da $B$ dic Säugetiere von Würmern abstammen. Die Ide müssen sich seither unzählige Male umgestaltet haben, die Determinanten, aus denen die Ide des Elefantenkeimplasma bestehen, müssen durchaus andere sein, als die des Wurmkeimplasma. Diese Veränderungen könnten niemals durch den Befruchtungsvorgang erklärt werden, der nur einen Austausch der Ide bewirkt, diese nur zu immer neuen Kombinationen zusammenstellt. Die auf diesem Wege zustande kommenden Varianten werden sich durchaus innerhalb der Grenzen des Artbildes halten müssen, aber nie etwas wirklich Neues zeigen können. Hierfür ist eine wirkliche Veränderung der Ide anzunehmen. Es ist bei diesen Überlegungen ganz gleich, ob unter "Id“ ein „,Vollid“, im Sinne der älteren Weismannschen Vorstellung verstanden wird, oder ein „Partialid“, entsprechend der späteren Änderung der Auffassung.

Die beiden wichtigsten Fragen, die sich aus diesen Überlegungen ergeben mußten, sind: unter welchen Einflüssen können wir uns diese Veränderungen der Ide entstanden denken, und in welcher Weise haben wir uns dieselben vorzustellen? Die Antwort auf diese Fragen mußte zugleich rechnen mit den im vorigen Abschnitt besprochenen Erscheinungen, die eine Ergänzung der Lehre von der Personalselektion durch die Annahme von innerhalb der Organismen selbst sich abspielenden Vorgängen forderten. Diese inneren Vorgänge mußten die Ursache der Variabilität sein, diese letztere aber zugleich bestimmten Gesetzen unterwerfen.

Alle diese Fragen beantwortet Weismann mit der Aufstellung der Lehre von der Germinalselektion, die die Keimplasmatheorie erst vollständig zum Abschluß brachte und eine bis dahin fühlbar gewesene Lücke derselben ausfüllte. Denn die Frage der Variabilität steht nun einmal am Anfang der ganzen Artumwandlungslehre Darwins. Ihrem Wesen nach steht diese letzte Beantwortung der Variationsfrage in fast diametralem Gegensatz zu der ersten. Diese hatte (I876) gelautet: „Der lebende Organismus enthält in sich selbst kein Prinzip der Veränderlichkeit, er ist das statische Moment in dem Entwicklungsprozesse der organischen Welt und würde stets nur wieder genaue Kopien seiner selbst liefern, wenn nicht die Ungleichheit der äußeren Einflüsse ein jedes neuentstehende Individuum in seiner Entwicklungsrichtung ablenkte; 
diese Einflüsse sind also das dynamische Element des Prozesses." Dabei war dem Organismus selbst und seiner physischen Natur nur ein Richtung gebender und beschränkender Einfluß̄̋ auf die Variationen zugesprochen. Nunmehr wird der Grund für alle Variationen in Vorgängen gesucht, die sich nicht nur fortwährend in den Organismen - und zwar in den Keimzellen derselben - abspielen, sondern auch zum weitaus größten Teil innerhalb des Einzelorganismus selbst ihre Ursache haben, und nur zu einem kleinen Teil von den äußeren Verhältnissen angeregt werden. Die direkte Bedeutung der letzteren tritt damit ganz zurück, und es wird nun ausdrücklich betont ${ }^{55}$ ): , Darin gerade liegt die hohe Bedeutung dieses Kräftespiels im Keimplasma, daß er ganz unabhängig von den Beziehungen des Organismus zur Außenwelt Variationen schafft." Es wird sich indessen zeigen, daß vom rein abstrakten theoretischen Standpunkt aus der Widerspruch nicht ganz so scharf ist, als er auf den ersten Blick erscheint. Denn gleich geblieben ist die Grundanschauung, daß die Keimsubstanz sich nicht infolge einer immanenten inneren Kraft umwandelt, sondern durch äußere Einflüsse dazu veranlaßt wird. In einem anderen Punkte aber bringt auch diese letzte Behandlung der Variationsfrage Weismanns früheren Standpunkt zur Geltung: die Auffassung, daß die Variationen nicht richtungsund regellos sind, kommt nunmehr zum AbschluB, die Schrift „Über Germinalselektion“ führt den Untertitel: „Eine Quelle bestimmt gerichteter Variation".

\section{Die verschiedene Ernährung der Determinanten als Grund fur ihre Veränderung.}

Die Gedankengänge der Lehre von der Germinalselektion sind von Weismann zum ersten Male in einer schon Ende I894 geschriebenen, aber erst I895 veröffentlichten Abhandlung: „Neue Gedanken zur Vererbungsfrage" in der Hauptsache festgelegt, später dann in einer besonderen Schrift (I890) und in den Vorträgen über Deszendenztheorie ausführlicher entwickelt worden. Sie beruhen auf der von W. Roux in die Wissenschaft eingeführten Übertragung des Selektionsprinzipes auf die Teile innerhalb des Organismus und nehmen den „Kampf der Teile“ (Roux) auch innerhalb des Keimplasmas an, das eben nach Weismann nicht eine 
homogene Masse, sondern aus zahlreichen Lebenseinheiten verschiedener Grade zusammengesetzt ist. Hier im Keimplasma, und zwar in jedem einzelnen Id, muß nach Weismanns Auffassung während derVermehrung der Keimzellen, die ja mit einer Vermehrung der Masse des Keimplasmas verbunden ist, ein Heranwachsen und eine Vermehrung der Determinanten stattfinden, auf Kosten des Nahrungsstromes, der zwischen sie eindringt. Dabei wird es nun durch Zufälligkeiten oder unter der Einwirkung erkennbarer und dauernd wirksamer äußerer Einflüsse zu Ungleichheiten und Unregelmäßigkeiten in diesem Säftestrom kommen können, der den bisher bestehenden Gleichgewichtszustand zwischen den Determinanten eines Chromosoms stören muß. Die einen werden mehr Nahrung erhalten, infolge dessen stärker wachsen und sich stärker vermehren, während die anderen, die unter ungünstige Ernährungsverhältnisse geraten sind, schwächer bleiben und sich langsamer vermehren. Ist eine solche Schwankung erst einmal eingeleitet, so wird sie sich mit einer gewissen GesetzmäBigkeit bei den weiteren Teilungen der Keimzellen leicht in der gleichen Richtung fortsetzen, da durch die bessere oder schlechtere Ernährung die Determinanten selbst in ihrer Assimilationskraft gestärkt oder geschwächt werden müssen, so daß nun auch die Verschiedenheit der aktiven Ernährung in dem gleichen Sinne weiter wirkt. So wird sich also hier im Keimplasma ein ähnlicher SelektionsprozeB im Kleinsten abspielen, wie er zwischen den Individuen besteht; die „Personalselektion" findet ihr Analogon in der ,,Germinalselektion“. (Germina d.h. Keime, bedeutet dabei die Determinanten) $\left.{ }^{56}\right)$. Die Veränderung der Determinanten muB sich dann bei der Entwicklung in Veränderungen der groben Teile, der Determinaten, bemerkbar machen. Auf diesem Kräftespiel im Keimplasma während der Teilung und Entwicklung der Keimzellen beruhen letzten Endes alle erblichen individuellen Variationen.

Betrachten wir zunächst dieses Kräftespiel und seine Wirkungen noch etwas genauer.

Beibehaltung der eingeschlagenen Variationsrichtung; Grenzen der Schwankungen; Korrelation der Determinanten.

Ein Umstand, auf den Weismann besonderen Wert legt, und der in der Tat das prinzipiell Wichtigste clarstellt, ist, daß durch 
den Prozeß der Germinalselektion die Beibehaltung einer einmal eingeschlagenen Variationsrichtung seitens des Keimplasmas, auch ohne Eingreifen von Personalselektion, verständlicher wird. Es geht das aus dem bereits Gesagten schon hervor. Wird durch eine zufällige auch nur vorübergehende Steigerung der Nahrungszufuhr eine Determinante besser ernährt, so steigert sich zugleich ihre Assimilationskraft, und daraus wird sich wieder eine weitere Verbesserung der Ernährungsbedingungen ergeben, d. h. die aufwärts gehende Variation wird sich im Laufe der weiteren Teilungen der Geschlechtszellen fortsetzen, ja auch in den Geschlechtszellen der nächsten Generation, die ja einen Teil des so veränderten Keimplasmas, der Kontinuitätslehre entsprechend, überliefert bekommen. So kann also während der Entwicklung der Geschlechtszellen eines Individuums eine Veränderung des Keimplasmas erfolgen, die an sich, wofern sie nicht durch das Eingreifen von Personalselektion gestört wird, die Tendenz hat, sich in den Abkömmlingen dieses Keimplasmas in den folgenden Generationen in gleichem Sinne fortzusetzen. Freilich ist nicht anzunehmen, daß eine jede Schwankung einer Determinante nach aufwärts oder abwärts sich unbegrenzt fortsetzen muß: es müßten ja dann alle Teile des Organismus sich in fortwährender Unruhe befinden.

Bei den meisten nur geringen Schwankungen wird man an eine Selbstkorrektion des Keimplasmas denken können, die den ursprünglichen Gleichgewichtszustand bald wiederherstellt. Daher wohl die Konstanz der Arten unter normalen Bedingungen, und das Wiederverschwinden vieler kleiner individueller Besonderheiten, z. B. beim Menschen. Einigermaßen größere Schwankungen aber werden sich zunächst fortsetzen. Handelt es sich dabei um eine Abänderung einer Determinante in aufsteigender Richtung, so wird dieselbe, wenn auch nach längerer Zeit (im Laufe zahlreicher Keimzellengenerationen), doch schließlich einmal schon aus inneren Verhältnissen zu einem Ende kommen: teils infolge der begrenzten Nahrungsmenge, die innerhalb eines Chromosoms zirkuliert, teils infolge des Widerstandes der Nachbardeterminanten; dagegen wird es für die Veränderung in absteigender Richtung keine innerlich bedingte Grenze geben, d. h. die fortschreitende Schwächung der Determinante muB schließlich zu ihrem vollständigen Schwund, ihrer Ausmerzung aus dem Keimplasma führen. Beide Vorgänge, 
die aufsteigende wie die absteigende Veränderung einer Determinante oder Determinantengruppe, werden aber endlich auch von Einfluß auf Nachbardeterminanten sein; zwischen den Elementen des Keimplasmas ist ,ein ganzes Heer von Beziehungen und Beeinflussungen“ anzunehmen, im Keimplasma liegt auch die Quelle aller korrelativen Abänderungen.

In der Germinalselektion ist also ein orthogenetisches Prinzip anerkannt, d. h. ganz im allgemeinen Sinne ein Prinzip, das damit rechnet, daß eine einmal eingeschlagene Entwicklungsrichtung geradlinig ( geht Weismann nicht so weit, zu behaupten, daß die Entwicklung in der einen Richtung schlechterdings unaufhaltsam weitergehen müsse; er nimmt vielmehr an, daß immer noch Schwankungen der Determinanten vorkommen, und da $B$ es somit an sich möglich wäre, auf dem Wege der Auslese durch ,Sammlung“ der relativ schwächeren Determinanten das Fortschreiten in der eingeschlagenen Richtung aufzuhalten und sogar die Richtung wieder umzukehren. Nur würde dazu sehr lange Zeit gehören. Praktisch wird es somit nicht oft in Frage kommen. Denn die einzige Kraft, die jene „,Sammlung“ der schwächeren Determinanten vornehmen könnte, ist Personalselektion; diese arbeitet aber sehr langsam und wird nicht immer die nötige Zeit zur Verfügung haben, um eine bedrohlich werdende Entwicklungsrichtung aufzuhalten oder umzukehren. So können denn auch einseitig hoch gesteigerte, exzessive Bildungen gelegentlich einmal zum Aussterben einer Art führen. Die Entwicklung in der einen Richtung wird hierbei zunächst so lange weitergehen, als das Resultat nützlich ist - die Germinalselektion wird dabei durch Personalselektion unterstützt werden - und kann so zu einer exzessiven Bildung führen; bei einem rasch eintretenden Wechsel der Lebensbedingungen könnte dieselbe aber auf einmal ihren Wert verlieren, ja sogar geradezu verhängnisvoll werden, und dann würde die langsam arbeitende Personalselektion nicht imstande sein, die Art von ihr zu befreien: die Art würde aussterben. Fälle dieser Art, in denen exzessive Bildungen den offenbaren Anlaß zum Aussterben einer Art abgegeben haben, sind von Paläontologen vielfach namhaft gemacht und zur Aufstellung orthogenetischer Theorien verwertet worden. Nach Weismannscher Auffassung sind sie in der Tat auf ein orthogenetisches Prinzip, 
dic Germinalselektion, zurückzuführen, indessen wäre, nach eben dieser Auffassung, es doch wohl nicht die Germinalselektion selbst, die in solchen Fällen einer Art den Untergang bereitet, ,, sondern das Unvermögen der Personalselektion, rascheren Wendungen der Lebensbedingungen $\mathrm{zu}$ folgen und exzessive Bildungen in kurzer Zeit um ein Beträchtliches herabzusetzen". Die Germinalselektion erscheint so als ein Prinzip der Orthogenese mit beschränkter Wirksamkeit.

\section{Wesen der Determinantenveränderungen; Wirkungen auf das Soma (die Determinaten).}

Das Wesen der angenommenen Veränderungen der Determinanten und ihre Wirkungen auf das Soma (die Determinaten) denkt sich Weismann folgendermaßen. Zwei Möglichkeiten der Determinantenvariation liegen nach seiner Auffassung iiberhaupt nur vor: gewisse Determinanten oder Gruppen von solchen werden durch die angenommenen Ernährungsschwankungen innerhalb des Einzelchromosoms entweder besser oder schlechter ernährt werden. Die dadurch bedingten Variationen werden in letzter Instanz alle quantitativer Art sein, d. h. sich in einer $\mathrm{Zu}$ - oder Abnahme der lebenden Teilchen (Biophoren) oder ihrer Konstituenten, der Moleküle, äußern.

So gibt es also letzten Endes nur zwei Variationsrichtungen: eine nach Plus und eine nach Minus vom Durchschnitt gerichtete. Diese Plus- und Minusvariation der kleinsten Teilchen, aus denen die Determinanten bestehen, wird dann, wenn sie gleichmäßig alle Teilchen betrifft, für die Determinanten selbst einfach eine Vergrößerung oder eine Verkleinerung bedeuten, wofern sie aber die Konstituenten ungleich betrifft, eine qualitative Veränderung der Determinanten bedingen. Es darf angenommen werden, daß sich auch an den durch die Determinanten bestimmten Organen, den Determinaten, entsprechende Veränderungen zeigen werden. Indem so der Ausgang für alle Veränderungen in die kleinsten lebenden Teilchen, ja in ihre zusammensetzenden Moleküle, verlegt wird, ergibt sich eine Möglichkeit, nicht nur Größenschwankungen der Teile, sondern auch qualitative Änderungen derselben, auf Veränderungen rein quantitativer Natur zurückzuführen. Was uns im großen als Qualitätsänderung erscheint, beruht eben letzten 
Endes auf quantitativen Änderungen in den kleinsten Teilchen, die das große Ganze aufbauen.

Indessen braucht nicht jede Veränderung einer Determinante oder Determinantengruppe sich auch wirklich in einer entsprechenden Veränderung der Determinate, also am Soma, bemerkbar zu machen. Denn der Weismannschen Auffassung zufolge ist ja bei allen Formen mit ,geschlechtlicher" Fortpflanzung in dem Kern der heranwachsenden Keimzelle die gleiche Determinantenart mindestens zweimal vorhanden, einmal in dem väterlichen und einmal in dem homologen mütterlichen Chromosom, wie das im sechsten Abschnitt auseinandergesetzt wurde. Ob eine bestimmte Abänderung einer Determinante später - bei der Ontogenese - Geltung erlangen wird, wird somit noch von einigen Zufälligkeiten abhängen: von dem Ergebnis der Reduktionsteilung (- die ja das betreffende Chromosom herausbefördern kann -) und von der folgenden Amphimixis, die in dem homologen Chromosom der kopulierenden Zelle eine gleich- oder entgegengesetztgerichtete Variante derselben Determinante zuführt. Die Möglichkeit, daß zwei entsprechend geartete Varianten einer Determinante sich wiederholt (zur Bildung einer ,Homozygote“) zusammenfinden, und damit eine bestimmte Richtung der Variation wirklich beschritten wird, wird ohne weiteres dann gegeben sein, wenn die Ursache der Ernährungsschwankungen und damit der Veränderungen der Determinanten in allgemeinen äußeren, z. B. klimatischen Veränderungen liegt (s. unten), sie wird aber auch bei spontanen, auf reinen Zufälligkeiten beruhenden Abänderungen oft genug vorliegen, da es, wie erörtert, überhaupt nur zwei Variationsrichtungen der Determinanten gibt: eine aufsteigende und eine absteigende. Kommen aber durch die Amphimixis zwei etwas verschieden geartete homologe Determinanten ( - in einer „Heterozygote“ -) zusammen, etwa die unveränderte und die nach Plus oder Minus abgeänderte, oder die Plıs- und die Minusvariante, so wird zwischen beiden bei der Ontogenese jener Wettbewerb um die Geltendmachung einsetzen, den wir im sechsten Abschnitt bei Besprechung der Determinantentheorie kennen lernten. Der Ausgang desselben wird dann davon abhängen, welche der beiden Determinanten die kräftigere ist. Diese wird sich in der Ontogenese zur Geltung bringen und der Determinate, dem fertigen ,,Merkmal", ihren Stempel aufdrücken; die andere wird latent bleiben. 
Doch wird auch diese, der Lehre von der Kontinuität des Keimplasmas zufolge, von der Keimzelle aus den folgenden Generationen mitgegeben und kann sich, wenn sie bei den Reduktionsteilungen dem Schicksal des Entferntwerdens entgeht, aber immer wieder mit kräftigeren andersgearteten homologen Determinanten zusammenkommt, viele Generationen hindurch forterhalten, ohne am Soma in die Erscheinung zu treten - bis der Zufall sie mit einer gleichgearteten zusammenführt und ihr dadurch wieder einmal zur Geltung verhilft. So können unveränderte Ahnendeterminanten Generationen hindurch in den Abkömmlingen eines Keimplasmas latent mitgeführt werden, um dann gelegentlich wieder einmal manifest zu werden. Die Erscheinungen des sogenannten Rückschlags würden auf diese Weise, vom Standpunkt der Determinantentheorie aus, ihre Erklärung finden (s. oben, S. I42). - Die frühere Vorstellung Weismanns, die in jedem Keimplasma eine sehr große Menge von Volliden, somit auch eine sehr große Menge homologer Determinanten annahm, machte an Stelle der hier erörterten Gedankengänge einige andere notwendig. Damit eine Determinantenabänderung Geltung erlangte, war es nötig, daß sie in gleichem Sinne in einer Majorität von Iden auftrat, aber nicht etwa nur auf ein Id oder auf deren wenige beschränkt blieb. Darin aber lag entschieden eine größere Schwierigkeit der Theorie. Dagegen war die alte Fassung derselben zur Erklärung der Rückschlagserscheinungen bequemer: wenn in jedem Keimplasma eine sehr große Menge homologer Determinanten angenommen wird, so ist leicht damit zu rechnen, daß, während einige derselben sich verändern, andere unverändert bleiben und in unverändertem Zustand lange Zeit weitergegeben werden, bis sie einmal auf dem Wege der Amphimixis durch andere unveränderte verstärkt werden und dadurch Geltung erlangen. -

\section{Ursachen der Ernährungsschwankungen. Spontane und indu- zierte Germinalselektion.}

Was endlich die Ursachen der angenommenen Ernährungsschwankungen anlangt, so kommen dafür, wie schon angedeutet wurde, in Betracht: I. „Zufälligkeiten“" der Nahrungszufuhr zu den Determinanten, und 2. Veränderungen in den äußeren Lebensbedingungen, namentlich klimatischer Art. Die auf Zufälligkeiten 
beruhende Form der Germinalselektion nennt Weismann die spontane, die durch äußere Einflüsse angeregte die induzierte; zwischen beiden müssen mehrere Unterschiede bestehen. Schwankungen der Ernährung, die lediglich auf Zufälligkeiten beruhen, werden demzufolge anch lediglich lokaler Natur sein, auf ein bestimmtes Chromosom beschränkt bleiben, nicht leicht aber in den beiden homologen Chromosomen zugleich in gleicher Weise auftreten, und somit auch nicht leicht die homologen Determinanten beider gleichsinnig treffen und verändern, noch weniger in allen Individuen einer Art eintreten. Dagegen werden Veränderungen der äußeren Lebensbedingungen in allen davon betroffenen Individuen ähnliche Veränderungen der keimplasmatischen Ernährung bedingen, d. h. alle homologen Determinanten - in den verschiedenen Individuen -, sofern sie überhaupt für die betreffende Ernährungsänderung empfindlich sind, in ähnlicher Weise verändern. Ferner besteht zwischen den beiden Formen der Germinalselektion ein Unterschied hinsichtlich ihres Verhaltens zur Personalselektion und damit hinsichtlich ihrer Bedeutung für die Artbildung. Spontane Variationen werden, als durch Zufallsschwankungen bedingt, sich durch Germinalselektion allein nur so lange steigern, bis sie dem Leben des Individuums nützlich oder schädlich werden, alsdann wird die Personalselektion über ihr weiteres Schicksal entscheiden; sie geben also die Grundlage und den Ausgang für die Selektionsprozesse höherer Ordnung ab; induzierte Variationen dagegen werden, solange der äußere Einfluß zu wirken anhält, sich steigern, bis das Maximum der Veränderung erreicht ist, das der Natur dieses Einflusses und der der betreffenden Determinanten entspricht, auch ohne Eingreifen der Naturzüchtung. Dem Wirken der letzteren wären gegenüber der ,,induzierten" Germinalselektion überhaupt Grenzen gezogen. Sie würde bei nützlichen Abänderungen mithelfen können, die höchste Steigerungsstufe der letzteren rascher zu erreichen; bei schädlichen Abänderungen aber nur versuchen können, durch Bevorzugung der auf den wirlssamen Reiz weniger stark reagierenden Individuen die allgemeine Abänderung der Art in der schädlichen Richtung aufzuhalten. Wäre die Reaktionsfähigkeit bei allen Individuen gleich groß, so würde dieNaturzüchtung keine Handhabe zum Eingreifen finden, und die Art müßte aussterben. 
Für die Umbildung der Formen besitzt somit die spontane Germinalselektion die weitaus größere Bedeutung. Auf sie ist das ganze Heer individueller Variationen zurückzuführen, die das Material für die Personalselektion abgeben, und an die sich unter der Mitwirkung dieser die Umbildung der Arten knüpft. Wie sie mit der Personalselektion zusammenwirkt, aber auch neben derselben als selbständige Kraft in orthogenetischem Sinne tätig ist, wird noch besonders zu besprechen sein.

In der induzierten Germinalselektion andererseits ist $\mathrm{zu}-$ nächst der Grund zu sehen für die seit Darwin bekannte erhöhte allgemeine Variabilität domestizierter Tiere und Pflanzen: dieselbe ist ein Ausdruck der Strömung, in die das altererbte Gleichgewicht des Keimplasmas unter dem Einfluß veränderter Existenzbedingungen gerät; weiterhin ist in ihr der Mechanismus gegeben für die Entstehung erblicher Abänderungen unter dem direkten Einflusse der äußeren Bedingungen, wie KKlima, Nahrung usw. Es wurde an anderer Stelle schon (Abschnitt IV und V) besprochen, daß Weismann ihnen für die Umwandlung der Arten keine sehr große Bedeutung beimißt. Die direkten Mediumeinflüsse auf das Keimplasma, die erbliche Abänderungen erzeugen, stehen denen auf das Soma, die nur passante Abänderungen bewirken, bedeutend nach. Auf induzierte Germinalselektion werden viele biologisch gleichgültige, rein morphologische, Merkmale zu beziehen sein, ganz besonders aber wohl auch die sogenannten Spielvariationen oder sprunghaften Abänderungen, d. h. Abänderungen größeren Betrages, die namentlich bei in Kultur befindlichen Pflanzen beobachtet werden und sich von vornherein als erbbeständig erweisen. Sie deuten auf stärkere Störungen des Gleichgewichtes innerhalb des Determinantensystems hin, auf eine länger dauernde, intensive gleichartige Beeinflussung, die eben am leichtesten auf die Einwirkung der äußeren Bedingungen zu beziehen ist. Ihre plötzliche Entstehung ist nach Weismann nur scheinbar: sie besitzen ein ,unsichtbares Vorspiel“ im Keimplasma, d. h. sie sind von langer Hand her durch Selektionsprozesse im Keimplasma vorbereitet, treten aber, scheinbar unvermittelt und sprungweise, erst dann in die Erscheinung, wenn die germinalen Abänderungen unter dem fortgesetzten Einfluß der äußeren Bedingungen und infolge von Amphimixis gleichsinnig veränderter 
homologer Determinanten eine gewisse Höhe erreicht haben. Weismann greift dabei auf die im sechsten Abschnitt besprochene Annahme zurück, da $B$ die Determinanten vermehrungsfähig, und da $B$ daher vielfach eine ganze Anzahl homologer (für ein Merkmal bestimmter) Determinanten in ein und demselben Id (Chromosom) vorhanden ist. Werden diese alle oder doch in einer größeren Majorität gleichsinnig verändert, so würde daraus eine Varietät hervorgehen, die von vornherein mehr Aussicht auf Erbbeständigkeit hätte. Das wäre bei den Spielvariationen anzunehmen, bei denen im übrigen wohl gleich an mehreren Determinantenarten Veränderungen vorauszusetzen sind. Die Bedeutung der Spielvarietäten wird, wie wir schon im siebenten Abschnitt sahen, für die Umbildung der Arten von Weismann nicht sehr hoch eingeschätzt und nur für die Erklärung der sekundären Geschlechtsmerkmale etwas höher bewertet ${ }^{57}$ ).

\section{Germinalselektion und Personalselektion.}

In den erörterten entoplasmatischen Vorgängen ist nun eine Kraft gegeben, die selbständig, für sich, Abänderungen der Formen anbahnt und sie in gleicher Richtung zu steigern vermag, eine im Organismus wirksame orthogenetische Entwicklungskraft, die sich neben die Personalselektion stellt, mit dieser die Umwandlung der Formen leitet und die Mannigfaltigkeit derselben schafft. Das Verhältnis der beiden Kräfte zueinander kann sich dabei etwas verschieden gestalten. Stets zwar vollzieht sich die Arbeit der Germinalselektion unter der fortwährenden Aufsicht der Personalselektion, aber es sind dabei doch noch zwei Möglichkeiten gegeben. In der Mehrzahl der Fälle arbeitet die Germinalselektion geradezu für die Personalselektion, bietet dieser nützliche und schädliche Abänderungen zur Verwendung an; innerhalb enger Grenzen aber darf sie auch, gewissermaßen für sich selbst, bleibende Abänderungen schaffen, freilich nur so weit, als ihre Erzeugnisse die Schwelle von Gut und Schlecht nicht überschreiten. Nur so weit läßt die Personalselektion sie gewähren; ist aber diese Schwelle überschritten, so greift jene unterstützend oder hemmend ein.

Das ist leicht verständlich. Ist die Variationsrichtung einer Determinante oder Determinantengruppe nützlich, so wird das Keimplasma, in dem sie auftrat, bei dem Wettbewerb der Individuen 
untereinander gegenüber anderen Keimplasmen der gleichen Art im Vorteil sein, die Auslese der Personen wird den Keimplasmen mit den günstig variierenden Determinanten zur größeren Geltung verhelfen und damit die Umwandlung im Sinne der letzteren beschleunigen. Dagegen werden die Träger ungünstig variierender Determinanten durch Personalselektion aus dem Stammbaum der Art entfernt, und es wird damit dieser Variationsrichtung ein Ziel gesetzt werden. So werden die entoplasmatischen Vorgänge durch Kombination mit den Prozessen der Personalselektion in verschiedenster Weise reguliert, zum Besten der Art ausgenutzt und gesteigert, oder in ihren etwaigen schädlichen Folgen eingeschränkt und aufgehoben werden. Solange aber die durch die Germinalselektion bewirkten Abänderungen indifferent sind, hat die Personalselektion keine Veranlassung einzugreifen, und die entoplasmatischen Vorgänge werden gemä $B$ dem ihnen innewohnenden Beharrungsvermögen ihren Fortgang nehmen, bis die inneren Verhältnisse, die Beziehungen der Determinanten untereinander, ihnen ein Halt zurufen.

Durch die inneren umwandelnden Vorgänge, die in der Germinalselektion gegeben sind, erklären sich dann auch alle die Erscheinungen, die durch die Faktoren der Darwinschen Zuchtwahllehre allein nicht erklärbar sind, und die wir oben (Abschnitt VII) kennen lernten.

I. Da das Kräftespiel im Keimplasma fortwährend vor sich geht, und da für jede Determinante nur zwei Schwankungsrichtungen bestehen, so liegt zunächst die Möglichkeit vor, daß die Anfangsstufen einer nützlichen Abänderung von Anfang an bei zahlreichen Individuen auftreten, was für ihre erfolgreiche Verwertung durch die Personalselektion wünschenswert, ja bei Fehlen einer Unterstützung durch besondere Umstände, wie Isolierung, geradezu notwendig ist.

2. Das Beharrungsvermögen in den Vorgängen der Germinalselektion eröffnet dann weiterhin ein Verständnis für die Steigerung eines bestimmten Merkmals, wie sie im Verlaufe künstlicher Züchtungsprozesse beobachtet und für die natürlichen demnach auch vorausgesetzt wird. Die Schwanzfedern der langschwänzigen Haushähne, die langen und die kurzen, die geraden und die krummen Schnäbel der Tauben, die Vermehrung der Schwanzfedern bei der Pfauentaube und unzählige andere solche künstlich 
gezüchtete Merkmale - bei denen ,Übung" und ,Vererbung von Übungsresultaten" ganz ausscheiden - zeigen, daß einmal vorhandene, durch Germinalselektion entstandene Richtungen der Abänderung beliebiger Teile scheinbar unbegrenzt weiter gehen, wenn man ihnen freien Lauf läßt, indem man die Träger entgegengesetzter Variationen von der Nachzucht ausschließt. Erst wenn die weitere Steigerung die Harmonie der Teile dauernd und unwiderbringlich zerstören würde, würde Naturzüchtung Halt gebietend eingreifen; da $B$ aber auch dann der innere Umbildungsproze $B$ noch nicht beendet zu sein braucht, lehren jene künstlich gezüchteten Taubenrassen, deren Schnäbel so klein und so weich sind, daß sic die Eischale nicht mehr zu sprengen vermögen und der Nachhilfe des Züchters bedürfen. Im Naturzustand hätte eine solche Rasse sich nicht herausbilden können; Personalselektion hätte früher oder später den Prozeß der Germinalselektion unterbrochen und sein Fortschreiten bis zu einem so exzessiven Grade verhindert.

3. Ganz dieselben Überlegungen lassen in der Germinalselektion auch die Kraft erkennen, die imstande ist, ein Merkmal, das zunächst zu unbedeutend ist, um Selektionswert zu haben, auch ohne Hinzutreten von Personalselektion - und ohne daB Steigerung durch die Funktion in Betracht kommen kann - bis zum Selektionswert $\mathrm{zu}$ steigern. Und damit ist dann

4. auch ein Verständnis der sogenannten rein morphologischen Charaktere angebahnt, bei denen ein besonderer Nutzen nicht einzusehen ist, und deren Konstanz somit durch Naturzüchtung nicht erklärt werden kann. Mag ihre Zahl auch gering sein, und mag vieles als bedeutungslos gelten, was tatsächlich einen ganz bestimmten Nutzen hat, so ist doch damit zu rechnen und auch von Weismann zugegeben worden, daß es Merkmale, auch konstante Artmerkmale gibt, die ,unter der Schwelle von Gut und Schlecht" stehen, wie die Zahl der Blütenblätter bei Pflanzen, manche Färbungen und anderes. Für die Herausbildung solcher Merkmale vermittelt die Germinalselektion ebenfalls ein Verständnis: kraft der entoplasmatischen Vorgänge geht die Entwicklung in einer bestimmten Richtung weiter, auch wenn Naturzüchtung gleichgültig und teilnahmslos dabeisteht. Ganz besonders wird für die Herausbildung von rein morphologischen Merkmalen, wie schon erwähnt, induzierte Germinalselektion in Frage kommen. 
In diesen Zusammenhang gehören auch manche Merkmale domestizierter Rassen, die den Formen selbst weder nützlich noch schädlich sind (z. B. die gespaltene Nase bei Doggen und Möpsen). Die Darwinsche Erklärung, daß sie auf Korrelation zu beziehen seien, mag zutreffen, wäre aber dahin zu erläutern, daß es sich um korrelative Abänderung von Teilchen im Keimplasma handelt, um eine Verschiebung im ganzen Determinantengebäude, die durch die künstliche Züchtung einzelner Charaktere angeregt war.

Vor allem aber würde ein orthogenetisches Prinzip, wie es die Germinalselektion darstellt, ein besseres Verständnis für zahlreiche Erscheinungen vermitteln, die beim Menschen als Erzeugnisse der Kultur erscheinen: die spezifischen Talente, für Musik, Malerei, Mathematik usw., sowie die moralischen Tugenden des zivilisierten Menschen, vor allem die Selbstlosigkeit. Sie wären unbeabsichtigte Nebenwirkungen der germinalen Umwandlungsvorgänge, die unter dem Einfluß der Kultur vor sich gehen. Daß bei den ,spezifischen Talenten" auch Amphimixis durch Kombination verschiedener Geistesgaben eine Rolle spielt, wurde an anderer Stelle besprochen (Abschnitt IV).

5. Endlich aber sieht Weismann in der Germinalselektion auch einen Weg, der zu einem Verständnis für die Rückbildung von Merkmalen und für das schlieBliche völlige Schwinden funktionslos gewordener Organe führt. Das Rudimentärwerden von Organen, die aus irgendeinem Grunde funktionslos geworden, hatte Weismann, wie wir sahen, unter Ablehnung des Lamarckschen Prinzipes erklärt aus dem Fortfall der konservierenden Tätigkeit der Naturzüchtung, aus der ,Panmixie“, der Erhaltung und Vermischung aller Individuen, auch der Träger von Minusvarietäten des betreffenden Organes. Indessen würde dieser Nachlaß der Personalselektion wohl die Verschlechterung eines Organes verständlich machen, aber nicht seine stetige Verkleinerung bis zum völligen Schwund. Hier tritt nun die Lehre von der Germinalselektion ergänzend ein, indem sie zeigt, daß ein Mechanismus denkbar ist, der eine der Rückbildung anheimgefallene Determinante in dieser Richtung festhält bis zu ihrem völligen Schwunde, wenn nicht Naturzüchtung eingreift. Das aber ist eben bei funktionslos, wertlos gewordenen Teilen der Fall; der Verschlechterung z. B. der Augen bei Tieren in lichtlosen Höhlen steht die Naturzüchtung gleichgültig gegen- 
über, und so werden auch die Minusvarietäten aller für das Auge bestimmten Determinantengruppen fortgepflanzt, und gemäß jenem Beharrungsvermögen werden sich die germinalen Rückbildungsvorgänge an diesen Determinanten fortsetzen bis zum völligen Schwund derselben. Und dieser Mechanismus, eine Kombination von Germinalselektion und Panmixie, muß in gleicher Weise für die Determinanten von aktiv und passiv funktionierenden Teilen Geltung haben, wie für solche von Charakteren, die lediglich eine Daseinswirkung haben (z. B. von Schutzfärbungen); er bietet weiterhin auch eine Erklärung für das allmähliche Rudimentärwerden von funktionslosen Organen bei sterilen Formen — also in den Fällen, bei denen das Lamarcksche Prinzip der Vererbung funktioneller Abänderungen von vornherein nicht in Frage kommen kann. Kombination von Germinalselektion mit Panmixie wäre somit auch für die mannigfachen Mängel des heutigen Kulturmenschen, schlechte Zähne, Kurzsichtigkeit, Muskelschwäche, Verschlechterung der Milchdrüsen $\mathrm{u}$. a. verantwortlich $\mathrm{zu}$ machen, und nicht minder für gewisse negative Merkmale unserer Haustiere, wie die Zahmheit. Weismann führt diese auf Verkümmerung von Instinkten, hier des ,Instinktes der Wildheit", zurück.

So wäre also die letzte Wurzel aller erblichen Variation in Schwankungen des Gleichgewichts des Determinantensystems zu sehen, Schwankungen, deren Richtıng zunächst in den meisten Fällen durch den Zufall bestimmt ist, die aber dann, einmal eingeleitet, die Tendenz haben, diese Richtung fortzusetzen. Durch sie erfolgt eine wirkliche Veränderung der Determinanten selbst, eine Veränderung des Keimplasmas, wie sie der Umwandlung der Formen zugrunde gelegen haben muB. In der hinzutretenden zweielterlichen Fortpflanzung ist dann ein Mittel gegeben, durch das die so veränderten Determinantengruppen zu immer neuen Kombinationen zusammengebracht werden. Diese wechselnden Kombinationen werden der Personalselektion angeboten, die als höhere Instanz das Wirken der Germinalselektion kontrolliert. Sie wacht darüber, begünstigt die nützlichen Varietäten, merzt die schädlichen aus - mögen sie in exzessiven, die Harmonie des Ganzen störenden, oder in minderwertigen Bildungen eines Teiles beruhen - und verwertet so das von der Germinalselektion gelieferte Varietätenmaterial im Interesse der Art. Damit aber wirkt sie auch wieder 
auf die Germinalselektion zurïck und zwingt dieselbe gewissermaßen, die günstigen Varietäten in immer höherer Steigerung hervorzubringen. Wo aber die Personalselektion nicht eingreift, wie gegenüber den Minusvariationen bei funktionslosen Teilen oder gegenüber an sich gleichgültigen Abänderungen irgendwelcher Teile, da setzen sich die entoplasmatischen Vorgänge ungehemmt in der einmal eingeschlagenen Richtung fort und führen dort zum völligen Schwund ganzer Teile, hier zur Schaffung konstanter Artmerkmale, die an sich biologisch gleichgültig sind und die somit durch Personalselektion nicht erklärt werden könnten. - So leistet die Germinalselektion einerseits eine Vorarbeit für die Personalselektion und andererseits auch eine selbständige ergänzende Arbeit neben derselben.

\section{Bedeutung der Lehre von der Germinalselektion.}

Die Bedeutung, die der Aufstellung der Lehre von der Germinalselektion zukommt, kann gar nicht hoch genug angeschlagen werden. Schon oben (Abschnitt VI) wurde gesagt, daß mit dieser Aufstellung im Jahre I895 für Weismann die Epoche des allzuweit gehenden Glaubens an die Leistungsfähigkeit der Zuchtwahllehre von Wallace und Darwin abschließt. In der Tat tritt ja nun neben dieselbe ein ganz anderes Prinzip, welches versucht, die Umwandlung der Formen in ihrer letzten Wurzel zu begreifen. Von der Zuchtwahl, die mit gegebenen individuellen Abänderungen arbeitet und sie summiert, richtet sich jetzt der Blick auf die Kraft, die diese Abänderungen zuerst schafft, in klarer Erkenntnis, daß sie die wichtigere ist, und daß ohne sie eine Zuchtwahl überhaupt unmöglich ist. „Alle Abänderungen müssen innere Ursachen haben, und ibr Verlauf muß von gesetzmäßig wirkenden Kräften geleitet werden ${ }^{58}$ ). Diese Tatsache an sich: die Verlegung des Schwerpunktes der ganzen Betrachtung von der causa summandi, wie Roux sagt, auf die wirkliche ca usa efficiens, auf die eigentliche Bildungskraft, die die Abänderungen schafft, und deren Erzeugnisse sich innerhalb gewisser Grenzen sogar unbeeinflußt von Selektionsprozessen halten können, muß unterschieden werden von der besonderen Vorstellung, die sich Weismann über das Zustandekommen dieser Kraft gebildet hat. Letztere ist vielfach angegriffen, als zu roh, zu grob bezeichnet worden. Sei dem, wie ihm wolle; 
jedenfalls wird eins zugegeben werden müssen: daß nämlich die Lehre von der Germinalselektion sich folgerichtig an die Determinantentheorie anschließt und nicht bloß äußerlich deren Schlußstein bildet. Sie ist durchaus aus derselben hervorgewachsen, gehört ihrem ganzen Gedankengange nach so mit ihr zusammen, daß man fast die Behauptung wagen möchte: wenn Weismann sie nicht selbst aufgestellt hätte, so hätte das von anderer Seite geschehen müssen. Wenn überhaupt Determinanten vorhanden sind und das Wesen aller Teile bestimmen, so müssen auch Veränderungen dieser Determinanten die letzte Quelle aller erblichen Variation sein, - und die Vorstellung über das Zustandekommen dieser Determinantenabänderungen ist ja nur eine Übertragung der für die großen Lebenseinheiten gültigen Gesetze auf die kleinsten.

Die Lehre von der Germinalselektion bedeutet aber auch ihrer Tendenz nach nur zu einem Teil etwas ganz Neues, zu einem anderen lediglich einen Versuch, Erscheinungen, die Weismann schon von Anfang an als zu Recht bestehend anerkannt hatte, theoretisch, und zwar vom Standpunkt der Determinantentheorie aus, zu fassen und zu verstehen. Denn damals schon, I868 und in den siebziger Jahren, hat ja Weisman n sich von der Zufallstheorie Darwins entfernt, indem er immer wieder betont, da $B$ die Variationen nicht richtungs- und regellos, sondern beschränkt, an bestimmte Richtungen gebunden sind, daß aber diese bestimmt gerichtete Variabilität nicht der Ausdruck einer der lebenden Substanz innewohnenden Entwicklungskraft ist, sondern in der ,,physischen Natur" der Organismen, d. h. in ihrer gegebenen Konstitution und der davon abhängigen besonderen Variationsfähigkeit, ihren Grund hat. Diese ,physische Natur" wird jetzt schärfer gefaßt als „Determinantenkomplex des Keimplasmas", dessen einzelne Determinanten eine bestimmte historisch gewordene Zusammensetzung besitzen und eben dadurch in ihren Variationsmöglichkeiten beschränkt sind. Auch in bezug auf die Frage nach den Faktoren, die den Ansto $B$ zu der Veränderung der ,,physischen Natur", d. h. des Determinantenkomplexes geben, weicht die neue Vorstellung weniger rein theoretisch, als sozusagen mehr praktisch von der früheren ab. Von jeher (s. oben, S. I9o) sah Weismann diesen Anstoß nicht in einer der lebenden Substanz immanenten, vorwärts drängenden Entwicklungskraft, sondern in ,,äußeren Ein- 
flüssen", wobei dieser Begriff allerdings ganz bestimmt gefaßt war und die natürliche Umgebung des Gesamtorganismus bedeutete. In der Lehre von der Germinalselektion erhält er eine andere Fassung: die ,äußeren Einflüsse“ sind jetzt zunächst die, die die kleinsten Teilchen, die Determinanten treffen, ausgelöst durch die Ernährungsverhältnisse innerhalb des Keimplasmas. Sie sind in ihrer Bedingtheit einstweilen nicht weiter zu bestimmen, höchstens nach der negativen Seite: traumatische und funktionelle Veränderungen des Soma kommen dafür nicht, und die direkten Einflüsse der äußeren Umgebung des Gesamtorganismus nur in beschränktem Umfange in Betracht. Darin liegt also ein Unterschied gegenüber der früheren Auffassung, die gerade die direkte Wirkung der äußeren Einflüsse auf den Gesamtorganismus als wichtigsten umwandelnden Faktor annahm. Der Anstoß zur Umwandlung wird jetzt vor allem in den Organismus, ja in das Keimplasma verlegt, ohne daß aber damit der lebenden Substanz selbst - die hier durch die Determinanten und Biophoren repräsentiert wird - der innere Trieb zur gesetzmäßigen Weiterveränderung zuerkannt würde. Nur die Möglichkeit zur Umwandlung wird ihr nach wie vor zugesprochen, die Fähigkeit, auf Veränderungen der äußeren Bedingungen zu reagieren.

Neu hinzugekommen ist aber die Vorstellung, daß einmal eingeleitete Variationen sich in gleichem Sinne fortzusetzen streben, daß also auch bei gleich bleibenden Bedingungen der Umwelt die im Organismus sich abspielenden Vorgänge wirksam sind und eine einmal begonnene Umwandlung weiter $\mathrm{zu}$ führen und zu steigern vermögen. Theorien, die in dieser Richtung sich bewegen, d. h. die Entwicklung in bestimmten vorgezeichneten Bahnen aus inneren Kräften heraus sich vollziehen lassen, werden, wie schon gesagt, als ,orthogenetische" bezeichnet und vielfach in verschiedenen Formen vertreten (besonders von Eimer, aber auch von paläontologischer Seite); Weismann hat sich früher ablehnend gegen sie verhalten, mit der Aufstellung der Germinalselektion aber doch auch ein orthogenetisches Element bei der Umbildung der Formen anerkannt, freilich in engster Verbindung und Wechselwirkung mit der natürlichen Zuchtwahl im Sinne von Darwin und Wallace. Die Entfernung von Darwins reiner ,Zufallstheorie“ aber hat damit nur noch zugenommen. 
Indessen auch darin liegt noch nicht die Anerkennung einer gesetzmäßig vorwärts drängenden phyletischen Entwicklungskraft, wie Nägeli sie annahm, vielmehr erfährt jenes Fortschreiten der Variation eine Erklärung und Begründung durch Grundeigenschaften der lebenden Substanz: Ernährung, Wachstum, Fortpflanzung, die auch für die kleinsten Lebenseinheiten, die Biophoren und Determinanten, vorausgesetzt werden. Und so basiert letzten Endes die Lehre von der Germinalselektion auf physiologischen Vorstellungen, auf der Überzeugung, daß auch die kleinsten Bestandteile des Keimplasmas, die Träger der Vererbungstendenzen, lebende Wesen sind. Indem sie dabei bis auf die molekulare Zusammensetzung der Determinanten zurückgeht, deutet sie zugleich, wenn auch nur in blassen Strichen, den Versuch an, die unendliche Fülle qualitativer Verschiedenheit in der organischen Welt letzten Endes auf quantitative Veränderungen zurückzuführen.

Auf der konsequenten Durchführung dieses physiologischen Gedankens beruht denn auch ein Gegensatz der neuen Auffassung gegenüber der älteren, auf den auch noch kurz hingewiesen sei. Wenn in den früheren Schriften Weismanns von einem direkt verändernden Einfluß der äußeren Bedingungen, z. B. des Klimas, auf das Soma oder auf dieses und zugleich auf die Keimzellen (,Parallelinduktion“, s. S. Io3) die Rede ist, so ist das wohl so gemeint, da $\beta$ durch die fraglichen Einwirkungen die lebende Substanz direkt in bestimmter Weise - in ihrer molekularen $\mathrm{Zu}$ sammensetzung - verändert wird. Die Ergebnisse der Schmetterlingsexperimente, die zunächst für eine Vererbung von direkten Mediumeinwirkungen zu sprechen schienen, wurden, wie wir sahen, später von Weismann dahin gedeutet, daß der abändernde Einfluß, hier die Temperatur, in jedem Individuum zugleich die Flügelanlage, also einen Teil des Somas, und das Keimplasma der in dem Tier enthaltenen Keimzellen trifft. ,,In der Flügelanlage verändert cr dieselben Determinanten, wie in den Keimzellen, nämlich diejenigen der betreffenden Flügelschuppen." Die Lehre von der Germinalselektion deutet das nun dahin, daß die abnorme Temperatur nicht etwa direkt eine Veränderung in der Konstitution der Determinanten oder ihrer Biophoren zur Folge hat, sondern zunächst nur eine solche der Ernährungsverhältnisse (der Qualität der die Determinanten ernährenden Säfte), die dann ihrerseits erst wieder 
den Wettbewerb unter den kleinsten Einheiten der lebenden Substanz anfachen und damit deren Veränderung einleiten. So wäre jetzt, streng genommen, von einem ,direkt verändernden Einfluß “ der äußeren Bedingungen auf die lebende Substanz überhaupt nicht mehr zu reden; dieser Einfluß würde stets erst vermittelt durch die entstandenen Veränderungen der Ernährungsverhältnisse. Auch die Biophoren unterliegen nicht passiv, wie anorganische, chemische Körper dem umwandelnden Einfluß der äußeren Bedingungen, sondern reagieren nur als Lebewesen auf die Veränderungen, die durch die letzteren geschaffen werden. Mit dieser feineren Analyse der Mediumwirkungen ist Weismann in merkwürdiger Weise wenigstens in diesem einen Punkte zu engerer Annäherung an den von ihm am meisten befehdeten Deszendenztheoretiker, La marck, gelangt: auch dieser lehnte den Gedanken an eine direkte Abänderung der tierischen Organisation durch die äußeren Verhältnisse $a b$ und ließ dieselbe nur durch Vermittelung eines anderen Faktors vor sich gehen. Freilich ist dieser Faktor ein anderer als bei Weismann: Annahme neuer Gewohnheiten bei Lamarck, Entfachung des Determinantenkampfes bei Weismann.

So ergänzt die Lehre von der Germinalselektion die Determinantentheorie. Diese gab anfangs nur eine ,Morphologie des Keimplasmas", eine Vorstellung von seiner Zusammensetzung; die Germinalselektion versucht über die Lebenserscheinungen der Determinanten Vorstellungen zu gewinnen, sie gibt gewissermaßen eine „Physiologie des Keimplasmas“ und sieht in den elementaren Lebenserscheinungen der Determinanten die Ursache der Veränderungen der Organismen. Wichtiger als diese Vorstellung ist die von den Faktoren, die jene Lebenserscheinungen beeinflussen und stören. Hier liegt wohl der Hauptangriffspunkt der Theorie. Denn bei weitem die größte Bedeutung für die Störung des Gleichgewichtes innerhalb des Determinantenkomplexes wird ja den ,,zufälligen Ernährungsschwankungen“ innerhalb des Keimplasmas zugeschrieben, und es ist schwer, dem Zufall bei der Umbildung der Organismen so viel Macht einzuräumen und seine Regulierung, seine zweckmäßige Verwertung ganz der nachfolgenden Personalselektion zu überlassen. Aber Zufall ist ein ganz relativer Begriff; die Ernährungsschwankungen im Id mögen für dieses einen $\mathrm{Zu-}$ fall bedeuten, an sich werden sie in jedem Einzelfalle mit unerbitt- 
licher Logik aus bestimmten bedingenden Ursachen folgen. Und damit ist auch dem Gedanken Raum gelassen, daß jene ,zufälligen“ Ernährungsschwankungen letzten Endes doch in den Einwirkungen der Umwelt oder in funktionellen Veränderungen des Organismus ihren Grund haben könnten ${ }^{59}$ ). So bietet nicht nur die Determinantenlehre an sich eine Möglichkeit, ja eine Voraussetzung für die erbliche Übertragung ,,erworbener" Eigenschaften, wie das schon Plate betont, sondern auch die Auffassung von den Lebenserscheinungen der Determinanten, wie Weismann sie in der ,Germinalselektion" entwickelt, würden für jene Annahme eine brauchbare theoretische Grundlage abgehen.

Bei der Leitung endlich der phyletischen Entwicklung stellt sich die Germinalselektion als mindestens gleichwertige Kraft neben die Personalselektion, die Zuchtwahl im Sinne von Darwin und Wallace. Die inneren Kämpfe um die Nahrung, die sich im Keimplasma abspielen, stellen eine innere Triebkraft dar, freilich nicht in dem Sinne, da $B$ darin eine die Entwicklung der gesamten Organismenwelt in bestimmte Bahnen lenkende Kraft zum Ausdruck käme, aber doch eine Triebkraft, die für die einzelnen Determinanten die Richtung bestimmt. Dadurch aber, und da sie immer in einem bestimmten, gegebenen Keimplasma wirksam ist, gewinnt sie allerdings auch einen gewissen Einfluß auf die Gesamtentwicklung. Nicht jedes Keimplasma kann jede beliebige Variation liefern; sein Determinantengehalt bedingt es, welche möglich und welche unmöglich ist. Darin aber liegt eine Beschränkung für die Tätigkeit der Naturzüchtung, und bis zu einem geringen Betrag auch eine steuernde, richtungsbestimmende Kraft der inneren Triebfeder, der Germinalselektion. Die Variationen sind nicht, wie Darwin meinte, von Hause aus zufällig und richtungslos und durch Naturzüchtung nur steigerungsfähig, sondern die Naturzüchtung findet schon Variationsrichtungen vor, die auch aus inneren Gründen sich zu steigern streben und von der Naturzüchtung dabei nur unterstützt oder gehemmt werden können. Ja, gegenüber den Determinantenvariationen, die unter dem direkten zwingenden Einfluß veränderter äußerer Bedingungen auftreten, kann die Naturzüchtung unter Umständen sogar machtlos sein, d. h. außerstande, jene Wirkungen zu neutralisieren. Damit ist die Wirkungssphäre der „Naturzüchtung“ - im alten eigentlichen Sinne - ein- 
geschränkt. Die Lehre von der Germinalselektion trägt den vielen Erscheinungen Rechnung, die darauf hinweisen, daß bei den Veränderungen der Organismen einmal eingeschlagene Richtungen auch ohne Zutun der Personalselektion, aus inneren Kräften heraus, beibehalten werden.

Erweiterung der Machtsphäre des Selektionsprinzips durch die Lehre von der Germinalselektion.

So ist mit der Aufstellung der Lehre von der Germinalselektion anerkannt, daß die Vorgänge der Naturzüchtung, im Sinne von Darwin und Wallace, in mancher Hinsicht in ihrer Wirkung beschränkt sind. Dem allgemeinen Prinzip aber, das in der alten Zuchtwahllehre zur Geltung kam, dem Selektionsprinzip an sich, ist dadurch eine bedeutend erweiterte Machtsphäre zugewiesen worden. Freilich ist zu beachten, daß, wenn auch der von Weismann selbst gewählte Name „Germinalselektion“ den Schwerpunkt auf die Ähnlichkeit der so bezeichneten Vorgänge mit denen der Personalselektion legt, diese Ähnlichkeit nicht ganz vollständig ist. Denn es wird ja, nach der Theorie, der erste Ansto $B$ zur Störung des Gleichgewichtszustandes innerhalb des Keimplasmas durch äußere Beeinflussung (ungleiche Ernährung) der Determinanten gegeben und es werden dadurch überhaupt erst die Ungleichheiten in der aktiven Assimilationsfähigkeit der Determinanten geschaffen, auf Grund deren sich Selektionsprozesse anbahnen können. Außerdem mag noch besonders darauf hingewiesen werden, da $\beta$ es sich bei den Vorgängen der Germinalselektion um Kämpfe zwischen den verschiedenen Determinanten, also ganz ungleichartigen Gebilden handelt, während bei dem Begriff „Personalselektion“ gewöhnlich zuerst an die Vorgänge gedacht wird, die sich zwischen den Variationen der Individuen einer Art, also gleichartigen Lebewesen abspielen und dadurch die dauerfähigsten dieser Variationen züchten. Freilich ist gleich hinzuzufügen, daß Darwin selbst den Begriff des „Kampfes ums Dasein“ in ganz weitem Sinne genommen hat, nicht nur als Konkurrenz gleichartiger Individuen, und daß auch der Kampf verschiedenartiger Individuen Selektionsprozesse einleiten kann.

Mit der Aufstellung der Lehre von der Germinalselektion hat Weismann das Selektionsprinzip auf einem neuen weiteren 
Gebiet zur Anwendung gebracht. Ein anderer Forscher, Wilhelm Roux, war ihm darin vorangegangen, hatte die Lehre vom Daseinskampfe auf alle Teile des Organismus übertragen, hatte insbesondere aus dem Kampf gleichartiger Teile (der Zellen desselben Gewebes, der Teilchen innerhalb der Zelle) um Nahrung, Raum und den funktionellen Reiz die Züchtung der Gewebsqualitäten abgeleitet, auf deren Grundlage dann im Individuum die einzelnen funktionellen Anpassungen zustande kommen. Weismann ergriff diesen Gedanken der Histonal- oder Gewebeauslese, wie er selbst die berührten Vorgänge nannte, mit freudiger Zustimmung, freilich, wie wir sahen, mit dem Vorbehalt, daß er den Resultaten dieser Ausleseprozesse, den Wirkungen des Gebrauches und Nichtgebrauches, nur für das Individuum selbst eine Bedeutung zuerkannte, ihre Vererbbarkeit und damit eine Bedeutung für die Umbildung der Formen aber leugnete. Dagegen erweiterte er selbst die Machtsphäre des Selektionsprinzipes aufs neue, indem er ihm auch die Vorgänge innerhalb des Keimplasmas unterordnete, es als Germinalselektion das Schicksal der kleinsten hypothetischen Lebenseinheiten beherrschen läßt. Und gerade diesen Ausleseprozessen auf dem kleinsten Gebiete, unter den kleinsten Lebenseinheiten, schreibt er die allergrößten Wirkungen zu: auf ihnen beruht alle Variation, beruht letzten Endes die ganze Entwicklungsfähigkeit der organischen Welt.

\section{Die verschiedenen Formen der Auslese.}

So wird das Selektionsprinzip zu dem großen allgemeinen Bildungsprinzip, das überall im Reiche des Organischen Geltung hat. Unter den Lebenseinheiten aller Stufen, den größten wie den kleinsten, herrschen dieselben Gesetze des Kampfes ums Dasein, des Kampfes um Nahrung und Vermehrung; auf ihnen beruht aller Fortschritt. Man müßte, streng genommen, so viel Arten von Selektionsprozessen unterscheiden, als es Kategorien von Lebenseinheiten gibt; entsprechend den Hauptstufen und Hauptbedingungen der Lebenseinheiten schlägt $W \mathrm{c}$ isma $\mathrm{n} n$ vor, deren vier auseinander zuhalten: Germinalselektion, Histonalselektion, Personalselektion und Kormalselektion. Letztere bedeutet den AusleseprozeB, der die Anpassung der Tier- und Pflanzenstöcke (Kormen) bewirkt und der auf dem Kampf der Stöcke untereinander beruht. 
Unter solcher Erweiterung der Selektionslehre bekennt sich Weismann auch noch in der letzten Auflage seiner "Vorträge" zu dem Ausspruch, - der allerdings früher eine andere Bedeutung hatte - : es beruht alles auf Anpassung, und alles wird geregelt durch Selektionsprozesse. Und nur wenn das Wort ,Naturzüchtung““ in ganz allgemeinem Sinne genommen, und darunter überhaupt nur das Wirken natürlicher Ausleseprozesse unter den Lebenseinheiten aller Stufen verstanden wird, würde es auch jetzt noch berechtigt sein, Weismann als Vertreter der ,Allmacht der Naturzüchtung" zu bezeichnen - eine Bezeichnung, mit der auch heute noch vielfach die alte Bedeutung verbunden wird, die ihr seit Aufstellung der Germinalselektion, also seit mehr als 20 Jahren, nicht mehr zukommt. 
Neunter Abschnitt.

\section{Entwicklung des Organismenreiches. Schluß.}

Variabilität, Vererbung, Auslese - das sind die drei großen Fragen, die von Weismann besonders behandelt worden sind; wir wissen, es sind die drei Fundamente, auf denen die Darwinsche Abstammungslehre beruht, die drei Faktoren, die Darwin ganz besonders für die Umbildung der Formen und ihre Anpassung an die Lebensbedingungen in Anspruch genommen hatte. Von der Überzeugung, da $B$ eine historische Entwicklung der Formen auseinander unter gleichzeitiger Umbildung stattgefunden hat, war Weismann ausgegangen, an sie knüpfte er seine Fragestellungen an, zu ihr kehrte er nach allen Streifzügen wieder zurück. Für den Deszendenzgedanken einzutreten ist er nicht müde geworden; auch seine Theorie der Vererbung und Ontogenese, die ,Keimplasmatheorie", entwickelte er in stetem Hinblick auf die großen Gesichtspunkte der Phylogenese, als eine Teilfrage der Deszendenzlehre.

Nach seiner Stellungnahme zu diesen Fragen lassen sich unschwer drei Perioden unterscheiden. Die erste reicht bis zum Anfang der achtziger Jahre und ist gekennzeichnet dadurch, daß Weismann hier noch im wesentlichen auf altem Darwinistischen Standpunkt steht, also neben der Naturzüchtung auch die Vererbung erworbener Eigenschaften gelten läßt. Personalselektion und Lamarckismus ist ihr Leitsatz. Eine Abweichung von der Darwinschen Auffassung bahnt sich aber bereits an: die Erkenntnis, da $\$$ die Variationen, auf denen die Umbildung der Arten beruht, nicht richtungs- und regellos sind, sondern durch die ,physische Natur" der Organismen eine Beschränkung und eine Lenkung 
in bestimmter Richtung erfahren. Dic genauere Beschäftigung mit dem Vererbungsproblem führt dann im Anfang der achtziger Jahre zu der bestimmten Überzeugung, daß Verletzungen, Verstümmelungen und funktionelle Veränderungen nicht vererbt werden, und damit zu einer bestimmten Ablehnung des Lamarckismus. Die berühmte Rede über die Vererbung, von $\mathrm{I} 883$, stellte weithin sichtbar diesen Grundsatz auf und eröffnet damit die zweite Periode, die bis zur Mitte der neunziger Jahre reicht. Es ist die arbeitsfreudigste: die Ausarbeitung der Lehre von der Kontinuität des Keimplasmas und von der Zusammensetzung desselben aus Determinanten, die theoretische Verknüpfung der Vererbungs-, Befruchtungs-, Fortpflanzungserscheinungen mit den Ergebnissen der zu gewaltigem Aufschwung gelangenden zytologischen Forschung vollzieht sich in ihr, vor allem aber ist sie gekennzeichnet durch den Kampf für die Zuchtwahllehre von Wallace und Darwin, durch den stets erneuten Versuch, die stammesgeschichtliche Entwicklung des Organismenreiches nunmehr, nach Verabschiedung des Lamarckschen Prinzipes, allein mit Hilfe der Faktoren der Zuchtwahllehre: Variabilität, Vererbung der blastogenen Abänderungen, Personalauslese im Kampfe ums Dasein, zu erklären. An die Stelle der alten Annahme: „Personalauslese und Lamarckismus“ ist nun die Frage getreten: „Personalauslese oder Lamarckismus?" - mit der Antwort: nur Personalauslese. Das starke Wort von der ,,Allmacht der Naturzüchtung“ drückt den Überschwang persönlicher Hingabe aus, mit der Weismann in dieser Zeit für die Zuchtwahllehre und gegen ihre Angreifer eintrat. Aber dieser Kampf führte ihn auch selbst dahin, der Erscheinung, auf der alle Zuchtwahl beruht, dem Auftreten individueller Varietäten, größere Beachtung zu schenken und in ihm das Wirken eines Prinzips zu erkennen, das bis zu einem gewissen Grade auch unabhängig von dem Eingreifen der Auslese bleibende Umgestaltungen schafft. Wo Auslese stattfinden soll, muß Auslese material in Form individueller Verschiedenheiten vorhanden sein; der Personalauslese muß eine andere Kraft vorarbeiten, die eigentliche Umbildungskraft, die jene Verschiedenheiten schafft, und manche Tatsachen zwangen dazu, ihr eine gewisse Selbständigkeit, oder richtiger: eigene Arbeitsregeln zuzusprechen. So trat, gewissermaßen an dic Stelle des aufgegebenen Lamarckschen Umwandlungs- 
prinzipes, ein anderes, orthogenetisches, die Germinalselektion; ihre Aufstellung im Jahre 1895 beginnt eine dritte Periode in Weismanns deszendenztheoretischen Anschauungen, mit der Devise: Germinalselektion und Personalselektion. Mit der Aufstellung dieses neuen Prinzipes ist die Lücke ausgefüllt, die bisher in jenen Anschauungen bestanden hatte, ist die elementare gestaltende Urkraft, die als notwendig vorauszusetzen ist, genauer festgelegt und analysiert. Diese Kraft wird in den Organismus verlegt und hergeleitet aus dem Kräftespiel der kleinsten lebenden Teilchen innerhalb des Keimplasmas, einem Kräftespiel, das in seinen Ursachen zurückgeführt wird zum kleineren Teil auf die Einwirkungen der Umwelt, die den Organismus umgibt, zum größeren Teil auf Einflüsse, die innerhalb des Organismus selbst entstehen und die vom Zufall bedingt werden. Nicht ein besonderes vitalistisches Prinzip wird damit aufgestellt, sondern es werden nur Erscheinungen, die an den großen Lebensprozessen unmittelbar zu beobachten sind, auf die kleinsten, unsichtbaren übertragen: es ist der allgemeine Kampf um die Nahrung, um das Recht auf Wachstum und Vermehrung, der jene umbildende Kraft zustande bringt. Das Selektionsprinzip ist aus dem Gebiet, auf dem es aufgestellt worden war, dem der Personen, herausgeführt und auf die kleinsten Lebenseinheiten übertragen. Nach der in dieser letzten Periode vertretenen Anschauung Weismanns wirken somit zur Umbildung der Lebewesen vor allem drei Faktoren zusammen: I. eine innere Bildungskraft, ausgelöst durch im Innern des Keimplasmas sich abspielende Vorgänge: die Germinalselektion, das eigentliche Gestaltungsprinzip, von dem auch die Erscheinungen der Korrelation beherrscht werden; 2. die Amphimixis mit den vorbereitenden Reifungsvorgängen, die fortwährende Kreuzung, Umkombinierung der Anlagen; 3. die Personalselektion in den beiden Formen der natürlichen und der sexuellen Zuchtwahl. Nach wie vor wird ihr eine hohe Bedeutung zugesprochen; von einer „Allmacht der Naturzüchtung" kann aber nicht mehr geredet werden, wofern wenigstens der Begriff "Naturzüchtung“ in seiner ursprünglichen Bedeutung genommen wird. Statt ihrer tritt das innere Bildungsprinzip der Germinalselektion in den Vordergrund.

Die Entwicklung des Organismenreiches gestaltet sich für Weismann nun etwa in folgender Weise. Als logische Notwendig- 
keit fordert er die Annahme einer Urzeugung; wie alles Lebendige als Organisches völlig vernichtet und in anorganische Körper verwandelt werden kann, so muß es auch einmal aus anorganischer Substanz entstanden sein. Weismann bekennt sich damit, und hat sich stets bekannt, zu einer ,,materialistischen“ Naturauffassung, die auch zwischen der organischen und der anorganischen Welt keine wirkliche unüberbrückbare Kluft gelten läßt und die Lebenserscheinungen letzten Endes auf chemisch-physikalische Prozesse zurückführt. Vitalistische Bestrebungen, die Annahme einer besonderen „Lebenskraft“, hat er stets abgelehnt $\left.{ }^{60}\right)$. - Weit unter der Grenze des Sichtbaren, uns unerkannt und ewig unerkennbar, müssen die ersten einfachsten Lebenseinheiten gedacht werden, die irgendwo und $\mathrm{zu}$ irgendeiner Zeit einmal durch den Zusammentritt bestimmter chemischer Moleküle sich gebildet haben.

„Die“ ersten Lebenseinheiten, - denn es ist anzunehmen, daß nicht ein Urorganismus, sondern deren zahlreiche durch Urzeugung entstanden, die auch schon von vornherein nicht als absolut gleich gedacht werden können, da die Umstände, unter welchen sie ins Leben treten, nicht absolut identisch gewesen sein können. Mit den ersten Lebewesen war zugleich der erste Grund für die Verschiedenheiten der Organismen gegeben; unter den Verschiedenartigkeiten der äußeren Bedingungen, unter die die Nachkommen jener Urorganismen gerieten, mußten sich jene ersten Verschiedenheiten nur immer weiter steigern. Die Vielgestaltigkeit der Organismen begann schon mit der Entstehung der ersten Organismen selbst, die als Biophoriden ein selbständiges Dasein führten. Und diese waren nicht nur von vornherein schon verschieden, sondern sie erhielten auch schon bei ihrer Entstehung die Fähigkeit mit, veränderten äußeren Einflüssen nachgeben zu können, auch weiterhin variabel zu sein. Anhäufung von Biophoriden führte nunmehr zur Bildung von Biophoridenkolonien, in denen dann nach dem Prinzip der Arbeitsteilung eine Differenzierung eintrat, wodurch die einzelne Biophoride ihre Bedeutung als selbständiges Wesen aufgab, als Biophore zu einem bestimmt differenzierten Teil einer höheren Einheit wurde. Die hypothetische kernlose IIonere Haeckels repräsentiert diesen Zustand einer Biophorenkolonie. Ihrem gleichförmigen Körper müssen wir noch die Fähigkeit zusprechen, durch direkte Wirkung äußerer 
Einflüsse verändert zu werden und diese Veränderungen auf die durch Teilung entstehenden Nachkommen zu übertragen.

Mit der Differenzierung verschiedener Arten von Biophoren innerhalb des Komplexes geht die ursprüngliche Gleichförmigkeit desselben verloren, und nun erhebt sich auch das Lebewesen auf die nächste Stufe der Vervollkommnung durch Bildung eines Ke rnes, er charakterisiert die Zelle. In dem Kern aber ist ein Reservedepot von Biophoren all der verschiedenen Differenzierungen zu sehen, dazu bestimmt, daß aus ihm bei der Teilung des einzelligen Wesens den beiden Teilungshälften die Biophorenkomplexe zur Erzeugung der Teile mitgegeben werden, die auf dem Wege der einfachen mechanischen Teilung des Körpers, wegen zu bedeutender Differenzierung desselben, ihnen nicht überliefert werden können. Jene Reservebiophoren stellen also Anlagen gewisser Teile dar; sie sind gruppenweise zu besonderen Anlagestücken oder Determinanten vereinigt, die ihrerseits wieder die Chromosomen des Kernes zusammensetzen. Die Chromosomen stellen die Anlagenträger dar.

Die Bildung des Kernes bedeutet die erste Sonderung einer Körper- und einer Keim- oder Anlagensubstanz, und damit einen sehr wichtigen Schritt auf dem Wege der Vervollkommnung der Organisation. An die im Kern zusammengedrängte Keimsubstanz (das Keimplasma) sind von jetzt ab die Vererbungserscheinungen geknüpft.

An die Einzelligen schließen sich die Kolonien von solchen an, und zwar zunächst solche, in denen die einzelnen Zellindividuen noch gleichartig sind, und ein jedes durch mehrfache Teilung wieder eine ganze Kolonie erzeugen kann (homoplastide Kolonien), und dann - der nächste bedeutungsvolle Schritt - solche, in denen eine Differenzierung der Individuen stattgefunden hat in Körper- und Geschlechtszellen (heteroplastide Kolonien). Nunmehr besitzen nur noch die Geschlechtszellen die Fähigkeit, die ganze Kolonie neu zu erzeugen, nur sie enthalten in ihren Kernen das dazu nötige, aus sämtlichen Determinanten zusammengesetzte Keimplasma und geben dies auf die folgenden Generationen weiter, so eine Kontinuität des Keimplasmas herstellend und selbst eine potentielle Unsterblichkeit bewahrend, wie sie die Einzelligen besaßen. Die Körperzellen dagegen übernahmen mannigfache andere 
Funktionen, sie werden dementsprechend auch morphologisch differenziert und bewahren auch in ihren Kernen nur noch ein spezifisches Idioplasma, das lediglich noch für ihre, der Körperzellen, charakteristischen Merkmale die nötigen Reservedeterminanten enthält und zugleich in seiner Reprodıktionskraft beschränkt ist, d. h. nur für eine beschränkte Anzahl von Zellfolgen ausreicht. Damit ist für die Körperzellen eine neue Eigenschaft eingeführt, die den Lebewesen von vornherein nicht zukam: sie unterliegen dem Tode, werden sterblich.

Das Prinzip der Arbeitsteilung waltet auch bei der Erreichung der nächsten Stufe: der Herausbildung der vielzelligen Organismen aus den Kolonien, und bei der Entfaltung derselben zu immer höheren, komplizierter gebauten, in unendlicher Formmannigfaltigkeit auseinandergehenden Organismen.

Frühzeitig wohl wurde aber noch eine andere Einrichtung eingeführt, die den Nachteil der weitgehenden Differenzierung in etwas milderte: die Regenerationsfähigkeit, geknüpft an geringe Mengen von Reservekeimplasma, das gewissen Körperzellen je nach Bedarf noch neben ihrem spezifischen Idioplasma mitgegeben wurde und sie in den Stand setzte, nötigenfalls nicht nur ihresgleichen, sondern ganze Körperteile, ja den ganzen Organismus zu regenerieren.

Die Voraussetzungen, unter denen sich alle diese Umwandlungen vollziehen, ändern sich nach Weismannscher Auffassung von dem Augenblick an, wo ein Kern und damit die erste Sonderung einer Keim- und einer Körpersubstanz auftritt. Während vorher, bei den kernlosen Lebensformen, damit gerechnet werden konnte, da $B$ alle Veränderungen des ganzen Lebewesens sich auch unmittelbar auf die Nachkommen übertragen, also erblich sind, ist von diesem Augenblick an jede erbliche Übertragung durchaus an die Keimsubstanz geknüpft. Diese allein bestimmt durch ihre Zusammensetzung das Wesen des Nachkommen; eine Veränderung des Keimplasmas bedingt, daß das unter seiner Herrschaft und Leitung entstehende Soma ebenfalls eine Veränderung gegenüber der früheren Generation aufweist. Somit setzt nunmehr auch jede erbliche Variation und damit alle dauernde Umbildung der Formen eine primäre Veränderung des Keimplasmas voraus. Solche primären Veränderungen des Keimplasmas waren die Ursache für die mannigfachen Differenzierungen der Einzelligen, sie bedingten, daß aus 
Einzelligen die homoplastiden, und aus diesen die heteroplastiden Zellkolonien entstanden, sie waren endlich die Ursache für die Weiterbildung der heteroplastiden Kolonien zu vielzelligen Organismen und für die Ausbildung der letzteren in unendlicher Mannigfaltigkeit.

Mit den Voraussetzungen für die Umbildungen ändern sich von dem Auftreten eines Kernes an, aber auch Art und Weise ihres Zustandekommens sowie ihre Ursachen. Jene Umwandlungen vollziehen sich nicht nach einem bestimmten, von vornherein festgelegten Schöpfungsplan, auch nicht auf Grund eines der lebenden Substanz innewohnenden Entwicklungstriebes, sondern, ganz allgemein gesprochen, im engsten Anschluß an die äußeren Bedingungen, unter denen sich die einer erblichen Veränderung fähigen elementaren Lebenseinheiten befinden. Bei den niedersten kernlosen Lebensformen fallen diese Bedingungen zusammen mit denen, unter denen sich das Lebewesen selbst befindet. Der Einfluß der äußeren Bedingungen vermag auf sie unmittelbar umgestaltend zu wirken, und die so bewirkten Veränderungen übertragen sich unmittelbar auf die Nachkommen, so kommt er zugleich als die Wurzel dauernder Umgestaltung der Formen in Betracht. Das ändert sich aber mit dem Augenblick, wo die für die Anbahnung erblicher Veränderungen maßgebende Substanz sich als Keimplasma konzentriert und sich in das Innere eines Soma zurückzieht. Wie konnte nun überhaupt eine Veränderung dieser Keimsubstanz erfolgen? Auf diese Frage antwortet die Lehre von der Germinalselektion. Sie lehnt auch für das Keimplasma eine zwangsmäßig in bestimmter Richtung ablaufende, durchaus schon durch die Struktur bedingte Umbildung desselben, eine phyletische Präformation, $a b$ und greift auf die allgemeinen Erscheinungen des Stoffwechsels zurück. Tief im Innern des Organismus, in der engen Werkstätte des Keimplasmas, kämpfen ihr zufolge die kleinsten hypothetischen Lebenseinheiten, die Biophoren und die aus ihnen zusammengesetzten Determinanten und Determinantengruppen um die Nahrung, deren Zufuhr mannigfachen Veränderungen unterworfen ist, und verändern sich dadurch selbst quantitativ und qualitativ. Die einen werden kräftiger, die anderen schwächer; ihre chemische Zusammensetzung erleidet Abänderungen. Und was hier im Keim an den Anlagen, den Determinanten, sich an- 
bahnt, tritt dann an dem entwickelten Organismus in den Merkmalen, den Determinaten, in die Erscheinung. So spielen sich im Keime, am Keimplasma, die Vorgänge ab, die die Umwandlungen der Formen anbahnen; sie bilden den Mechanismus, durch den diese Umwandlungen zustande kommen.

Ihre unmittelbare Ursache sind Ernährungsschwankungen, also auch wieder Bedingungen, die außerhalb der Lebensteilchen sich finden. Als Ursache dieser Schwankungen kommen aber nun nur noch in sehr geringem Maße die äußeren Bedingungen, die den ganzen Organismus umgeben, in Betracht, in weit höherem Maße die innerhalb des Organismus sich abspielenden Vorgänge, die nur für die Determinanten des Keimplasmas als , „äußere" zu gelten haben, und die, da sie sich unserer Einsicht entziehen, als „Zufälligkeiten " zu bezeichnen sind. Sie vor allem bedingen jene Ernährungsschwankungen und regen damit jenes Kräftespiel im Keimplasma an, das die eigentliche causa efficiens der Umbildung der Formen abgibt. Ihnen gegenüber spielen die äußeren Verhältnisse, die den ganzen Organismus umgeben und auf ihn wirken, wie Klima, Ernährung u. dgl. eine untergeordnete Rolle für die Umwandlung der Formen. Sie wirken zunächst und vor allem auf die Körpersubstanz, und die durch sie bedingten Veränderungen des Soma sind ebensowenig erblich wie die, die an dem letzteren durch Übung oder Nichtgebrauch eines Organes zustande kommen. Es sind nur passante Veränderungen, die nicht zu dauerndem Besitz der Art werden. Immerhin kann, wenn auch in seltenen Fällen, doch gelegentlich einmal auch durch die äußeren Einflüsse der Umgebung jenes Kräftespiel im Keimplasma angeregt, und damit zugleich mit dem Soma auch das in ihm eingeschlossene Keimplasma gleichsinnig verändert werden, so daß dann bei dem Nachkommen wieder die gleiche Veränderung des Soma hervortritt, die der Elternorganismus zeigte, und so der Schein einer Vererbung direkter Mediumeinflüsse auch bei höheren Formen zustande kommt. Diese Überlegungen gelten sowohl für die Einzelligen, bei denen das Soma nur durch den Zellkörper, und die Keimsubstanz durch den Kern dargestellt wird, wie für die Vielzelligen, bei denen das Soma aus einer sehr großen Menge von Zellen besteht, und die Keimsubstanz in Form der Keimzellenkerne in ihm eingeschlossen ist.

Die Abänderung der Formen, die auf die eben geschilderte 
Weise eingeleitet wird, erfährt eine weitere Steigerung durch eine Einrichtung, die ebenfalls schon auf einer tiefen Stufe des Organismenreiches, jedenfalls schon bei den Einzelligen, in Wirksamkeit trat: die Amphimixis, die Vermischung zweier Individuen. Ihre Bedeutung liegt in einer Vermischung der Keimplasmen und damit der Anlagekomplexe zweier Individuen. Anfangs, d. h. auf der niederen Stufe der Organisation, nachdem sich eine Keim- und eine Körpersubstanz eben erst gesondert hatten, war jene, das Keimplasma, nur einwertig, d. h. es enthielt den Anlagekomplex für nur ein Individuum; durch den Vorgang der Amphimixis wurden zwei solcher Komplexe zu dauernder gemeinsamerWirksamkeit zusammengeführt, und damit die Möglichkeit geschaffen, daß das aus dem neu zustande gekommenen zweiwertigen Keimplasma hervorgehende Geschöpf Merkmale zweier Organismen, - seiner beiden Eltern in sich vereinigt. Freilich schiebt sich hier zunächst wieder ein Kampf ein: ein Kampf eben dieser beiden Anlagekomplexe - d. h. ihrer einzelnen Determinanten mit den entsprechenden der anderen Herkunft - die nach ihrer Vereinigung darnach streben, sich bei der Entfaltung des neuen Individuums zur Geltung zu bringen. Erst auf dem Wege dieses Wettbewerbes entsteht aus dem zweiwertigen Keimplasma ein Geschöpf, das Merkmale beider Elternorganismen in sich vereinigt. So wird diese Einrichtung zu einer neuen Quelle für Verschiedenheiten der Organismen, zwar nicht hinsichtlich der einzelnen Merkmale selbst, wohl aber hinsichtlich der Kombination derselben zu einem Ganzen, zu einem Merkmalskomplex. Sic führte in der Folge zu einer weiteren Differenzierung im Sinne einer Arbeitsteilung: zu der Ausbildung männlicher und weiblicher Geschlechtszellen, ja, männlicher und weiblicher Individuen, die nun bei der Vereinigung als väterliche und mütterliche in Betracht kommen.

Eine weitere Einrichtung, die ebenfalls im Sinne der Vermehrung individueller Verschicdenheiten wirksam werden mußte, gesellte sich als Folge der erstmaligen Amphimixis hinzu: die einer jeden folgenden Amphimixis vorausgehende Reduktion der Anlagen im Keimplasma auf die Hälfte. Durch sic wurde erreicht, daß auch neue Vermischungen im Laufe der Generationen die Zahl der Anlagekomplexe innerhalb eines Keimplasmas doch nie größer als zwei werden ließen, und eine Anhäufung von ,,Ahnenplasmen“ 
im Keimplasma verhindert wurde. Die beiden vereinigten Anlagekomplexe - der väterliche und der mütterliche - aus denen, nachdem einmal die Amphimixis eingeführt war, jedes Individuum hervorgeht, und von denen unverbrauchte Reste auch in jeder seiner Keimzellen deponiert werden, werden zur Vorbereitung für eine Amphimixis wieder zerlegt, und ihre einzelnen Anlagen auf zwei Zellen verteilt, und erst eine so wieder einwertig gewordene Keimzelle vermag mit einer anderen in gleicher Weise präparierten sich zu vereinigen. Dabei bleibt es aber dem Zufall überlassen, in welcher Weise jene Verteilung erfolgt; die Anlagenträger väterlicher und mütterlicher Herkunft werden in neuer Weise zusammengestellt. So war denn auch die Möglichkeit eröffnet, da $B$ auch bei wiederholter Amphimixis eines und desselben Elternpaares von beiden Seiten doch immer wieder verschieden zusammengesetzte Anlagenkomplexe zusammenkamen: der geschilderte Reduktionsvorgang wurde zu einer neuen Quelle individueller Variabilität.

Alle die aus der gemeinsamen Quelle der Amphimixis und der sie vorbereitenden Prozesse fließenden Verschiedenheiten betreffen aber, um es noch einmal zu betonen, nur die Kombination der Merkmale zu neuen Komplexen; die Veränderung der elementarsten Komponenten derselben bleibt den Vorgängen innerhalb des Keimplasmas überlassen.

Alle die genannten Faktoren wären aber noch nicht imstande gewesen, das Organismenreich in der Gliederung, die wir kennen, und vor allem mit der innigen Anpassung an die äußeren Verhältnisse, die wir bewundern, hervorzubringen, wenn nicht diese äußeren Verhältnisse selbst regulierend eingegriffen hätten. Die erblichen Abänderungen der Formen erfolgen in kleinen Schritten, sie treten als individuelle Variationen in die Erscheinung. Sie sind zwar nicht ganz ziel- und richtungslos, sondern streben zufolge ihrer Entstehung darnach, die einmal eingeschlagene Richtung beizubehalten, aber doch sind sie recht mannigfaltiger Art und für die Individuen, an denen sie auftreten, von sehr verschiedenem Werte. Sie bedeuten für diese, wenigstens in ihrer großen Mehrheit, Vorteile oder Nachteile, machen sie mehr oder weniger leistungsfähig in den Wettbewerben, die sie mit ihresgleichen und mit ganz anderen Formen um die notwendigsten Lebensbedingungen $\mathrm{zu}$ führen haben, erhöhen oder schwächen ihre Widerstandskraft gegen die Einflüsse 
der unbelebten und belebten Umgebung, vermehren oder vermindern ihre Fähigkeit, die von ihrer Umgebung ihnen gebotenen Existenzbedingungen auszunutzen, - kurzum, machen sie mehr oder weniger ,dauerfähig“ (Roux) in all den vielen Beziehungen, die seit Darwin unter der Bezeichnung ,Kampf ums Dasein“ zusammengefaßt werden. Diese neue Instanz des Kampfes, der Kampf zwischen den Individuen oder Personen, führt automatisch zu einer Auslese, einem Erhaltenbleiben und einer Häufung der sich am meisten „,bewährenden“ Qualitäten und züchtet dieselben im Laufe der Generationen zu festen dauernden Merkmalen der Arten, durch Ausmerzung der weniger günstig veranlagten Individuen. So entstehen die Merkmale der Organismen in Anpassung an die Lebensbedingungen: die Organismen sind in erster Linie Anpassungskomplexe. Dazu gesellen sich, aber in geringerem Umfang, Merkmale, die in gleicher Weise entstanden, aber biologisch bedeutungslos sind und somit in den Merkmalsbestand der Art eingefügt werden, ohne deren Dauerfähigkeit zu erhöhen: „,rein morphologische“ Merkmale.

Die Instanzen des Kampfes und der dadurch bedingten Auslese, die im Leben und Werdegang der Organismen bestimmend wirken, sind aber damit noch nicht erschöpft. Auch während seiner eigenen individuellen Lebensdauer ist der Organismus der Schauplatz solcher Kämpfe, d. h. solcher Vorgänge des Wettbewerbes, die sich zwischen seinen einzelnen Teilen, insbesondere innerhalb der Gewebe zwischen den Elementen derselben abspielen. Diese Kämpfe führen innerhalb des Individuums zum alleinigen Erhaltenbleiben der zweckmäßigen dauerfähigen Qualitäten; sie haben insbesondere Anteil gehabt an der stammesgeschichtlichen Herausbildung einer der allerwertvollsten Eigenschaften, die daher auch zum Allgemeingut aller Organismen wurde: der Fähigkeit zur funktionellen Anpassung (Roux), d. h. zu all den zweckmäßigen Veränderungen, die die Organismen in ihren einzelnen Teilen durch Gebrauch oder Nichtgebrauch erleiden. Aber die Bedeutung dieser Kämpfe und auch die Bedeutung der funktionellen Anpassungsfähigkeit ist beschränkt: sie führen zwar die zweckmäßige Ausgestaltung des Individuums bis in die letzten Feinheiten seines Baues durch, aber ihre Wirkungen bleiben auf das Individuum beschränkt, sie vermögen nicht eine korrespondierende Veränderung 
auch des Keimplasmas zu erzeugen, die ihnen die Erblichkeit sicherte. Die Wurzel aller erblichen Abänderungen und damit aller Umbildungen der Formen liegt in jenen primären Veränderungen des Keimplasmas; über Bestand und Erhaltung der Abänderungen entscheidet ihre Brauchbarkeit, begutachtet durch die äußeren Lebensbedingungen.

Eine ganze Reihe von Kämpfen, sowie von Ausleseprozessen, die auf ihnen beruhen, leitet so die Entwicklung des Einzelindividuums und der gesamten Lebewelt. Sie spielen sich ab zwischen den Lebenseinheiten aller Kategorien. Im Keimplasma, bei der Entwicklung jeder Geschlechtszelle, kämpfen die verschiedenen Determinanten miteinander um die Nahrung, - auf diesen Kämpfen und ihrem Ergebnis, der Germinalselektion, beruht letzten Endes die Umwandlung der Formen. Zweimal greift dann der , $\mathrm{Zu}$ fall“" ein: bei der endgültigen Reifung der Geschlechtszelle und bei ihrer Vereinigung mit einer anderen. Mannigfaltige Kombinationen der gegebenen elementaren Anlagen sind die Folge. Nunmehr tritt wieder der Kampf in seine Rechte: bei der Entwicklung des Individuums wetteifern die beiden vereinigten Determinantenkomplexe um die Geltendmachung, unter den durch die äußeren Verhältnisse gegebenen Bedingungen. Die überlegenen Determinanten setzen sich durch; sie bestimmen in Wechselwirkung mit den äußeren Verhältnissen die Merkmale der Individuen. Diese, die Individuen oder Personen, kämpfen dann in all den verwickelten Beziehungen des Kampfes ums Dasein um ihre Geltendmachung, um Durchsetzung: Personal- oder Individualauslese ist das Ergebnis. Es kommt nicht nur den für erhaltenswert befundienen Individuen selbst zugute, sondern auch dem Keimplasma, das in ihnen eingeschlossen ist, als Rest dessen, dem sie selbst ihre Entstehung verdanken. So reicht die Bedeutung der Personalauslese weit über die Grenze des individuellen Lebens hinaus: das Dauerfähige, was sich in den äußeren Verhältnissen bewährt hat, stirbt nicht notwendig mit seinem Träger, sondern hat Aussicht, in Nachkommen fortzuleben. Aber auch das Individuum selbst ist der Schauplatz noch weiterer Kämpfe: der Kämpfe seiner Teile. Seine Ausgestaltung im einzelnen nach der Seite der Zweckmäßigkeit hin ist hier das Ergebnis. Aber dies Ergebnis kommt den Nachkommen nur unmittelbar zugute, nur dadurch, daß es seinem Besitzer die Waffen 
in den äußeren Kämpfen schärft; diese Waffen selbst weiter zu vererben, ist diesem versagt.

So vollzieht sich die Entwicklung des Organismenreiches von der ersten Entstehung des Lebens an zwar nicht nach einem von vornherein festgelegten Plan, aber nach einem festen Mechanismus, d. h. ohne daß fortwährend irgendeine außerhalb stehende Kraft ordnend und richtend eingriffe. Bestimmend und Richtung gebend sind nur die äußeren Bedingungen. Darin liegt der große grundsätzliche Unterschied zwischen der Entwicklung eines Einzelwesens aus dem Ei und der Entwicklung des Organismenreiches. Jene läuft mit absoluter Zielstrebigkeit ab: aus dem Ei des Huhnes wird unter allen Umständen wieder ein Huhn, vielleicht ein unvollkommenes, verkrüppeltes, aber doch nicht etwas ganz anderes; aus den ersten einfachsten Lebewesen aber hätte ganz gut auch eine ganz andere Kette von Organismen werden können, wenn die Bedingungen andere gewesen wären. Diese bestimmten, was erhalten bleiben sollte, und so kam die Harmonie zwischen den Organismen und ihren Lebensbedingungen zustande, die wir bewundern. - Aber diese mechanistische Naturauffassung führt nicht notwendig zu einer materialistischen Weltauffassung, sondern gestattet, ja fordert durchaus die Annahme einer teleologischen zwecksetzenden Kraft hinter diesem Mechanismus, an dem Anfang der Dinge. Diesen Gedanken, da $B$ das Prinzip der Teleologie mit dem der mechanistischen Auffassung verbunden werden könne und müsse, entwickelt Weismann schon 1876 in einem besonderen Aufsatz. Ein teleologisches Prinzip, wie es Carl Ernst von Baer und Eduard von Hartmann fordern, ist anzuerkennen, nur darf man sich die zwecktätige Kraft nicht fortwährend in den Mechanismus der Welt direkt mit eingreifend vorstellen, sondern vielmehr hinter demselben als letzte Ursache dieses Mechanismus, wie der Uhrmacher den Mechanismus der Uhr herstellt, aber den einmal in Gang gebrachten sich selbst überläßt. Kausale und teleologische Kräfte wirken nicht gleichzeitig zusammen, aber doch schließen Mechanismus und Teleologien einander nicht aus, sondern bedingen sich gegenseitig: ohne Teleologie wäre kein Mechanismus, sondern ein wirres Durcheinander roher Kräfte, und ohne Mechanismus keine Teleologie, denn wie sollte dieselbe ihre Zwecke ausführen? So ist denn nach Weismanns Überzeugung auch die 
Befürchtung unberechtigt, daß durch die neueren Naturanschauungen den Menschen das Beste abhanden kommen könne, was sie besitzen: Sittlichkeit und echt humane Geisteskultur. „Wer mit Baer die Naturgesetze als die ,permanenten Willensäußerungen eines schaffenden Prinzips' ansieht, für den ist es klar, daß ein weiterer Fortschritt in der Erkenntnis dieser Gesetze den Menschen nicht von der Bahn fortschreitender Vervollkommnung ablenken, sondern ihn fördern muß, daß die Erkenntnis der Wahrheit unmöglich einen Rückschritt bedeuten könne, möge dieselbe nun lauten wie sie wolle. Man stelle sich kühn auf den Boden der neuen Erkenntnis und ziehe die richtigen Konsequenzen aus ihr, und wir werden weder Sittlichkeit, noch das beruhigende Gefühl, einem harmonischen Weltganzen als notwendiges, entwicklungsfähiges und einem Ziele zustrebendes Glied eingefügt zu sein, aufgeben müssen." Die mechanische Naturauffassung kann nicht nur, sondern $m u B$ mit einer teleologischen Weltauffassung verbunden werden. In dieser bestimmten Weise hat sich Weisma nn hierüber später nicht wieder ausgesprochen; die Schlußworte der „Vorträge“ enthalten aber doch ähnliche Gedanken: die ausdrückliche Feststellung, daß nur die eine Hälfte der Welt, die uns zugängliche, Gegenstand der Erforschung für uns ist, der Erforschung ihres wundersamen Mechanismus mit seinem harmonischen Ineinandergreifen der zahllosen Räder, daß wir aber trotz aller Fortschritte dieser Erkenntnis vor der Welt als Ganzem immer noch wie vor einem großen Rätsel stehen. Hier fängt das Gebiet des Glaubens an. Auch die Lehre von der Entwicklung kann den Glauben nicht enttronen, das Bedürfnis einer ethischen Weltanschauung, einer Religion, nicht zerstören; nur wird diese Religion ihre Formen wechseln müssen, entsprechend dem Voranschreiten unseres Wissens von der Welt. Die Erkenntnis von den diesem Wissen gesteckten Grenzen braucht uns aber nicht zur Resignation zu führen, denn die uns zugängliche Welt bietet uns einen so unerschöpflichen Reichtum an Erscheinungen und einen so hohen, nie versagenden Genuß, daß ihre Erforschung wohl wert ist, unser Leben auszufüllen. „Auch brauchen wir nicht zu fürchten, daß es uns jemals an neuen, noch zu lösenden Fragen und Problemen fehlen könnte. Wäre es selbst der Menschheit vergönnt, noch jahrhundertelang in Ruhe und in der vielseitigen und rastlosen Weise weiter zu 
forschen, wie es in dem verflossenen Jahrhundert zum ersten Male seit Menschengedenken der Fall gewesen ist, so würde doch jede neue Lösung wieder neue Fragen bringen, und nach oben wie nach unten, in den unendlichen Räumen des Sternhimmels wie in der Welt mikroskopischer und ultramikroskopischer Kleinheit wird uns immer wieder neue Einsicht aufgehen, wird uns neue Befriedigung bringen, und unsere Begeisterung über die Wunder dieses so unbegreiflich verwickelten und doch in so herrlicher Klarheit sich a bwickelnden Weltmechanismus wird nie erlöschen, sondern immer wieder von neuem emporflammen und unser Leben erwärmen und erleuchten."

Mit diesen tiefempfundenen Worten wollen wir Abschied nehmen von Weismanns Lebenswerk, von der gewaltigen, fruchtbaren und bewundernswert schönen Arbeit eines großen Forschers, der zugleich ein großer Mensch gewesen.

\section{Schluß.}

Alles in allem dürfen wir in Weismann einen der bedeutendsten Biologen der letzten Jahrzehnte sehen. Das tragische Schicksal, das ihn zwang, seine trotz aller Kürze ungemein erfolgreiche Arbeit auf dem Gebiete der Spezialforschung vor der Zeit zu unterbrechen, wurde dank seiner außerordentlichen Energie zu einem Teil jener Kraft, die das Böse will und das Gute schafft. Unter dem Zwange dieses Schicksals kam neben der Begabung Weismanns zur Naturbetrachtung auch seine besondere Veranlagung für theoretisches Durchdenken der Einzeltatsachen zur vollen Entfaltung und zeitigte Früchte von bleibender Bedeutung. Denn in Weismann vereinigten sich, was ja durchaus nicht immer der Fall ist, eben diese beiden Fähigkeiten zur Beobachtung und zur zusammenfassenden geistigen Verarbeitung der Einzelbeobachtungen, die in der Naturforschung Hand in Hand gehen sollen, in glücklichster Weise. Die Bedingung, daß der Naturforscher in erster Linie Naturbeobachter sein soll, hat Weismann in vollstem Maße erfüllt. Seine zahlreichen und zum Teil sehr umfangreichen Arbeiten legen davon ein unanfechtbares Zeugnis ab; er selbst hat auch ganz bestimmt ausgesprochen, wie hoch er die empirische Spezialforschung bewertete. Er hatte sich auf botanischem, physikalischem, chemi- 
schem Gebiet eingehend betätigt und chemische Arbeiten veröffentlicht, ehe er sich der zoologisch-anatomischen Forschung zuwandte. Hier kam ihm zunächst seine Vorbildung und Schulung als Mediziner zugute. Er gehörte zu den nicht wenigen bedeutenden Zoologen, die ursprünglich Mediziner waren, und bezeugte so mit vielen anderen die außerordentlich große Bedeutung, die es für jeden Biologen haben muß, einen Organismus ganz gründlich zu kennen, nicht nur in seinem groben, feinen und feinsten Bau, sondern auch in seinen normalen Lebensäußerungen und unter pathologischen Verhältnissen. So ist denn auch seine Betätigung auf dem Gebiete der biologischen Forschung außerordentlich vielseitig, hinsichtlich der Probleme wie der Methodik. Ihm verdanken wir eingehende Beschreibungen ganzer Tierformen und ihrer Baueigentümlichkeiten mit Rücksicht auf deren funktionelle Bedeutung; in großem Umfang hat er histologische und embryologische Untersuchungen angestellt. Schon die Vermehrung der Kenntnis des empirischen Tatsachenmateriales, die ihm zu danken ist, würde vollauf berechtigen, ihm einen geachteten Platz unter den Naturforschern seiner Zeit anzuweisen. Trotz seiner empfindlichen Augen verfügte er über eine ausgedehnte Anschauung und Kenntnis von Tatsachen, und in seinen Arbeiten wie in seinem umfangreichen Werke über die Deszendenztheorie spricht er nicht leicht über Dinge, die ihm nicht aus eigener Erfahrung bekannt waren.

Aber freilich, das bloße Sammeln zusammenhangloser Tatsachen, das planlose Beobachten aufs Geratewohl war nicht seine Sache. Denn ,,der Wert und die Bedeutung, welche wir einer Tatsache beilegen", ist ja ,,immer nur ein relativer und kann einzig und allein gemessen werden nach dem Maße von Einsicht, von neuer Erkenntnis, welches sie uns gewährt". So hielt er wenig von den Beobachtungen, die ohne leitende Gesichtspunkte angestellt werden: ,vieles daran kann gut und richtig sein, aber es fehlt oft gerade das, worauf es bei der wissenschaftlichen Untersuchung vor allem ankam", - das wurde ihm selbst fühlbar, als er seine Arbeit über die Zeichnung der Sphingidenraupen unternahm und auch hier genötigt war, sich das nötige Tatsachenmaterial durch eigene Beobachtung selbst zu verschaffen. So sind denn auch seine, ,deskriptiven" Arbciten durchaus nicht rein deskriptiv, sondern behandeln alle Einzelbeobachtungen von einem großen allgemeinen 
Gesichtspunkte aus und ordnen sie diesem unter. Den Grundsatz, daß die Einzelarbeit dic großen allgemeinen Gesichtspunkte nicht außer acht lassen darf und erst im Zusammenhang mit diesen ihre volle Bedeutung erlangt, hat Weismann auch seinen Schülern stets zul eigen $z u$ machen gesucht.

Noch schärfer spricht sich diese Orientierung der Arbeit aut die großen Gesichtspunkte in den experimentellen Arbeiten aus. Sie gehen ja von einer ganz bestimmten Fragestellung aus und fordern von der Natur die Antwort auf diese. Es berührt wunderbar, wenn in einer modernen Geschichte der biologischen Theorien Weismann ausdrücklich unter den, ,klassischen Darwinisten" genannt wird, die keine Experimentatoren waren ${ }^{61}$ ). Im Gegenteil: Weismann war einer der ersten Experimentatoren auf dem Gebiete der Abstammungs- und Vererbungslehre. Nach Dorfmeister war er der erste, der Versuche über den Einfluß der Temperatur auf Schmetterlingspuppen anstellte und so Abänderungen der Formen durch künstliche Eingriffe erstrebte; ihm verdanken wir ausgedehnte Experimente über den Generationswechsel der Daphnoiden, die berühmten Versuche über die Umwandlung des Axolotl in das Amblystoma, die von Frl. v. Chauvin erfolgreich zu Ende geführt wurden, die an 30 Generationen von Mäusen vorgenommenen Versuche, die über die Vererbung von Verstümmelungen Aufschluß geben sollten, die Versuche über Regenerationsfähigkeit innerer Organe bei Tritonen. Etwa vom Jahre 1869 an bis in seine letzte Lebenszeit hat er immer wieder experimentiert, hat damit Ergebnisse von bleibendem Werte erzielt und zu weiteren Versuchen angeregt.

Von so breiter und fester Grundlage aus konnte er sich an die höchste Aufgabe wagen: die spekulative Zusammenfassung der Einzeltatsachen und die Ermittelung der ihnen zugrunde liegenden allgemeinen gesetzmäßigen Vorgänge. Er wurde der bedeutendste Theoretiker der Abstammungslehre. Die reiche Anlage, die er auch für diese Aufgabe mitbrachte, entfaltete sich unter den besonderen Umständen scines Lebens zu höchster Leistungsfähigkcit. Ihm war es vergönnt, die ausgedehnte Fülle der Tatsachen, über deren Kenntnis er verfügte, mit einem vortrefflichen Gedächtnis zusammenzuhalten, mit genialem Blick zu überschauen, aus ihnen das Gemeinsame herauszulesen und in 
anschaulicher Darstellung zu gestalten. Goethes ,Naturgeheimnis werde nachgestammelt" steht als Motto vor dem Werke über das Keimplasma. Die großen Probleme der Abstammungslehre, die in der zweiten Hälfte des verflossenen Jahrhunderts eine Erregung der Geister hervorriefen, wie sie die Menschheitsgeschichte kaum wieder gesehen hat, und, in engem Zusammenhang damit, die Vererbungslehre, wurden die Gebiete, auf denen er der Natur ihre Geheimnisse abzulauschen suchte. Auf beiden hat er bahnbrechend, aufstörend, antreibend gewirkt und Bleibendes geschaffen, und die Spuren seines Wirkens werden für lange Zeiten nicht verwischt werden. Da rwin war kein Embryolog oder Histolog gewesen, die Medizin hatte ihn kühl gelassen, die Anatomie abgestoßen. So muBten ihm später, trotz aller Arbeit an sich selbst, manche Lücken in der biologischen Durchbildung bleiben, und seine Betrachtung bei dem mehr unmittelbar Sinnfälligen, Groben der Erscheinungen Halt machen. Weismann konnte vermöge seiner vielseitigen Schulung weiter gehen, die Frage nach den zellulären Vorgängen bei der Vererbung, der Entstehung der Variabilität, aufwerfen und in Anknüpfung an die glänzenden Entdeckungen seiner Zeit auf dem Gebiete der Zellen-, Befruchtungs-, Eireifungslehre ( von Flemming, O. Hertwig, v. Beneden, Bütschli, Boveri u. a. - ) eine Theorie ausarbeiten, die die verschiedensten Probleme unter einheitlichen Gesichtspunkten und unter der Annahme weniger, wirksamer Faktoren vereinigt. Die Erörterung über die verschiedenen Probleme der Abstammungslehre erweitert zu haben, indem er sie auf das Gebiet der feineren Vorgänge iibertrug, für diese neue Betrachtung klar und bestimmt die wichtigsten Fragen festgelegt und im AnschluB an die vorliegenden Beobachtungen ihre Beantwortung versucht zu haben, das ist wohl sein größtes, besonderstes Verdienst. Und wie auch der Einzelne über den Wert dieser Antworten denken, und wie viel oder wie wenig auch sich als dauernd von seinen theoretischen Vorstellungen erhalten möge - die große Bedeutung, die sie für die Klärung in den verschiedensten Fragen gehabt haben, wird wohl niemand leugnen wollen. Gar manches von dem, was erst Weismann in stets erneuter Gedankenarbeit behandelt hat, ist uns heute ganz geläufig geworden und beherrscht letzten Endes auch Vorstellungen, die sich äußerlich in einen Gegensatz zu ihm stellen möchten. Die Lehre 


\section{- $269-$}

von der Kontinuität des Keimplasmas, der Begriff der Determinanten, die scharfe Betonung des Gegensatzes zwischen Soma und Keimzellen - das sind Weismannsche Vorstellungen, die sich als ungemein fruchtbar erwiesen haben, und deren Wirksamkeit allenthalben in den Vererbungstheorien $\mathrm{zu}$ spüren ist. Ja, noch mehr: gerade die neuere experimentelle Forschung ist in manchen Punkten, in der Annahme von Vererbungseinheiten, in der Auffassung des Befruchtungsvorganges und anderen, in überraschender Weise zu ähnlichen Vorstellungen gekommen wie Weismann auf dem Wege der theoretischen Spekulation. Und für viele empirische und experimentelle Forschungen hat er die Fragestellung vorbereitet, die Gedankengänge vorgedacht. Anf dem Gebiete der Abstammungslehre begegnet sein Versuch, die ganze Umbildung der Formen unter Ausschaltung des Lamarckismus, d. h. unter Ausschaltung einer Vererbung funktioneller Abänderungen zu verstehen, auch jetzt noch starkem Widerspruch, ja dieser Widerspruch wird gerade in neuerer Zeit immer stärker und allgemeiner, - immerhin kann wohl nicht behauptet werden, daß die Frage schon für Lamarck endgültig entschieden wäre, und selbst, wenn das einmal der Fall wäre, würde es immer eine bewundernswerte Tat bleiben, daßWeismann, unbeirrt von der Tagesmeinung, mit scharfer Kritik auf diesem Gebiete einsetzte, mit einer Menge leichtgläubig überlieferter Erzählungen aufräumte und den Mut hatte, das, was er nach gewissenhafter Prüfung als nichtvorhanden ablehnen mußte, nun auch wirklich aus der Rechnung auszuschalten. Wie er selbst dabei dann zu dem Schlusse kam, daß durch „Naturzüchtung“ allein die Umwandlung der Formen nicht erklärt werden kann, und wie er an Stelle des entthronten Lamarckismus sein selbsttätiges in den Organismen wirksames Umbildungsprinzip aufstellte, wurde ausführlich besprochen.

Alle diese Ergebnisse flogen ihm nicht zu und waren nicht aus der Luft gegriffen, sondern in ernster Gedankenarbeit erlangt. In der erzwungenen Beschränkung des Verkehres mit der sichtbaren Außenwelt entfaltete sich die ganze ihm als Deutschen innewohnende Kraft zum grüblerischen Sichversenken in die Erscheinungen, zum geistigen Durchdenken und Verarbeiten der Tatsachen. Ebensowenig wie die zusammenhanglose Einzeltatsache vermochte er den nur flüchtig gefaßten und ausgesprochenen Gedanken schon an sich als be- 
sonders wertvoll für den Fortschritt der Wissenschaft zu achten; das kann er erst werden, wenn er ,,soweit irgend möglich durchgedacht und auf seine Durchführbarkeit geprüft" worden ist. Darnach hat er mit deutscher Gründlichkeit gehandelt, und or hat sich nicht gescheut, es einzugestehen, wenn beim wiederholten Durchdenken eines Gedankens - wie das nicht zu verwundern war - ihm eine frühere Schlußfolgerung als unrichtig und unhaltbar erschien, oder wenn neue Tatsachen sich mit einer Vorstellung nicht in Einklang bringen ließen. Freilich, so ohne weiteres war er nicht umzustimmen, das Recht der Kritik wahrte er sich, und für rasch fertige, einem beschränkten Kreis von Kenntnissen entspringende Urteile hatte er, der von hoher Warte ein weites, großes Tatsachengebiet überschaute, nur scharfe Zurückweisung.

Die Kenntnis eines ausgedehnten Tatsachenmateriales berechtigte ihn dazu, aus den Tatsachen allgemeine Gesetze abzuleiten, sie ließ ihn auch seine theoretischen Vorstellungen im steten Anschluß an dieselben entwickeln. Seine Vorträge zur Deszendenztheorie zeigen diese innige Verbindung von Theorie und praktischer Nutzanwendung, oder richtiger von tatsächlicher Grundlage und theoretischer Abstraktion auf jeder Seite. Sein Denken blieb soweit als irgend möglich, ,gegenständlich", um den bezeichnenden Ausdruck, den Goethe so schätzte, zu gebrauchen. Und wo er über das Bereich der sichtbaren Erscheinungen hinausgehen mußte, da blieb doch die künstlerische Begabung, die ihm von der Mutter her geworden, seine Führerin, trieb ihn seine Phantasie immer wieder, nach greifbaren anschaulichen Vorstellungen $\mathrm{zu}$ suchen, sich die Gebilde, zu deren Annahme er gelangte, möglichst konkret zu denken.

Aus dem mehr unbestimmten Idioplasmabegriff Nägelis wurde in seiner Hand das Keimplasma, als Keimsubstanz der Keimzellen ohne weiteres sichtbar und in seinem Verhalten in der Form der Chromosomen bei der Befruchtung und bei den Zellteilungen zu verfolgen, eine Substanz von ganz bestimmter gesetzmäßiger Architektur, zusammengesetzt aus Determinanten und Biophoren, die zwar jenseits der Grenze des Sichtbaren liegen, aber doch nicht als wesenlose Begriffe, sondern als real vorhandene Teilchen $\mathrm{zu}$ denken sind. Wenn durchaus nach Schwächen seiner Theorie gesucht werden soll - bei welcher Theorie wären die nicht zu finden! so wäre es höchstens die, daß sie nach zu großer Anschaulich- 
keit strebt. Ihn aber unter die ,phantasielosen Beweismänner" $z$ u rechnen, wie es ein moderner Historiker der Biologie tut, dürfte wohl nicht berechtigt sein. Gerade die Vereinigung scharfen Denkens mit künstlerischer Phantasie befähigte ihn zur Aufstellung seiner Theorie, wie sie ihn befähigte, seine Gedanken nicht nur logisch und überzeugend zu entwickeln, sondern auch in klarer Form zum Ausdruck zu bringen. Darauf beruht ja auch der starke Erfolg, der seinen Schriften zuteil geworden ist.

$\mathrm{Da} B \mathrm{We}$ ismann sich für seine Ideen immer mit voller Energie eingesetzt hat, ist selbstverständlich; nur dadurch war es ja möglich, ihre Leistungs- und Dauerfähigkeit zu erproben. Daß ihre wo immer vorhandenen Schwächen von anderen mit der genügenden Schärfe hervorgehoben werden würden, darum brauchte er nicht zu sorgen. Seine theoretischen Vorstellungen aber etwa als der Weisheit letzten Schluß hinstellen zu wollen, das ist ihm nicht entfernt eingefallen. Auf den gegen ihn gerichteten Ausspruch eines Kritikers, es scheine, die Naturphilosophie sei noch nicht tot, erwiderte er (r899): „Hoffentlich nicht! Und hoffentlich wird sie es a uch niemals sein, denn zu allen Zeiten wird der Fortschritt in unserer Erkenntnis von der philosophischen Verarbeitung der uns bekannten Tatsachen abhängen, da wir dadurch uns neue Ziele der Beobachtung zu stecken, neue Tatsachen zu finden vermögen, die tiefere Einsicht geben. Wenn aber unter "Naturphilosophie“ nur die Ausartungen einer philosophischen Naturbetrachtung gemeint sind, wie sie Oken, Schelling u. a. am Anfang dieses Jahrhunderts übten, so sollte doch der Unterschied nicht verkannt werden, der zwischen diesen Begriffsspielereien und Konstruktionen der Natur aus freier Hand und meinen Versuchen besteht, die Tatsachen unter gemeinsamen Gesichtspunkten zusammenzufassen. Das eine sind Phantasien, aus denen niemals etwas Festes hervorgehen konnte, das andere sind gewissermaßen Zentralstellen für wissenschaftliche Aufgaben, welche dem Forscher vorläufige Annahmen zur Bestätigung oder Widerlegung überliefern, oder auch ihm biologische Formeln oder Symbole in die Hand geben, die zwar für jetzt nicht weiter aufzulösen sind, die aber mit Vorteil in die Rechnung gewisser Probleme eingesetzt werden." Als solche ,Symbole" hat er selbst die Biophoren und Determinanten bezeichnet. Die Überzeugung, daß auf einem so verwickelten schwierigen 
Gebiet, wie es das der Vererbung ist, eine von brauchbarer Grundlage ausgehende, konsequent durchgearbeitete Theorie unter allen Umständen von großem Werte für den Fortschritt der Erkenntnis sein müsse, schon weil sie bestimmte Fragestellungen anregen muB, ließ ihn auch leichter über die vielen Angriffe hinwegkommen, denen nicht nur seine theoretischen Vorstellungen, sondern auch seine Person ausgesetzt waren, und die in den mancherlei Änderungen, die er im Laufe der Zeit an seinen Auffassungen vornehmen mußte, Nahrung fanden. Daß er selbst sich nicht gescheut hat, diese Änderungen vorzunehmen, wo es ihm nötig schien, wurde schon betont, es ist im übrigen selbstverständlich bei einer so durchaus ehrlichen und aufrichtigen, nach Wahrheit strebenden, kraftvollen Persönlichkeit. Der Vervollkommnungstrieb, den er als allgemeines Entwicklungsprinzip in der organischen Natur ablehnte, wirkte um so mehr in ihm selbst und veranlaßte ihn zur Arbeit an sich und an seiner Theorie. Darüber aber, daß seine beiden Hauptannahmen, die Annahme einer Kontinuität des Keimplasmas und die von der Zusammensetzung des letzteren aus substantiellen lebendigen Bestimmungsstücken, brauchbar seien, um auf ihnen als Grundlagen den Aufbau einer Theorie der Vererbung zu versuchen, kann wohl nach den Ergebnissen der neueren Vererbungsforschung kein Zweifel herrschen. Jedenfalls mußte die Frage einmal von diesen Grundlagen aus durchgearbeitet werden; dadurch allein war ihre Tragfähigkeit zu erproben. Daß Weismann diese Durcharbeitung offen und ehrlich und mit Selbstverleugnung vorgenommen hat, sollten auch seine sachlichen Gegner anerkennen.

Als Weismann sich im Jahre I863 für Zoologie habilitierte, da geschah es in der medizinischen Fakultät, in der die Zoologie von dem Physiologen als Nebenfach vertreten wurde. Seitdem haben sich die Zeiten gewaltig verändert. Die Zoologie ist selbständig geworden, und in Freiburg war es Weismann selbst, für den das erste zoologische Ordinariat gegründet wurde. Von der medizinischen Fakultät wurde sie dabei herausgenommen und der philosophischen eingefügt. Hier und da, so in Freiburg selbst, ist sie seitdem auch von der philosophischen Gesamtfakultät entfernt und mit den übrigen Naturwissenschaften zusammen in einer naturwissenschaftlichen Fakultät vereinigt worden. Deutlich spricht sich darin der ungeheuere Aufschwung aus, den sie selbst und mit ihr die gesamten 
Naturwissenschaften in dem letzten halben Jahrhundert genommen. Mit Recht konnte bei Weismanns 70. Geburtstag der Dekan der philosophischen Fakultät, der Physiker Heimstedt, dem Jubilar aussprechen: ,An diesem gewaltigen Aufschwunge, den die Zoologie in den letzten Dezennien genommen hat, nicht nur mitgearbeitet zu haben, sondern als einer der ersten, als einer der vornehmsten Führer die Ziele gesteckt und die Wege zu sieghaftem Vordringen gewiesen zu haben, das wird von Ihren Fachgenossen neidlos, als unvergängliches Verdienst Ihnen zugesprochen." Insbesondere die gewaltige Bedeutung, die die Gedanken der Entwicklung und der Auslese im Wettbewerbe um die Daseinsbedingungen in dieser Zeit auf allen Gebieten des Lebens gewonnen haben, ist zu einem sehr großen Teile dem Wirken Weismanns zuzuschreiben. Und wenn sie je, wie manche meinen, sich als völlig falsch und unbegrünclet erweisen sollten - wozu aber wohl noch ein weiter Weg ist -- würde der Historiker einer späteren Zeit an der Anerkennung der Tatsache nicht vorbeikommen, einen wie ungeheueren belebenden und befruchtenden Einfluß diese Gedanken auf allen Gebieten und auf dem der organischen Naturwissenschaften insbesondere gehabt haben. Und in Zusammenhang damit wird auch Weismanns Name als der eines der rastlosesten Vorkämpfer und folgerichtigsten. unerschrockensten Vertreter jener Gedanken genannt werden. Die Überzeugung, daß zwischen allen Lebenseinheiten ein Kampf besteht und bestehen mu $\mathrm{B}$, wenn das Leistungsfähigste zur dauernden Geltung kommen soll, ist der Hauptgedanke, für den er sich eingesetzt hat, mit Gedanken und Worten, aber auch mit der persönlichen Tat: im Kampfe gegen ein schweres persönliches Geschick, im Kampfe für seine Wissensehaft und seine Überzeugung. Mit ganz besonderem Rechte gilt für Weis man n das Wort seines großen Frankfurter Landsmannes, daß er ein Mensch gewesen, „und das heißt, ein Kämpfer sein". 


\section{Anmerkungen.}

I) zu S. 5. Außer den im Vorwort erwähnten Mitteilungen habe ich für die Darstellung des Lebens und der Persönlichkeit Weismanns vor allem noch benutzt:

I. Bericht über die Feier des 7o. Geburtstages von August Weismann am 17. Januar 1904 in Freiburg i. Br. Herausgegeben von dem Komitee zur Stiftung der Weismann-Büste. Jena I904.

2. Das Curriculum vitae, das Weismann selbst seinem Gesuch um $\mathrm{Zu}$ lassung zur Habilitation für das Fach der Zoologie in der medizinischen Fakultät zu Freiburg i. Br. beigefügt hat. Das Gesuch ist datiert: Frankfurt a. M., II. Januar I 863 .

3. Doflein, F., August Weismann zum 8o. Geburtstag. Akademische Mitteilungen. Organ f. d. gesamten Interessen der Studentenschaft an der Albert-Ludwigs-Universität in Freiburg i. Br., N. F., XV. Sem., Nr. 7, 7. Januar 19r4, S. $47-48$ (Freiburg i. Br., herausg. v. Hans Speyer, Universitätsbuchhändler).

4. Ders., Weismann als Forscher. Ebenda, N. F., XVII. Sem., Nr. 6, 15. Dezember 1914, S. 27.

5. Himstedt, F., August Weismann (Nachruf am Grabe). Ebenda, N. F., XVII. Sem., Nr. 6, I5. Dezember 1914, S. 25-26.

2) zu S. 5. Der Name ist Weismann (mit einem s) zu schreiben. Gegen die Schreibweise mit ss hat Weismann selbst, wenn er sie in den Testierbüchern der Studierenden antraf, wiederholt sehr bestimmten Einspruch erhoben. Auffallend ist die falsche Schreibweise in der Überschrift zu der Arbeit über den Salzgehalt der Ostsee, im Mecklenburgischen Archiv für Landeskunde; man kann nur annehmen, da $B$ die Überschrift dem Verfasser der Arbeit nicht zur Korrektur vorgelegen hat.

3) zu S. 5. Folgende genealogische Angaben sind mir von Frau Regierungsrat Schepp freundlichst zur Verfügung gestellt worden.

\section{Männliche Aszendenz.}

I. Valentin W., Bürger in Weierburg, Oberösterreich, in der ersten Hälfte des 17. Jahrhunderts, starb als Märtyrer in Wien. In einer Schrift, die zur Leichenfeier seines Enkels, des Prälaten und Abtes in Maulbronn, Ehrenreich W., herausgegeben ist, wird berichtet, daB Valentin W. unter Kaiser Ferdinand III. bei Nacht unvermutet gefangen und nach Wien geschleppt wurde, wo er im Stadtgraben bei grausamer Zwangsarbeit sein Leben ließ. Dies muß in den letzten Jahren des Dreißigjährigen hrieges gewesen sein. 
2. Johannes W., Pfleger bei Baron von Teuffel in Weierburg, Oberösterreich. Als Protestant vertrieben, kam I 856 nach Northeim i. Württemberg, wo er Lehrer wurde. $\infty$ mit Christine Berger.

3. Ehrenreich (Erichs) W., * Weierburg I64I, $\dagger$ I7I7. $\infty$ mit Maria Elisabeth Canstetter. Prälat und Abt in Maulbronn. War erst I I Jahre in Preßburg, kam I656 nach Heilbronn.

4. Johann Ehrenreich W., Kirchenratssekretär in Stuttgart. $\infty$ mit Christine Juliane Maria Steinmark, fürstl. Hoftronıpeterstochter. (Sein Bruder Eberhard W. War Professor der Theologie in Tübingen. $\dagger$ kinderlos.)

5. Christoph Tobias Friedrich W., Amtspfleger und Bürgermeister in Alpirsbach, $\infty$ mit Friederike Margarete Zahn.

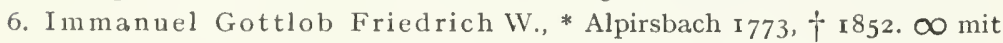
Juliane Deimling aus Karlsruhe. Kam als Kaufmann nach Frankfurt a. M.

7. Johann Konrad W., * Frankfurt a. M., 3I. Oktober r804, † r88o. Gymnasialprofessor in Frankfurt a. M.

8. August W.

\section{Mütterliche Aszendenz.}

I. Chr. Leopold Lübbren, * r766, † r85r. $\infty$ mit .... Römhild, Pfarrerstochter aus der Nähe von Bremen. War Bürgermeister und Landrat in Stade.

2. Elise Lübbren, Tochter der vor., * Stade, I803. $\infty$ mit Johann Konrad Weismann, dem Vater August Weismanns.

4) zu S. 6. Der Titel der Doktordissertation lautet nach Weismanns eigener Angabe: De acidi hippurici in corpore humano generatione. Diss. inaug. Francofurti I 857. Die Dissertation selbst zu erlangen, ist mir nicht möglich gewesen; auch die Kgl. Universitätsbibliothek in Göttingen, in der sie, wenn irgendwo, doch wohl am ersten zu erwarten war, besitzt sie nicht und konnte sie auch bibliographisch nicht ermitteln. In dem mir von dort gewordenen Bescheid ist die Vermutung ausgesprochen, daß sie wie viele Dissertationen jener Zeit gar nicht im Druck erschienen ist. Das „Francofurti $1857^{\prime \prime}$ spricht allerdings gegen diese Vermutung. Inhaltlich steht sie mit der in dem gleichen Jahre vollendeten Preisarbeit offenbar in engstem Zusammenhang, auch dürfte sie im wesentlichen in der Arbeit „Über die Bildung der Hippursäure beim Menschen", die I 858 in der Zeitschrift für rationelle Medizin erschienen ist, enthalten sein. Vorhanden sind in der Göttinger Bibliothek das Doktordiplom Weismanns, ausgefertigt am 9. Juli i 856 ,,post adprobatam examine egregiam scientiam et disputationem publice habitam", sowie die von Weismann eingereichten: ,,Theses quas gratiosi medicorum ordinis auctoritate atque consensu in Academia Georgia Augusta pro summis in medicina, chirurgia arteque obstetricia honoribus rite obtinendis die IX. M. Julii A. MDCCCLVI publice defendet Augustus IVeismann Moeno-Francofurtensis, opponentibus: Ottone Heusinger, Med. Dd. Alexandro Spiess, Med. Dd. Die Thesen lauten: I. Nulla hodie sine chemia pathologia. II. In necrosi phosplore causata secretio acidi phosphorici per renes non 
aucta est. III. Glutinum praeformatum in corpore humano est, non solum coctione telae cellulosae ovitur. IV. Lupus aptissime Kali caustico sanatur. V. Chloroformum in partibus normalibus aptum esse nego.

5) zu S. 6. Das Titelblatt der Preisschrift enthält auf der Rückseite folgenden Vermerk:

Die medizinische Fakultät hatte am 4. Juni 1856 zum zweiten Male die Aufgabe gestellt:

Accurata investigatione chemica respondeatur ad quaestionem, num eae plantae, quibus animalia herbivora, imprimis equi et boves, plerumque vescuntur, prae ceteris igitur gramina pratorum, acidum benzoicum vel conjunctionem benzoylicam contineant, unde derivari possit acidum hippuricum, quod in illorum animalium urina constanter apparere solet.

\section{Urteil der Fakultät.}

Der Hauptaufgabe, diese Frage durch Versuche und Beobachtungen zu beantworten, ist von dem Verfasser auf befriedigende Weise entsprochen worden. Er hat eine große Reihe von eigenen mühsamen Versuchen und chemischen Operationen vorgenommen, aus denen mit Sicherheit das wissenschaftlich wertvolle Resultat hervorgegangen ist, daß die Futterkräuter der Pflanzenfresser keine eigentliche Benzoylverbindung, im gewöhnlichen Sinne des Wortes, enthalten, aus der die Entstehung der Hippursäure auf die Weise abgeleitet werden könnte, wie sie erfahrungsgemäß nach dem Genusse von Benzoesäure und deren Durchgang durch das Blut stattfindet. Der Verf. sucht zu zeigen, daß dennoch die Erzeugung der Säure in bedeutendem Maße von der Pflanzennahrung abhängig sei, und nimmt, freilich nur vermutungsweise und nicht hinreichend auf Beobachtungen gestützt an, da $\beta$ sie vorzugsweise aus der inkrustierenden Zellensubstanz, dem sogenannten Lignin, entstehe.

Wenn auch für die Entstehungsweise der Hippursäure durch diese Arbeit keine entscheidende positive Erklärung gegeben worden ist, - eine Frage, die überhaupt mit der noch ungelösten, so schwierigen Aufgabe der exakten Erklärung der chemischen Vorgänge bei der Reproduktion und dem Stoffwechsel im lebenden Organismus zusammenfällt, - so ist dadurch doch die eigentliche Frage genügend beantwortet worden, und es verdienen der Fleiß und die Beharrlichkeit, mit denen diese zum Teil recht schwierige und selbst kostspielige Arbeit durchgeführt wurde, die große Mühe, die mit der Ausführung der sehr zahlreichen Versuche verbunden war, die gründlichen chemischen und physiologischen Kenntnisse und die Bekanntschaft mit der richtigen Methode der Forschung in den Naturwissenschaften und mit der Literatur über diesen Gegenstand, welche der Verfasser an den Tag gelegt hat, die vollste Anerkennung.

6) zu S. 7. Die genaueren Angaben über Weismanns Rostocker Tätigkeit verdanke ich den Nachforschungen des Herrn Privatdozenten Dr. R. Wegner in Rostock. Derselbe fand nach sehr mühseligem Suchen unter den Quittungsbelegen für das Stadtkrankenhaus die Angabe (Kassenbelege, Band I856 - ad 99c und $99 \mathrm{~d}$ ), daß Dr. Weismann ab Johannis (24. Juni I 856 ) als akademischer Assistenzarzt am Krankenhause angestellt wurde (Reskript des Vizekanzlers Dr. v. Both 
vom 21. Juli 1856). Er verlicß diese Stellung mit dem 1. April 1857. Direktor dieses Krankenhauses war Obermedizinalrat Prof. C. F. Strempel, der die medizinischchirurgische Klinik $1830-\mathbf{1} 872$ leitete. Neben ihm wirkte gleichfalls als Ordinarius Obermedizinalrat Prof. Spitta (1825-1860). Aus dem Unniversitätsarchiv ließ sich weiter feststellen, daß Weismann von Ostern 1857 bis Ostern 1858 als Studiosus cheniae immatrikuliert war; das Personalverzeichnis führt für das S.-S. I 857 und (las W.-S. $1857 / 5^{8}$ den Dr. A. Weismann aus Frankfurt an (Mitt. der Bibliothek in Rostock). Er wohnte im chemischen Institut am Blücherplatz, dessen Direktor Franz Schulze war. In den Kollegiengeldbüchern desselben findet sich Weismann nicht verzeichnet, er hat also keine Gebühren für dessen Vorlesungen bezahlt und ist somit wohl eine Art Volontärassistent bei Schulze gewesen. Ein offizielles Gehalt hat er, wie sich aus den Belegen der Universitätskasse nachweisen läßt, nicht bezogen, da ein anderer Assistent genannt wird, und nur für diesen eine Remuneration überhaupt vorgesehen war. - Die Arbeit über den Salzgehalt der Ostsee ist veröffentlicht im Mecklenburgischen Archiv für Landeskunde; als selbständige Schrift ist sie in der Universitätsbibliothek in Rostock, - nach Mitteilung derselben, nicht vorhanden, und die Anmerkung, die sich im Archiv für Landeskunde findet, läßt darauf schließen, daß sie selbständig nicht erschienen ist.

7) zu S. 9. Sein Gesuch um Zulassung zur Habilitation ist datiert: Frankfurt a. M., I1. Januar 1863; am 17. Januar 1863, also an seinem Geburtstag, beschloß die medizinische Fakultät nach dem Bericht des damaligen Dekans, des berühmten Botanikers Anton de Bary, den Dr. med. Weismann zur Habilitation für das Fach der Zoologie zuzulassen. Am 27. Januar I 863 gab das Großh. Ministerium seine Genehmigung dazu, und im Mai I 863 erfolgte die Habilitation. Schon am 4. September I 865 wurde er a. o. Professor der Zoologie und provisorischer Mitdirektor des zoologischen Institutes (mit Otto Funke, dem physiologischen Ordinarius, der die Zoologie nebenbei vertrat). Am 4. April 1867 erfolgte die Ernennung zum etatsmäßigen a. o. Professor der Zoologie, mit definitiver Übertragung der Lehrkanzel, als welcher er am 7. Juli r 868 seine Antrittsrede über die Berechtigung der Darwinschen Theorie hielt. Zum ordentlichen Professor in der philosophischen Fakultät wurde er am 4. April 1873 ernannt, womit überhaupt der erste ordentliche zoologische Lehrstuhl in Freiburg errichtet wurde. Die philosophische Fakultät Freiburg verlieh ihm am x6. Mai 1879 die Würde eines Dr. phil. h. c.

8) zu S. I3. E. Rádl in seiner gewiß sehr verdienstvollen ,,Geschichte der biologischen Theorien“" (II. Teil, Leipzig I909, S. 4lo u. ff.) hat es fertig gebracht, über Weismann in einem Tone zu reden, daß der, der Weismann nicht kennt, notwendig zu dem Schluß kommen muß, es hier mit einem Charlatan zu tun zu haben, der von vornherein gar nicht ernst zu nehmen ist. Noch niemals dürfte über einen anerkannten Forscher mit so viel giftiger Bosheit gesprochen worden sein, wie es hier geschieht. ,Ein bekanntes Gesellschaftsspiel besteht darin, daß einem Mitglied der Gesellschaft ein Thema aufgegeben wird, über welches er angenehm und geistreich eine Rede halten muß." Dieses Mitglied der Gesellschaft ist Weismann, ein ,geistvoller Causcur" ; das Thema, das die Gesellschaft für iln bestimmte, lautet: „Das Keimplasma“. „Eine wirklich schwierige Aufgabe, aus diesem leeren Worte, das überdies nicht dem eigenen Geistc entstammt, eine Rede zu entwickeln, 
die die Welt befriedigen soll." Aber Weismann wagt es und redet; - ,sehließlich scheint er sich in seine Ideen zu heftig hineingeredet zu haben, und sich nicht mehr von ihnen losreißen zu können; die Gesellschaft beginnt zu murren - die Sache ernst zu nehmen, war ja nicht abgemacht". - "Glücklicher Causeur! Glückliche Gesellschaft! Was gehen sie Menschen an, welche in trüber Einsamkeit alle Kräfte anspannen müssen, um ihrem Geiste eine lebendige Idee abzuringen, welche den Leser nötigen, einen ebenso harten Kampf mit ihrem Werk zu bestehen; was gehen sie Menschen an, welche ihr feuriger Glaube an eine neue Wahrheit in den schmutzigen Kampf des wirklichen Lebens treibt, um der Idee die ganze Welt zu unterjochen ?” Sollte man das für möglich halten gegenüber einem Manne, der wie wenige sein ganzes Leben hindurch seine Kräfte bis zum Äußersten, bis zur schweren Schädigung seiner Gesundheit, im Dienste der Forschung, im Ringen um lebendige Ideen und im Kampfe für dieselben, angespannt hat? Im übrigen hat Weismann stets auch in der Form die Würde der Wissenschaft hoch gehalten; und auch Gegnern gegenüber ist er niemals in den Ton journalistischer Effekthascherei verfallen, wie er hier ihm gegenüber angewendet wird. Wenn Rádl die Anschauungen Weismanns nicht teilt, so ist das sein gutes Recht; die Arbeiten über Insektenentwicklung, über die Daphnoiden, die Hydromedusen und so viele andere hätten aber ihren Urheber wohl davor schützen können, daß man ihm den wissenschaftlichen Ernst abspricht und ihn lächerlich zu machen sucht. Freilich scheint Rádl von Weismanns Arbeiten nicht allzuviele zu kennen; so sind ihm, wie aus einer Bemerkung auf S. $54^{8}$ seines Werkes hervorgeht, die vielen experimentellen Arbeiten desselben unbekannt geblieben. Es lohnt wirklich nicht, im Einzelnen auf Rádl einzugehen.

9) zu S. I3. Weismanns Kinder sind: I. Therese, * I868, verh. mit $(\dagger)$ Regierungsrat Schepp; 2. Hedwig, * I870, verh. mit Prof. W. N. Parker in Cardiff; 3. Elise, * I871, verh. mit Prof. Dr. Heinrich Riese, Direktor des Kreiskrankenhauses Lichterfelde; 4. Bertha, * I 873, verh. mit Oberbürgermeister Dr. Hans Riese in Eisleben (Bruder des vorigen) ; 5. Meta, * I 875, † I876; 6. Julius, *1879, Komponist in Schachen am Bodensee.

Io) zu S. 23. Im zweiten Beitrag zur Naturgeschichte der Daphnoiden (Über die Eibildung bei den Daphnoiden). 1877.

I I) zu S. 34. Das geht hervor aus einer Bemerkung auf S. 669 der Arbeit von I895 (Neue Versuche zum Saisondimorphismus der Schmetterlinge).

I2) zu S. 39. In den hier angeführten Worten (I 876, S. 75) erscheint zum ersten Male der Begriff ,Allmacht der Naturzüchtung“" aber nicht als Kennwort eines Bekenntnisses, sondern als Bezeichnung eines Problemes.

I3) zu S. 42. Die Arbeit von Weismann selbst ist 1875 erschienen und enthält einen kurzen Bericht über die Versuche, von Frl. v. Chauvin, sowie Erörterungen wesentlich theoretischer Art, von Weismann; die ausführliche Darstellung der Versuche hat Frl. von Chauvin selbst 1876 gegeben (in der Zeitschrift $\mathrm{f}$. wiss. Zoologie, Bd. XXVII). In diesem letzteren Jahr erschien dann auch der zweite Abdruck der Weismannschen Arbeit im zweiten Heft der ,,Studien zur Deszendenztheorie".

I4) zu S. 46. Weismann schreibt: Daphnoiden und braucht diese Bezeichnung, im alten Sinne, als gleichbedeutend mit dem jetzt gebräuchlicheren Ausdruck: 
Cladoccra. Gemeint ist also damit die ganze Unterordnung der Phyllopoden, die die Familien der Daphnidae, Polyphemidae, Sididae, Lynceidae umfaßt. Das ist $z u$ beachten angesichts der Tatsachen, daß jetzt gewöhnlich von der "Naturgeschichte der Daphniden" gesprochen und damit der Eindruck erweckt wird, als ob es sich nur um die Familic handelt, die jetzt als Daphnidac bezeichnet wird (vgl. den zweiten Beitrag, in der Zcitschrift f. wiss. Zoologie, Bd. XXVIII, r877, S. 93, Anm.) Weismann teilt dort dic Ordnung der Daphnoidea oder Cladocera nur in zwei Familien, ,Daphnida“ und „Polyphemida“" cin; daß er diesen aber auch die Sididae und Lynceidac einordnet, geht aus den Arbeiten selbst hervor.)

I5) zu S. 47. Der historisch begründete und überall eingebürgerte Name ist „Parthenogenese“; in Interesse einer einheitlichen Nomenklatur wäre aber "Parthenogonie“ vorzuziehen. Denn in allen neueren Zusammensetzungen mit y'́r'roıs (Ontogenese, Phylogenese, Histo-, Chondro-, Osteo-, Spermio-, Oogenese usw.) bedeutet dieses: „Entwicklung“", „Bildung“, und der jeweilige Zusatzbegriff ist im Sinne des Genetivs, = des sich Entwickelnden, aufgefaßt (Chondrogenese = Bildung des Knorpels usw.), während in den Zusammensetzungen mit yoría dieses die Bedeutung "Zeugung“ hat, und durch den Zusatz, der meist ein Substantivstamm, aber auch manchmal ein Adverbium ist, der Erzeuger oder die Art der Erze ugung bezeichnet wird (Tokogonie, Amphigonie, Monogonie, Antagonie, Gamo-, Sporo-, Schizogonie usw.). Wenn „Elternzeugung" „Tokogonie“ genannt wird, so ist , Jungfernzeugung“ „,Parthenogonie“ zu nennen. Tokogenese, Parthenogenese usw. würden nach denı oben festgestellten Sprachgebrauch etwas ganz anderes bedetuten. Ganz entsprechend sollte man aber auch Metagonie und Paedogonie (nicht, wie gebräuchlich, Metagenese und Paedogenese) sagen. Die verschiedenen Formen kombinierter Fortpflanzung (Metagonie, Heterogonie und den primitiven Generationswechsel bei Sporozoen) könnte mann unter dem Namen Cyclogonie zusammenfassen.

16) zu S. 74. Darwin, Entstehung der Arten. Deutsche Übersetzung von J. V. Carus, 7. Aufl., Stuttgart, I884, S. 33.

I7) zu S. 75. Die drei angeführten Stellen finden sich in: Studien zur Deszendeztheorie, II., I876, S. 306; Über die Berechtigung der Darwinschen Theorie. I 868, S. 25; Beiträge zur Naturgeschichte der Daphnoiden, VII, I879 (I880), S. 25 I.

г8) zu S. 75. Kontinuität des Keimplasmas, i 885 , S. 4.

19) zu S. 83. Roux, Wilhelm, Über die bei der Vererbung blastogener und somatogener Eigenschaften anzunehmenden Vorgänge. Verhandlungen des naturforschenden Vereins in Brünn, Bd. XLIX, I9II, S. 269-323.

2o) zu S. 93. "Nützliche Teile" und "Nutzlose Teile“.

I. Eupraktisch.

a) aktiv funktionierend,

b) passiv funktionierend,

2. Apraktisch.

Zwischen nützlichen und nutzlosen stehen solche, die unter erschwerten Bedingungen wirksam sind, z. B.: oberflächlicher Hohlhandbogen des Fußes. Rudimentärwerden ist auch an Funktionsbehinderung geknüpft. 
In dem ",Kampf der Teile" unterscheidet Roux:

S. I45 passiv fungierende Organe (Stützsubstanzen: Bindegewebe, Knorpel, Knochen) und aktiv tätige Organe oder Arbeitsorgane (Muskeln, Drüsen, Nerven, Ganglienzellen und Sinneszellen),

S. 162 zwei Hauptgruppen von Organen,

S. 204 Organe, die keine aktive oder passive Funktion haben, sondern bloß durch ihre Anwesenheit, ihr Sichtbarsein nach außen nützen.

21) zu S. 95. Übrigens ließen sich ähnliche Erwägungen wie für die chitinigen Skeletteile der Arthropoden auch für die knöchernen der Wirbeltiere anstellen, die doch gewiß eine hohe funktionelle Anpassungsfähigkeit besitzen. Für die Ausgestaltung der Teile des Innenskeletts mit ihren vielfachen statisch-mechanischen Beanspruchungen würde das Lamarcksche Prinzip, wenn es Geltung hätte, gewiß auf Schritt und Tritt Verwendung finden können, wie aber steht es mit den Teilen des Exoskelettes, den oberflächlich in der Haut sich bildenden Knochenpanzern, den kleinen und großen Schuppen der Fische, den breiteren Knochenplatten, den Deckknochen, die etwa auf dem Primordialkranium der Ganoiden als Verstärkungen des weicheren Knorpels sich bilden, und von denen die Schädeldeckenknochen der übrigen Formen abgeleitet werden? Durch ihr bloßes Vorhandensein bilden sie sicherlich einen für das Tier sehr nützlichen Schutz, aber welches ist neben dieser bloßen „Daseinswirkung" noch die besondere Inanspruchnahme, die ihre weitere Ausbildung auf Grund funktioneller Anpassung verständlich machen könnte? Auch hier kann das Prinzip des Lamarckismus wohl nicht für die stammesgeschichtliche Entwicklung in Anspruch genommen werden. Der Hinweis läßt übrigens auch deutlich erkennen, da $B$ mit den ,passiv wirkenden Teilen“ Weismanns etwas ganz anderes gesagt sein soll, als mit den ",passiv funktionierenden Organen" von Roux.

22) zu S. 10o. Der Vortrag von Hubermann, der mir nicht zugänglich war, hat nach Kammerer den Titel: „Meine Kunst" und ist im Neuen Wiener Tageblatt, So., 22. Januar I9Ix, Nr. 22, S. 7 erschienen. Kammerers Schrift betitelt sich: „Über Erwerbung und Vererbung des musikalischen Talentes" und ist erschienen bei Theod. Thomas in Leipzig, 1912. Kam merer knüpft an den Vortrag von $H u b e r m a n n$ an, in dem die Ansicht vertreten wird, daß es eine spezielle Begabung nicht gibt, also auch keine musikalische. „Es gebe nur verschiedene Grade einer allgemeinen Begabung, und das Gebiet, auf welchem sie ihre besonderen Leistungen entfaltet, sei völlig abhängig von dem, was wir Zufall nennen. zumeist also von der äußeren Lebenslage, die den Beruf entscheidet." Gegenüber dieser Ansicht, die durch ihren Gewährsmann von Interesse ist und sich mit der anfänglichen von Weismann nahe berührt, vertritt Kammerer die Auffassung, daß allerdings eine solche allgemeine Begabung, die nur durch sekundäre Umstände in eine bestimmte Bahn gelenkt wird, existiert, und daß vielleicht gerade Hubermann sie besitzt, daß aber außerdem auch eine spezifisch musikalische Begabung besteht, die durch Ubung im Laufe der Generationen gesteigert werden kann. Kammerer, einer der energischsten modernen Verfechter des Lamarckschen Prinzipes, betont, daß ,,musikalisches" und im allgemeinen gutes, scharfes Gehör durchaus nicht identische Dinge sind, er weist auf den Wandel und die Anpassungsfähigkeit hin, die das musikalische Empfinden im Laufe der Musikgeschichte zeigt, 
auf die so oft hervorgchobenc Tatsache, da $B$ das Beethovensche Orchester von den Zeitgenossen lärmend genannt wurde, während dem modernen Publikum gegenüber erst eine doppelte Besetzung, namentlich in den Bläsern, die ergreifendstc Wirkung hervorzurufen vermag; ja er sagt geradezu: „Die heute auf die Welt kommenden Generationen bedürfen keiner besonderen Gewöhnung mehr, um in einer Beethovenschen Symphonie, ja in sämtlichen Bühnenwerken R. Wagners sofort die gewaltigste, ergreifendste Melodik und durchsichtigste Klarheit aller Stimmen zu erkennen, vorausgesetzt, daB die betreffenden Individuen halbwegs musikalisch eindrucksfähig sind." So glaubt er denn auch, daß Musikausübung seitens des Vaters dem Sohne durch Vererbung zugute kommen könne: wenn der junge Wolfgang Amandus Mozart als dreijähriges Kind ganz ohne vorausgegangene Übung Melodien spielen konnte und mit wunderbar wenig Übung das Pianoforte vollends meistern lernte, so hieße es, Kammerers Ansicht zufolge, ,wahrlich den Tatsachen Gewalt antun, wollte man auch hier annehmen, daß diese phänomenale Fähigkeit ohne erblichen Einflu $B$ seitens des ebenfalls pianistisch tätigen Vaters Leopold Mozart zustandegekommen sei"“; ja, er hält es sogar für möglich, daß der Müllerberuf des ältesten Stammvaters der Familie Bach ,,für Erweckung des rhythmischen Sinnes von höchster Bedeutung gewesen“" sei, und setzt hinzu: ,,ich wäre versucht, den Einfluß hiervon noch in Werken von Joh. Seb. Bach ausfindig zu machen, müßte ich nicht fürchten, daß hier die Phantasie mit nüchternen Wahrnehmungen, wie sie dem Naturforscher ziemen, ihr Spiel treiben könnte." Schärfer kann die Ủberzeugung von dem Fortwirken persönlicher Eindrücke auch auf die Nachkommen kaum ausgesprochen werden. Ein näheres Eingehen darauf ist hier nicht am Platze; doch mag bezüglich des Stammvaters der Bache die Angabe von Weismann erwähnt sein: „Auch der obengenannte Ahnherr der Familie Bach spielte viel auf einem Cythringen, einem guitarreartigen Instrument, das er von seinen Wanderjahren mit in seine Mühle gebracht hatte, und ,das ist gleichsam der Anfang zur Musik bei seinen Nachkommen gewesen', sagt Sebastian Bach von ihm." Jedenfalls ist darnach eins sicher: daß nämlich schon jener Stammvater Bach musikalisch war, woraus wir, entsprechend dem bekannten Musikerworte ,Am Anfang war der Rhythmus", wohl auch schließen dürfen, daß ihm der Sinn für Rhythmus nicht erst durch das Klappern seiner Mühle erweckt zu werden brauchte. Mit seiner Auffassung hinsichtlich der Unterscheidung einer ,, universellen“ und einer „spezifisch musikalischen" Begabung dürfte Kammerer ebenso im Rechte sein, wie mit der Betonung, daß ausgezeichnete Hörschärfe und musikalisches Gehör noch etwas verschiedenes sind. Hinsichtlich des ersten Punktes wäre es von Interesse, nach dem Urteil von Hubermann einmal das von anderen Geigern zu hören, die, man möchte sagen, besonders „,violinistisch" veranlagt sind.

23) zu S. ror. Roux in: Ergebnisse der Anatomie und Entwicklungsgeschichte, Bd. II, I 892, Artikel: Entwicklungsmechanik, S. 4 I9.

24) zu S. ro6. Semon, R. Die Mneme als erhaltendes Prinzip im Wechsel des organischen Geschehens, I1. Aufl. Leipzig 1908.

25) zu S. ro9. Die für das Folgende in Betracht kommenden Darstellungen sind hauptsächlich der Vortrag über die Bedeutung der sexuellen Fortpflanzung für die Selektionstheorie (1886) und der Aufsatz über die Amphimixis (I89r). 
26) zu S. I20. Gregor Mendel, Versuche über Pflanzenhybriden. Zwei Abhandlungen (1865 und 1869). Herausg. v. Erich Tschermak. Ostwalds Klassiker der exakten Naturwissenschaften, Nr. I21. Leipzig r9or.

Es sei hingewiesen auf: Bateson, W., Mendels Principles of Heredity. Cambridge 1913 (auch Deutsch).

Baur, E., Einführung in die experimentelle Vererbungslehre. 2. Aufl. Berlin 1900.

Goldschmidt, R., Einführung in Vererbungswissenschaft. Leipzig rgrı.

Haecker, V., Allgemcine Vererbungslehre. 2. Aufl. Braunschweig rgiz.

Johannsen, W., Elemente der exakten Erblichkeitslehre. Mit Grundzügen der biologischen Variationsstatistik. Zweite deutsche, neubearbeitete und sehr erweiterte Ausgabe in 30 Vorlesungen. Jena r9r3.

Plate, L., Vererbungslehre. (Handbücher der Abstammungslehre, Bd. II.) Leipzig r9r3.

27) zu S. 128. Die Ansicht, daß die Vererbungssubstanz in Chromatin des Kernes zu suchen ist, hat Weismann zuerst in der Kontinuität des Keimplasmas ( 1885 ) mit Bestimntheit ausgesprochen, erst nach Strasburger und Hertwig. Es ist aber sicherlich berechtigt, wenn er darauf hinweist (Vorträge über Deszendenztheorie, III. Aufl., I913, Bd. I, S. 285, Anm.), daß seine früheren Schriften ihm die Selbständigkeit des Gedankens bezeugen.

28) zu S. x35. Die Änderung, die Weismann an seinen Vorstellungen bezüglich der Zusammensetzung des Keimplasmas aus einer Mehrzahl von Volliden vorgenommen hat, läßt die Frage aufwerfen, ob denn in den früheren (oben, auf S. 132) angeführten) Gedankengängen, die doch zur Annahme einer schr großen Zahl von Volliden im Keimplasma führten, etwa ein Feller steckte. Die Frage liegt folgendermaßen. Nach Weismanns Auffassung erfolgt bei der Reifung der Geschlechtszellen durch die Reduktionsteilungen eine Halbierung der Zahl der Ide, durch die darauf folgende Befruclitung wird die ursprüngliche Zahl der Ide wiederliergestellt. So wäre also in der Tat, vorausgesetzt, daß die Reduktion von jeher der Befruchtung vorausging, eine Vermehrung der Idzahl im Laufe der Stammesgeschichte ausgeschlossen gewesen. (Natürlich kann es sich hier nur handeln um eine Häufung von Iden, die nach Herkunft und individueller Färbung verschieden sind; - eine bloße Zahlvermehrung, etwa durch Selbstteilung von Iden, kommt hier nicht in Frage.) Die Annahme einer Vielheit der Ide im Keimplasma enthielt somit zugleich dic stillschweigend gemachte Voraussetzung, daß die Reduktionsteilung erst eingeführt wurde, nachdem die Amphimixis schon eine Zeitlang ohne eine solche im Gange war und so die Zahl der Ide auf eine beträchtliche Höhe gesteigert hatte. Weismann deutet dies selbst in dem Aufsatz über Amphimixis an (S. 18 der Sonderausgabe). Eine Schlußfolgerung - die Weismann selbst allerdings nicht gezogen hat - mußte dann die sein, daß von diesem Augenblick der Einführung der Reduktionsteilung an die Zahl der Ide bei allen Formen konstant blieb: es müßte, wofern dieser Vorgang nur ein mal, an einer ganz bestimmten Stelle der phyletischen Entwicklung erfolgte, bei allen Formen, bei denen heutzutage Amphimixis und Reduktionsteilung bestehen, - und das sind ja sogar schon Einzellige! - die ganz gleiche Zahl von Iden im Keimplasma vorhanden sein. Eine Schlußfolgerung, die 
bei der sehr versehiedenen Anzahl von Cliromosomen bei den einzelnen Arten recht unwalırscheinlich erseheinen $m u ß$, die allerdings vermieden werden könnte, durch die Annahme, daB die Reduktionsteilung zu verschiedenen Malen, bei verschiedenen Formen selbständig eingeführt worden ist. Diesen maneherlei Bedenken geht die neue Auffassung, daß dic Anlagen zu einem Individuum nur zweimal im Keimplasma enthalten seien, aus den Wege; sie gestattet die Annahme, die wohl die natiirlichste und nächstliegende ist: $\mathrm{da} B$ die Reduktionsteilung schon im Anschluß an die erstmalige Amphimixis eingeführt wurde. Somit ist die Frage nach dem Zeitpunkt der phyletischen Entwicklung, zu den die Reduktionsteilung eingeführt wurde, der Punkt, der von dem Wechsel der Anschauungen Weismanns ganz besonders betroffen wird. Die neue Auffassung erlaubt es auch leichter, sich nit der Tatsache der ungleichen Chromosomenzahl bei verschiedenen Formen abzufinden, einem Artmerkmal, das als solches ebenso wie andere Artmerkmale der Veränderliclıkeit unterworten scheint. In manchen Beziehungen bietet sie freilich größere Schwierigkeiten als die alte Vorstellung.

29) zu S. 136. Die Begründung für die Notwendigkeit, die frühere Auffassung zu ändern, und zugleich die Begründung für die neue Auffassung findet sich in zweiundzwanzigsten der ,Vorträge zur Deszendenztheorie“, der in der 3. Auflage neu hinzugekommen ist. Hier sind die Chromosomen - wenigstens für die höheren Organismen - als "Teilide" definiert und die Mendelschen Vererbungserscheinungen unter Zugrundelegung dieser neuen Auffassung behandelt. Dort ist auch die Möglichkeit erörtert, daß in gewissen Fällen ( $z$. B. bei den sozialen Hymenopteren) neben den Teiliden auch noch Vollide im Kern weiter bestehen. Die Auffassung, daß für jedes Merkmal die Determinante doppelt vorhanden ist, wird mehrfach ausdrücklich ausgesprochen und der Betrachtung zugrunde gelegt (Vorträge, 3. Aufl., Bd. II, S. 56, I 15, I I 7, I22, I 27 und an anderen Orten). Die Hilfsvorstellung, daB vielfach für dasselbe Merkmal eine Vielheit von Determinanten in demselben Id vorhanden ist, wird vor allem begründet im 24. Vortrag (Vorträge, Bd. II, S. 58) : „Ob nun freilich die Zahl der in zwei Iden liegenden homologen Determinanten stets die gleiche ist, so etwa, wie die Zahl der Ide in homologen Zellen derselben Art stets die gleiclıe ist, das läßt sich nicht sehen und ich möchte es auch für wahrscheinlich halten. Es kann recht gut sein, daß die Determinanten in dem einen der homologen Ide zahlreicher als im anderen sind und wenn wir das annehmen, so ließe sich daraus eine Ursache der ungleichen Stärke homologer Determınanten ableiten; es könnte die größere Stärke einfach der Ausdruck einer größeren Anzahl gleicher Determinanten auf der einen Seite sein. Das liegt um so näher, als wir uns die Determinanten wohl meist im Plural zu denken haben. Bestimmt doch ,eine Determinante' meist nicht eine Einheit, sondern eine Vielheit gleicher Teile, seien es Blumenblätter, Finger oder Haare; das Bestimmende muß sich also nach Bedarf vermehren können; diese Vermehrung wird aber um so rascher und intensiver geschehen, je größer die Determinantenzahl schon von Anfang war. Da hätten wir also eine Erklärung für die Tatsache der Dominanz oder Rezessivität, die sich noch durch mancherlei bestätigen läßt; vor allem durch die Erscheinungen des Rückschlages, zu dem wir uns jetzt wenden wollen." In den nun folgenden Auseinandersetzungen über Rückschlag bezielıt sich Weismann 
aufs neue auf die Hypothese, nach der die Dominanz nicht nur auf der An- oder Abwesenheit einer Determinante, sondern auch auf der Quantität, in welcher sie vorhanden ist, beruht. Die gleiche Vorstellung von der Vielheit der Determinanten für ein Merkmal findet sich auch an anderen Stellen verwertet, so bei der Erklärung der Spielvarietäten. Vortäge, II, S. I30: ,denn solche sprungweise auftretenden Spielvariationen sind bei Pflanzen, die aus dem Samen gezogen wurden, meist samenbeständig, und pflanzen sich, mit eigenem Pollen befruchtet, rein fort, ein Beweis, $\mathrm{da} \beta$ die gleichen Veränderungen an einer ganzen Gruppe homologer Determinanten im Id eingetreten sein müssen. Denn wir haben schon frü hergesehen, da $B$ wir uns die Determinanten meist als ein Mehrfaches vorzustellen haben." Hier ist also ausdrücklich von einer ganzen Gruppe homologer Determinanten innerhalb eines Ides (Chromosoms) gesprochen, und damit jedes Mißverständnis ausgeschlossen. Ebenso S. I3I: die Fortpflanzung der Knospenvariationen durch Samen ist ein Beweis dafür, ,daß auch hier eine gewisse Zahl von Determinanten der gleichen Art sich verändert haben müssen, vielleicht nicht immer alle homologen Determinanten des Ids, aber doch eine Überzahl von ihnen". Die Annahme einer Vielheit von Determinanten für dasselbe Merkmal wird eben von manchen Erscheinungen gefordert, und nachdem die alte Vorstellung von der Vielheit der Vollide im Keimplasma fallen gelassen worden war, blieb nichts anderes übrig, als die Vielheit der Determinanten innerhalb des Einzelides zu suchen. - Übrigens finden sich, wie schon in der biographischen Skizze gesagt wurde, in der 3. Auflage der , Vorträge " mehrere Stellen, die aus den früheren Auflagen unverändert übernommen worden sind, trotzdem sie inhaltlich nicht mehr berechtigt sind, da in ihnen noch die frühere Anschauung herrscht, daß das Keimplasma in jeder Keimzelle aus einer sehr großen Anzahl von „Volliden" zusammengesetzt ist. Solche Stellen sind: Teil I, S. 3I9, von Abschnitt 2 an bis zum Schlusse der Vorlesung; Teil II, S. I42, die beiden letzten Abschnitte; S. 284 und S. 285 (Unterschied zwischen fluktuierender Variabilität und Mutation) u. a.

30) zu S. r46. Roux, W., Der Kampf der Teile im Organismus, r 88ז, S. I 78.

3r) zu S. 148. Plate, L., Selektionsprinzip und Probleme der Artbildung. Ein Handbuch des Darwinismus, 4. Aufl., Leipzig r9r3, S. $45^{\circ} \mathrm{u}$. ff.

32) zu S. I48. Roux, S. Anm. ig zu S. 43.

33) zu S. I5I. S. die vorige Anm.

34) zu S. r6r. Rádl, E., Geschichte der biologischen Theorien. Teil II, Leipzig 1909. S. 371: ,Innerhalb des ganzen Darwinismus wiederholt sich diese logische Eigentümlichkeit, daß die Begriffe sowohl logische Abstraktionen, als auch Namen für ein Geschehen oder für eine Erscheinung bedeuten. Die Bedeutung der Worte ,Zoologie' und 'Tierreich', die Wissenschaft und ihr Objekt zu verwechseln, ist nicht möglich; im Darwinismus aber bedeuten die Worte ,Phylogenie', ,Ontogenie' eine Wissenschaft und zugleich auch ihr Objekt; ebenfalls bedeuten die Worte ,natürliche Zuchtwahl' sowohl einen Begriff als auch ein Geschehen." Das ist in der "Tat ganz richtig, und dieser Doppelgebrauch"der Worte hat manche Irrtümer verschuldet. Auch Weismann braucht" das" Wort „Naturzüchtung" bald für das Erklärungsprinzip, bald für die hypothetisch angenommene Kraft; in dem jedes maligen Zusammenhang kann es aber wohl nie zweifelhaft sein, was gemeint ist. 
35) zu S. 163. Der Begriff sexueller Dimorphismus ist von Weismann gebildet worden. Einfluß der Isolierung usw., I872, S. I7.

36) zu S. 165. Kölliker I 864 (Ưber die Darwinsche Schöpfungstheorie. Zeitschrift $\mathrm{f}$. wissensch. Zoologie, Bd. XIV, I 864) und I 872 (Anatomisch-systematische Beschreibung der Alcyonarien. Erste Abteilung: Die Pennatuliden, Schluß; in den Schlußbemerkungen von S. 206 an).

37) zu S. I65. Hierüber und über das Folgende s. besonders den Aufsatz über die Selektionstheorie von r9o9.

38) zu S. I66. Darwin spricht über diese biologisch gleichgültigen Abänderungen nur beiläufig, z. B. in der „Entstehung der Arten“" (7. Aufl. der deutschen Übersetzung von J. V. Carus, I 884, S. Ioo): „Abänderungen, welche weder vorteilliaft noch nachteilig sind, werden von der natürlichen Zuchtwahl nicht berührt und bleiben entweder ein schwankendes Element, wie wir es vielleicht in den sogenannten polymorphen Arten sehen, oder werden endlich fixiert infolge der Natur des Organismus oder der Natur der Bedingungen."

39) zu S. I67. Úber den Rückschritt in der Natur, I 886, S. 5 .

40) zu S. I68. Dieser Einwurf wird sehr scharf ausgesprochen von E. Rádl (Geschichte der biologischen Theorie, Bd. II, Leipzig I909, S. 373): „Eine andere Eigentümlichkeit der Zuchtwahllchre ist der Gedanke, daß der Fortschritt für sie ein bloßes Passivum bedeutet. Seit je verstand man unter ,Leben' eine Tätigkeit, eine Entwicklung zur Macht, eine Wirkung auf die Umgebung; von dem Fortschritte in der Welt glaubte man und ist man noch immer überzeugt, daß es durch ein Streben, durch einen Kampf für Ideale, durch eigene Kraft vor sich geht. Diese Auffassung wird von Darwin indirckt bekämpft; das Leben vermag nach ihm nichts, sondern ist nur ein Spielzeug in den Händen der verschiedensten äußeren Faktoren; es gibt bei Darwin keinen Fortschritt, sondern nur einen Fortschub (,du glaubst zu schieben und du wirst geschoben'), denn wenn ein Organismus irgend einen Vorzug vor anderen hat, so verschafft er ihm die gelıörige Geltung und Vertietung keineswegs durch eigenes Bemühen: mit seinem Tode werden alie seine Ideale hinfällig; nur derjenige hat Hoffnung auf Sieg, der viel Kinder erzeugt - das ist der Sinn der Zuchtwahltheorie." Wie jemand das als , Sinn“ aus der Zuclitwahltheorie herauslesen kann, einer Theorie, die gerade von der verschiedenen $Q u$ alität auch der kleinsten individuellen Abweichungen ausgeht, und für die die Quantität der Nachkonmen sehr wenig, die Qualität alles ist, ist mir unverständlich. Was aber die Geltendmachung der Vorzüge anlangt, so meine ich, daß wenigstens die tierischen Organismen dazu durch eigenes Benühen recht wohl beitragen können, und wenn sie das tun, so brauchen ihre ,Ideale“ durchaus nicht mit dem Tode hinfällig zu werden, sondern haben Aussicht, in Nachkommen weiter zu leben. Das ist wohl mit größerem Recht als "Sinn der Zuchtwahltheorie" zu bezeichnen.

4I) zu S. 169. Ich habe diesen Punkt hicr herausgegriffen, nicht als ob er zuerst oder ausschließlich von Weismann hervorgehoben worden wäre, sondern lediglich, weil die angeführte Stelle bei Weismann guten Anlaß gibt, ihn einmal schärfer zu betonen, als das gewöhnlich geschieht. Die landläufigen Darstellungen des Darwinismus erwähnen ihn meist gar nicht. Sehr klar spricht sich Plate darüber aus (Selektionsprinzip und Probleme der Artbildung, 4. Aufl., 1913, S. 227): 
,- denn hierin liegt nur das Divergenzprinzip der natürlichen Zuchtwahl, daß nämlich diejenigen Individuen, welche von ihren Genossen und Eltern möglichst verschieden sind, die meiste Aussicht haben, unbenutzte Plätze im Haushalt der Natur anzutreffen, es fehlt aber darin der wichtigere Hinweis auf die Anpassungen, und außerdem genügt zur Anwartschaft auf das Überleben nicht jede Veränderung, sondern nur eine solche, die entweder eine Verbesserung einer schon vorhandenen Bildung darstellt oder neue unbesetzte Plätze durch eine Neubildung ausnützt." S. auch Weismann, Vorträge, 3. Aufl., Teil II, S. 326.

42) zu S. I77. Plate, Selektionsprinzip usw., 4. Aufl., I913, S. I75.

43) zu S. I80. Z. B. in dem Aufsatz über die Bedeutung der sexuellen Fortpflanzung (S. 8 u. ff.), der von den späteren Schriften wohl am ausführlichsten auf die Nägelische Theorie eingeht.

44) zu S. I 84 . Die Selektionstheorie, I909, S. I 5 I.

45) zu S. 200. Roux, W., Der Kampf der Teile im Organismus. Ein Beitrag zur Vervollständigung der mechanischen Zweckmäßigkeitslehre. Leipzig I 88I . Neu abgedruckt und mit Anmerkungen und Zusätzen versehen unter dem Titel: „Der züchtende Kampf der Teile“" oder die „Teilauslese“ im Organismus. Zugleich eine Theorie der ,funktionellen Anpassung“; in: „Gesammelte Abhandlungen über Entwicklungsmechanik der Organismen“ “, Bd. I, Leipzig I895 (Nr. 4). Außerdem seien von den späteren Schriften genannt: „,Beiträge zur Morphologie der funktionellen Anpassung“. I. Struktur eines hoch differenzierten bindegewebigen Organes (der Schwanzflosse des Delphin). Archiv f. Anatomie u. Physiologie, Anatom. Abteil., I883, I Taf. u. 4 Textfig. - sowie: Anpassungslehre, Histomechanik und Histochemie. Mit Bemerkungen über die Entwicklung und Formgestaltung der Gelenke. Berichtigungen zu R. Thomas gleichnamigem Aufsatz. Virchows Archiv f. pathologische Anatomie u. Physiologie u. f. klinische Medizin I9I 2, Bd. CCIX.

46) zu S. 2 Iо. I 878 , in der Arbeit über die Schmuckfarben der Daphnoiden.

46a) zu S. 2 I I. Einen neuen, wie es scheint, sehr fruchtbaren Gedanken zu ihrer Weiterbildung hat Weismanns Schüler K. Günther ausgesprochen. (,,Zur geschlechtlichen Zuchtwahl" ", Arch. f. Rassen- und Gesellschaftsbiologie, Bd. II, S. 32I.) Er erklärt die Steigerung vieler männlichen Sexualcharaktere, wie Bärte, Kämme, Schweife, Stimme usw. mit der "Auslese des stärker Scheinenden“ Männchens.

47) zu S. 213. Die Selektionstheorie, I909, S. I4.

48) zu S. 2I 5. Vorträge, II, S. 267.

49) zu S. 2I 7. Das Wort von der Allmacht der Naturzüchtung, das, wie schon S. I6o bemerkt worden ist, bereits 1876 im zweiten Teil der Studien zur Deszendenztheorie auftaucht, ist gelegentlich auch falsch verstanden worden. Es ist ihm der Untergang so vieler Tierformen im Laufe der Erdgeschichte entgegengehalten worden, als Beweis, daß es mit dieser ,Allmacht" vielfach sehr schlecht bestellt war, da sie jenen Untergang nicht zu verhindern vermochte. Darin liegt aber wohl ein Mißverständnis, beruhend auf dem Doppelsinn des Wortes „Naturzüchtung“", auf den schon oben (S. I6I) aufmerksam gemacht wurde. ,Allmacht der Naturzuichtung" soll doch wohl nicht bedeuten, daß die Naturzüchtung, als personifizierte Kraft genommen, alles zu leisten, insbesondere jede Art über alle Schwierigkeiten 
hinwegzuführen imstande sei, sondern: daß das Erklärungsprinzip der Naturzüchtung alle Erscheinungen im Organismenreich zu erklären vermag. Auch in diesem Sinne aufgefaßt, ist das Wort nicht richtig, ist es zu vielsagend, aber das Aussterben ganzer Arten gehört nicht zu den Erscheinungen, denen gegenüber es versagt. Weismann hat sich auch darüber oft genug ausgesprochen und in den „,Vorträgen“ dem „,Artentod" mehrere Seiten gewidmet. Er hat hier ganz ausdrücklich die Ansicht bekämpft, als gebe es ein „,Greisenalter“ und einen ,,physiologischen Tod der Art" aus inneren Ursachen, wie es ein Altern und einen natürlichen Tod des Individuums gibt, und hat demgegenüber das Aussterben der Arten darauf zurückgeführt, daß die Lebensbedingungen, denen sie angepaßt waren, sich änderten, und daB es ihnen aus irgend einem Grunde nicht möglich war, sich den ne uen Bedingungen anzupassen. Das ist also eine Erklärung durchaus nach dem Naturzüchtungsprinzip.

50) zu S. 218 . Über vererbbare und passante Veränderungen findet sich eine beachtenswerte Äußerung in dem Aufsatz Weismanns über die Bedeutung der sexuellen Fortpflanzung (1886, S. 30): „Denken wir uns eine Art, deren Individuen völlig gleich sind, so werden auch ihre Nachkommen durch beliebig viele Generationen gleich bleiben müssen, wenn wir absehen von jenen passanten Unterschieden, wie sie durch verschiedene Ernährung usw. hervorgerufen werden, ohne aber vererbbar zu sein. Die Individuen dieser Art würden also tatsächlich zwar verschieden sein können, virtuell aber dennoch identisch sein; die Keime aller müßten genaı dieselben Vererbungstendenzen enthalten, und wenn es möglich wäre, sie unter genau denselben Einflüssen sich entwickeln zu lassen, so müßten sie auch völlig identische Individuen aus sich hervorgehen lassen." Diese letzten Sätze enthalten einen Gedanken, der in der neuesten Erblichkeitslehre, von Johannsen (Elemente der exakten [s. Anm. 26]), grundlegende Bedeutung erlangt hat: die scharfe Unterscheidung des "Phaenotypus" und des "Genotypus" (Johannsen), von denen der erste die sichtbare, feststellbare Beschaffenheit eines gegebenen Organismus, seine ,persönlich realisierten Eigenschaften“, d. h. die Reaktionen seiner inneren Konstitution auf die wechselnden Faktoren der Lebenslage bedeutet, während der zweite (Genotypus) die Summe der Elemente dieser seiner inneren Konstitution ausdrückt.

51) zu S. 219. In dem Aufsatz über die mechanische Auffassung der Natur $(1876$, S. 304$)$.

52) zu S. 222. I 880, S. $250 / 25$ I.

53) zu S. 224. Vorträge (3. Aufl., II, S. 68 und ro3).

54) zu S. 225. Die hier erörterten Gedanken finden sich vornehmlich in den Aufsätzen über die Bedeutung der sexuellen Fortpflanzung (I886) und die Amphimixis (r89r).

55) zu S. 228. In den Vorträgen zur Deszendenztheorie (3. Aufl., Bd. II, S. I 13 ).

56) zu S. 229. Germina ist der Plural von germen, Keim, und bezeichnet somit die Determinanten; Germinalselektion bedeutet die zwischen den Germina stattfindende Auslese, wie Personalselektion die Auslese zwischen den Personen bedeutet. Es ist somit nicht ganz richtig, wenn Weismann von einem ,intra"“- 
germinalen Nahrungsstrom oder von „intra"-germinalen Schwankungen der Ernährung usw. spricht; es müßte „inter" -germinal heißen. Ich habe dafür entoplasmatisch gebraucht. Im übrigen wäre für die Determinantenauslese ein anderer Ausdruck statt Germinalselektion, vielleicht Gemmalselektion, wohl besser gewesen. Die Bezeichnung Germinalselektion hätte dann für die Auslese unter den verschiedenen Keimplasmen zweckmäßig Verwendung finden können. Denn wenn auch nach Weismanns Auffassung die „Person" (das Soma) nur der Wirt ist, der das Keimplasma beherbergt, ohne von sich aus einen unmittelbaren umwandelnden Einflu $\beta$ auf dasselbe ausüben zu können, und wenn auch Weismann selbst wiederholt betont, daß die Personalauslese nur dadurch eine Bedeutung für die Fortbildung der Art besitzt, daB sie in den Personen bestimmte Keimplasmen auswählt, so sind doch ,Personalauslese" und "Keimplasmenauslese" nicht ohne weiteres identisch. Denn die Personen, unter denen die Auslese erfolgt, sind schon Phaenotypen im Sinne Johannsens, Produkte aus den Keimplasmen und den besonderen Bedingungen, unter denen sich diese entfalten konnten, sie geben also von den eigentlichen Anlagen nicht immer ein deutliches und zutreffendes Bild. Daß durch Personalauslese, die doch nun einmal nur mit den Phaenotypen rechnen kann, auch einmal eine unrichtige unerwünschte Keimauslese getroffen werden kann, ist eine Uberlegung, die z. B. Fanatiker der Rassenhygiene bedenken sollten. So wäre es also ganz erwünscht, einen besonderen Ausdruck für Keimplasmaauslese zu haben, und als solcher wäre Germinalselektion (von germen,

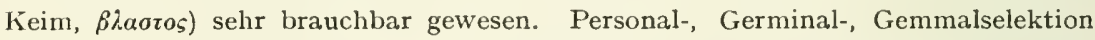
wären dann die drei für die Umbildung der Formen wichtigen Ausleseprozesse. Durch die Bedeutung, die IVeismann dem Begriff Germinalselektion untergelegt hat, ist die Verwendung in dem genannten Sinne nun nicht möglich, und die Schaffung eines Begriffes für die „Keimplasmenauslese" bleibt Desiderat.

57) zu S. 237. Auf Grund der älteren Auffassung, daß in dem Keimplasma jeder Zelle die Anlagenkomplexe („Vollide“) für eine sehr große Anzahl von Individuen vorhanden seien, erklärte Weismann früher das Auftreten von ,, Spielvarietäten“ “, d. h. von Varietäten größeren Betrages, die von vornherein erbbeständig sind, durch die Annahme der gleichen intensiven Veränderung homologer Determinanten in den meisten jener Vollide. Nach der neueren Form der Theorie muß dafür die Fassung eintreten, da $B$ es sich um gleichsinnige Veränderung homologer Determinanten innerhalb desselben Ids (Chromosoms) handelt. Daß in der 3. Auflage der Vorträge bei Besprechung der Mutationstheorie (Teil II, S. 284 und 285) noch die alte Erklärung beibehalten und von einer „,Majorität von Iden“ die Rede ist, kann nur auf einem Irrtum beruhen.

58) zu S. 242 . Vorträge, II, S. 259.

59) zu S. 247. In den Vorträgen zur Deszendenztheorie (3. Aufl., II, S. 239) heißt es: „Die Möglichkeit einer Abänderung auch des Keimplasmas durch solche direkte Wirkung äußerer Einflüsse soll aber damit keineswegs in Abrede gestellt werden. A priori schon muß man eine solche annehmen, wenn man, wie wir es getan haben, dic individuelle erbliche Variation auf die Schwankungen in der Ernăhrung der einzelnen Determinanten des Keimplasmas bezieht. Es ist von vornherein wahrscheinlich, daß manche allgemeine Ernährungsabänderungen oder 
klimatische Faktoren auch das Keimplasma treffen, und es ist durchaus nicht undenkbar, daß sie hier zuweilen nicht alle, sondern nur ganz bestimmte Determinanten allein verändern'". Damit ist theoretisch die Möglichkeit zugegeben, daß auch die ,spontane" Germinalselektion Folge der das Individuum treffenden äußeren Einflüsse ist, und der Gegensatz zwischen ,,spontaner" und ,,induzierter" Germinalselektion würde nur darin zu sehen sein, daß die Einflüsse, die die „spontane" Germinalselektion anregen, nicht so grober Natur sind, feiner, unmerklicher und daher einstweilen unserer Kenntnis und genaueren Analyse entzogen.

6o) zu S. 254. Schon I 876 erschien als vierter Aufsatz des zweiten Heftes der Studien zur Deszendenztheorie die Abhandlung ,Über die merhanische Auffassung der Natur" ", die durchaus für eine solche Auffassung eintritt und die Annahme einer besonderen Lebenskraft auch auf dem Gebiete der Stammesgeschichte für ebenso grundlos erklärt wie für die Erklärung des individuellen Lebens.

6I) zu S. 267. Diese Behauptung findet sich bei Rádl (Geschichte der biologischen Theorien) auf S. 548: „Der Darwinismus war dem auf Experimente sich stïtzenden Konstruieren der Natur abhold und wollte die Natur, wie sie ist, erkennen. Zwar experimentierte auch Darwin (obwohl seine Versuche sehr elementar zu sein pflegten); aber die klassischen Darwinisten, Haeckel, Huxley, Wallace, Galton, Weis mann, waren keine Experimentatoren; nur hier und da wurde ein schüchternes Experiment angestellt (von Romanes, Preyer, Pflüger), aber kaum beachtet; erst als der Darwinismus den Höhepunkt überschritten hat, nahm man das Experimentieren energischer in Angriff." Das ist im großen ganzen richtig; die Nennung von Weismanns Namen in diesem Zusammenhang ist aber falsch. 


\section{Verzeichnis der Schriften Weismanns.}

1857. Weismann, August, De acidi hippurici in corpore humano generatione. (Göttingen.) Disertatio inauguralis. Francofurti 1857 .

- U Uber den Ursprung der Hippursäure im Harn der Pflanzenfresser. Eine von der medizinischen Fakultät der Georgia Augusta am I3. Juni I 857 gekrönte Preisschrift. Göttingen I 857 .

I 858. - Über die Bildung der Hippursäure beim Menschen. Zeitschrift für rationelle Medizin, 3. Reihe, Bd. II, S. 33 I-344. I 858.

- - Untersuchungen über den Salzgehalt der Ostsee. Archiv für Landeskunde in den Großherzogthümern Mecklenburg, 8. Jahrg., S. 289-304. I858. (Der Name ist fälschlich ,Weissmann" geschfieben. Die Arbeit trägt folgende Bemerkung: Die nachstehende Abhandlung ist der philosophischen Fakultät der Universität Rostock als Konkurrenzschrift $\mathrm{zu}$ dem im vorigen Jahre gestellten Preise überreicht und ist dem Verfasser solcher unter der Verpflichtung zuerkannt worden, dieselbe im ,Archiv für Landeskunde" zu veröffentlichen. D. Red.)

- Analysen des Ostseewassers. Archiv für Landeskunde in den Großherzogthümern Mecklenburg, 8. Jahrg., S. 437-444. I858. (Ohne Angabe des Verfassers.) Die Einleitung lautet: „Die nachfolgenden Analysen des Ostseewassers sind zum Zweck der im vorigen Hefte des Archiv mitgeteilten Arbeit über den Salzgehalt der Ostsee von Dr. Weismann unter spezieller Leitung des Herrn Prof. Dr. Schulze zu Rostock ausgeführt. Wir teilen sie als Nachtrag zu jener Abhandlung mit, weil wenige derartige mit Genauigkeit angestellte Analysen vorhanden sind und die nachstehenden daher ein um so größeres wissenschaftliches Interesse haben."

I859. - Über Nervenneubildung in einem Neurom. Zeitschrift für rationelle Medizin, 3. Reihe, Bd. VII, I 859 , S. 209-2I8. I Taf.

1861. - Über das Wachsen der quergestreiften Muskeln nach Beobachtungen am Frosch. Zeitschrift für rationelle Medizin, 3. Reihe, Bd. X, I86r, S. 263 bis 284.2 Taf.

- U Uber den feineren Bau des menschlichen Nabelstranges. Zeitschrift für rationelle Medizin, 3. Reihe, Bd. XI, I861, S. I40-I66. 3 Taf.

- - Uber die Verbindung der Muskelfasern mit ihren Ansatzpunkten. Zeitschrift für rationelle Medizin, 3. Reihe, Bd. XII, I86I, S. I26-I 44. 3 Taf.

- U Uber die Neubildung quergestreifter Muskelfasern. Eine Erwiderung an Herrn Prof. Budge. Zeitschrift für rationelle Medizin, 3. Reihe, Bd. XII, I 86 I, S. $354-359$. 
I861. - Uber die Muskulatur des Herzens beim Menschen und in der Tierreile. Archiv für Anatomie, Physiologie und wissenschaftliche Medizin, Jahrg. I 86I, S. 4 I-63. 3 Taf.

1862. - Uber die zwei Typen kontraktilen Gewebes und ihre Verteilung in die großen Gruppen des Tierreichs, sowie über die histologische Bedeutung ihrer Formelemente. Zeitschrift für rationelle Medizin, 3. Reihe, Bd. XV, I862, S. $60-103.5$ Taf.

-- - Nachtrag zu der Abhandlung: , Über die zwei Typen kontraktilen Gewebes und ihre Verteilung in die großen Gruppen des Tierreichs, sowie über die histologische Bedeutung ihrer Formelemente." Die Bildung der Muskeln im Ei der Insekten. Zeitschrift für rationelle Medizin, 3. Reihe, Bd. XV, I 862 , S. $279-282$. 5 Fig.

I863. - Uber die Entstehung des vollendeten Insekts in der Larve und Puppe. Ein Beitrag zur Metamorphose der Insekten. Abhandlungen, herausg. v. d. Senckenbergischen Naturforschenden Gesellschaft, Bd. IV, r862-63. 3 Taf. Habilitationsschrift der medizinischen Fakultät Freiburg i. B. r863.

- - Die Entwicklung der Dipteren im Ei, nach Beobachtungen an Chironomus spec., Musca vomitoria und Pulex Canis. Zeitschrift für wissenschaftliche Zoologie, Bd. XIII, 1863, S. 107-220. 7 Taf.

1864. - Die nachembryonale Entwicklung der Musciden nach Beobachtungen an Musca vomitoria und Sarcophaga carnaria. Zeitschrift für wissenschaftliche Zoologie, Bd. XIV, I 864 , S. $187-336.7$ Taf.

- Zur Embryologie der Insekten. Archiv für Anatomie, Physiologie und wissenschaftliche Medizin, Jahrg. I 864 , S. 265-277. I Taf.

1865. - Zur Histologie der Muskeln. Zeitschrift für rationelle Medizin, 3. Reihe, Bd. XXIII, I 865 , S. 26-45. (Abgedr. in Jenaische Zeitschrift, Bd. II.)

- Die Metamorphose der Corethra plumicornis. Zeitschrift für wissenschaftliche Zoologie, Bd. XVI, I866, S. 45-127. 5 Taf.

I868. - Utber die Berechtigung der Darwinschen Theorie. Ein akademischer Vortrag gehalten am 8. Juli 1868 in der Aula der Universität zu Freiburg im Breisgau. Leipzig r 868, W. Engelmann. (Mit einem An hang: Über den Einfluß der Wanderung und räumlichen Isolierung auf die Artbildung.)

1872. - Uber den Einfluß der Isolierung auf die Artbildung. Leipzig 1872, W. Engelmann.

1874. - Uber Bau und Lebenserscheinungen von Leptodora hyalina Lillgeborg. Zeitschrift für wissenschaftliche Zoologie, Bd. XXIV, I874, S. 348-418. 6 Taf.

1875. - Studien zur Deszendenztheorie. I. Über den Saisondimorphismus der Schmetterlinge. 2 Taf. Leipzig 1875 . (Sonderabdruck aus den Annali del Museo Civico di Storia Naturale di Genova, Bd. VI, I874.)

- U Uber die Umwandlung des mexikanischen Axolotl in ein Amblystoma. Zeitschrift für wissenschaftliche Zoologie, Bd. XXV, Supplementband, I875, S. $297-334$.

1876. - Studien zur Deszendenztheorie. II. Utber die letzten Ursachen der Transmutationen. (I. Die Entstehung der Zeichnung bei den Schmetterlingsraupen. 
II. Über den phyletischen Parallelismus bei metamorphischen Arten. III. Über die Umwandlung des mexikanischen Axolotl in ein Amblystoma. IV. Uber die mechanische Auffassung der Natur.) 5 Taf. Leipzig 1876.

1876. - Das Tierleben im Bodensee. Schriften des Vereins für Geschichte des Bodensees und seiner Umgebung, Heft 7, 1876, S. 132-16r. 5. Abb. (Einige Bemerkeungen zu der Frage nach dem Auf- und Absteigen der pelagischen Crustaceen finden sich in der Diskussion zu einem Vortrag von Forel in: ,Amtlicher Bericht der 50. Versammlung Deutscher Naturforscher und Arzte in München, 1877 , S. 172.)

- - Zur Naturgeschichte der Daphnoiden. I. Uber die Bildung von Wintereiern bei Leptodora hyalina. Zeitschrift für wissenschaftliche Zoologie, Bd. XXVII, I 876, S. 5I-II2. 3 Taf. (Die gesamten Abhandlungen sind als „,Beiträge zur Naturgeschichte der Daphnoiden" als selbständige Monographie bei W. Engelmann in Leipzig erschienen. Leipzig 1876-1879.) Weismann faßt unter Daphnoidea die beiden Familien der Daphnida und Polyphemida zusammen. Daphnoidea = Ordnung der Wasserflöhe, der gebräuchlichere Name an Stelle des neueren "Cladocera" (Zeitschrift für wissenschaftliche Zoologie, Bd. XXVIII, I877.)

1877. - Uber die Fortpflanzung der Daphnoiden. Amtlicher Bericht über die 50. Versammlung Deutscher Naturforscher und Arzte in München vom 17.-22. September 1877 , S. 178 .

- - Diskussionsbemerkung zu dem Vortrag von A. Forel: Uber den Ursprung der verschiedenen Faunen unserer Süßwasserseen. Amtlicher Bericht über die 50. Versammlung Deutscher Naturforscher und Arzte in München vom 17.-22. September 1877 , S. 172 .

- - und Gruber, August, Ưber einige neue oder unvollkommen gekannte Daphniden. Abhandlungen der Naturforschenden Gesellschaft zu Freiburg i. B., 1877 .

- Weismann, August, Beiträge zur Naturgeschichte der Daphnoiden. II. Die Eibildung bei den Daphnoiden. III. Die Abhängigkeit der Embryonalentwicklung vom Fruchtwasser der Mutter. IV. Über den Einfluß der Begattung auf die Erzeugung von Wintereiern. Zeitschrift für wissenschaftliche Zoologie, Bd. XXVIII, I877, S. 93-254. 5 Taf.

I878. - Rechtfertigung. Zeitschrift für wissenschaftliche Zoologie, Bd. XXX, I 878 , S. I $94-202$.

- Utber die Schmuckfarben der Daphnoiden. Zeitschrift für wissenschaftliche Zoologie, Bd. XXX, Suppl., 1878, S. 123-165. I Taf.

- Uber Duftschuppen. Zoologischer Anzeiger, Jahrg. 1, 1878, S. 98-99.

- - und Wiedersheim, R., Aus dem zoologischen und anatomischen Institut der Universität Freiburg i. Br. Zoologischer Anzeiger, Jahrg. I, I878, S. 6-7.

I879 (1880). Weismann, Beiträge zur Naturgeschichte der Daphnoiden. Abhandlung VI und VII. (VI. Samen und Begattung der Daphnoiden. VII. Die Entstehung der zyklischen Fortpflanzung bei den Daphnoiden.) Zeitschrift für wissenschaftliche Zoologie, Bd. XXXIII, Heft I und 2, I879 (Jahreszahl des Bandes: 1880), S. 55-270. 6 Taf. 
1880. - Zur Frage nach dem Ursprung der Geschlechtszellen bei den Hydroiden. Zoologischer Anzeiger, Jahrg. 3, 1880, S. 226-233.

- Über den Ursprung der Geschlechtszellen bei den Hydroiden. Zoologischer Anzeiger, Jahrg. 3, 1880, S. 367-370.

- Parthenogenese bei den Ostracoden. Zoologischer Anzeiger, Jahrg. 3. I 880 , S. $82-84$.

1880/81. - Observations sur l'origine des cellules sexuelles des Hydroides. Annales des sciences naturelles, Tome XI.

r881. - Beobachtungen an Hydroid-Polypen. I. Pulsieren des Körperschlauchs. II. Selbständige Bewegungen des Ektoderms. III. Die Entstehung der Eizellen in der Gattung Endendrium. Zoologischer Anzeiger, Jahrg. 4, 1881, S. 61 bis $64 ; \mathrm{S}$. III $\mathrm{I} \longrightarrow \mathrm{II}_{4}$.

- Uber die Dauer des Lebens. Tageblatt der 54. Versammlung Deutscher Naturforscher und Arzte in Salzburg vom 18.-24. September 1881, S. 98 bis 114 . (Vortrag, gehalten in der II. allgemeinen Sitzung am 21. September 1881.)

- (1882). - Ưber eigentümliche Organe bei Endendrium racemosum Cav. Mitteilungen aus der zoologischen Station zu Neapel, Bd. III, Heft I und 2, I881, S. I-I4. I Taf. (Jahreszahl des Bandes: 1882.)

1882. - Uber die Dauer des Lebens. Jena 1882. (Erweiterte Form des in Salzburg gehaltenen Vortrages.)

- - Beiträge zur Kenntnis der ersten Entwicklungsvorgänge im Insektenei. Beiträge zur Anatomie und Embryologie, als Festgabe Jacob Henle zum 4. April I882 dargebracht von seinen Schülern. Bonn I882. S. 80-III. 3 Taf.

1883. - Die Entstehung der Sexualzellen bei den Hydromedusen. Zugleich ein Beitrag zur Kenntnis des Baues und der Lebenserscheinungen dieser Gruppe. Mit Atlas von 24 Tafeln. Jena 1883.

- - Uber die Vererbung. Jena, G. Fischer. (Vortrag, gehalten bei der Feier der Ubergabe des Prorektorates in Freiburg i. Br., 21. Juni 1883.)

- Uber die Ewigkeit des Lebens. Akademisches Programm der AlbertLudwigs-Universität zur Feier des Geburtstages S. Kgl. H. des Großherzogs Friedrich. Freiburg i. Br. 1883 .

1884. - Über Leben und Tod. Eine biologische Untersuchung. Mit 2 Holzschnitten. Jena 1884. (Erweiterte Form der Programmschrift ,Uber die Ewigkeit des Lebens.)

1884. (1885). - Die Entstehung der Sexualzellen bei den Hydromedusen. (Autoreferat.) Biologisches Zentralblatt, Bd. IV, Nr. I, 1884, S. 12-31. (Jahreszahl des Bandes: 1885.)

1885. - Zur Frage nach der Unsterblichkeit der Einzelligen. Biologisches Zentralblatt, Bd. IV, 1885 , S. $65 \mathrm{I}-665$; S. $677-69 \mathrm{I}$.

- - Die Kontinuität des Keimplasmas als Grundlage einer Theorie der Vererbung. Jena 1885 .

- - Uber die Bedeutung der geschlechtlichen Fortpflanzung für die Selektionstheorie. Tageblatt der 59. Versammlung Deutscher Naturforscher und Arzte 
in Straßburg, 18.-23. September I885. Straßburg 1885. S. 42-56. (Vortrag, gehalten in der I. allgemeinen Sitzung der Versammlung, I9. September I 885.)

I885. - Diskussionsbemerkung zu dem Vortrag von Virchow: Über Akklimatisation. Tageblatt der 58 . Versammlung Deutscher Naturforscher und Arzte in Straßburg, 18. -23. September I 885. S. 550-551. (Behandelt die Vererbung erworbener Eigenschaften und die Frage, was unter ,erworbener Eigenschaft" zu verstehen sei. Direkte Klimaeinwirkungen sind nicht erblich, doch kann Akklimatisation unter dem Einfluß des Klimas durch Selektion erfolgen.)

1886. - Zur Annahme einer Kontinuität des Keimplasmas. Berichte der Naturforschenden Gesellschaft zu Freiburg i. Br., Bd. I, I886, S. 89-99.

- - Die Bedeutung der sexuellen Fortpflanzung für die Selektionstheorie. Jena I 886.

1886 (I 887 ). - Uber den Rückschritt in der Natur. Berichte der Naturforschenden Gesellschaft zu Freiburg i. Br., Bd. II, Heft I, I886, S. I-30. (Jahreszahl des Bandes: 1887.)

1886. - Zur Geschichte der Vererbungstheorien. Zoologischer Anzeiger, Jahrg. 9, I 886 , S. $344-350$.

- - Richtungskörper bei parthenogenetischen Eiern. Zoologischer Anzeiger, Jahrg. 9, I 886 , S. 570-573.

- Z Zur Frage nach der Vererbung erworbener Eigenschaften. Biologisches Zentralblatt, Bd. VI, Nr. 2 (I 5. März I 886), S. 33-48. (Jahreszahl des Bandes: I 887.)

I887. - Über die Zahl der Richtungskörper und über ihre Bedeutung für die Vererbung. Jena 1887 .

- - On the signification of the polar globules. Nature. Vol. XXXVI, I887. (Paper read by Prof. August Weismann before the Brit. Assoc. at Manchester.)

I 888. (a) - und Ischikawa, C., Über die Bildung der Richtungskörper bei tierischen Eiern. Berichte der Naturforschenden Gesellschaft zu Freiburg i. Br., Bd. III, I 888, S. I-44. 4 Taf. Wahrscheinlich handelt es sich um ein Autoreferat, da es mit Weismann unterzeichnet ist.

- (b) - U Úber die Befruchtungserscheinungen bei den Dauereiern von Daphniden. Biologisches Zentralblatt, Bd. VIII, I 888 , S. $430-436$.

- Weismann, August, Botanische Beweise für eine Vererbung erworbener Eigenschaften. Biologisches Zentralblatt, Bd. VIII (I $888-\mathbf{r} 889$ ), S. $65-79$, S. 97 - Io9.

- - Das Zahlengesetz der Richtungskörper und seine Entdeckung. Morphologisches Jahrbuch, Bd. XIV, I888, S. 490-506.

- (1889). - und Ischikawa. Weitere Untersuchungen zum Zahlengesetz der Richtungskörper. Zoologische Jahrbücher, Abteilung für Anatomie und Ontogenie der Tiere, Bd. III, Heft 3, I888, S. 575-610. 4 Taf. (Jahreszahl des Bandes: 1889.) 
I889. - - Uber partielle Befruchtung. Berichte der Naturforschenden Gesellschaft zu Freiburg i. Br., Bd. IV, x889, S. 5I-53. (Das Manuskript ist schon am I2. Dezember I 887 eingereicht; eine ,Nachschrift" trägt das Datum 21. Mai I 888.)

- - Nachtrag zu der Notiz uiber "partielle Befruchtung“. Berichte der Naturforschenden Gesellschaft zu Freiburg i. Br., Bd. IV, 1889, S. 55-58.

- Weismann, August, Über die Hypothese einer Vererbung von Verletzungen. Vortrag, gehalten am 20. September I 888 auf der Naturforscherversammlung zu Köln. Jena r889.

- - und Ischikawa, C., Uber die Parakopulation im Daphnidenei, sowie über Reifung und Befruchtung desselben. Zoologische Jahrbücher, Abteilung für Anatomie und Ontogenie der Tiere, Bd. IV, Heft 1, 1889, S. I55-I96. 7 Taf. (Jahreszahl des Bandes: I891.)

- Weismann, August, Gedanken über Musik bei Tieren und beim Menschen. Deutsche Rundschau, Oktober 1889, Bd. LXI, S. 50-79. (Vortrag, gehalten im März 1889 in der Gesellschaft für Kunst und Wissenschaft zu Hamburg.) r89o. - Bemerkungen zu einigen Tagesproblemen. Biologisches Zentralblatt, Bd. X, I 890, S. I-I 2 ; S. 33-44.

1981. - Amphimixis oder: Die Vermischung der Individuen. Jena I891.

I89o. - Bemerkungen zu Ischikawas Umkehrungsversuchen an Hydra. Archiv für mikroskopische Anatomie, Bd. XXXVI, I890, S. 627-638. 8 Fig.

1892. - Aufsätze über Vererbung und verwandte biologische Fragen. Mit I9 Abb. im Text. Jena, G. Fischer. (Enthält II der von I882-1891 erschienenen Aufsätze.) (Englische Ausgabe, übersetzt von Poulton und Shipley, Oxford I 892. Französische Ausgabe, übersetzt von de Varigny. Paris I 892.)

- - Das Keimplasma. Eine Theorie der Vererbung. (Englische Ausgabe, übersersetzt von W. N. Parker und Harriet Roennefeldt. London I893.) 1893. - Die Allmacht der Naturzüchtung. Eine Erwiderung an Herbert Spencer. Jena i893. (Englische Ausgabe. London 1893.)

1894. - Außere Einflüsse als Entwicklungsreize. Jena, G. Fischer, I894. (Verdankt seine Entstehung der Aufforderung der Universität Oxford, die ,, Romanes-Lecture" zu halten. Enthält im Vorwort Erinnerungsworte auf Romanes.) (Englische Ausgabe. London und Oxford 1894.)

1895. - Neue Gedanken zur Vererbungsfrage. Eine Antwort an Herbert Spencer. Jena I 895 .

- - Neue Versuche zum Saisondimorphismus der Schmetterlinge. Zoologische Jahrbücher, Abteilung für Systematik, Bd. VIII, I 895, S. 6I I-684. (Englische Ausgabe, übersetzt von W. E. Nicholson. London I 895.)

- Wie sehen die Insekten? Deutsche Rundschau, Bd. LXXXIII, I895,

S. $434-45^{2}$.

1896. - Ubber Germinalselektion, eine Quelle bestimmt gerichteter Variation. Jena 1896. (Nach einem Vortrag auf dem internationalen Zoologischen Kongreß in Leyden, I6. Sept. 1895.)

1899. - Tatsachen und Auslegungen in bezug auf Regeneration. Anatomischer Anzeiger, Bd. XV, I899, S. 445-474. (Englische Übersetzung. London I 899.) 
1900. - Uber die Parthenogenese der Bienen. Anatomischer Anzeiger, Bd. XVIII, I900, p. $492-499$.

1902. I904. - Vorträge über Deszendenztheorie, 2 Bände. Jena I902. - II. Aufl. I904. (III. Aufl. I9I3.)

1903. - Versuche über Regeneration bei Tritonen. Anatomischer Anzeiger, Bd. XXII, I903, S. 425-431. 3 Abb.

1906. - Richard Semons "Mneme" und die „Vererbung erworbener Eigenschaften“. Archiv f. Rassen- u. Gesellschaftsbiologie, Jahrg. 3, 1906, S. I-27.

I908. - Eine hydrobiologische Einleitung. Internationale Revue der gesamten Hydrobiologie und Hydrographie, Bd. I, I908, S. I-9.

I909 (a). - Die Selektionstheorie. Eine Untersuchung. I Taf. und 3 Textfig. Jena I909. (Ist eine weitere Ausführung eines Aufsatzes, den Weismann für die Festschrift der Universität Cambridge zum 100.Geburtstag von Darwin verfaßt hat, und der in dieser [Darwin and modern science. Cambridge, at the University Press. 1909] erschienen ist.)

- (b). - Carles Darwin und sein Lebenswerk. Festrede, gehalten zu Freiburg i. Br. am 12. Februar 1909. Jena, G. Fischer, I909.

- Uber die Trutzstellung des Abendpfauenauges. Naturwissenschaftliche Wochenschrift, N. F., Bd. VIII (der ganzen Reihe 24. Band), I909, Nr. 46, S. $72 \mathrm{I}-726.4$ Fig.

I913. - Vorträge über Deszendenztheorie. Gehalten an der Universität Freiburg i. Br. III. verb. Aufl. Jena Igr3.

\section{Biographisches über Weismann.}

Folgende biographische Notizen und Nekrologe sind dem Herausgeber bekannt geworden - der Krieg hat es verhindert, daß, wie es sonst wohl der Fall gewesen wäre, deren Zahl ein Vielfaches der hier verzeichneten geworden ist. Aus dem feindlichen Ausland sind, falls Nachrufe erschienen sind, hier keine bekannt geworden außer dem von E. P. P., dessen Aufführung hier der Herausgeber aus Schonung fur den Autor, den Oxforder Professor E. P. Poulton, sich lange überlegte. Er möge aber ruhig genannt sein als Zeuge des augenblicklichen geistigen Zustandes auch hochstehender Engländer, bringt er es doch fertig, Weismann al. Bekompfer des preußischen Militarismus hinzustellen. - E. F.

I904. - Bericht über die Feier des 70. Geburtstages von August Weismann am 17. Januar I904 in Freiburg i. Br. Herausgegeben von dem Comité zur Stiftung der Weismann-Büste. Jena I904.

1909. Kühn, A., August Weismann (mit einer Kunstbeilage), „Neue Weltanschauung" (Red. Dr. Breitenbach), Heft 6, Stuttgart igog.

I914. Doflein, F., August Weismann zum 80. Geburtstag. Akademische Mitteilungen, N. F., 15. Sem., Nr. 7. Freiburg, Januar 19I4.

- Himstedt, F., August Weismann (Nachruf am Grabe). Akademische Mitteilungen, N. F., 17. Sem., Nr. 6. Freiburg I9I4.

- Doflein, F., Weismann als Forscher, Akademische Mitteilungen, N. F., I7. Sem., Nr. 6. Freiburg I9I4. 
I91.. . . Gelicimrat A. Wcismann. Freiburger Zeitung, Nr, 304, 6. November 1914 .

- Teichmann, E. Zu August Weismanns Tod. Frankfurter Zeitung, Nr. 309 (Abendbl.), 7. November 1914.

- $($ (= Otto Ammon), August Weismann $\dagger$. Schwäbische Chronik, des Schwäb. Merkurs, 2. Abt., Nr. 521, I9I4.

J. K., August Wcismann. Berliner Tageblatt (Morgenausgabe), 7. November I9I4.

- Strohl, J., August Weismann. Neue Züricher Zeitung, Nr. 1528 und I532 (13., 14. November), 1914 .

- Mauthner, Fritz, Kleine Erinnerungen an A. Weismann. Berliner Tageblatt (2. Beiblatt), 6. Dezember I9I4.

I9I5. Ziegler, H. E., A ugust Weismann. Neue Rundschau, Januar-Heft I9r5. - v. Hanstein, R., August Weismann. Naturwissenschaftliche Wochenschrift, N. F., Bd. XIV (Bd. XXX), Nr. 8, I9I5.

1916. E. P. P., August Friedrich Leopold Weismann. Obituary Notico from the Proceed. of the Royal Soc. B. Vol. LXXXIX. I9I6.

Berichtigung.

Seite 74 , Zeile 21 muß es ${ }^{16}$ ) statt ${ }^{26}$ ) heißen. 
<smiles>c1ccccc1</smiles> 




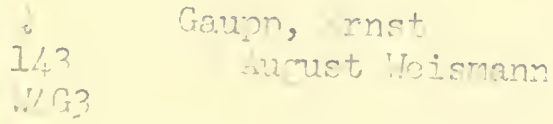

P\&A Sci.

PLEASE DO NOT REMOVE

CARDS OR SLIPS FROM THIS POCKET

UNIVERSITY OF TORONTO LIBRARY 


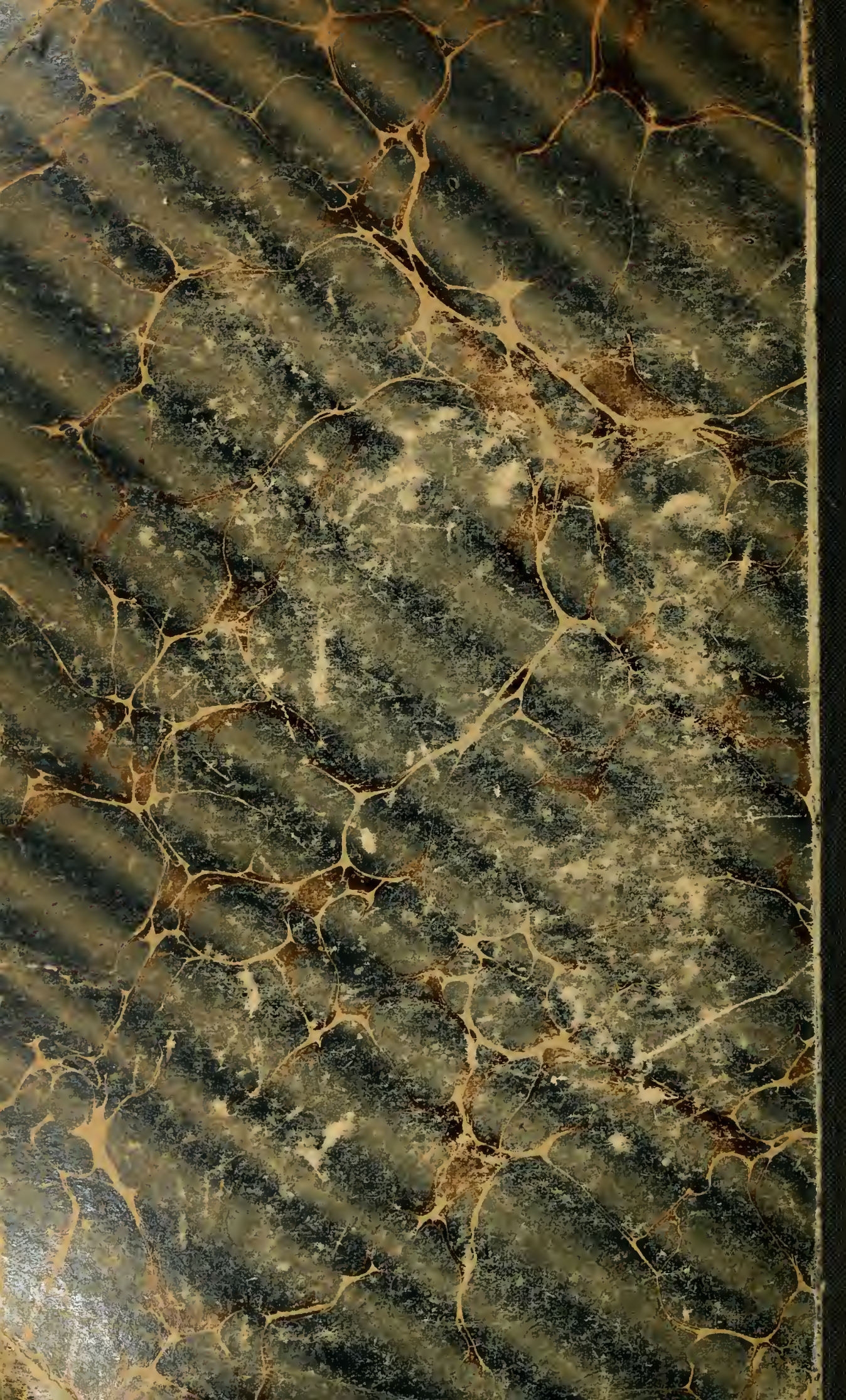

